Editora Poisson

\section{Gestão da Produção em Foco Volume 44}

1a Edição

Belo Horizonte

Poisson

2020 
Editor Chefe: Dr. Darly Fernando Andrade

\section{Conselho Editorial}

Dr. Antônio Artur de Souza - Universidade Federal de Minas Gerais

Ms. Davilson Eduardo Andrade

Dra. Elizângela de Jesus Oliveira - Universidade Federal do Amazonas

MS. Fabiane dos Santos

Dr. José Eduardo Ferreira Lopes - Universidade Federal de Uberlândia

Dr. Otaviano Francisco Neves - Pontifícia Universidade Católica de Minas Gerais

Dr. Luiz Cláudio de Lima - Universidade FUMEC

Dr. Nelson Ferreira Filho - Faculdades Kennedy

Ms. Valdiney Alves de Oliveira - Universidade Federal de Uberlândia

Dados Internacionais de Catalogação na Publicação (CIP)

G393
Gestão da Produção em Foco - Volume 44/ Organização Rafael Alves
Pedrosa - Belo Horizonte - MG: Poisson, 2020
Formato: PDF
ISBN: 978-65-5866-032-3
DOI: 10.36229/978-65-5866-032-3
Modo de acesso: World Wide Web
Inclui bibliografia
1. Gestão 2. Produção. 3. I. PEDROSA, Rafael Alves II. Título.
Sônia Márcia Soares de Moura - CRB 6/1896

O conteúdo dos artigos e seus dados em sua forma, correção e confiabilidade são de responsabilidade exclusiva dos seus respectivos autores.

Baixe outros títulos gratuitamente em www.poisson.com.br contato@poisson.com.br 


\section{SUMÁRIO}

Capítulo 1: Viabilidade econômica dos veículos híbridos: Uma análise comparada baseada no payback. 06

Yohana de Azevedo Carvalho, Luiza Maciel Gonçalves, Rodrigo Zaban Cipriano, Felipe Amorim Soares Macedo, Luan Santos

DOI: $10.36229 / 978-65-5866-032-3 . C A P .01$

Capítulo 2: Análise financeira de uma empresa do setor de consumo: 0 caso das Lojas Renner no período de 2005 a 2014 14

Paula Prenholato Alves, Ruth Margareth Hofmann

DOI: $10.36229 / 978-65-5866-032-3 . C A P .02$

Capítulo 3: Transporte rodoviário: Os principais riscos ocupacionais no cotidiano dos motoristas de caminhão. 24

Ivana Salvagni Rotta, Fernando Cesar Mendonça

DOI: $10.36229 / 978-65-5866-032-3 . C A P .03$

Capítulo 4: Avaliação da interrupção no desenvolvimento de novas tecnologias nas micro e pequenas empresas do setor químico do ABC Paulista com base no TRL ........ 33 Jayson Luis da Silva Ribeiro, Anderson Orzari Ribeiro, Ricardo Gaspar

DOI: 10.36229/978-65-5866-032-3.CAP.04

Capítulo 5: Desenvolvimento de modelos de apresentação de conteúdo baseados em estilos de aprendizagem

Brunno José Fagundes, Rejane Frozza, Liane Mahlmann Kipper, Thaisi dos Santos Fagundes, Danielli Cossul

DOI: $10.36229 / 978-65-5866-032-3 . C A P .05$

Capítulo 6: Melhoria da qualidade e produtividade na linha de produção de uma empresa de ar-condicionado do Polo Industrial de Manaus.

Luciana Oliveira do Valle Carminé, Adriano Franco da Silva, Michelle Teles de Abreu, Luiz Vitor de Oliveira Gonzaga

DOI: 10.36229/978-65-5866-032-3.CAP.06

Capítulo 7: Melhoria no controle de estoque: Estudo de caso em uma empresa no Polo Industrial de Manaus - AM 55

Luciana Oliveira do Valle Carminé, Carlos Alberto Santos Nascimento, Claudemir Moraes de Sá, Daniel Maciel de Menezes

DOI: $10.36229 / 978-65-5866-032-3 . C A P .07$ 


\section{SUMÁRIO}

Capítulo 8: Aplicabilidade da ferramenta kaizen em uma empresa de ar-condicionado em Manaus 65

Luciana Oliveira do Valle Carminé, Clayberson Alves Carvalho, Paulo Christian Bezerra Pastor, Kennedy França Kramer

DOI: $10.36229 / 978-65-5866-032-3 . C A P .08$

Capítulo 9: Análise de capacidade produtiva baseada na simulação de processos..... 74 Reginaldo Otto Nau, Silvio Luiz dos Santos Alvim, Ottomar Antônio Galizio de Oliveira DOI: $10.36229 / 978-65-5866-032-3 . C A P .09$

Capítulo 10: Análise da capacidade em uma empresa no setor de confecções: Um estudo de caso acerca de fatores que causam perdas produtivas. 83

Rafael de Azevedo Palhares, Jedson Oriel de Melo Nogueira, Denyeivisson da Silva Freire, Joel da Costa Câmara Neto Segundo, Marcos Antônio Araújo da Costa

DOI: $10.36229 / 978-65-5866-032-3 . C A P .10$

Capítulo 11: Aplicação do MASP: Um estudo de caso de pizzaria em Belo Horizonte93 Bárbara Gabrielle Silva, Ana Luiza Figueiredo Viegas, Paulo Fernandes Sanches Junior, Luciano dos Santos Diniz

DOI: 10.36229/978-65-5866-032-3.CAP.11

Capítulo 12: Melhoria do processo produtivo de uma pequena empresa através da análise do mapeamento de fluxo e valor 104

Luiz Claudio Lopes Pinheiro, Carlo Rossano Manica

DOI: 10.36229/978-65-5866-032-3.CAP.12

Capítulo 13: Os desafios da empresa contemporânea: Lean Manufacturing \& Sustentabilidade.

Antonio Carlos Freire Roboredo

DOI: 10.36229/978-65-5866-032-3.CAP.13

Autores. 


\section{Capítulo 1}

\section{Viabilidade econômica dos veículos híbridos: Uma análise comparada baseada no payback}

\section{Yohana de Azevedo Carvalho \\ Luiza Maciel Gonçalves \\ Rodrigo Zaban Cipriano \\ Felipe Amorim Soares Macedo \\ Luan Santos}

Resumo: Este trabalho procura analisar, a partir da aplicação da técnica de payback, se a aquisição de um veículo híbrido (movido à gasolina e à energia elétrica) possui vantagens econômicas e financeiras, além das vantagens ambientais relacionadas a redução de emissão de poluentes em comparação com veículos movidos somente a combustão. Para isso, definiu-se dois automóveis com características semelhantes, um híbrido e um movido à gasolina, para comparação e cálculo do tempo de retorno de investimento. Tal estudo será feito através de pesquisas bibliográficas, documentais, artigos, leis e sites. 0 resultado demonstra que o payback para aquisição do carro híbrido é realizado em 6,99 anos. Nota-se que esse período é elevado em comparação com o tempo em que o motorista utiliza o mesmo carro. Dessa forma, constata-se que a aquisição de um veículo híbrido não apresenta vantagens econômicas em relação aos modelos tradicionais. Porém, questões importantes devem ser consideradas, como a redução da emissão de gases tóxicos pelos veículos híbridos.

Palavras-chave: Payback, Carro Híbrido, Automóvel, Retorno de Investimento. 


\section{INTRODUÇÃO}

Em 1908, o engenheiro americano Henry Ford inovou os meios de produção dos automóveis ao desenvolver a produção em larga escala, fator relevante para tornar o valor do automóvel mais acessível. O primeiro modelo, Ford T, vendeu 15 milhões de unidades entre os anos de 1908 e 1927 (WEBMOTORS, 2008). Este modelo de produção revolucionou a indústria automobilística e se estendeu a outros segmentos industriais, proporcionando o surgimento das linhas de montagem e provocando uma mudança nos métodos e conceitos de fabricação (RACHID DA SILVA, 2011). Como consequência, o Fordismo tem sua importância reconhecida até os dias atuais.

No Brasil, atualmente existem 67 empresas inscritas na Associação Nacional dos Fabricantes de Veículos Automotores (ANFAVEA), com unidades distribuídas por 44 municípios. 0 ramo de atuação dessas indústrias envolve os setores de máquinas agrícolas, de veículos automotivos, de motores e componentes. Em 2007, foram produzidos em torno de 2,3 milhões de automóveis no país e, em relação ao tipo de combustível utilizado, 15,5\% são movidos a gasolina, 83,1\% são flex (álcool e gasolina) e 1,4\% são movidos a diesel. (ANFAVEA, 2019)

Embora o automóvel possua papel importante para a globalização e mobilidade social, o crescente aumento de veículos trouxe grandes impactos para a sociedade e meio ambiente, como emissão de $\mathrm{CO}_{2}$, poluição sonora, acidentes de trânsito, entre outros fatores.

Atualmente, o excesso de veículos automotores presentes nas ruas passou a ser direcionado como o maior responsável pela contaminação ambiental nas grandes cidades. Aproximadamente $70 \%$ poluentes do ar são produzidos pelos veículos, principalmente nas grandes cidades, como Rio de Janeiro e São Paulo (EPELBAUM, AGUIAR, 2002).

Neste contexto, a preocupação com questões ambientais e com o uso de recursos naturais tem se tornado cada vez maior. Em 2015, discutiu-se mundialmente os Objetivos de Desenvolvimento Sustentável (ODS) na Cúpula das Nações Unidas em que foram definidos 17 objetivos compostos por 169 metas a serem atingidas até 2030. Além de uma seção exclusivamente voltada para o meio ambiente, a agenda também apresenta outras seções importantes voltadas para as temáticas sociais, econômicas e institucionais.

Sendo assim, a adoção aos carros elétricos seria uma proposta para atender a agenda desenvolvida pela Organização das Nações Unidas, especialmente aos objetivos 12 e 13, Consumo e produção responsáveis e Ação contra a mudança global do clima, respectivamente. Comparados aos veículos de combustão pela queima de combustíveis fósseis, os carros elétricos apresentam grandes vantagens em redução da emissão de poluentes

Nesse sentido, este trabalho apresenta um estudo sobre a análise de investimento de um carro elétrico do tipo híbrido utilizando técnica de payback, buscando entender se sua aquisição é rentável em comparação a outro carro de características semelhantes. Partindo disso, busca-se analisar a viabilidade de compra de um carro híbrido, não só por questões ambientais, mas também por questões financeiras e econômicas.

\section{VEÍCULOS HÍBRIDOS E VEÍCULOS À COMBUSTÃO}

Segundo Vaz et al. (2015), os automóveis mais utilizados são os movidos por um motor a combustão interna, em geral a gasolina ou a diesel. E o seu princípio de funcionamento é baseado na compressão da mistura entre ar e combustível que ocorre no interior do motor. A compressão dessa mistura gera uma explosão, ocasionando na transferência da energia capaz de provocar o movimento do veículo.

Entretanto, o processo de combustão produz gases nocivos ao meio ambiente, sendo eliminados pelo escapamento do automóvel e liberados na atmosfera. Para Cesar et al. (2013), o aumento do número de veículos automotivos a combustão ao redor do planeta contribui para a poluição, o que para a WHO (2012), possui forte ligação com o desenvolvimento de doenças cardiovasculares e diversos tipos de câncer na população.

Cordani (1997), ressalta que na busca por estabilizar as concentrações de gases do efeito estufa na atmosfera e pela substituição de combustíveis fósseis por energias alternativas, foi sediado pelo Brasil em 1992, a Rio-92, conferência da Organização das Nações Unidas (ONU), marcada por estimular a conscientização global pela melhoria da qualidade do ar do planeta.

Após esta conferência, o setor automotivo foi estimulado a buscar por veículos mais eficientes e com menor impacto ambiental, voltando seu interesse para os veículos elétricos. Foi então que em 1997 no 
Japão, o Toyota Prius chegou ao mercado como o primeiro veículo híbrido produzido em massa (VAZ et al., 2015).

Raskin e Shah (2006), afirmam que veículos híbridos (Hybrid Electric Vehicles ou simplesmente HEV) são aqueles que combinam um motor a combustão interna com um gerador, bateria e um ou mais motores elétricos, com a intenção de reduzir o gasto de energia provocado pela ineficiência dos processos mecânicos do motor a combustão interna.

Entretanto, de acordo com Vaz et al. (2015), as baterias dos HEVs não podem ser carregadas diretamente na rede elétrica por não possuírem a estrutura necessária para realizar esse tipo de conexão. Portanto, segundo Santos et al. (2009), os veículos hibridos não dispensam o uso do combustível, pois a carga utilizada para recarregar sua bateria provém do próprio motor a combustão e de outros mecanismos. Porém, como o motor a combustão dos automóveis híbridos é menor do que o motor dos veículos movidos apenas à combustão, os HEVs emitem menores quantidades de gases poluentes e por um menor período de tempo.

Ressalta-se, porém, que no mercado automobilístico atual, outro modelo de veículo híbrido também existente é o Plug-in Hybrid Electric Vehicles (PHEV), caracterizado por um sistema de "plug-in", permitindo a conexão com a rede de elétrica para abastecimento da bateria utilizada para alimentar o motor elétrico do PHEV (SOUZA et al., 2016).

Além desses modelos, existem também os veículos puramente elétricos, desprovidos de motor de combustão interna: o movimento realizado por esses automóveis é gerado por utilização de baterias, placas fotovoltaicas, ou da própria rede elétrica, por exemplo (SOUZA et al., 2016). Os modelos elétricos e os PHEVs não serão abordados nesta pesquisa pois o Brasil não possui postos de abastecimento próprios para esse tipo de automóvel. Ademais, a análise sobre o tipo de energia utilizado para o abastecimento seria relativamente mais complexa, pois existem diversas fontes de produção de energia em território brasileiro.

No quesito eficiência de automóveis híbridos ou movidos a gasolina, Castro e Ferreira (2010), afirmam que apenas $15 \%$ da energia potencial de um combustível em um automóvel é efetivamente utilizada para movimentá-lo, além de que grande parte da ineficiência energética dos motores a combustão vem da dissipação de calor. Em contrapartida, de acordo com Vaz et al. (2015), os veículos híbridos, são de 30\% a 40\% mais eficientes que os modelos tradicionais a combustão interna, além de emitirem menos CO2.

Além disso, Raskin e Shah (2006), ressaltam que os sistemas elétricos tendem a quebrar com menos frequência do que os sistemas mecânicos convencionais. E, apesar da existência de um pequeno motor a combustão em veículos híbridos, estes não são utilizados para dar a partida, sendo utilizado o motor elétrico para o arranque, reduzindo as consequências do arranque a frio, como a emissão de gases tóxicos.

Para Raskin e Shah (2006), o mundo está à beira de uma grande transição para os veículos híbridos, que usam motores elétricos altamente eficientes. Este cenário de mudança de tecnologia promete aumentar a eficiência energética substancialmente, disponibilizando uma ampla gama de combustíveis e reduzindo significativamente a demanda por petróleo no setor de transporte. A tecnologia híbrida já está comercialmente disponível e, dentro de alguns anos, todas as principais montadoras oferecerão veículos híbridos.

\section{FUNDAÇÃO INSTITUTO DE PESQUISAS ECONÔMICAS (FIPE) E O IMPOSTO SOBRE A PROPRIEDADE DE VEÍCULOS AUTOMOTORES (IPVA)}

A Fundação Instituto de Pesquisa Econômicas, a Fipe, é uma fundação de direito privado, sem fins lucrativos. Usando a instrumentação teórica para estudar os fenômenos sociais e econômicos, ela contribuí para o desenvolvimento de políticas econômicas e sociais, desenvolvimento sustentável e um debate sobre os problemas socioeconômicos do Brasil.

Um dos indicadores que a Fipe formula é a tabela sobre os preços dos veículos. Ela expressa os preços médios de veículos anunciados pelos vendedores, no mercado nacional, servindo apenas como parâmetro para as negociações e avaliações sobre esses veículos. Os preços sofrem alteração dependendo do estado de conservação, região do país, cor e acessórios ou qualquer outro fator que altere a função de oferta e procura do veículo. Os valores são expressos em reais do mês/ano de referência. 
O Imposto sobre a Propriedade de Veículos Automotores (IPVA) é recolhido pelos governos estaduais e é dividido entre os governos municipais, estaduais e federal, com seus valores recolhidos sendo investidos em várias áreas, não necessariamente em mobilidade.

No estado do Rio de Janeiro, existe a Lei no 2877, de 22 de dezembro de 1997. Por ela, é estabelecido que esse imposto é anual. No Art. 8o que estabelece a base de cálculo para carro novo diz que: "o valor venal será o preço comercial tabelado pelo órgão competente ou, na sua falta, o preço à vista constante do documento fiscal emitido pelo revendedor." No Art. $10^{\circ}$ que alterado pela lei 7068/2015 estabelece uma alíquota de 4\% sobre o valor da tabela FIPE para automóveis de passeio à gasolina e diesel. Essa mesma lei também acrescenta na lei original de 1997 a taxa de 1.5\% para veículos híbridos que possuem mais de um motor de propulsão, usando cada um seu tipo de energia para funcionamento sendo que a fonte energética de um dos motores seja a energia elétrica.

Segundo o §2을 do Art. 11으 da lei 2877, de 22 de dezembro de 1997 o governador do estado do Rio de Janeiro estabeleceu no decreto no 46.516 de 05 dezembro de 2018 que quando o IPVA é pago em cota única antes da data de vencimento há um desconto de $3 \%$ do seu valor total.

\section{METODOLOGIA}

\subsection{ANÁLISE DE INVESTIMENTO: PAYBACK}

Diante de um cenário de intensa concorrência empresarial, uma gestão financeira eficaz é imprescindível para a sustentabilidade e sobrevivência das organizações. Segundo Neto (1992), o estudo de avaliação de investimentos refere-se às decisões de aplicações de capital em projetos que prometem retornos por vários períodos consecutivos.

Alguns métodos utilizados para este tipo de estudo são: Valor Presente Líquido (VPL), Taxa interna de Retorno (TIR) e Payback. Neste trabalho, aplicaremos a técnica de Payback que é uma das mais populares técnicas de análise de investimento (ROSS et al., 2015). De forma complementar, para Nogueira (2011), payback é um método que avalia o tempo de recuperação do capital investido. Dessa forma, se o tempo de retorno do capital investido na alternativa em análise estiver dentro do prazo estabelecido pela empresa, a alternativa será viável.

Além disso, ressalta-se que há dois tipos de cálculo do payback: payback simples e payback descontado. 0 payback simples calcula o tempo de retorno do investimento inicial até o momento no qual o ganho acumulado se iguala ao valor deste investimento. Este método apresenta vantagens como sua simplicidade, facilidade de compreensão e de cálculo. Como desvantagem, tem-se o fato de que não é considerado o valor do dinheiro no tempo.

Por outro lado, o payback descontado considera-se o valor do dinheiro no tempo. Porém, os dois métodos apresentam a desvantagem da miopia financeira, pois a análise só é realizada até a recuperação do capital, sem considerar os fluxos de caixa posteriores.

\subsection{PROCEDIMENTO}

Será realizada uma análise comparativa entre duas opções especificas de automóvel disponíveis no mercado brasileiro. Uma delas envolve um veículo com motor abastecido por gasolina, que, embora tenha um preço de venda mais acessível, possui como fonte de alimentação uma combustão altamente poluente, além de relativamente cara. A outra opção, o veículo híbrido, possui menor destaque no país, apresentando em torno de oito modelos disponíveis no mercado. No entanto, é valido ressaltar que o mesmo apresenta uma drástica redução de poluentes, por depender menos de uma alimentação à gasolina.

Como forma de comparação que melhor se adequasse à pesquisa proposta, dois modelos foram escolhidos, seja em potência dos motores, preço e consumo de combustível. 0 automóvel com alimentação à gasolina se trata do Ford Focus 2.0 1.6V SE Plus Flex 5p Aut, com o valor de $\mathrm{R} \$ 83.400,00$. Já o veículo de modelo híbrido é o Toyota Prius Hybrid 1.8 16V 5p Aut., com o valor de R\$ 119.784,00, ambas informações retiradas da tabela FIPE.

Para que o tema tenha um detalhamento mais preciso, optou-se por tomar como objetivo, o método de pesquisa descritiva e exploratória, baseada em estudos e análises dos motores com as duas funcionalidades especificas. Tal metodologia tem por finalidade aprofundar o conhecimento sobre ambos 
e, a partir de analises comparativas, financeiras e ambientais, a médio e a longo prazo, mostrar com clareza qual opção é mais viável, tanto para determinado consumidor, quanto para a natureza.

Partindo de uma abordagem quali-quantitativa, será possível adquirir uma análise completa do tema proposto. Pois, com um estudo quantitativo, conhecimentos detalhados de condições físicas e de rendimento serão analisados e, partindo deles, cálculos e analises de comparação poderão ser feitas a partir de uma abordagem qualitativa. Para que tais abordagem sejam completas, serão necessários métodos matemáticos de payback descontado.

Com a intenção de enriquecer a abordagem anterior, um método mais indutivo e dialético será primordial para uma análise criteriosa do estudo. De forma dialética, será possível comparar as principais características dos diferentes modelos apresentados e, partindo desse pressuposto, uma análise indutiva poderá inferir os resultados de forma definitiva. Portanto, para trazer um maior embasamento ao método proposto, serão utilizados dados estruturais descritivos e concretos, vindos de estudiosos e pesquisadores do cenário automobilístico. Além disso, será necessário um auxilio exploratório, utilizando de ferramentas como o FIPE e valores retirados do IPVA para aquisição de dados específicos e detalhados dos modelos de veículo analisados. Com isso, uma pesquisa mais aprofundada e estratégica será posta em prática, para que haja a possibilidade de ser tomada como exemplo de opinião na decisão de compra.

0 enfoque deste tema é de severa relevância, com suma relação ao impacto ambiental que assola de forma crescente o planeta. Além disso, tal pesquisa é importante para apresentar a possível viabilidade de compra do veículo híbrido, que poderá trazer economia ao consumidor, e uma forma de reduzir drasticamente a emissão de poluentes.

Por fim, o procedimento mais viável para o andamento do estudo, será realizado a partir de pesquisas bibliográficas e documentais, para um estudo especifico de rendimento, duração e viabilidade dos veículos analisados, partindo de estudos acadêmicos sobre o assunto, de leis e de sites especializados.

\section{RESULTADOS}

Primeiramente, para a escolha dos carros a serem comparados considerou-se os fatores: preço, potência do motor a combustão e o consumo de combustível dos automóveis. Além disso, ressalta-se que foi fixado uma distância para o cálculo da utilização da gasolina.

Os carros escolhidos foram o Toyota Prius Hybrid 1.8 16V 5p Aut., com o valor de R $\$ 119.784,00$ e o Ford Focus 2.0 1.6V SE Plus Flex 5p Aut, com o valor de R \$ 83.400,00, ambas informações retiradas da tabela FIPE. Fixamos os preços da data de acesso da tabela para os carros escolhidos e, como o calculo do IPVA leva em consideração esse valor, ele estando fixo também não ocorrerá alteração no seu valor. Justifica-se a escolha desses veículos através da semelhança entre as características dos fatores definidos como critério de escolha.

Para inicio dos cálculos, foi considerado um morador de Rio das Ostras que trabalha na cidade de Macaé e percorre diariamente, de segunda a sexta, uma distância de 54 quilômetros. Aos fins de semana, ele percorre uma distância de 27 quilômetros. Além disso, fixou-se o preço da gasolina, conforme reportagem apresentada pelo Balanço Geral (2019) na cidade de Macaé-RJ, no mês de junho, de R \$ 5,19.

Para determinar a quantidade de litros de gasolina que cada carro utiliza a partir da quilometragem definida no parágrafo anterior, os valores foram dados a partir da resolução da fórmula descrita abaixo.

$$
\text { Cosumo de gasolina }(L)=\frac{\operatorname{distância~}(K m)}{\operatorname{Eficiência~do~} \operatorname{carro}\left(\frac{K m}{L}\right)}
$$

Além disso, estabeleceu-se para a utilização nos cálculos de gasto mensal, o valor de 23 dias úteis e 7 dias de fim de semana. A partir desses valores, chegou-se ao resultado de 1.431 quilômetros mensalmente percorridos.

Ao realizar-se os cálculos, obteve-se o valor de 9,7km/L de consumo mensal de combustível para o veículo Ford Focus e o valor 18,9 km/L para o veículo Toyota Prius. Ambos valores foram multiplicados por 12, para a estipulação do consumo anual de combustível dos automóveis. 


$$
\begin{aligned}
& \text { Consumo do Ford Focus }(L)=\frac{1.431(\mathrm{Km})}{9,7\left(\frac{\mathrm{Km}}{\mathrm{L}}\right)} \times 12=1.770,24(\mathrm{~L}) \\
& \text { Consumo do Toyota Prius }(L)=\frac{1.431(\mathrm{Km})}{18,9\left(\frac{\mathrm{Km}}{\mathrm{L}}\right)} \times 12=908,52(\mathrm{~L})
\end{aligned}
$$

A partir do o valor de consumo dado em litros, estimou-se o gasto anual utilizando o preço da gasolina apresentado anteriormente.

$$
\begin{aligned}
& \text { Gasto do Ford Focus }(R \$)=1.770,24(L) \times 5,19\left(\frac{R \$}{L}\right)=9.187,55(R \$) \\
& \text { Gasto do Toyota Prius }(R \$)=908,52(L) \times 5,19\left(\frac{R \$}{L}\right)=4.715,22(R \$)
\end{aligned}
$$

Além disso, também se considerou os valores de IPVA para o cálculo do payback. Para definição dos valores do imposto, utilizou-se as taxas definidas por lei para os carros à gasolina e híbridos, as quais incidem sobre os valores dos automóveis disponíveis na tabela FIPE. Como a taxa é de 4\% para automóveis de passeio à gasolina, para o carro Ford Focus, o valor do IPVA é de $\mathrm{R} \$ 3.336,00$. Por outro lado, o automóvel híbrido Toyota Prius, possui uma taxa de 1,5\%, logo, o valor do seu IPVA é de R\$1.796,76. Ressalta-se que o preço do IPVA foi considerado fixo para todos os anos do cálculo.

Para o cálculo do método de investimento payback descontado foi utilizado como investimento inicial a diferença dos preços de compra, conforme fórmula abaixo.

$$
\text { Investimento Inicial }(R \$)=119.784,00(R \$)-83.400,00(\mathrm{R} \$)=36.384,00(\mathrm{R} \$)
$$

Para a anuidade de retorno, fez-se a diferença dos gastos anuais de cada carro com combustível mais o IPVA, conforme mostrado abaixo:

$$
\begin{aligned}
\operatorname{Retorno}(R \$) & =[9.187,55(R \$)+3.336,00(R \$)] \\
& -[4.715,22(R \$)+1.1796,76(R \$)]=6.011,57(R \$)
\end{aligned}
$$

Para cálculo da taxa, utilizou-se a taxa de inflação do ano 2018, de 3,75\%, conforme informado pela Agência Brasil.

A partir desses dados, formulou-se no Excel, uma tabela com os valores referentes ao ano, fluxo, fluxo descontado e saldo, conforme necessário para cálculo do payback descontado, descrita a seguir.

Tabela 1 - Payback Descontado

\begin{tabular}{|c|c|c|c|}
\hline ANO & FLUXO (R\$) & $\begin{array}{c}\text { FLUXO DESCONTADO } \\
(\mathrm{R} \$)\end{array}$ & SALDO (R\$) \\
\hline 0 & -36384 & -36384 & -36384 \\
\hline 1 & 6011,57 & 5794,284337 & $-30589,716$ \\
\hline 2 & 6011,57 & 5584,852373 & $-25004,863$ \\
\hline 3 & 6011,57 & 5382,990239 & $-19621,873$ \\
\hline 4 & 6011,57 & 5188,424327 & $-14433,449$ \\
\hline 5 & 6011,57 & 5000,890918 & $-9432,5578$ \\
\hline 6 & 6011,57 & 4820,135824 & $-4612,422$ \\
\hline 7 & 6011,57 & 4645,914048 & 33,4920667 \\
\hline
\end{tabular}

Baseando-se nos dados a cima, foi realizado o cálculo do prazo real no qual ocorre o retorno do investimento inicial e obteve-se o resultado abaixo. 


$$
\text { Período de retorno }(\text { ano })=6(\text { ano })+\frac{4.612,422(R \$)}{4.645,914(R \$)}=6,99(\text { ano })
$$

\section{CONCLUSÕES}

A partir dos dados analisados na comparação entre os dois modelos de automóveis selecionados, constatou-se que o payback ocorre em 6,99 anos. Segundo o InfoMoney (2019), o brasileiro é a população que mais troca de carro, possuindo um tempo médio de 1,7 ano de permanência com um mesmo veículo. Nota-se, então, que o payback para o investimento no veículo híbrido é superior à média do período de apropriação de um mesmo carro. Sendo assim, constata-se que, por questões financeiras e econômicas, o carro híbrido não apresenta grandes vantagens em relação aos carros movidos somente à combustão.

Todavia, como discutido anteriormente, os automóveis híbridos são até $40 \%$ mais eficientes que os automóveis com motores somente à combustão. Além disso, emitem uma quantidade consideravelmente menor de gases de efeito estufa (GEE), responsáveis pelas mudanças climáticas, sendo esta uma importante questão a ser considerada durante o estudo de aquisição de um automóvel.

Sovacool e Hirsh (2009) ressaltam também que veículos elétricos ou híbridos tendem a apresentar menores índices de "quebra" ou "falha" em relação aos modelos tradicionais, sendo também uma vantagem importante a ser considerada nesta comparação.

Em relação às limitações da pesquisa, destaca-se a falta de dados e informaç̧ões sobre o assunto abordado. Também se constatou que há poucos estudos exploratórios em relação a análise econômica em investimentos de carros elétricos ou híbridos. Para este assunto, é muito abordado as vantagens sobre as questões ambientais.

Evidencia-se que ainda há um baixo número de modelos de carros elétricos e híbridos fabricados e comercializados no Brasil, por isso, seus preços de comercialização ainda são superiores aos modelos tradicionais. Porém, espera-se que a tecnologia utilizada seja ainda mais difundida e que, nos próximos anos, esse valor adotado seja reduzido, trazendo assim a inclusão de vantagens financeiras na aquisição de veículos híbridos aos clientes.

\section{REFERÊNCIAS}

[1] AMÉRICO LOURENÇO DA SILVA, Juliana. Brasil tem a População que mais troca de carro. InfoMoney, 21 jul. 2014. Disponível em: <https://www.infomoney.com.br/minhas-financas/carros/noticia/3462560/brasil-tempopulacao-que-mais-troca-carro>. Acesso em: 29 jun. 2019.

[2] ASSAF NETO, A. Os métodos quantitativos de análise de investimentos. Scielo Analytics. São Paulo, outubro, 1992. Caderno de estudos no 6 .

[3] Associação Nacional dos Fabricantes de Veículos Automotores (ANFAVEA). (2019). Anuário da Indústria Automobilística Brasileira 2018. São Paulo.

[4] BRASIL. Decreto № 46.453, 10 de outubro de 2018. Dispõe sobre a aplicação da Lei Complementar Estadual № 182, de 20 de setembro de 2018, que estabelece a redução de multas e juros relativos aos débitos tributários de ICMS e de IPVA, inscritos ou não em dívida ativa, bem como multas impostas pelo TCE/RJ. Governador do Estado do Rio de Janeiro, Rio de Janeiro, RJ. Disponível em: < http://www.fazenda.rj.gov.br/sefaz/faces/oracle/webcenter/portalapp/pages/navigationrenderer.jspx?_afrLoop=22078577752490739\&datasource=UCMServer\%23dDocName\%3AWCC334363\&_adf.ctrlstate=dvhzb3inr_9>. Acesso em: 29 jun. 2017.

[5] BRASIL. Lei № 2877, 22 de dezembro de 1997. O imposto sobre a propriedade de veículos automotores (IPVA). Assembleia Legislativa do Estado do Rio de Janeiro, Rio de Janeiro, RJ. Disponível em: <http://alerjln1.alerj.rj.gov.br/CONTLEI.NSF/b24a2da5a077847c032564f4005d4bf2/fa1a422b516211130325657a0 064293f?OpenDocument>. Acesso em: 29 jun. 2017.

[6] CASTRO, Bernardo Hauch Ribeiro de; FERREIRA, Tiago Toledo; Veículos elétricos e Veículos elétricos: aspectos básicos, perspectivas e oportunidades. Veículos, BNDES Setorial 32, p. 267-310. 2010.

[7] CESAR, G. C. A.; NASCIMENTO, C. F. L.; CARVALHO, A.J. Associação entre exposição ao material particulado e internações por doenças respiratórias em crianças. Revista de Saúde Pública, v.47, n.6, p.1209-12, 2013.

[8] CORDANI, Umberto G.; MARCOVITCH, Jacques; SALATI, Eneas. Avaliação das ações brasileiras após a Rio-92. Estudos Avançados, 1997. Disponível em: <http://www.scielo.br/pdf/ea/v11n29/v11n29a19.pdf>. Acesso em: 28 
jun. 2019.

[9] EPELBAUM, Michel; AGUIAR, Alexandre. A influência da gestão ambiental na competitividade na cadeia automobilística. 2002. 15p. Engenharia de Produção, USP.

[10] FIPE. Fundação Instituto de Pesquisas Econômicas, c1973. Página inicial. Disponível em: <https://www.fipe.org.br/>. Acesso em: 29 jun. 2019.

[11] LEONARDO ANDRADE. Ford Focus Sedan 2019: preço, motor, consumo, versões (detalhes). Notícias Automotivas, c2005. Disponível em: < https://www.noticiasautomotivas.com.br/ford-focus-sedan/>. Acesso em: 29 jun. 2017.

[12] MOMENTo de ação global para as pessoas e o planeta. Nações Unidas Brasil. Disponível em: < https://nacoesunidas.org/pos2015/> Acesso em: 28 jun. 2019.

[13] NOGUEIRA, Edemilson. Introdução à Engenharia Econômica. São Carlos. EdUFSCar. 2011.

[14] OBJETIVOS de Desenvolvimento Sustentável (ODS). Itamaraty. Disponível em: <http://www.itamaraty.gov.br/pt-BR/politica-externa/desenvolvimento-sustentavel-e-meio-ambiente/134objetivos-de-desenvolvimento-sustentavel-ods> Acesso em: 28 jun. 2019.

[15] RACHID DA SILVA, Elenice. Análise do crescimento da motorização no Brasil e seus impactos na mobilidade urbana. 2011. 142p. UFRJ/COPPE.

[16] RASKIN, A.; SHAH, S. The emergence of hybrid vehicles: ending oil's stranglehold on transportation and the economy. Alliance Bernstein Research on Strategy Change, jun. 2006. Disponível em: <http://www.alliancebernstein.com/CmsObjectCareers/pdf/BlackBook_HybridVehicles_0606.pdf >. Acesso em: 27 jun. 2019.

[17] RICARDO DE OLIVEIRA. Toyota Prius 2019: preço, consumo, fotos, equipamento (e detalhes). Notícias Automotivas, c2005. Disponível em: <https://www.noticiasautomotivas.com.br/toyota-prius/>. Acesso em: 29 jun. 2019.

[18] ROSS, S. A; WESTERFIELD, R.W; JAFFE, J; LAMB, R. Administração Financeira. Porto Alegre. AMGH Editora. $10^{\mathrm{a}}$ edição. 2015.

[19] SAMY, Rodrigo. Ford T, primeiro carro do mundo produzido em série, faz cem anos. Webmotors. 2008. Disponível em: < https://www.webmotors.com.br/wm1/cultura-auto/ford-t-primeiro-carro-do-mundo-produzidoem-serie-faz-cem-anos> Acesso em: 26 jun. 2019.

[20] SANTOS, Gustavo Antônio Galvão dos; SANTOS, Bruno Galvão dos; MEDEIROS, Rodrigo Loureiro; D’ARAUJO, Roberto Pereira. Carro elétrico, a revolução geopolítica e econômica do século XXI e o desenvolvimento do Brasil. OIKOS, Rio de Janeiro, v.8, n.2, p.325-353, 2009.

[21] SOUZA, L. P.; LORA, E. E. S.; PALACIO, J. C. E.; ROCHA, M. H.; RENÓ, M. L. G. Análise do ciclo de vida de veículos convencional, elétrico e híbrido plug-in para condições brasileiras. Revista Ibero-Americana de Ciências Ambientais, v.7, n.3, p.144-159, 2016. Disponível em <http://doi.org/10.6008/SPC2179-6858.2016.003.0012>. Acesso em 28 jun. 2019.

[22] SOVACOOL, Benjamin; HIRSH, Richard. Beyond batteries: an examination of the benefits and barriers to plugin-hybrid electric vehicles (PHEVs) and a vehicle-to-grid (V2G) transition. 3 Ed. Energy Policy, n. 37, p. 1095-1103. Elsevier, 2009.

[23] VAZ, Luiz Felipe Hupsel; BARROS, Daniel Chiari; CASTRO, Bernardo Hauch Ribeiro de. Veículos híbridos e elétricos: sugestões de políticas públicas para o segmento. BNDES Setorial, Rio de Janeiro, n. 41, p. [295]-344, mar. 2015.

[24] VITOR ABDALA. Inflação oficial fecha 2018 em 3,75\%. Agencia Brasil, 11 de jan. 2019. Disponível em < http://agenciabrasil.ebc.com.br/economia/noticia/2019-01/inflacao-oficial-fecha-2018-em-375>. Acesso em: 29 jun. 2019.

[25] WHO - World Health Organization. IARC: Diesel Engine Exhaust Carcinogenic. 2012. Disponível em: <https://www.iarc.fr/wp-content/uploads/2018/07/pr213_E.pdf>. Acesso em: 27 jun. 2019. 


\section{Capítulo 2}

Análise financeira de uma empresa do setor de consumo: 0 caso das Lojas Renner no período de 2005 a 2014

Paula Prenholato Alves

Ruth Margareth Hofmann

Resumo: A valorização de uma empresa é construída principalmente através de resultados positivos gerados pela empresa, seja no aspecto de gestão, finanças, marketing ou qualidade dos produtos ou serviços da empresa. Para qualificar o resultado financeiro de uma empresa, é de extrema importância a análise minuciosa de suas condições internas antes de qualquer decisão estratégica para a organização. E para tal, são particularmente relevantes os indicadores construídos no âmbito da Análise Financeira de Empresas (AFE), que são importantes ferramentas gerenciais de estratégias orientadas pela valorização das empresas. 0 presente trabalho teve por objetivo realizar uma análise financeira das Lojas Renner S.A., tomando como base seu desempenho entre 2005 e 2014. Calcularam-se os índices de liquidez, lucratividade, endividamento, rentabilidade, entre outros, a partir de documentos contábeis da empresa. A partir das análises, têm-se indícios de que há viabilidade em investir nas Lojas Renner S.A.

Palavras-chave: Análise Financeira de Empresas, Indicadores Financeiros, Investimento. 


\section{INTRODUÇÃO}

O setor de varejo contempla diversas formas de comércio, dentre elas estão lojas de departamentos, vestuário, eletrodomésticos e eletrônicos, etc. É um setor conhecido principalmente pela venda de uma grande diversidade de produtos e caracterizado por uma alta competitividade, visto que existem várias empresas vendendo produtos semelhantes. Na classificação da BM\&FBOVESPA, o setor de varejo está especificado como um setor de consumo cíclico e, dentro deste setor, há a ramificação em subsetores que agrupam os segmentos relacionados a seus respectivos subsetores. De uma maneira geral, é possível afirmar que o setor varejista é marcado por uma alta sensibilidade frente ao mercado econômico, principalmente por envolver produtos de consumo cíclico. Isso significa que o cenário econômico pode afetar aspectos como, por exemplo, o poder aquisitivo das classes sociais, o que influencia diretamente o consumo desses produtos. Dentro desse contexto, o objetivo do presente trabalho é realizar uma análise financeira de uma empresa do setor de varejo, as Lojas Renner, analisando se é viável investir na empresa. Para chegar em tal parecer, é necessário não apenas avaliar o desempenho da empresa através de indicadores financeiros.

A análise financeira de empresas é um tipo de análise dentro da avaliação de empresas, também conhecida como valuation, cujo foco principal é o de possibilitar meios para que os investidores possam decidir qual a melhor forma de alocar seus recursos. Assim, a análise financeira é de interesse dos investidores e também da empresa no sentido de retornar informações que são vantajosas para a gestão financeira da empresa. É possível que, baseando-se em uma análise financeira, a empresa tome decisões de forma a direcionar seu planejamento para obter resultados melhores, pensando na perspectiva dos investidores. É nessa nessa linha de pensamento que o presente trabalho visa analisar financeiramente as Lojas Renner, apresentando a evolução de indicadores considerados pertinentes para medir seu desempenho no período de 2005 a 2014. (Penman, 2007; Palepu et al, 2004 e Galdi, 2008)

Criado em 1912, o Grupo A. J. Renner iniciou suas atividades produzindo capas de lã e, mais tarde, optou pela separação de seus negócios devido ao crescimento, surgindo as Lojas Renner S.A. em 1965, que atua no segmento de vestuário, calçados, acessórios, moda íntima, cosméticos, perfumaria, além de seguros, empréstimos e títulos de capitalização. A empresa possui sede em Porto Alegre, Rio Grande do Sul e hoje conta com cerca de 13.350 funcionários. As Lojas Renner S.A. abriu seu capital em 1967 com o código de negociação LREN3, comercializando suas ações através do Novo Mercado da BM\&FBOVESPA. Como parte das exigências para poder parcipar da lista de empresas do Novo Mercado, a empresa tem a obrigação de divulgar suas informações financeiras.

Em relação à estrutura do trabalho, há 4 seções além da presente introdução. Com o intuito de desenvolver uma análise financeira consistente, selecionou-se o período de 2005 a 2014, uma vez que nesse período foi possível encontrar um padrão na metodologia de elaboração dos documentos financeiros da empresa. A seção 2 abrange a revisão literária relacionada à Análise Financeira de Empresas (AFE) como campo de conhecimento e aos indicadores financeiros selecionados para a análise. A seção 3 diz respeito à metodologia utilizada no desenvolvimento deste trabalho. Finalmente, a seção 5 conta com os resultados encontrados e, na sequência, as considerações finais.

\section{A ANÁLISE FINANCEIRA DE EMPRESAS (AFE) E SEUS INDICADORES}

A análise financeira consiste em um método capaz de fornecer informações determinantes sobre a performance de uma empresa. Essa técnica de análise é importante não apenas para auxiliar os investidores na alocação de seus recursos, mas também é contribuinte para a própria empresa no sentido de se auto-avaliar e tomar as decisões mais sensatas de acordo com o desempenho encontrado na análise. Matarazzo (1998) reforça dizendo que o principal objetivo de uma análise financeira é o de avaliar a empresa com vistas a tomar as melhores decisões de acordo com o cenário em que esta se encontra. 0 autor explica ainda que, seguindo a técnica de análise financeira, deve-se primeiro selecionar os indicadores mais pertinentes para medir o desempenho da empresa, comparar os resultados destes indicadores com o que é considerado um padrão, interpretar tais resultados e tirar conclusões sobre eles e, finalmente, tomar as decisões viáveis para a empresa. Para Helfert (2000), os principais envolvidos diretamente ao comportamento financeiro de uma empresa são os investidores, os administradores e os fornecedores/credores. Ele esclarece que a gestão da empresa acaba estando mais próxima da performance da empresa, uma vez que estes são os responsáveis pelos resultados atingidos pela empresa, sejam positivos ou negativos. Além disso, os investidores estão diretamente envolvidos com a rentabilidade que a empresa pode proporcionar sobre seus patrimônios líquidos e investimentos, preocupados em obter como resultado a valorização da empresa. Os fornecedores e credores, por sua vez, 
concedem recursos financeiros para a empresa e possuem como principal receio a capacidade que a empresa tem em arcar com suas obrigações, pagando aquilo que deve.

Em relação à contribuição proporcionada pela Análise Financeira de Empresas (AFE), como já foi comentado anteriormente, um assunto de destaque é o aumento do valor das empresas, algo de extrema importância para os investidores e proprietários da empresa. Nesse contexto, Benjamin Graham foi um dos precursores na literatura acerca da análise de valor, também conhecida como Valuation. Graham (2007) salienta alguns pontos que mostram a expressividade da avaliação de empresas, tais como a significância das ações de uma empresa para o proprietário, a aletoriedade presente no mercado acionário, a relação risco e retorno presente em um investimento e a margem de segurança ao investir. No entanto, o autor alerta que no caso de previsões futuras sobre a performance de uma empresa, não se pode levar em conta os resultados encontrados na análise a não ser que eles sejam os causadores dessa performance.

Assim, tendo em vista a relevância da análise financeira, foram selecionados alguns indicadores que se destacam na literatura existente sobre o assunto, conforme se pode observar no Quadro 1:

Quadro 1- Índices Financeiros utilizados no contexto da análise de empresas: cálculo e interpretação

\begin{tabular}{|c|c|c|}
\hline Índice & $\begin{array}{l}\text { Fórmula } \\
\text { Liquidez }\end{array}$ & Indica \\
\hline $\begin{array}{l}\text { Índice de Liquidez } \\
\text { Corrente (ILC) }\end{array}$ & $I_{L C}=\frac{\text { Ativo Circulante }}{\text { PassivoCirculante }}$ & $\begin{array}{l}\text { Capacidade de honrar } \\
\text { compromissos em curto prazo com } \\
\text { suas disponibilidades financeiras, } \\
\text { contas a receber e estoques. }\end{array}$ \\
\hline $\begin{array}{l}\text { Índice de Liquidez } \\
\text { Imediata (ILI) }\end{array}$ & $I_{L I}=\frac{\text { Disponível }}{\text { PassivoCirculante }}$ & $\begin{array}{l}\text { Capacidade de cumprir com } \\
\text { obrigações no curto prazo contando } \\
\text { com suas disponibilidades. }\end{array}$ \\
\hline $\begin{array}{l}\text { Índice de Liquidez } \\
\text { Seca (ILS) }\end{array}$ & $I_{L S}=\frac{(\text { Ativo Circulante }- \text { Estoques })}{\text { PassivoCirculante }}$ & $\begin{array}{l}\text { Capacidade de honrar } \\
\text { compromissos no curto prazo sem } \\
\text { levar em conta os estoques. }\end{array}$ \\
\hline \multicolumn{3}{|c|}{ Lucratividade } \\
\hline $\begin{array}{l}\text { Margem de Lucro } \\
\text { Líquido }\left(\mathrm{M}_{\mathrm{LL}}\right)\end{array}$ & $M_{L L}=\frac{\text { Lucro Líquido }}{\text { Receita Líquida de Vendas }}$ & $\begin{array}{l}\text { Eficiência em gerar lucro em sua } \\
\text { atividade operacional após o } \\
\text { pagamento do Imposto de Renta e } \\
\text { dividendos. }\end{array}$ \\
\hline $\begin{array}{l}\text { Margem de Lucro } \\
\text { Operacional (MLO) }\end{array}$ & $M_{L O}=\frac{\text { Lucro Operacional }}{\text { Receita Líquida de Vendas }}$ & $\begin{array}{l}\text { Eficiência em gerar lucro em sua } \\
\text { atividade operacional. }\end{array}$ \\
\hline \multicolumn{3}{|c|}{ Endividamento } \\
\hline $\begin{array}{l}\text { Índice de } \\
\text { Alavancagem }\left(\mathrm{I}_{\mathrm{A}}\right)\end{array}$ & $I_{A}=\frac{\text { PassivoTotal }}{\text { PatrimonioLíquido }}$ & $\begin{array}{l}\text { Proporção entre dívidas e capital } \\
\text { dos proprietários no financiamento } \\
\text { do ativo. }\end{array}$ \\
\hline $\begin{array}{l}\text { Índice de } \\
\text { Endividamento } \\
\text { Bancário (IEB) }\end{array}$ & $\begin{array}{l}I_{E B} \\
=\frac{\text { Empréstimos Bancários de Curto Prazo }}{\text { Passivo Circulante }}\end{array}$ & $\begin{array}{l}\text { Percentual de representação dos } \\
\text { empréstimos bancários de curto } \\
\text { prazo sobre o total de dívidas de } \\
\text { curto prazo. }\end{array}$ \\
\hline $\begin{array}{l}\text { Índice de } \\
\text { Endividamento Total } \\
\left(\text { IET }_{\text {ET }}\right.\end{array}$ & $I_{E T}=\frac{\text { Passivo Total }}{\text { Ativo Total }}$ & $\begin{array}{l}\text { Percentual de recursos de terceiros } \\
\text { no financiamento do ativo. }\end{array}$ \\
\hline \multicolumn{3}{|c|}{ Rentabilidade } \\
\hline $\begin{array}{l}\text { Retorno sobre o } \\
\text { Investimento (ROI) }\end{array}$ & $R O I=\frac{\text { Lucro Líquido }}{\text { Ativo Total }}$ & $\begin{array}{l}\text { Eficiência global em gerar lucros } \\
\text { com seus ativos. }\end{array}$ \\
\hline $\begin{array}{l}\text { Retorno sobre o } \\
\text { Patrimônio Líquido } \\
\text { (RPL) }\end{array}$ & $R P L=\frac{\text { LucroLíquido }}{\text { PatrimônioLíquido }}$ & $\begin{array}{l}\text { Eficiência global em gerar lucros } \\
\text { sobre o que foi investido pelos } \\
\text { proprietários. }\end{array}$ \\
\hline
\end{tabular}

Fonte: Elaborado a partir de Santos (2010).

Na visão de Artuso (2012), os indicadores de liquidez tem como principal propósito apresentar a situação da empresa em relação às obrigações que ela possui. 0 autor evidencia que o bom resultado que uma empresa pode atingir de acordo com seu desempenho depende principalmente de como é feita a gestão financeira, equilibrando e gerenciando a necessidade do uso de capital de terceiros e os próprios recursos da empresa, por exemplo. No entanto, Santos (2010) alerta que tais índices só podem ser vistos como 
satisfatórios caso os aumentos ou reduções no valor de ativos circulantes não impactem a capacidade que a empresa possui de pagar suas obrigações, bem como acarretar em perdas financeiras. De acordo com Silva (2010), a interpretação dos índices de liquidez segue a lógica, em geral, de que quanto maior o valor atingido pelo índice, melhor, desde que os demais fatores envolvidos tenham se mantido constantes.

Já em relação aos indicadores de lucratividade, Santos (2010) explica que as margens de lucratividade são capazes de indicar se a empresa gerou eficiência a partir de sua atividade operacional dentro de um determinado período. 0 autor afirma que uma situação favorável para a empresa consiste no aumento tanto das margens de lucratividade quanto da receita líquida de vendas da empresa. Entretanto, ele adverte que entre a Margem de Lucro Operacional $\left(\mathrm{M}_{\mathrm{LO}}\right)$, e a Margem de Lucro Líquido $\left(\mathrm{M}_{\mathrm{LL}}\right)$, o primeiro indicador é mais aconselhado para ser analisado, uma vez que este está ligado diretamente com o risco de a empresa faturar mais com seu negócio do que ter despesas, enquanto o segundo indicador pode não evidenciar a situação real da empresa quando há o envolvimento de venda de ativos da empresa.

Segundo Matarazzo (2010), os indicadores de endividamento ou também conhecidos como indicadores de estrutura de capital são determinantes para a tomada de decisão por parte da gestão financeira de uma empresa, pois a partir de seus resultados serão traçadas as estratégias para os recursos da empresa. Silva (2008) esclarece que os riscos envolvidos com a decisão de investir ou financiar recursos exigem uma análise criteriosa da gestão da empresa para que isso não prejudique seu desempenho. Além disso, Santos (2010) salienta que tais indicadores são vistos como satisfatórios caso a variação observada nestes gere aumento nas margens de lucratividade da empresa.

Santos (2010) explica que os índices de rentabilidade são obtidos a partir do confronto entre a Demonstração de Resultados do Exercício e o Balanço Patrimonial da empresa e estão relacionados com o retorno que a empresa obteve através dos capitais investidos. Na concepção de Matarazzo (2010), é por meio destes indicadores que se apuram os resultados atingidos pela empresa tendo em vista os recursos que foram investidos. Assim, analisando esses indicadores, é possível verificar quanto de retorno se obteve dentro de um determinado período. No entanto, Santos (2010) deixa claro que caso haja o envolvimento de venda de ativos da empresa, é recomendável que seja utilizado o lucro operacional ao invés do lucro líquido para o cálculo e afirma que o aumento do indicador de um ano para o outro é uma situação favorável e desejável.

\section{PROCEDIMENTOS METODOLÓGICOS}

0 presente trabalho consiste em um estudo de caso de caráter quantitativo. Tendo em vista o objetivo de analisar financeiramente as Lojas Renner, o trabalho buscou contemplar a literatura existente acerca da Análise Financeira de Empresas (AFE), apresentando os conceitos e as definições mais relevantes dentro desse contexto para orientar o desenvolvimento dos resultados. Dentro dessa perspectiva, foram calculados indicadores considerados pertinentes para a análise a partir de documentos financeiros disponibilizados pela empresa, tais como Relatórios Anuais, Demonstrativos Financeiros, Balanços Sociais, entre outros. No decorrer da análise, o foco foi identificar variações na evolução desses indicadores, comparando-as com o cenário encontrado no mercado econômico durante o período compreendido entre 2005 e 2014. 0 período de análise foi selecionado levando-se em conta a metodologia utilizada para o desenvolvimento dos documentos financeiros, buscando encontrar todas as informações necessárias nesse período. Além disso, foram selecionadas informações que pudessem destacar o potencial da empresa no mercado em que ela atua, tais como a comparação da empresa com as outras que atuam no mesmo segmento. A comparação entre o desempenho da empresa medido pelos indicadores usados na análise e o desempenho da economia brasileira medido por indicadores de conjuntura econômica teve como propósito destacar se houve algum impacto da economia no desempenho da empresa dentro do período analisado. Dessa forma, dispondo dessas informações, é possível ter indícios sobre o potencial do desempenho da empresa, o que é relevante para que os investidores possam decidir se é viável ou não investir nas ações da empresa.

\section{RESULTADOS}

Os resultados encontrados foram obtidos através de cálculos baseados nos documentos financeiros disponibilizados pela empresa. Além disso, o período de análise selecionado para contemplar esses dados utilizados para o cálculo foi o de 2005 a 2014, tendo em vista que durante esses período foi possível encontrar documentos desenvolvidos por metodologias semelhantes. 


\subsection{EVOLUÇÃO DOS ÍNDICES DE LIQUIDEZ}

Os índices de liquidez utilizados para o trabalho foram: Índice de Liquidez Corrente $\left(\mathrm{I}_{\mathrm{LC}}\right)$; Índice de Liquidez Imediata $\left(\mathrm{I}_{\mathrm{LI}}\right)$ e Índice de Liquidez Seca $\left(\mathrm{I}_{\mathrm{LS}}\right)$. É possível observar os valores referentes aos índices, bem como suas variações percentuais ao longo dos anos através das tabelas a seguir:

Tabela 1 - Índices de Liquidez das Lojas Renner (2005-2014)

\begin{tabular}{|c|c|c|c|c|c|c|c|c|c|c|}
\hline Índices & 2005 & 2006 & 2007 & 2008 & 2009 & 2010 & 2011 & 2012 & 2013 & 2014 \\
\hline ILC $_{\text {I }}$ & 1.62 & 1.41 & 1.27 & 1.36 & 1.47 & 1.92 & 1.92 & 1.45 & 1.55 & 1.72 \\
\hline I LI & 0.56 & 0.46 & 0.32 & 0.21 & 0.42 & 0.70 & 0.55 & 0.40 & 0.41 & 0.41 \\
\hline
\end{tabular}

Fonte: Elaborado a partir dos documentos financeiros disponibilizados pela Lojas Renner (2015)

Tabela 2 - Variação dos Índices de Liquidez das Lojas Renner (2005-2014)

\begin{tabular}{|c|c|c|c|c|c|c|c|c|c|c|}
\hline Variação & 2005 & 2006 & 2007 & 2008 & 2009 & 2010 & 2011 & 2012 & 2013 & 2014 \\
\hline \% ILC & - & $-13 \%$ & $-9 \%$ & $6 \%$ & $8 \%$ & $31 \%$ & $0 \%$ & $-25 \%$ & $7 \%$ & $11 \%$ \\
\hline$\%$ ILI $_{\text {LI }}$ & - & $-18 \%$ & $-29 \%$ & $-34 \%$ & $97 \%$ & $65 \%$ & $-22 \%$ & $-27 \%$ & $5 \%$ & $-1 \%$ \\
\hline$\%$ ILS & - & $-16 \%$ & $-8 \%$ & $2 \%$ & $11 \%$ & $30 \%$ & $-5 \%$ & $-24 \%$ & $9 \%$ & $10 \%$ \\
\hline
\end{tabular}

Fonte: Elaborado a partir dos documentos financeiros disponibilizados pela Lojas Renner (2015)

Analisando a evolução do Índice de Liquidez Corrente ( $\mathrm{I}_{\mathrm{LC}}$ ), percebe-se que os anos de 2010 e 2011 foram os anos em que a empresa teve a maior capacidade em cumprir com suas obrigações no curto prazo dentro do período analisado. 0 maior crescimento para esse indicador foi no biênio 2009-2010 e, apesar de ter tido o maior decréscimo em 2012, o índice tem voltado a crescer nos últimos anos, o que é favorável para a empresa.

Para poder medir a capacidade da empresa em quitar suas obrigações em um curto prazo contando apenas com as disponibilidades da empresa, calculou-se o Índice de Liquidez Imediata ( $\mathrm{I}_{\mathrm{LI}}$ ) ao longo do período analisado, que mostra que o ano de 2010 foi o ápice para esse índice. No entanto, ele apresentou queda entre 2005 e 2008, voltando a subir consideravelmente até 2010 e no biênio 2010-2012 caiu novamente. No último ano, a empresa melhorou bem pouco a sua capacidade em pagar suas obrigações a curto prazo com suas disponibilidades financeiras. 0 baixo índice em 2008 se explica como um reflexo da crise econômica mundial e já entre 2008 e 2010 houve um aumento significativo nas disponibilidades da empresa. Outro fator relevante em 2010 foi a retomada da aceleração econômica, bem como a queda dos índices de desemprego, baixos graus de inadimplência e a expansão salarial, que teve impacto no crescimento econômico.

Já o Índice de Liquidez Seca $\left(\mathrm{I}_{\mathrm{LS}}\right)$, por outro lado, apresenta a capacidade de a empresa quitar suas obrigações no curto prazo sem levar em conta os estoques que ela possui, já que estes podem ou não serem vendidos. Assim, analisando a evolução deste indicador, observa-se que assim como os outros índices de liquidez, este indicador apresentou decrescimento nos primeiros anos, tendo seu menor valor em 2007. Apesar de depois disso este indicador ter diminuído, nos últimos anos ele tem voltado a crescer, o que traz boas expectativas para a empresa nos próximos períodos.

0 Gráfico 1 apresenta a evolução de todos os índices de liquidez calculados para as Lojas Renner. 
Gráfico 1 - Evolução dos Índices de Liquidez das Lojas Renner (2005-2014)

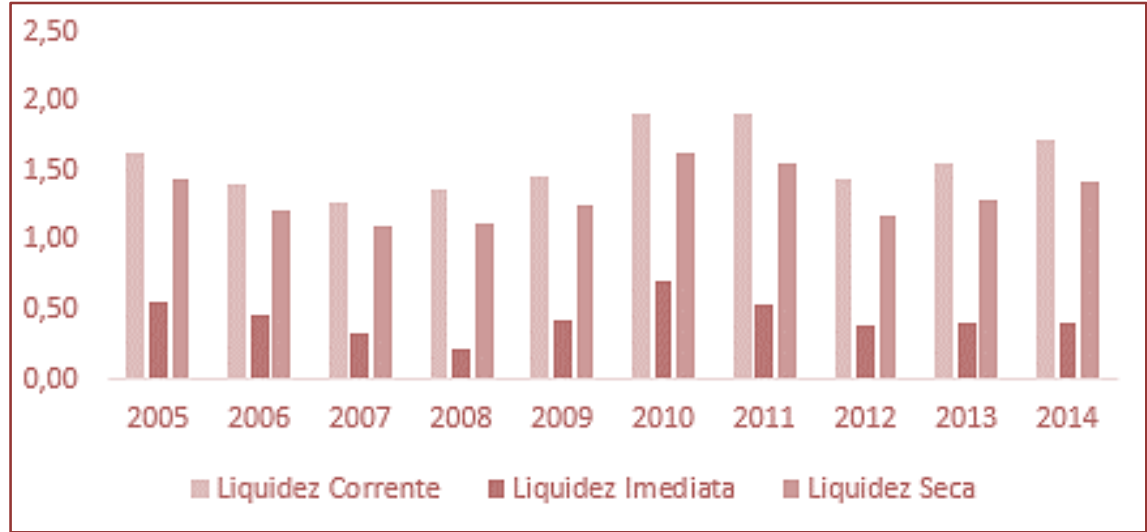

Fonte: Elaborado a partir dos documentos financeiros disponibilizados pela Lojas Renner (2015)

\subsection{EVOLUÇÃO DOS ÍNDICES DE LUCRATIVIDADE}

Com o objetivo de medir a capacidade de a empresa gerar lucro através de suas operações, foram calculados os seguintes índices de lucratividade: Margem de Lucro Líquido $\left(\mathrm{M}_{\mathrm{LL}}\right)$ e Margem de Lucro Operacional $\left(\mathrm{M}_{\mathrm{LO}}\right)$. A Tabela 3 e a Tabela 4 apresentam, respectivamente, os valores referentes aos índices e sua variação percentual dentro do período de análise.

Tabela 3 - Índices de Lucratividade das Lojas Renner (2005-2014)

\begin{tabular}{|c|c|c|c|c|c|c|c|c|c|c|c|} 
Índices & 2005 & 2006 & 2007 & 2008 & 2009 & 2010 & 2011 & 2012 & 2013 & 2014 \\
\hline $\mathrm{M}_{\mathrm{LL}}$ & $7 \%$ & $6 \%$ & $8 \%$ & $7 \%$ & $8 \%$ & $11 \%$ & $10 \%$ & $9 \%$ & $9 \%$ & $9 \%$ \\
\hline $\mathrm{M}_{\mathrm{LO}}$ & $10 \%$ & $9 \%$ & $11 \%$ & $10 \%$ & $15 \%$ & $18 \%$ & $18 \%$ & $14 \%$ & $15 \%$ & $15 \%$ \\
\hline
\end{tabular}

Fonte: Elaborado a partir dos documentos financeiros disponibilizados pela Lojas Renner (2015)

Tabela 4 - Variação dos Índices de Lucratividade das Lojas Renner (2005-2014)

\begin{tabular}{|c|c|c|c|c|c|c|c|c|c|c|}
\hline Variação & 2005 & 2006 & 2007 & 2008 & 2009 & 2010 & 2011 & 2012 & 2013 & 2014 \\
\hline$\% \mathrm{M}_{\mathrm{LL}}$ & - & $-9 \%$ & $21 \%$ & $-5 \%$ & $8 \%$ & $40 \%$ & $-7 \%$ & $-12 \%$ & $1 \%$ & $-3 \%$ \\
\hline$\% \mathrm{M}_{\mathrm{LO}}$ & - & $-6 \%$ & $24 \%$ & $-7 \%$ & $44 \%$ & $22 \%$ & $0 \%$ & $-21 \%$ & $3 \%$ & $3 \%$ \\
\hline
\end{tabular}

Fonte: Elaborado a partir dos documentos financeiros disponibilizados pela Lojas Renner (2015)

A evolução da Margem de Lucro Líquido $\left(\mathrm{M}_{\mathrm{LL}}\right)$ mostra que o melhor resultado obtido pela empresa gerando lucros foi em 2010, ano no qual também houve o maior crescimento para o indicador. No entanto, é notório que após este ano, houve uma diminuição nesse indicador e é um padrão que se manteve nos últimos anos.

Já a evolução da Margem de Lucro Operacional ( $\left.\mathrm{M}_{\mathrm{LO}}\right)$ reflete um aumento de 44\% no biênio 2008-2009, crescimento da eficiência, gerando lucros na sua atividade operacional, mas nos últimos anos essa eficiência não aumentou expressivamente, o que gera preocupação em relação ao cenário dos próximos períodos.

É possível observar a evolução dos índices de lucratividade a partir do Gráfico 2. 
Gráfico 2 - Evolução dos Índices de Lucratividade das Lojas Renner (2005-2014)

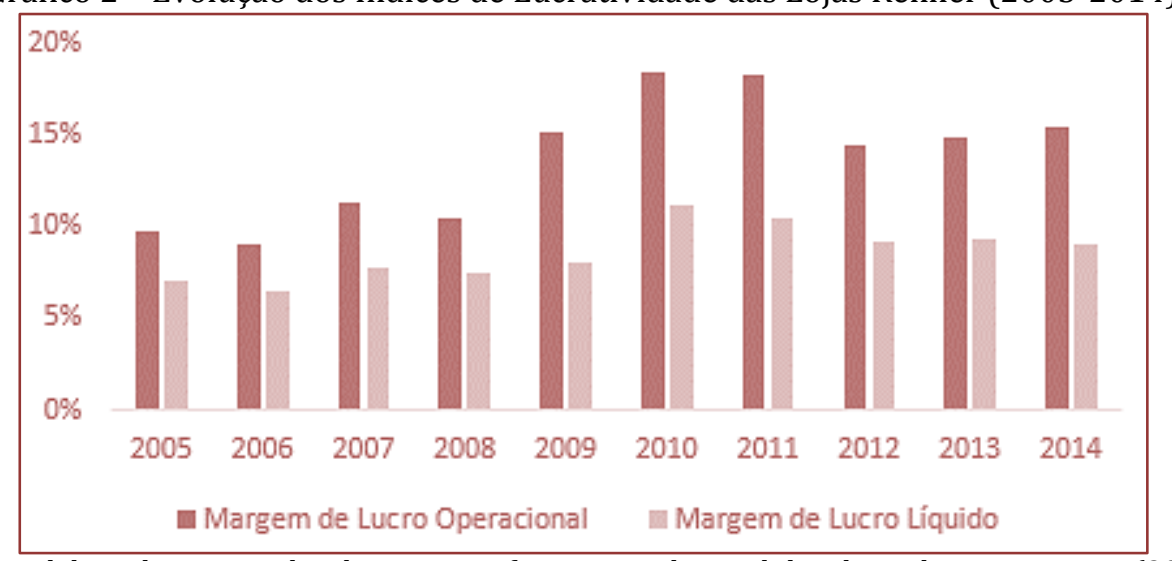

Fonte: Elaborado a partir dos documentos financeiros disponibilizados pela Lojas Renner (2015)

\subsection{EVOLUÇÃO DOS ÍNDICES DE ENDIVIDAMENTO}

Os índices de endividamento calculados para verificar o grau, a composição e a utilização de recurso de terceiros nos ativos da empresa foram: Índice de Alavancagem $\left(\mathrm{I}_{\mathrm{A}}\right)$, Índice de Endividamento Bancário $\left(\mathrm{I}_{\mathrm{EB}}\right)$ e Índice de Endividamento Total $\left(\mathrm{I}_{\mathrm{ET}}\right)$. A partir da Tabela 5 e da Tabela 6, é possível observar os índices e suas respectivas variações ao longo do tempo.

Tabela 5 - Índices de Endividamento das Lojas Renner (2005-2014)

\begin{tabular}{|c|c|c|c|c|c|c|c|c|c|c|}
\hline Índices & 2005 & 2006 & 2007 & 2008 & 2009 & 2010 & 2011 & 2012 & 2013 & 2014 \\
\hline $\mathrm{I}_{\mathrm{A}}$ & 0.99 & 1.21 & 1.64 & 1.29 & 1.22 & 1.40 & 1.58 & 1.89 & 2.02 & 1.87 \\
\hline $\mathrm{I}_{\mathrm{EB}}$ & $13 \%$ & $15 \%$ & $13 \%$ & $0 \%$ & $1 \%$ & $1 \%$ & $4 \%$ & $2 \%$ & $2 \%$ & $10 \%$ \\
\hline IET $_{\mathrm{E}}$ & $50 \%$ & $55 \%$ & $62 \%$ & $56 \%$ & $55 \%$ & $58 \%$ & $61 \%$ & $65 \%$ & $67 \%$ & $65 \%$ \\
\hline
\end{tabular}

Fonte: Elaborado a partir dos documentos financeiros disponibilizados pela Lojas Renner. (2015)

Tabela 6 - Variação dos Índices de Endividamento das Lojas Renner (2005-2014)

\begin{tabular}{|c|c|c|c|c|c|c|c|c|c|c|}
\hline Variação & 2005 & 2006 & 2007 & 2008 & 2009 & 2010 & 2011 & 2012 & 2013 & 2014 \\
\hline$\% \mathrm{I}_{\mathrm{A}}$ & - & $22 \%$ & $36 \%$ & $-22 \%$ & $-5 \%$ & $15 \%$ & $13 \%$ & $19 \%$ & $7 \%$ & $-8 \%$ \\
\hline$\% \mathrm{I}_{\mathrm{EB}}$ & - & $16 \%$ & $-11 \%$ & $-100 \%$ & $8710 \%$ & $37 \%$ & $208 \%$ & $-46 \%$ & $11 \%$ & $347 \%$ \\
\hline$\% \mathrm{I}_{\mathrm{ET}}$ & - & $10 \%$ & $14 \%$ & $-10 \%$ & $-2 \%$ & $6 \%$ & $5 \%$ & $7 \%$ & $2 \%$ & $-3 \%$ \\
\hline
\end{tabular}

Fonte: Elaborado a partir dos documentos financeiros disponibilizados pela Lojas Renner. (2015)

Sobre a evolução do Índice de Alavancagem $\left(\mathrm{I}_{\mathrm{A}}\right)$ ao longo do período de análise, percebe-se que para cada $\$ 1,00$ de capital dos proprietários financiando o ativo, a proporção de recursos de terceiros vem aumentando, o que é desfavorável para a empresa. Nota-se que apenas entre 2007 e 2008 houve uma redução considerável dessa proporção, o que mostra que há uma dificuldade para a gestão conter esse índice. É possível relacionar esse indicador ao Índice de Endividamento Total ( $\mathrm{I}_{\mathrm{ET}}$ ) da empresa, já que neste vem crescendo a participação de recursos de terceiros no financiamento ativo. Isso decorre do aumento das obrigações da empresa em relação aos direitos, bens e disponibilidades. Em relação à alavancagem, o aumento progressivo se deve ao aumento das obrigações em relação ao capital dos próprios proprietários, o que acarreta em uma alta proporção de recursos de terceiros e pode ser relacionado com o agravamento do cenário econômico com o acontecimento da crise econômica mundial.

Em relação ao Índice de Endividamento Bancário ( $\mathrm{I}_{\mathrm{EB}}$ ) da Renner, é possível concluir que a empresa adotou como estratégia diminuir os empréstimos de curto prazo, ou seja, uma estratégia de baixo endividamento. A empresa reduziu significantemente seu endividamento ao longo do período analisado, sobretudo a partir de 2008, o que é favorável para seu desempenho. Relacionando tal fato com o cenário econômico, é possível que a empresa tenha optado por diminuir este índice para enfrentar um período economicamente desfavorável para seu desempenho. 
Já analisando a evolução do Índice de Endividamento Total ( $\left.\mathrm{I}_{\mathrm{ET}}\right)$ da Renner ao longo do período analisado, é possível afirmar que apenas no biênio de 2007-2008 a empresa conseguiu reduzir consideravelmente o índice de endividamento total. No entanto, nos últimos anos ele vem aumentando, o que é desfavorável para a empresa. Pode-se notar que há uma dificuldade da empresa conter a participação de recursos de terceiros no financiamento ativo. Isso significa que as obrigações da empresa têm aumentado em relação às disponibilidades, direitos e bens. De acordo com os relatórios disponibilizados pela empresa, esse fato decorre principalmente do cenário econômico negativo nos últimos anos, o que tornou necessário o endividamento da empresa para que ela conseguisse manter seu desempenho financeiro.

O gráfico a seguir contempla a evolução dos índices de endividamento utilizados para análise:

Gráfico 3 - Evolução dos Índices de Endividamento das Lojas Renner (2005-2014)

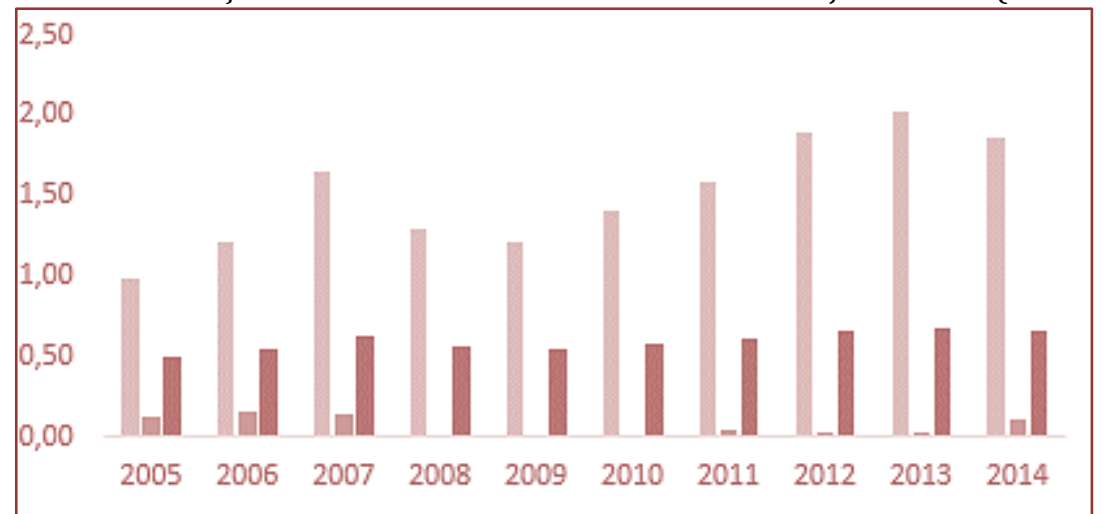

Fonte: Elaborado a partir dos documentos financeiros disponibilizados pela Lojas Renner (2015)

\subsection{EVOLUÇÃO DOS ÍNDICES DE RENTABILIDADE}

Para mensurar o retorno sobre o investimento realizado pelo capital da empresa, foram calculados os seguintes índices de rentabilidade: Retorno sobre o Investimento (ROI) e Retorno sobre o Patrimônio Líquido (RPL). As tabelas a seguir apresentam tanto os valores referentes aos indicadores, bem como sua variação:

Tabela 7 - Variação dos Índices de Rentabilidade das Lojas Renner (2005-2014)

\begin{tabular}{|c|c|c|c|c|c|c|c|c|c|c|c|}
\hline Índices & 2005 & 2006 & 2007 & 2008 & 2009 & 2010 & 2011 & 2012 & 2013 & 2014 \\
\hline ROI & $8 \%$ & $8 \%$ & $10 \%$ & $10 \%$ & $10 \%$ & $13 \%$ & $11 \%$ & $9 \%$ & $9 \%$ & $9 \%$ \\
\hline RPL & $16 \%$ & $18 \%$ & $26 \%$ & $23 \%$ & $22 \%$ & $30 \%$ & $29 \%$ & $27 \%$ & $27 \%$ & $25 \%$ \\
\hline
\end{tabular}

Fonte: Elaborado a partir dos documentos financeiros disponibilizados pela Lojas Renner. (2015)

Tabela 8 - Variação dos Índices de Rentabilidade das Lojas Renner (2005-2014)

\begin{tabular}{|c|c|c|c|c|c|c|c|c|c|c|}
\hline Variação & 2005 & 2006 & 2007 & 2008 & 2009 & 2010 & 2011 & 2012 & 2013 & 2014 \\
\hline$\%$ ROI & - & $6 \%$ & $19 \%$ & $2 \%$ & $-1 \%$ & $27 \%$ & $-10 \%$ & $-17 \%$ & $-4 \%$ & $-2 \%$ \\
\hline$\%$ RPL & - & $17 \%$ & $42 \%$ & $-12 \%$ & $-4 \%$ & $38 \%$ & $-3 \%$ & $-7 \%$ & $0 \%$ & $-7 \%$ \\
\hline
\end{tabular}

Fonte: Elaborado a partir dos documentos financeiros disponibilizados pela Lojas Renner. (2015)

Analisando a evolução do Retorno sobre o Investimento (ROI), conforme consta no Gráfico 4, conclui-se que apesar da crise econômica mundial em 2008 e do cenário econômico desfavorável, a empresa conseguiu manter o retorno sobre o capital investido por todos os supridores. No entanto, nos últimos anos esse lucro gerado a partir desses investimentos vem caindo, o que é desfavorável para o desempenho da Renner. Desde 2010, a empresa traçou um planejamento estratégico e a partir deste decidiu-se investir no crescimento e desenvolvimento da empresa, o que se refletiu principalmente em 2012 e 2013 devido ao grande investimento. 
Em relação ao Retorno sobre o Patrimônio Líquido (RPL), como se observa no Gráfico 4, nota-se que entre 2005 e 2007 o retorno aumentou e em 2008 e 2009, caiu. 0 maior lucro gerado pelo capital dos proprietários foi em 2010, mas nos últimos anos a empresa não conseguiu aumentar esse retorno, o que também é desfavorável para o seu desempenho.

Gráfico 4 - Evolução dos Índices de Rentabilidade das Lojas Renner (2005-2014)

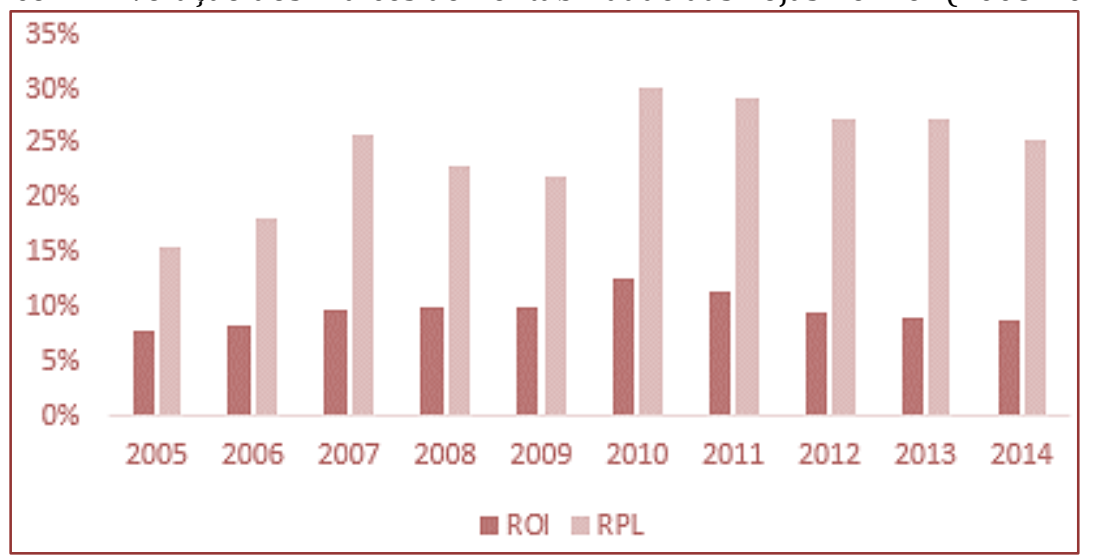

Fonte: Elaborado a partir dos documentos financeiros disponibilizados pela Lojas Renner (2015)

\section{CONSIDERAÇÕES FINAIS}

Partindo do propósito de realizar uma análise financeira das Lojas Renner S.A., foram quantificados índices de liquidez, lucratividade, endividamento e rentabilidade. Ademais, vale ressaltar que se buscou compreender o desenvolvimento da empresa desde o início de suas atividades no mercado varejista e dois fatos se destacaram: a abertura de capital da empresa ainda na década de 60 e o fato de a empresa ter sido a primeira companhia brasileira a se tornar uma corporação. Isso significa que a expansão da empresa foi rápida e que o conselho teve independência para trabalhar e apresentar resultados. Outro fato que se destacou foi o de que o fundador da empresa, A. J. Renner, sempre valorizou muito seus funcionários desde a criação da empresa, sendo inclusive pioneiro em oferecer alguns benefícios aos colaboradores, tais como a participação nos lucros da empresa, cooperativa de crédito e consumo, creche e atendimento à saúde.

Analisando a Renner em relação ao desempenho econômico, pode-se destacar que a empresa conseguiu sobreviver à crise econômica de 2008, já que obteve faturamento e lucro em todos os anos. No entanto, a empresa aumentou significantemente suas obrigações nesse período, sobretudo o endividamento total e a alavancagem. A redução do endividamento bancário foi algo positivo para o desempenho da empresa. Um fato interessante é o de que em 2014, a empresa apareceu entre as mais generosas em dividendos no Brasil, obtendo um retorno com dividendos nos últimos 12 meses de 2,23\%. Seus investimentos têm sido focados no crescimento e desenvolvimento da empresa, o que é interessante para os próximos anos. Isso significa que a empresa é preocupada com o mercado e busca melhorar seu desempenho. Analisando o desempenho da empresa, principalmente nos últimos anos, as expectativas estão boas para a empresa.

Finalmente, pode-se concluir que se têm indícios de que há uma viabilidade em investir na Renner, já que em geral as expectativas são boas e ela é uma empresa que tem se destacado por seu desempenho, além de ter conseguido sobreviver à crise econômica mundial. Nota-se também que há uma preocupação por parte da empresa com o retorno aos acionistas. Em relação à gestão, conclui-se que as iniciativas de A. J. Renner permitiu que a empresa alcançasse o patamar no qual se encontra atualmente. Isso é evidente principalmente em relação às iniciativas do fundador que estão presentes na cultura da empresa, algo que foi fruto de sua experiência ao longo de sua trajetória. 


\section{REFERÊNCIAS}

[1] ARTUSO, A. R. Análise multivariada e filtros de Graham: reconhecimento de padrões aplicado ao mercado acionário brasileiro. Tese (Doutorado) - Universidade Federal do Paraná, 2012.

[2] Balaços Anuais da Renner. Disponível <http://www.lojasrenner.com.br/investidores;jsessionid=1nhXJpGLrsT8pRfXGQcDhfG3LkwL9rlvqvKQJz0qfCsfCBG2 22hZ!2132173524>. Acesso em: 31/10/2014.

[3] BANCO CENTRAL DO BRASIL. Disponível em: <http://www.bcb.gov.br/pt-br/paginas/default.aspx>. Acesso em: $11 / 11 / 2014$.

[4] BM\&FBOVESPA. Empresas listadas na Bolsa de Valores. Disponível em: <http://www.bmfbovespa.com.br>. Acesso em: 10/09/2014.

[5] BM\&FBOVESPA. Participação dos investidores. Disponível em: <http://www.bmfbovespa.com.br/rendavariavel/BuscarParticipacaoInvestimento.aspx?Idioma=pt-br> Acesso em: 26/06/2014.

[6] CNAE - Classificação Nacional de Atividades Econômicas. Disponível em: <http://www.cnae.ibge.gov.br/>. Acesso em: 10/09/2014.

[7] DOS SANTOS, J. O. Avaliação de Empresas: cálculo e interpretação do valor das empresas. 2. ed. São Paulo: Saraiva, 2008.

[8] FALEIROS, J. P. M. Comércio varejista: uma análise do comportamento do volume de vendas sob uma perspectiva não linear. Revista do BNDES , v. 32, p. 157-181, 2009.

[9] GALDI, F. C. Estratégias de investimento em ações baseadas na análise de demonstrações contábeis: é possível prever o sucesso? Tese (Doutorado) - Universidade de São Paulo, 2008.

[10] GEREMIA, W. Avaliação das Lojas Renner (Monografia). Associação dos analistas e profissionais de investimento do mercado de capitais STDS (SECRETARIA DO TRABALHO E DO DESENVOLVIMENTO SOCIAL).

[11] Governança Corporativa da Renner. Disponível em: <http://www.lojasrenner.com.br/investidores;jsessionid=1nhXJpGLrsT8pRfXGQcDhfG3LkwL9rlvqvKQJz0qfCsfCBG2 22hZ!2132173524>. Acesso em: 31/10/2014.

[12] GRAHAM, B. O investidor inteligente: um guia prático de como ganhar dinheiro na bolsa. Rio de Janeiro: Nova Fronteira, 2007.

[13] HELFERT, E. A. Técnicas de Análise Financeira: Um guia prático para medir o desempenho dos negócios. 9a edição. Porto Alegre: Bookman, 2000.

[14] IBGE. Instituto Brasileiro de Geografia e Estatística. Disponível em: <http://www.ibge.gov.br/home/>. Acesso em: 10/11/2014.

[15] MATARAZZO, D. Análise financeira de balanços: abordagem básica e gerencial. 7. ed. São Paulo: Atlas, 2010.

[16] PALEPU, K. G.; HEALY, P. G.; BERNARD, V. L. Business Analysis and Valuation: Using Financial Statements. 3rd ed. Ohio: South-Western College Publishing, 2004.

[17] PENMAN, S. H. Financial Statements Analysis and Security Valuation. 3rd ed. New York: McGraw-Hill, 2007.

[18] Relatórios de Sustentabilidade da Renner. Disponível em: <http://portal.lojasrenner.com.br/renner/responsabilidade/content.action?id=467\&tela=S>. Acesso em: $31 / 10 / 2014$.

[19] SANTOS, A. M. M.; COSTA, C. S. Características gerais do varejo no Brasil. BNDES Setorial, n. 5, 1997.

[20] SILVA, J. P. Análise financeira das empresas. 9. ed. São Paulo: Atlas, 2008.

[21] Site da empresa Lojas Renner S.A. Disponível em: <http://www.lojasrenner.com.br>. Acesso em: 03/09/2014. 


\section{Capítulo 3}

\section{Transporte rodoviário: Os principais riscos ocupacionais no cotidiano dos motoristas de caminhão}

\section{Ivana Salvagni Rotta}

Fernando Cesar Mendonça

Resumo: Dentre os cinco tipos de modais existentes no transporte de cargas, o rodoviário destaca-se no Brasil, apresentando uma participação de 61,1\% na matriz. Os transportes são responsáveis pela circulação de itens fundamentais aos processos produtivos, como materiais, equipamentos, suprimentos e mão de obra. Os motoristas de caminhão são responsáveis principalmente pela movimentação, coleta, e entrega de produtos em geral, e enfrentam em seu cotidiano condições adversas capazes de trazer prejuízos para sua saúde e integridade. Este trabalho tem como objetivo identificar os principais riscos ocupacionais associados ao cotidiano de trabalho dos motoristas de caminhão. A metodologia utilizada foi à pesquisa bibliográfica em diferentes bases de dados a fim de identificar na literatura os artigos relacionados à ocorrência dos riscos físicos, químicos, biológicos, ergonômicos e de acidentes no setor de transportes. Através da análise dos dados obtidos, constatou-se que a adoção de medidas efetivas tanto para a conscientização desses profissionais acerca da existência desses riscos em seu trabalho, quanto para seu controle e prevenção, é de extrema importância na preservação da saúde e integridade física desses profissionais.

Palavras-Chave: Motoristas de caminhão, setor de transporte, riscos ocupacionais. 


\section{INTRODUÇÃO}

Iida (2005) compara a importância dos transportes para a economia de um país ao sangue para o organismo, uma vez que são responsáveis pela circulação de materiais, equipamentos, suprimentos e mão de obra, fundamentais aos processos produtivos, além de possuírem o importante papel de distribuição dos produtos, permitindo que estes cheguem até o consumidor. No Brasil, o modal rodoviário é o que apresenta maior participação na matriz do transporte de cargas $(61,1 \%)$, sendo responsável pela movimentação anual de 485 milhões de toneladas por quilômetro útil (CNT, 2017; 2018).

No setor, destaca-se a categoria dos motoristas de caminhão. De acordo com a Confederação Nacional do Transporte (CNT, 2016) a maior parte destes profissionais é autônoma (68,4\%), predominantemente do sexo masculino (99,8\%), com idade média de 44,3 anos e Ensino Médio completo (31,3\%). Entretanto, o dimensionamento exato do número destes profissionais é dificultado por fatores como a informalidade presente no setor, a grande extensão territorial e a falta de estatísticas oficiais; associações brasileiras estimam que haja cerca de 1,5 milhão de caminhoneiros (BARIFOUSE, 2018).

Em relação à saúde e condições de trabalho, a CNT (2016) revela que, dos problemas médicos apresentados (ou tratados) por esses profissionais, os de coluna foram os mais frequentemente apontados, com $16,2 \%$. No que se refere ao índice de massa corporal, apenas um total de $20,7 \%$ se encontrava no peso normal; $42,3 \%$ se encontravam acima do peso; $25,1 \%$ com obesidade, cerca de $24 \%$ relatou sofrer alguma pressão no trabalho e, entre os motoristas que se envolveram em acidentes nos dois anos anteriores à pesquisa, os 5 motivos mais citados foram distração $(20,7 \%)$, condições precárias da rodovia $(18,2 \%)$, cansaço $(17,4 \%)$, problemas mecânicos $(14 \%)$ e imprudência de terceiros $(10,7 \%)$.

Ainda de acordo com CNT (2016), deve ser destacado consumo de álcool e drogas: quase metade dos profissionais $(45,6 \%)$ já recebeu oferta de algum tipo de substância ilícita para se manterem acordados, sendo o rebite a mais comum $(87,7 \%)$. Dos que receberam oferta, $26,5 \%$ afirmou ter experimentado. Em relação ao álcool, $43,8 \%$ declarou consumir fora da jornada de trabalho. Um dado alarmante é que uma pequena parcela $(2,5 \%)$ relatou o consumo eventual durante a jornada.

Sobre as horas de trabalho, a Lei no 13.103 (BRASIL, 2015) estabelece uma jornada diária, para motoristas profissionais, de 8 horas, que pode se prorrogar por até 2 horas extraordinárias ou por até 4 horas, desde que estabelecido em convenção ou acordo coletivo. Em média, 17,5\% dos motoristas entrevistados trabalham entre 13 e 16 horas por dia e 7,2\% relataram trabalhar mais de 17 horas diárias (CNT, 2016).

As horas de sono desses profissionais foram apontadas como sendo, em média, de 7,1 por dia, contudo uma pequena parte $(1,6 \%)$ revelou que dorme 3 horas ou menos por dia e $35,6 \%$ afirmaram ter entre 4 e 6 horas de sono. 0 sono ruim ou péssimo foi apontado por um total de 10,8\% dos motoristas (CNT, 2016).

Condições inadequadas podem ter implicações sobre sua saúde e integridade: a monotonia, a postura praticamente fixa durante um longo período de tempo pode resultar na fadiga muscular e deterioração da atividade motora (IIDA, 2005); a elevada carga de trabalho e esforço físico acima dos padrões determinados por normas também podem ser danosos (KILESSE et al., 2006); a exposição continuada a níveis elevados de pressão sonora pode estar associada à perda auditiva induzida por ruído - PAIR (MINISTÉRIO DA SAÚDE DO BRASIL, 2001, p.262) e a ausência de pausas para descanso pode estar associada a dores musculoesqueléticas na coluna vertebral (LEMOS; MARQUEZE; MORENO, 2014).

Andrusaitis, Oliveira e Barros Filho (2006) verificaram a associação entre o número de horas de trabalho e a ocorrência de lombalgia em motoristas, constatando que cada hora de trabalho diário aumenta em $7 \%$ o risco de o motorista apresentar dor lombar.

Nascimento, Nascimento e Silva (2007), relataram envolvimento em acidentes nas estradas devido ao uso de anfetaminas.

O presente trabalho busca identificar, por meio de pesquisa bibliográfica em diferentes bases de dados, os principais riscos ocupacionais associados à profissão de motoristas de caminhão do transporte de cargas, avaliando-os conforme sua natureza. 


\section{FUNDAMENTAÇÃO TEÓRICA}

\subsection{RISCOS NO AMBIENTE DE TRABALHO, ACIDENTES E DOENÇAS RELACIONADAS AO TRABALHO}

Os riscos presentes no ambiente de trabalho consistem em um tema que vem sendo estudado em diferentes áreas do conhecimento (COLVERO; SOUZA, 2016; DALRI; ROBAZZI; SILVA, 2010; DUTRA, 2018; NOGUEIRA; BASTOS; COSTA, 2010;RODRIGUES; SANTANA, 2010).

O termo "risco" denota incerteza em relação a eventos futuros, podendo ser compreendido, de modo geral, como a probabilidade de ocorrer acidentes, causando danos (COSTA; COSTA, 2004; PORTO, 2000).

Do ponto de vista legal, as doenças profissionais, desencadeadas pela realização do trabalho peculiar a uma atividade específica, e as doenças laborais, provocadas pelas condições especiais de execução do trabalho também são consideradas acidentes de trabalho (BRASIL, 1991).

Além de serem causadores de grande sofrimento e problemas para os trabalhadores e suas famílias, acidentes e doenças influenciam a produtividade e capacidade de trabalho e geram custos elevados para as empresas e a sociedade (MINISTÉRIO DO TRABALHO E EMPREGO, 2010; OIT, 2013).

A prevenção dos acidentes e doenças está relacionada, entre outros fatores, à adoção de medidas de controle dos riscos existentes no ambiente de trabalho, visando sua redução ou eliminação (MINISTÉRIO DO TRABALHO E EMPREGO, 2010). Todavia, para que possa haver o controle e minimização dos riscos, é necessário, antes de tudo, reconhecer sua existência e identificá-los corretamente.

\subsection{NORMAS REGULAMENTADORAS E CLASSIFICAÇÃO DOS RISCOS OCUPACIONAIS}

De acordo com Porto (2000), riscos ambientais são definidos como os agentes presentes no ambiente de trabalho potencialmente capazes de trazer prejuízos à saúde dos colaboradores, considerando fatores como natureza, concentração e tempo de exposição e um importante indicativo da existência de riscos no ambiente labora e de seu descontrole, são os acidentes e doenças relacionadas ao trabalho.

Figura 1 - Classificação dos principias riscos ocupacionais segundo sua natureza

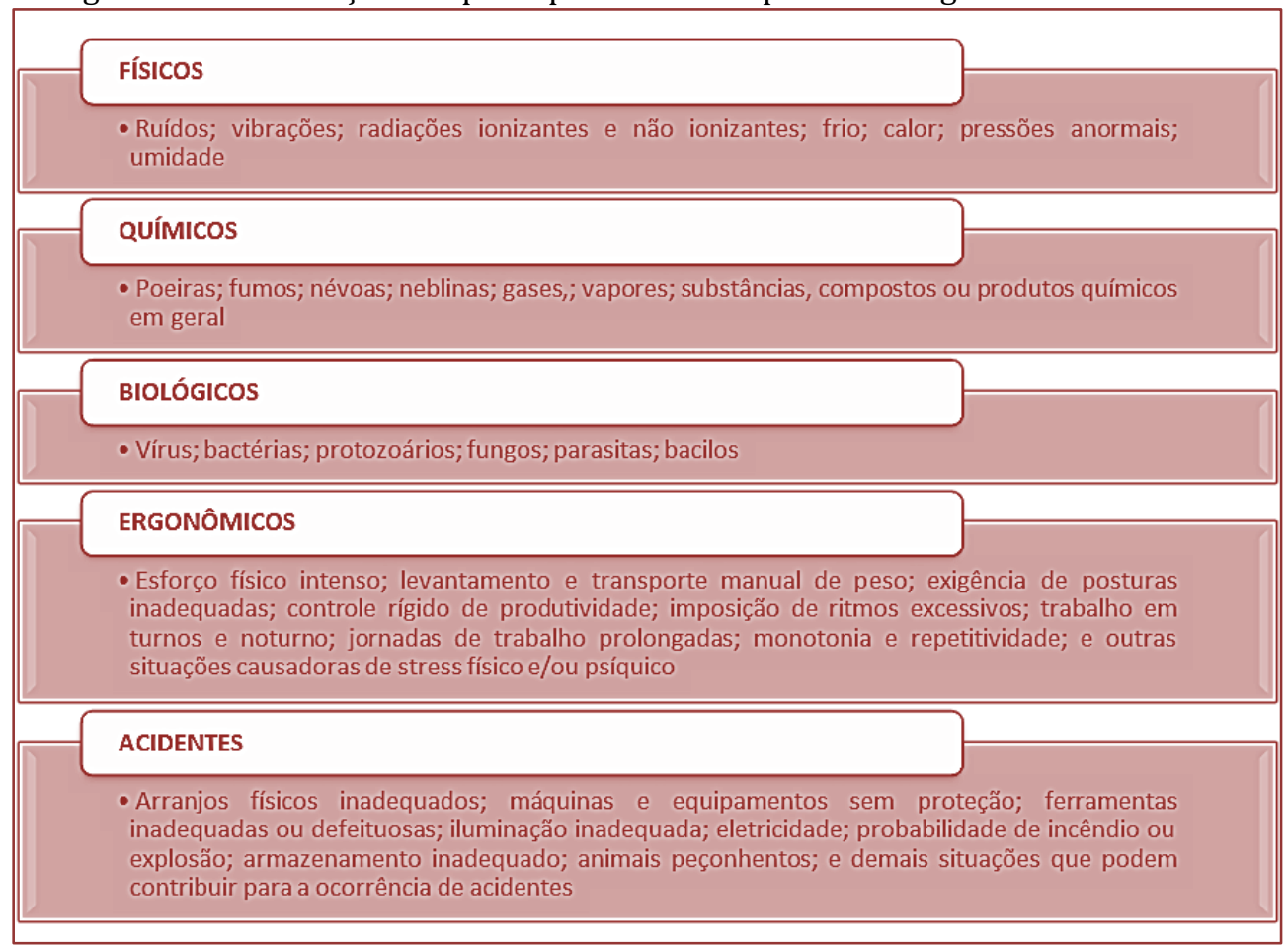

Fonte: adaptado de Brasil (1994) 
No Brasil, as Normas Regulamentadoras (NRs) estabelecem as obrigações, direitos e deveres que devem ser cumpridos tanto por empregadores quanto pelos trabalhadores a fim de garantir o trabalho seguro e sadio, de forma a prevenir as doenças e acidentes de trabalho (MINISTÉRIO DO TRABALHO, 2018). A NR 9 enfoca o Programa de Prevenção de Riscos Ambientais (PPRA) e tem por objetivo a preservação da saúde e integridade dos trabalhadores por meio da antecipação, reconhecimento, avaliação e controle da ocorrência dos riscos ambientais já existentes ou que possam vir a existir no ambiente de trabalho, considerando a proteção do meio ambiente e dos recursos naturais (BRASIL, 1994). A figura abaixo apresenta os cinco grupos de riscos ocupacionais.

É importante ressaltar os agentes psicossociais, fatores como qualidade de vida, salário, alimentação não adequados, e tempo despendido no deslocamento entre ida e volta do trabalho, embora não sejam contemplados pelas normas, podem apresentar grande influência sobre ações de saúde e segurança no trabalho.

\subsection{RISCOS OCUPACIONAIS NO SETOR DE TRANSPORTES}

Souza et al (2017), avaliaram os riscos aos quais os motoristas de ônibus estavam expostos: físicos (ruídos provenientes do motor e do trânsito, vibrações devido ao movimento do transporte, e temperatura externa); químicos (poeira oriunda do pó de asfalto, monóxido de carbono decorrente do trânsito e graxas); ergonômicos (má condição do assento, movimentos repetitivos relacionados à ação de dirigir, longas jornadas de trabalho e inadequação da iluminação, relacionada ao desconforto causado pela luz do sol); mecânicos (acidentes de trânsito e contato com ferramentas pontiagudas utilizadas na manutenção do veículo).

Assis, Pereira e Neves (2018), realizaram pesquisas com motoristas de caminhão de lixo e observaram que o trabalho os expõe a riscos como ruído intenso; calor excessivo; frio; vibração; movimentos repetitivos e posturas inadequadas.

\section{METODOLOGIA}

0 presente estudo caracteriza-se como uma pesquisa descritiva, segundo seus objetivos mais gerais, e bibliográfica em relação à metodologia empregada (GIL, 2010). Nesse caso, os riscos ocupacionais presentes no cotidiano de trabalho podem ser considerados como as características a serem descritas, enquanto os motoristas de caminhão constituem a população específica. A metodologia desse estudo foi dividida em três etapas. A primeira consistiu na formulação da questão da pesquisa: "quais os riscos ocupacionais presentes e/ou associados ao cotidiano de trabalho de motoristas de caminhão do transporte de cargas? ". Com base nesse questionamento, iniciou-se então a segunda etapa, constituída pela pesquisa bibliográfica, com buscas online na SciELO, Portal de Periódicos CAPES e Google Scholar, utilizando os descritores apresentados na figura 2.

Figura 2: Palavras chave utilizadas nas buscas online

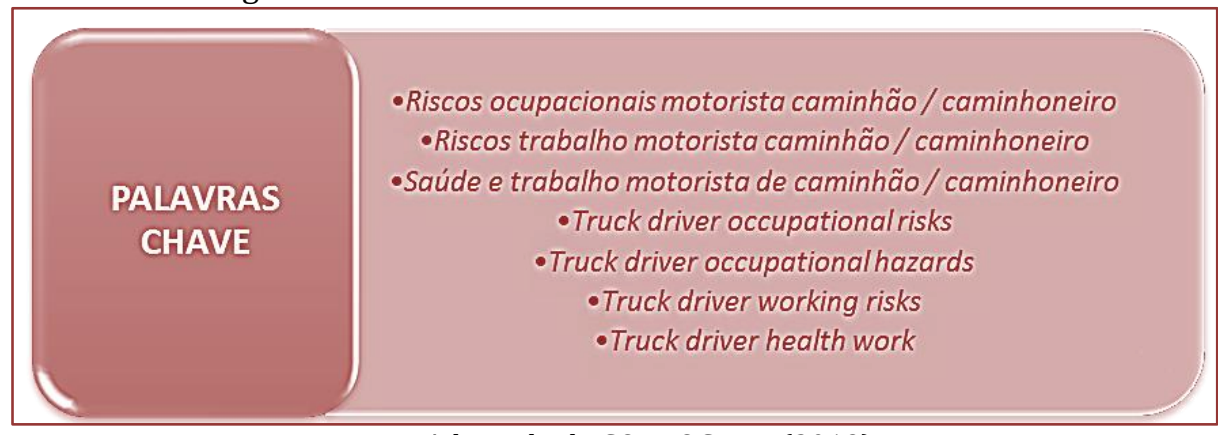

Fonte: Adaptado de CORROCHER (2019)

As obras resultantes foram selecionadas conforme originalidade, pertinência ao tema, ano de publicação (2013 a 2018), tipo de material (somente artigos e artigos de revisão) e idioma (inglês/português). A Figura 3 representa a sequência das etapas empregadas. 
Figura 3: Sequência das ações da metodologia

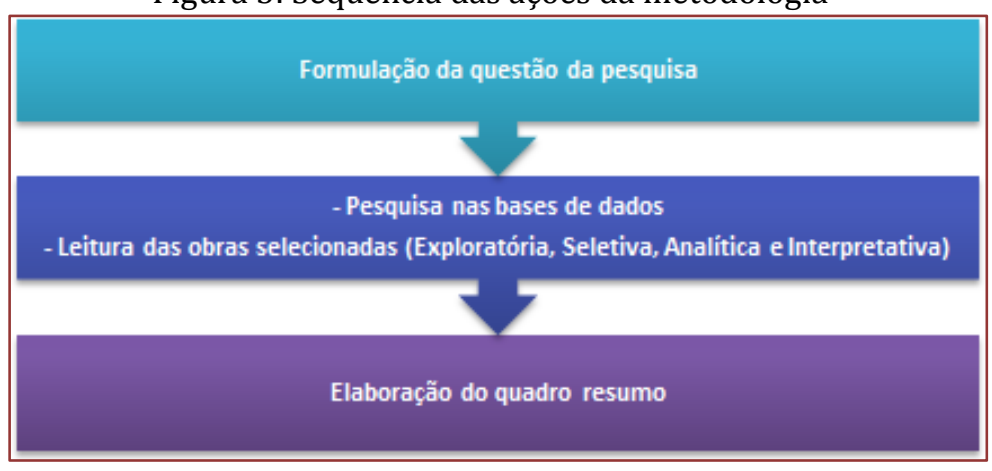

Fonte: Adaptado de CORROCHER (2019)

\section{DISCUSSÃO DOS RESULTADOS}

Os artigos selecionados foram analisados sob a ótica de riscos proposta por Porto (2000).Em relação aos acidentes de trânsito (AT), Oliveira et al. (2016) analisaram 535 motoristas no estado de São Paulo, observando que, no período de 2012 a 2013, 48\% deles relataram já ter sofrido algum AT pelo menos uma vez na vida; quase $11 \%$ afirmaram ter sofrido ao menos um AT no ano e $2,6 \%$ nos trinta dias anteriores à pesquisa. Os autores verificaram que os fatores associados à ocorrência de AT foram os poucos anos de experiência profissional, o fato de cometer alguma multa de trânsito no período de um ano e trabalhar mais de 12 horas por dia. Oliveira et al. (2016) descreveram a relação entre a ocorrência de acidentes e jornadas de trabalho maiores que doze horas diárias. Esta relação também foi observada em Ruiz et al. (2015), que verificaram um efeito protetor em relação a acidentes para motoristas que trabalhavam menos de 12 horas por dia e a exposição a acidentes revelou-se quatro vezes maior para os caminhoneiros que viajavam durante a noite.

Além desses fatores, é observada uma relação entre o uso de substâncias psicoativas e o comportamento de risco no trânsito, incluindo a ocorrência de AT (ANTONIASSI JUNIOR et al., 2016; NASCIMENTO; NASCIMENTO; SILVA, 2007; PONCE; LEYTON, 2008).

Segundo Oliveira et al. (2015), o consumo apresenta estreita relação com as condições ocupacionais. Takitane et al. (2013) constataram a presença dessa substância em 10,8\% das amostras de urina analisadas de caminhoneiros abordados em duas rodovias do estado de São Paulo, sendo que os profissionais relatavam utilizá-la para se manterem acordados e cumprirem os prazos estipulados. A manutenção do estado de vigília também foi a principal justificativa desses trabalhadores para o uso de anfetaminas para Belan et al. (2017), porém nesse caso o estudo mostrou que, em 2013, 77,5\% dos 40 caminhoneiros entrevistados naquele ano relataram o consumo de rebites; já em 2016, os dados obtidos de outros 40 entrevistados nesse mesmo estudo revelaram que, embora tenha havido uma pequena queda, esse índice ainda se manteve alto, tendo atingido $60 \%$.

Considerando que vários fatores citados (pouca experiência profissional, comportamento de risco no trânsito, jornadas de trabalho longas, trabalho noturno e ao uso de substâncias psicoativas) apresentam um caráter ocupacional e que os AT podem implicar em mortes e lesões para esses profissionais, tais fatores caracterizam-se como possíveis riscos ocupacionais segundo a definição adotada.

Em relação aos sofrimentos, as dores na coluna destacaram-se nas pesquisas bibliográficas como um problema de saúde frequentemente enfrentado por esses trabalhadores. De acordo com Pereira et al. (2014), em 165 caminhoneiros do estado do Ceará, uma parcela significativa dos motoristas estudados $(52,7 \%)$ referiu a elas como um dos problemas de saúde adquiridos. Lemos, Marqueze e Moreno (2014), por sua vez, também observaram a prevalência de dores na coluna vertebral em 53,5\% dos motoristas, que foram associadas principalmente ao sono de má qualidade desses trabalhadores, à ausência de pausas e cochilos no decorrer de sua jornada; ao medo de ser assaltado, morrer ou sofrer acidentes no trabalho e ao estresse e fadiga decorrentes do desconforto de dirigir o caminhão. Takitane et al. (2013) verificaram que as regiões mais frequentemente referidas pelos caminhoneiros que transitam nas estradas e referemse a alguma dor foram a lombar e a cervical. Segundo Pedroso et al. (2013), as dores na região da coluna lombar (lombalgias), são responsáveis por um índice de incapacitação moderada de $24 \%$ dos profissionais com mais de cinco anos de experiência. Nesse caso, há um prejuízo na realização de atividades cotidianas, como sentar-se, levantar-se e ficar em pé. 
Da mesma forma que anteriormente observado para a ocorrência de acidentes de trânsito, existem diversos fatores que estão ou podem estar associados às dores na coluna em geral para os motoristas do transporte de cargas, sendo que muitos desses fatores decorrem de condições do trabalho, constituindo possíveis riscos ocupacionais.

Silva et al. (2014) mostraram que, em seu cotidiano de trabalho, os caminhoneiros estão expostos também ao ruído ocupacional. Um dos possíveis agravos decorrente dessa exposição é a PAIR. Embora possa ser temporária no início, a perda auditiva torna-se um dano permanente com a repetitividade do estímulo, de tal forma que, quanto mais intenso e repetitivo o ruído, maiores serão os danos auditivos (KROEMER; GRANDJEAN, 2005). A exposição ao ruído possui também possui efeitos extra-auditivos que interferem na qualidade de vida e bem-estar dos indivíduos: alterações do sono e psicoafetivas, dificuldade no entendimento das falas, aumento da pressão sanguínea, aceleração da frequência cardíaca, aumento da tensão muscular, piora do desempenho e produtividade, fadiga, dor de cabeça e distúrbios gastrointestinais (KROEMER; GRANDJEAN, 2005; MINISTÉRIO DA SAÚDE DO BRASIL, 2001). É comum coexistir outros fatores que também podem agredir o órgão auditivo e influenciar no desenvolvimento de sua perda por meio da interação com os níveis de pressão sonora: agentes químicos (solventes, fumos metálicos e gases asfixiantes); físicos (vibrações, radiação e calor) e biológicos (vírus e bactérias) (MINISTÉRIO DA SAÚDE DO BRASIL, 2001). Além da possível influência sobre o desenvolvimento da perda auditiva, a exposição ocupacional a agentes químicos pode ter outras implicações graves para os trabalhadores. Pamphlett e Rikard- Bell (2013) relataram que os motoristas de caminhão representavam a ocupação profissional que apresentou o maior risco para esclerose lateral amiotrófica esporádica, que incluía tanto indivíduos com diagnóstico da doença quanto o grupo controle, ambos com ocupações diversas; a exposição aos produtos resultantes da combustão do diesel revelou-se como o fator ambiental que mais provavelmente predispunha os profissionais a tal problema.

Outra questão de saúde relacionada aos caminhoneiros e abordada na literatura envolve a exposição às doenças sexualmente transmissíveis (DSTs). Pereira et al. (2014) revelam que 38\% dos entrevistados declararam já ter contraído DSTs: 67\% adquiriram gonorreia, 20\% herpes, $7 \%$ sífilis e 6\% hepatite B e/ou C. Antoniassi Junior et al. (2016), evidenciaram um comportamento de risco desses profissionais em relação às DSTs ao revelar que cerca de 60\% deles afirmam não usar preservativo nas relações sexuais mantidas nas estradas.

A figura 4 apresenta de forma resumida os principais riscos observados nos artigos analisados.

Figura 4 - Riscos ocupacionais para o trabalho de motoristas de caminhão

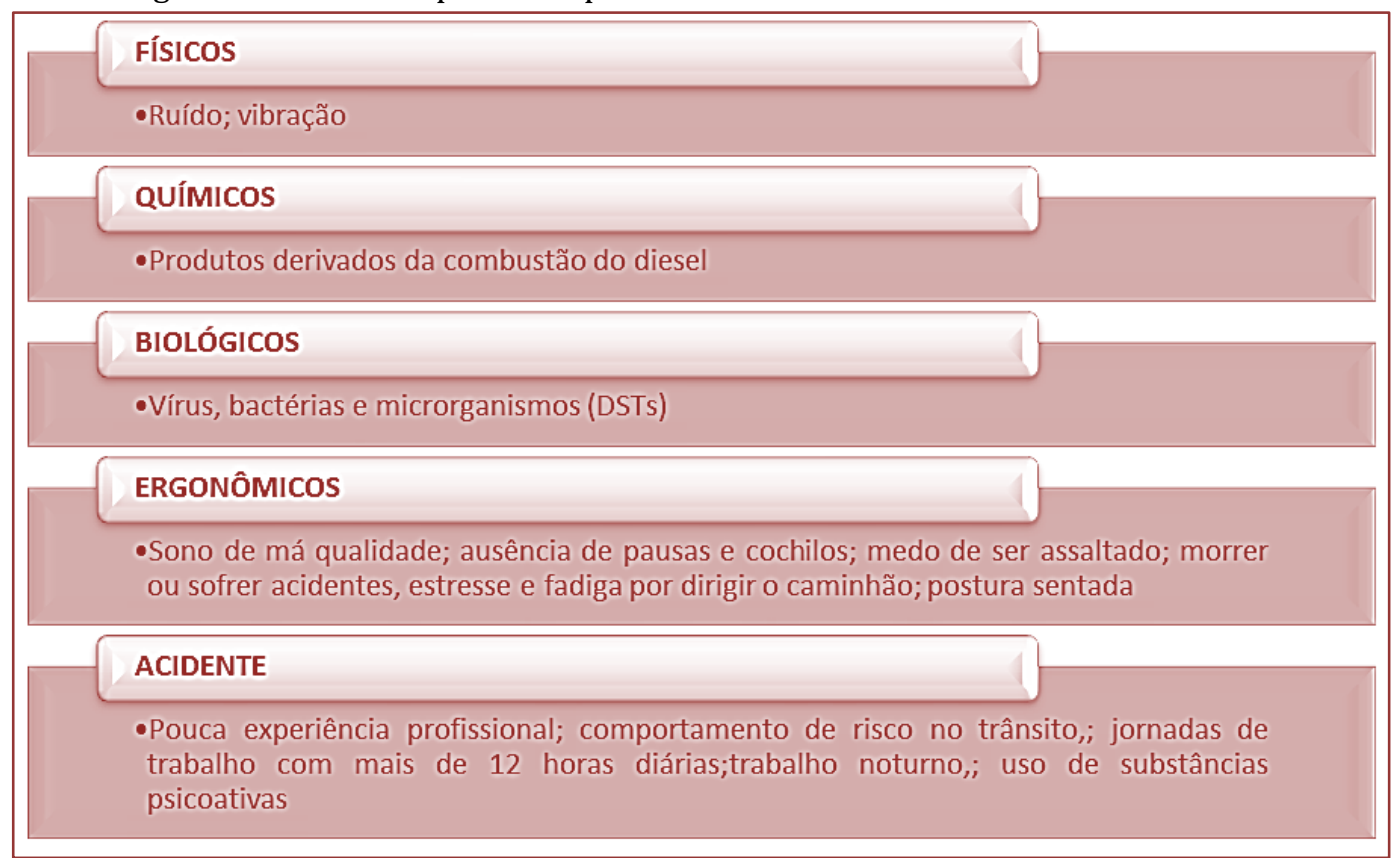

Fonte: Adaptado de CORROCHER (2019) 


\section{CONSIDERAÇÕES FINAIS}

A partir dos artigos analisados, os riscos inerentes à atividade profissional de motoristas de caminhão foram identificados e classificados conforme a Portaria no 25 (BRASIL, 1994). Observou-se, a ocorrência de riscos físicos (ruídos e vibrações), químicos (emissões do diesel), biológicos (vírus, bactérias e microrganismos relacionados às DSTs), ergonômicos (sono de má qualidade; ausência de pausas e cochilos; medo de ser assaltado, morrer ou sofrer acidentes; estresse e fadiga; postura sentada) e de acidentes (poucos anos de experiência profissional; comportamento de risco no trânsito; jornadas de trabalho maiores que 12 horas diárias; trabalho noturno e uso de substâncias psicoativas).

Considerando os sofrimentos que os acidentes de trânsito e os problemas decorrentes das condições ocupacionais podem causar, é de extrema importância a adoção de medidas efetivas tanto para a conscientização desses profissionais sobre desses riscos no seu cotidiano de trabalho, quanto para seu controle e prevenção, a fim de preservar a saúde e integridade física desses trabalhadores.

Cabe ressaltar que os riscos apresentados nesse estudo envolvem apenas aqueles que foram identificados nos artigos amostrados conforme pertinência e relevância ao tema e delimitada pelos fatores ano de publicação, material e idioma. Assim, é possível que existam muitos outros riscos abordados anteriormente na literatura, mas que, devido ao critério utilizado na seleção dos artigos, não são tratados no presente estudo. É importante destacar que esse trabalho envolve uma pesquisa simplificada sobre o tema, e deve ser aprofundado futuramente com a realização de estudos de caso ou pesquisas de campo que permitam confrontar os dados obtidos na literatura com os dados práticos.

\section{REFERÊNCIAS}

[1] ANDRUSAITIS, Silvia Ferreira; OLIVEIRA, Reginaldo Perilo; BARROS FILHO, Tarcísio Eloy P. Study of the prevalence and risk factors for low back pain in truck drivers in the state of São Paulo, Brazil. Clinics, [s.l.], v. 61, n. 6, p.503-510, 2006. FapUNIFESP (SciELO). http://dx.doi.org/10.1590/s1807-59322006000600003.

[2] ANTONIASSI JUNIOR, Gilmar et al. 0 uso de drogas por motoristas caminhoneiros e o comportamento de risco nas estradas. Revista de Epidemiologia e Controle de Infecção, Santa Cruz do Sul, v. 6, n. 4, p.158-162, out. 2016. APESC - Associação Pro-Ensino em Santa Cruz do Sul. http://dx.doi.org/10.17058/reci.v6i4.7968.

[3] ASSIS, Alessandra Monteiro; PEREIRA, Shirlei Luana Chaves e Souza; NEVES, Patricia Carla de Brito. Compreensão dos riscos ergonômicos a partir da percepção e função dos motoristas de caminhões em uma empresa na cidade de Itabira - MG. Revista Eletrônica Engenharia de Interesse Social, [online], v. 1, n. 3, p.1-15, 2018.

[4] BARIFOUSE, Rafael. Faltam caminhoneiros nos Estados Unidos. E no Brasil? 2018. Disponível em: <https://www.bbc.com/portuguese/internacional-44378094>. Acesso em: 21 ago. 2018.

[5] BELAN, Tayná Oliveira et al. Prevalência do uso de anfetaminas por caminhoneiros. Acta Biomédica Brasiliensia, [s.l.], v. 8, n. 2, p.71-82, dez. 2017. Universidade Iguacu - Campus V. http://dx.doi.org/10.18571/acbm.141.

[6] BRASIL. Lei 8.213, de 24 de Julho de 1991. Brasília: Congresso Nacional, 1991. Disponível em: <http://www.planalto.gov.br/ccivil_03/Leis/L8213cons.htm>. Acesso em: 18 out. 2018.

[7] BRASIL. Lei $\mathrm{n}$ o 13.103, de 2 de março de 2015. Disponível em: <http://www.planalto.gov.br/ccivil_03/_Ato2015-2018/2015/Lei/L13103.htm>. Acesso em: 05 out. 2018.

[8] BRASIL. Ministério do Trabalho e Emprego. Portaria no 25, de 29 de Dezembro de 1994. Brasília: Congresso Nacional, $1994 . \quad$ Disponível em: $<$ https://www.agencia.cnptia.embrapa.br/Repositorio/Portaria+n.+25+SSST+MTb+29+dezembro+1994+Aprova $+\mathrm{a}+\mathrm{NR}+9+$ sobre+o+Programa+de+Prevencao+e+riscos+ambientais_000gvpl14yq02wx7ha0g934vgrnn5ero.PD F>. Acesso em: 09 out. 2018.

[9] CNT - CONFEDERAÇÃO NACIONAL DO TRANSPORTE. Boletim Estatístico - CNT - Maio 2018. Disponível em: <http://cms.cnt.org.br/Imagens\%20CNT/BOLETIM\%20ESTAT\%C3\%8DSTICO/BOLETIM\%20ESTAT\%C3\% 8DSTICO\%202018/Boletim\%20Estati\%CC\%81stico\%20-\%2005\%20-\%202018.pdf>. Acesso em: 28 jul. 2018.

[10] CNT - CONFEDERAÇÃO NACIONAL DO TRANSPORTE. Pesquisa CNT: Perfil dos caminhoneiros 2016. Brasília: $\begin{array}{llll}\text { CNT,n } & 2016 . & \text { Disponível } & \mathrm{n}\end{array}$ http://cms.cnt.org.br/Imagens\%20CNT/PDFs\%20CNT/Pesquisa\%20de\%20Perfil\%20dos\%20Caminhoneiros/Pe squisa_CNT_de_Perfil_dos_Caminhoneiros_2016_Completo.pdf>. Acesso em: 26 jul. 2018. 
[11] CNT - CONFEDERAÇÃO NACIONAL DO TRANSPORTE. Transporte Rodoviário: Desempenho do Setor, Infraestrutura e Investimentos. Brasília: CNT, 2017. Disponível em: <http://cms.cnt.org.br/Imagens\%20CNT/PDFs\%20CNT/Estudos\%20CNT/estudo_transporte_rodoviario_infraes trutura.pdf>. Acesso em: 28 jul. 2018.

[12] COLVERO, Diogo Appel; SOUZA, Sibele Maki de. Avaliação de riscos ocupacionais aos catadores de materiais recicláveis: estudo de caso no município de Anápolis, Goiás, Brasil. Revista Tecnologia e Sociedade, Curitiba,

[13] v. 12, n. 26, p.161-177, ago. 2016. Universidade Tecnológica Federal do Paraná (UTFPR). http://dx.doi.org/10.3895/rts.v12n26.4518.

[14] CORROCHER, Maria Carolina, O Cotidiano de Trabalho de Motoristas de Caminhão do Transporte de Cargas: Identificação e Avaliação dos Principais Riscos Ocupacionais Presentes Nessa Profissão. Trabalho de Conclusão de Curso de Engenharia de Produção. Fundação Hermínio Ometto, Araras, SP, 2019.

[15] COSTA, Marco Antonio F. da; COSTA, Maria de Fátima Barrozo da. Segurança e Saúde no Trabalho: Cidadania, Competitividade e Produtividade. Rio de Janeiro: Qualitymark, 2005. 196 p.

[16] DALRI, Rita de Cássia de Marchi Barcellos; ROBAZZI, Maria Lúcia do Carmo Cruz; SILVA, Luiz Almeida da. Riscos ocupacionais e alterações de saúde entre trabalhadores de enfermagem brasileiros de unidades de urgência e emergência. Ciencia y Enfermería, [s.l.], v.16, n. 2, p.69-81, ago. 2010.

[17] DUTRA, Camila. Identificação e avaliação de riscos ocupacionais: estudo de caso em uma indústria madeireira de pequeno porte. 2018. 39 f. Monografia (Especialização) - Curso de Engenharia de Segurança do Trabalho, Universidade do Sul de Santa Catarina, Tubarão, SC, 2018.

[18] GIL, Antonio Carlos. Como elaborar projetos de pesquisa. 5. ed. São Paulo: Atlas, 2010. 200 p. IIDA, Itiro. Ergonomia: Projeto e Produção. 2. ed. São Paulo: Edgard Blucher, 2005. 630 p.

[19] KILESSE, Renan et al. Avaliação de fatores ergonômicos em postos de trabalho de motoristas de caminhões utilizados no meio agrícola. Engenharia na Agricultura, Viçosa, MG, v. 14, n. 3, p.202-211, jul./set. 2006.

[20] KILESSE, Renan. Fatores ergonômicos em postos de trabalho de motoristas de caminhão. $2005.66 \mathrm{f}$. Dissertação (Mestrado) - Curso de Engenharia Agrícola, Universidade Federal de Viçosa, Viçosa, MG, 2005. Disponível em: <http://www.locus.ufv.br/bitstream/handle/123456789/9740/texto\%20completo.pdf?sequence=1>. Acesso em: 02 ago. 2018.

[21] KROEMER, Karl H. E.; GRANDJEAN, Etienne. Manual de Ergonomia: Adaptando o trabalho ao homem. 5. ed. Porto Alegre: Bookman, 2005. 328 p.

[22] LEMOS, Lucia Castro; MARQUEZE, Elaine Cristina; MORENO, Claudia Roberta de Castro. Prevalência de dores musculoesqueléticas em motoristas de caminhão e fatores associados. Revista Brasileira de Saúde Ocupacional, São Paulo, v. 39, n. 129, p.26-34, jun. 2014. FapUNIFESP (SciELO). http://dx.doi.org/10.1590/0303-7657000062212.

[23] MINISTÉRIO DA SAÚDE DO BRASIL. Doenças relacionadas ao trabalho: manual de procedimentos para os serviços de saúde. $\quad$ Brasília, $2001 . \quad$ Disponível em: <http://bvsms.saude.gov.br/bvs/publicacoes/doencas_relacionadas_trabalho1.pdf>. Acesso em: 08 out. 2018.

[24] MINISTÉRIO DA SAÚDE. O que são IST. Disponível em: <http://www.aids.gov.br/pt-br/publico-geral/o-quesao-ist>. Acesso em: 02 nov. 2018.

[25] MINISTÉRIO DO TRABALHO E EMPREGO. Guia de Análise: acidentes de trabalho. [s.l.], 2010. Disponível em: <http://www.sinaees-sp.org.br/arq/mtegat.pdf >. Acesso em: 25 set. 2018.

[26] MINISTÉRIO DO TRABALHO. Normatização. Disponível em: <http://trabalho.gov.br/seguranca-e-saude-notrabalho/normatizacao>. Acesso em: 22 ago. 2018.

[27] NASCIMENTO, Eurípedes Costa do; NASCIMENTO, Evania; SILVA, José de Paula. Uso de álcool e anfetaminas entre caminhoneiros de estrada. Revista de Saúde Pública, [s.l.], v. 41, n. 2, p.290-293, abr. 2007. FapUNIFESP (SciELO). http://dx.doi.org/10.1590/s0034-89102007000200017.

[28] NOGUEIRA, Sumaia Austregesilo; BASTOS, Luciana Freita; COSTA, Iris do Céu Clara. Riscos Ocupacionais em Odontologia: Revisão da Literatura. UNOPAR Científica. Ciências biológicas e da saúde, [s.l.], v.12, n.3, p.11- 20, 2010.

[29] OIT - ORGANIZAÇÃO INTERNACIONAL DOTRABALHO. A prevenção das doenças profissionais. 2013. Disponível em: <http://www.ilo.org/public/portugue/region/eurpro/lisbon/pdf/safeday2013_relatorio.pdf>. Acesso em: 30 set. 2018.

[30] OLIVEIRA, Lucio Garcia de et al. Acidentes de trânsito envolvendo motoristas de caminhão no Estado de São Paulo: prevalência e preditores. Ciência \& Saúde Coletiva, [online], v. 21, n. 12, p.3757-3767, dez. 2016. FapUNIFESP (SciELO). http://dx.doi.org/10.1590/1413-812320152112.11182015.

[31] OLIVEIRA, Lúcio Garcia de et al. Occupational conditions and the risk of the use of amphetamines by truck drivers. Revista de Saúde Pública, [online], v. 49, n. 61, p.1-9, 2015. FapUNIFESP (SciELO). http://dx.doi.org/10.1590/s0034-8910.2015049005944. 
[32] PAMPHLETT, Roger; RIKARD-BELL, Anna. Different Occupations Associated with Amyotrophic Lateral Sclerosis: Is Diesel Exhaust the Link?. Plos One, [s.l.], v. 8, n. 11, p.1-10, 2013. Public Library of Science (PLoS). http://dx.doi.org/10.1371/journal.pone.0080993.

[33] PEDROSO, Amarilda Aparecida dos Santos et al. Índice de incapacitação das lombalgias em motoristas de caminhão. Abcs Health Sciences, São Paulo, v. 38, n. 3, p.142-145, $2013 . \quad$ NEPAS. http://dx.doi.org/10.7322/abcshs.v38i3.19.

[34] PEREIRA, Francisco Gilberto Fernandes et al. Relação entre processo de trabalho e saúde de caminhoneiros. Revista Brasileira em Promoção da Saúde, Fortaleza, v. 27, n. 4, p.462-469, dez. 2014. Fundação Edson Queiroz. http://dx.doi.org/10.5020/18061230.2014.p462.

[35] PONCE, Julio de Carvalho; LEYTON, Vilma. Drogas ilícitas e trânsito: problema pouco discutido no Brasil. Revista de Psiquiatria Clínica, [s.l.], v. 35, n. 1, p.65-69, 2008.

[36] PORTO, Marcelo Firpo de Souza. Análise de riscos nos locais de trabalho: Conhecer para transformar. Cadernos de Saúde do Trabalhador. [online], p. 3-42. jun. 2000. Disponível em: <http://www.cerest.piracicaba.sp.gov.br/site/images/caderno3_analise_de_risco.pdf>. Acesso em: 03 out. 2018.

[37] RODRIGUES, Luciano Brito; SANTANA, Nívio Batista. Identificação de Riscos Ocupacionais em uma Indústria de Sorvetes. Unopar Científica. Ciências Biológicas e da Saúde, [online], v. 12, n. 3, p.31-38, 2010. Disponível em: <http://pgsskroton.com.br/seer/index.php/JHealthSci/article/viewFile/1294/1239>. Acesso em: 05 out. 2018.

[38] RUIZ, Francieli S et al. Accident Risk Factors among Brazilian Shift-Working Truck Drivers. Health Science Journal, [online], v. 9, n. 7:2, p.1-9, 2015.

[39] SILVA, Jorge Luiz Lima da et al. O ruído causando danos e estresse: possibilidade de atuação para a enfermagem do trabalho. Avances En Enfermería, [s.l.], v. 32, n. 1, p.124-138, 2014. Universidad Nacional de Colombia. http://dx.doi.org/10.15446/av.enferm.v32n1.46074.

[40] SOUZA, Krisllen Samara Feitosa de et al. Análise preliminar de risco em uma empresa privada da Paraíba: uma abordagem voltada para um motorista de ônibus. In: ENCONTRO NACIONAL DE ENGENHARIA DE PRODUÇÃO (ENEGEP), 37., 2017, Joinville. Anais do Encontro Nacional de Engenharia de Produção - Enegep. Joinville: Abepro, 2017. p. 1 - 18.

[41] TAKITANE, Juliana et al. Uso de anfetaminas por motoristas de caminhão em rodovias do Estado de São Paulo: um risco à ocorrência de acidentes de trânsito?. Ciência \& Saúde Coletiva, [s.l.], v. 18, n. 5, p.1247-1254, maio 2013. FapUNIFESP (SciELO). http://dx.doi.org/10.1590/s1413-81232013000500009. 


\section{Capítulo 4}

Avaliação da interrupção no desenvolvimento de novas tecnologias nas micro e pequenas empresas do setor químico do ABC Paulista com base no TRL

\section{Jayson Luis da Silva Ribeiro}

Anderson Orzari Ribeiro

\section{Ricardo Gaspar}

Resumo: fomentar a inovação mercadológica por meio de novos produtos e serviços é um desafio global que envolve expressivos investimentos em Pesquisa, Desenvolvimento e Inovação (PDI). Quando o desenvolvimento de uma tecnologia fracassa devido à falta de recursos físicos e financeiros, o mercado perde competitividade, desestimulando a inovação. 0 conceito de Valley of Death (exemplificado através da análise do método de avaliação do nível de maturidade no desenvolvimento de uma tecnologia - Technology Readiness Level - TRL) é objeto de estudo no campo de conhecimento e gestão da inovação. Através do método de aplicação de questionário, esta pesquisa buscou a compreensão das variáveis envolvidas na mortalidade PDI nas etapas de escalonamento de uma tecnologia em Micro e Pequenas Empresas (MPES) do setor químico da região do ABC Paulista, como resultado foi verificada a relevância de tais custos no abandono de projetos de pesquisa, elencando as maiores dificuldades enfrentadas pelas empresas analisadas e contribuindo assim com a compreensão dos fatores relacionados ao abandono PDI e levantando alternativas para o fomento à inovação nas MPES.

Palavras-chave: Infraestrutura P\&DI; Valley of Death; Technology Readiness Level (TRL); Hélice Triplice; Inovação. 


\section{INTRODUÇÃO}

A região do $\mathrm{ABC}$ paulista representa um polo econômico e industrial de importante relevância no cenário nacional. Primeira sede da indústria automobilística brasileira e com forte atuação petroquímica, a região tem buscado ao longo dos anos a diversificação e fortalecimento de sua economia através do projeto eixo Tamanduateí e da criação de arranjos produtivos locais (APL) para as cadeias de autopeças, ferramentaria e plásticos, estimulando especialmente as micro e pequenas empresas (MPE) participantes no fornecimento de insumos para as grandes empresas da região.

Responsáveis pela geração de parcela significativa dos empregos e renda na região, as micro e pequenas empresas do segmento químico contribuem expressivamente com a economia nacional. A indústria química representa o terceiro lugar no produto interno bruto (PIB) da indústria de transformação nacional (IBGE - PIA Empresas Unidade de Investigação, 2015). Segundo dados da agência de desenvolvimento econômico do ABC, $19 \%$ do PIB do grande $A B C$ é oriundo do segmento químico. No tocante a arrecadação de impostos, $50 \%$ do ICMS de Santo André é advindo da indústria química, em Mauá esse montante chega a $65 \%$, fato este que demonstra a relevância deste segmento também na economia local.

Ainda que o Brasil esteja presente entre as maiores economias no segmento químico mundial, ocupando a 8o posição segundo dados da Associação Brasileira da Indústria Química - ABIQUIM (2017), países como a china e os Estados Unidos apresentam um faturamento líquido $1749,54 \%$ e $704,59 \%$ superior respectivamente. Estes dados demonstram o potencial existente neste mercado e os desafios presentes no segmento químico brasileiro no que se refere a ganho de competitividade, pesquisa científica, desenvolvimento de novas tecnologias e inovação em um mercado globalizado.

Um dos maiores gargalos para inovação e desenvolvimento de novos produtos em micro e pequenas empresas está relacionada às dificuldades no escalonamento de uma tecnologia. 0 conceito de Valley of death (etapas do método de avaliação do nível de maturidade de uma tecnologia - Technology Readiness Level - TRL) é objeto de estudo no campo de conhecimento e gestão da inovação. Essas etapas se referem à necessidade de angariar recursos para o desenvolvimento de protótipos para escalonamento de tecnologias, que representam um ponto crítico para o desenvolvimento de produtos e serviços (The House of commons science and technology committee, 2013).

O Brasil vem empenhando esforços no tocante ao fomento da inovação através do fortalecimento de práticas de pesquisa via Sistema Nacional de Inovação (SNI). Ainda que existam esforços promovidos para incentivo de PDI (lei de Inovação, lei do bem, lei do fundo nacional de desenvolvimento científico e tecnológico - FNDCT) faz-se necessário maiores estudos para a compreensão das variáveis envolvidas no abandono das pesquisas durante as etapas de escalonamento de uma nova tecnologia. E a dificuldade para superar esta etapa no desenvolvimento de novos produtos e serviços é ainda mais relevante quando analisamos o ecossistema das micro e pequenas empresas (MPE).

Em um mercado globalizado e extremamente competitivo, as empresas buscam na inovação um fator chave para sobrevivência e diferenciação perante as concorrentes. Segundo Zilber, Perez e Lex (2009), quanto maior o grau de inovação de um produto, maiores são os retornos esperados. Isto demonstra a existência de uma demanda de mercado que prioriza o consumo de produtos inovadores. É esperado de qualquer empresa que exista uma constante renovação em seus produtos, evitando assim a perda de competitividade e aumento de participação de mercado (market share) frente às empresas concorrentes.

O problema que se coloca atualmente sobre a inovação e desenvolvimento de tecnologias é que nem todas as pesquisas idealizadas são capazes de atingir a sua etapa final, ou seja, sua comercialização. Ainda que parte desta taxa de abandono de novas pesquisas esteja relacionada à inviabilidade técnica, pesquisas abandonadas pela falta de recursos físicos e financeiros representam uma perda significativa de conhecimento e aprimoramento de tecnologias e produtos no mercado. A universidade é um dos pilares responsáveis por este processo, mas como será apresentado a seguir, este estudo traz outras importantes variáveis para a análise do insucesso no desenvolvimento de novos produtos, dentre estas, destaca-se: a maturidade da tecnologia (TRL), a infraestrutura presente no seu desenvolvimento e a interação entre indústria, governo e ICTs ("Tríplice Hélice").

Ainda que o vale da morte da pesquisa tenha sido alvo de estudos internacionais sobre o tema, a região do grande $\mathrm{ABC}$ carece de estudos que avaliem e realidade das micro e pequenas empresas locais neste contexto. A presente pesquisa buscou identificar as causas do abandono de projetos de pesquisa durante as etapas de escalonamento de uma nova tecnologia, avaliando a existência do já abordado na literatura, vale da morte da pesquisa, em um contexto regional e segmentado. Paralelamente, avaliamos o papel e 
relevância dos agentes da hélice tríplice (Universidade / ICTs, governo e empresas) como possível instrumento para a redução deste tipo de evento.

\section{REVISÃO BIBLIOGRÁFICA}

\subsection{TECHNOLOGY READINESS LEVEL (TRL) COMO FERRAMENTA DE AVALIAÇÃO DA MATURIDADE NA PESQUISA, DESENVOLVIMENTO E INOVAÇÃO (PDI)}

O TRL foi idealizado em 1984 pelo pesquisador da NASA Stan Sadin e formalizado em 1989, contendo sete níveis de prontidão tecnológica identificados até aquele momento. Em 1995, o método foi aprimorado com a adição de mais dois níveis de prontidão tecnológica, resultando assim no modelo atual de gestão do processo de desenvolvimento de novas tecnologias e inovação como é conhecido até os dias atuais. (SADIN et. al, 1989, p.4; ALTUNOK et. al, 2010, p.9).

Os nove níveis de prontidão tecnológica que representam a incerteza e o risco associado à utilização de determinada tecnologia são listados a seguir, em tradução livre:

a) TRL1 - Os princípios básicos são analisados e relatados: fase em que existe, por exemplo, uma análise das propriedades básicas de determinado material;

b) TRL2 - Os princípios básicos são observados e aplicação (conceito) da tecnologia é formulado; como exemplo, podemos citar a análise de potenciais aplicações para o material pesquisado;

c) TRL3 - Prova de conceito analítica e experimental de características ou funções críticas; foco em ajustar a tecnologia à um conceito. Estudos laboratoriais são requeridos para avaliar se a tecnologia é viável. Como exemplo pode-se mencionar a integração com novos componentes que não existiam anteriormente;

d) TRL4 - Validação de componentes ou breadboard em ambiente de laboratório: Análise do protótipo em laboratório. Como exemplo pode-se mencionar testes de comportamento do material;

e) TRL5 - Validação de componentes (protótipo) ou breadboard em ambiente relevante: 0 protótipo é submetido a teste em ambiente simulado de modo realístico. A confiabilidade deve aumentar significativamente;

f) TRL6 - Demonstração de modelo ou protótipo de sistema ou subsistema em ambiente operacional: o protótipo é testado em ambiente laboratorial de alta fidelidade ou ambiente operacional simulado;

g) TRL7 - Demonstração de protótipo de sistema ou subsistema em ambiente real: 0 protótipo é testado em um sistema real;

h) TRL8 - Sistema real complexo e "provado em voo" por meio de testes e demonstrações: prova de funcionamento em sistema nas condições especificadas e certificação de uso. Integra-se a tecnologia em um sistema real existente;

i) TRL9 - Sistema real "provado em voo" por meio de operação em missões bem sucedidas: Aprovado em todos os testes e pronto para lançamento comercial.

Mediante a aplicação do TRL pode-se evidenciar se determinada tecnologia está próxima da etapa inicial de desenvolvimento ou próxima de sua comercialização, assim como pode-se analisar qual a estratégia mais adequada para cada etapa de pesquisa, desenvolvimento e inovação de determinada tecnologia. Diante deste contexto pode-se inferir que:

a) Entre as fases TRL 1 e TRL 2, as necessidades envolvidas no processo possuem um contexto próximo da pesquisa básica da tecnologia desenvolvida;

b) Entre as fases TRL 2 e TRL3, a necessidade está voltada a pesquisa para análise de viabilidade de uma tecnologia;

c) Entre as fases TRL 3 e TRL 5, as atenções estão direcionadas ao desenvolvimento da tecnologia;

d) Entre as fases TRL 5 e TRL 6, o foco está na demonstração da tecnologia;

e) Entre as fases TRL 6 e TRL 8, a necessidade está relacionada ao desenvolvimento de um sistema ou subsistema;

f) Entre as fases TRL 8 e TRL 9, inicia-se a etapa de testes do sistema e operação. 
Uma das principais barreiras referentes à transferência de conhecimento e formalização de parcerias hélice tríplice está relacionada com a geração de patentes, exclusividade e confidencialidade empresarial. Perkmann (2013) discorre sobre o assunto e afirma que o papel do pesquisador vem mudando ao longo dos anos e cada vez mais ve-se a figura do cientista focado na transferência de conhecimento e no relacionamento universidade - indústria através da obtenção de recursos para pesquisas, intervenções políticas e fomento a transferência de conhecimento e comercialização.

\subsection{O PROCESSO DE ESCALONAMENTO E A RELEVÂNCIA DO FOMENTO PARA O ESCALONAMENTO DE TECNOLOGIAS}

No contexto da manufatura produtiva os processos de escalonamento foram criados com o objetivo de avaliar e otimizar as diferentes variáveis envolvidas em um sistema de produção, intercalando e priorizando ações de acordo com a relevância para conclusão do projeto no menor tempo disponível e com a maior economia de recursos possível.

Os processos de escalonamento têm como diretriz maximizar a produtividade e prover interação entre usuários, assim como o balanceamento na utilização de recursos e minimização de sobrecarga do sistema e do tempo de resposta para os usuários. Ocorre que, por diversas vezes, universidades e pequenas e médias empresas não possuem a infraestrutura necessária para o desenvolvimento de uma tecnologia a partir do nível TRL3.

O processo de escalonamento envolve por muitas vezes a análise de variáveis complexas interrelacionadas, fator este que torna este processo extremamente trabalhoso e requer das organizações uma grande habilidade de planejamento e adaptação para analisar com agilidade demandas de baixa previsibilidade. Segundo Rabelo e Klen (2000), afirmam que, do ponto de vista interno da empresa, seus sistemas precisam estar preparados para absorver os problemas de instabilidade do chão-de-fábrica, oriundos de eventos que, se não causam uma interrupção na produção, causam a necessidade de constantes replanejamentos e reescalonamentos.

Rabelo et al. (1996), afirmam que escalonamento ágil é a atividade ou sistema com a capacidade de suportar as ações de: escalonamento dinâmico e ágil adaptação: capacidade de permitir uma flexível adaptação de toda a estrutura de produção de uma empresa de acordo com as características e requisitos de um dado processo de negócios. Diante do exposto, projetos inovadores oriundos principalmente de pesquisa universitária e parcerias entre as instâncias hélice tríplice, passam naturalmente pelas etapas de concepção, desenvolvimento, maturação e consequentemente pela necessidade de ganho de escala para produção e comercialização.

Após a globalização e fortalecimento de algumas economias consideradas polos produtores de conhecimento e mão de obra, as empresas têm buscado cada vez mais reinventar seus produtos e otimizar a utilização de recursos, entregando produtos com valor agregado diferenciado e mantendo um controle rígido sobre os custos de produção. Eficiência nos processos de pesquisa, desenvolvimento e inovação têm sido fatores chave no ganho de competitividade no nosso atual modelo econômico e diante disso, surgiu a figura do escalonamento cooperativo, também conhecido como escalonamento intraorganizacional ou escalonamento integrado, como uma alternativa inovadora para a produção e execução conjunta de projetos.

Para Rabelo e Klen (2000), o escalonamento integrado pode ser definido como um processo de forte interação entre atividades, em especial às relacionadas ao planejamento e supervisão de execução, não sendo possível sua concepção em forma de atividade isolada. Considerando um contexto de produção multiusuário ou empresa virtual, na qual a execução de um produto é realizada pela integração de processos individuais e inter-relacionados entre agentes, a coordenação de variáveis torna-se algo extremamente complexo, pois as relações entre os participantes da cadeia de pesquisa e desenvolvimento possuem restrições na divulgação de dados, formando uma dinâmica que dificulta a comunicação entre os envolvidos. Neste contexto, tornam-se necessários maiores estudos no tocante a modelos de compartilhamento de infraestrutura de pesquisa para que seja possível atingir a agilidade e eficiência necessárias ao bom desenvolvimento de projetos de PDI. 
O conceito de hélice tríplice originou-se em Boston com o objetivo de identificar os protagonistas em um sistema de inovação regional na Rota 128 , termo este utilizado para se referir ao corredor de empresas de tecnologia instaladas ao longo dessa região. Este modelo está no centro das pesquisas relacionadas à inovação, fomento à produção e desenvolvimento econômico. Por meio do estudo entre as relações existentes e modelos de pesquisa, desenvolvimento, produção e inovação, pesquisadores têm contribuído para o fortalecimento econômico, ganho em escala e eficiência produtiva de projetos inovadores desenvolvidos em laboratórios, centros de pesquisa e universidades (ETZKOWITZ et al, 2017).

Originado como uma metodologia para examinar os pontos fortes e fracos existentes nas relações entre governos, indústrias e universidades, o conceito de hélice tríplice busca desenvolver estratégias de alto desempenho em inovação por meio da identificação de lacunas nas relações entre seus agentes base. 0 estudo das interações entre indústria, governo e universidade culmina no entendimento e fortalecimento das fontes geradoras do desenvolvimento socioeconômico baseado no conhecimento técnico-científico gerado em laboratório objetivando atender a um mercado em específico.

A universidade tem protagonizado um papel chave no desenvolvimento de tecnologias, patentes e inovação. Ainda que por anos ela tenha assumido papel secundário neste processo, por meio da adoção do ensino como responsabilidade primordial e exclusiva, atualmente seu objetivo abrange novas responsabilidades que incluem pesquisas com foco no desenvolvimento de tecnologias para o mercado, patentes e geração de conhecimento, papel este equivalente ao do governo e da indústria na economia global (BRUNEEL et al, 2010).

Este aspecto deu origem a uma configuração diferente em nossa sociedade. Se antes os pesquisadores davam início a uma tecnologia embrionária e nunca tinham controle sobre suas criações, hoje o pesquisador acompanha todo o processo de transferência de tecnologia (ETZKOWITZ et al, 2017). No entanto, tem-se notado que nem sempre as interações da hélice estão unidas a ponto de produzir mudanças significativas, e existem poucos estudos sobre como reduzir esta distância, especialmente entre empresas e universidades (BRUNEEL et al, 2010).

A literatura aponta alguns princípios adotados pela hélice tríplice: a) os espaços atuantes desta metodologia incluem conhecimento, consenso e inovação; b) a universidade torna-se alvo de empreendedorismo e passa a protagonizar o cenário de inovação; c) o nascimento de empresas baseadas no conhecimento são resultados da interação entre atores primários e secundários de inovação; d) o governo não é controlador, mas media as relações entre empresa e universidade; e) o capital de risco pode cooperar na interação universidade-governo-indústria; f) as agências de inovação cooperam entre si, interligando-se em prol do desenvolvimento tecnológico; g) a inovação é um processo que tem início, mas está continuamente produzindo novas tecnologias (ETZKOWITZ et al, 2000). Com isso surge a necessidade de novos estudos relacionando o processo de inovação com a interação da hélice tríplice, uma das variáveis envolvidas no escalonamento de produtos tecnológicos, como objetiva a presente pesquisa.

\section{METODOLOGIA}

0 método utilizado nesta pesquisa consistiu na aplicação de questionário. Foram entrevistadas 13 empresas do segmento químico que atuaram no desenvolvimento de novos produtos na região do grande ABC Paulista.

O processo de seleção dos indivíduos que compõe a amostra teve como base os seguintes fatores: a) Atuar na região do grande $\mathrm{ABC}$ no estado de São Paulo; b) Participar do segmento químico; c) Investir esforços e recursos no desenvolvimento de novas tecnologias; d) Participação prévia em projeto de consultoria para fomento à inovação regional.

Para efeito de comparação e análise dos resultados, as empresas participantes foram divididas em dois grupos, sendo: a) Grupo de empresas com enquadramento fiscal como micro ou pequena empresa (MPE), com faturamento inferior ou igual a $R \$ 3.600 .000,00$ e até 99 funcionários, e; b) Grupo de empresas com enquadramento fiscal como média ou grande empresa, incluindo multinacionais e sociedades anônimas (S/A), com faturamento superior ou igual a $R \$ 3.600 .000,01$ e acima de 100 funcionários.

A coleta dos dados iniciais foi realizada através de questionário eletrônico aplicado junto a empreendedores brasileiros, investigando a relevância de uma infraestrutura de PDI no desenvolvimento de novas tecnologias. 
Os dados resultantes da presente pesquisa foram analisados estatisticamente, compondo um cenário atual sobre a mortalidade no desenvolvimento de novos produtos nas empresas analisadas e sua relação com uma eventual ausência de uma infraestrutura de pesquisa adequada ao desenvolvimento de tecnologias e inovação.

\section{RESULTADOS E CONCLUSÕES}

Foram levantados dados sobre o abandono de projetos de pesquisa em 13 empresas do segmento químico no Grande ABC Paulista. 0 questionário aplicado contém um total de 17 perguntas distribuídas entre abertas e fechadas que buscaram compreender e explorar casos reais sobre a interrupção de projetos de pesquisa e desenvolvimento de novos produtos nas empresas analisadas.

Primeiramente, analisando o perfil da amostra, verificamos que dentre as empresas analisadas contou-se com uma proporção equilibrada entre portes, sendo $53,84 \%$ das empresas respondentes enquadradas como micro e pequenas empresas, distribuídas entre 15,38\% de ME's e 38,46\% de EPP's, e o restante $46,16 \%$ enquadradas como empresas de médio e grande porte, incluindo multinacionais e Sociedades Anônimas (S/A). Esta divisão por níveis de faturamento facilitou a análise e comparação de resultados por porte e estrutura. Foi possível verificar uma adequação da amostra com o problema de pesquisa levantado, pois todas as empresas participantes atuam na região do Grande ABC Paulista e pertencem ao segmento da indústria química.

Avaliando a quantidade de funcionários percebeu-se que 54\% das empresas possuem mais de 100 funcionários, fator este relevante para análise de porte e que demonstra a maturidade de algumas MPE's no tocante à capital humano e estrutura para negócios. Segundo dados do SEBRAE (2017), uma das maneiras de avaliar o porte de uma empresa é através da análise de seu quadro funcional, considerando que a partir de 100 funcionários uma empresa começa a apresentar estrutura mais desenvolvida, equivalente às organizações de médio porte.

Os dados do eixo 2 avaliaram informações no tocante ao desenvolvimento de novas tecnologias, práticas de inovação e ambiência inovadora. Foi verificado que dentre as empresas analisadas, 53,85\% possuem menos de $10 \%$ dos funcionários envolvidos com o desenvolvimento de novos produtos e inovação. Contudo, $23,08 \%$ afirmaram que possuem mais de $25 \%$ do seu quadro funcional trabalhando em atividades de pesquisa e inovação.

No tocante aos esforços para o desenvolvimento de novas tecnologias e inovação, a totalidade das empresas participantes informou ter empenhado esforços no desenvolvimento de novas tecnologias nos últimos 5 anos, sendo que deste total $92 \%$ informaram o desenvolvimento de mais de um projeto. Fator este que reforça o perfil inovador das empresas analisadas.

Em continuidade a análise, buscou-se identificar taxas de insucesso diante dos esforços para o desenvolvimento de novas tecnologias nas empresas pesquisadas, e foi possível perceber que $23 \%$ das empresas tiveram problemas na finalização dos projetos de pesquisa e desenvolvimento iniciados, dentre as quais a totalidade é constituída por MPE's.

Depois de verificada a existência de interrupção no desenvolvimento de novas tecnologias por $23 \%$ das empresas pesquisadas, buscou-se abordar tal realidade mais a fundo identificando as causas para este abandono de pesquisa. Dentre as respostas obtidas foram verificadas as seguintes variáveis: a) falta de recursos financeiros; b) falta de conhecimento dos processos; c) falta de mão de obra especializada; d) falta de infraestrutura de pesquisa e desenvolvimento; e) falta de conhecimento teórico; f) prazos curtos; g) mutação do mercado; h) localização de parte da estrutura de PD fora do território nacional (Estados Unidos e Alemanha); i) necessidade de manter a produtividade.

Os itens mais mencionados como parte integrante das dificuldades no desenvolvimento de novas tecnologias foram a falta de mão de obra especializada com $36 \%$ das respostas, seguidos pela falta de infraestrutura de PDI com $24 \%$ e falta de recursos financeiros com 16\%, respectivamente.

Fato interessante de se notar é que ainda que seja fator determinante no desenvolvimento de uma tecnologia, a falta de recursos financeiros não é a principal dificuldade abordada pelas empresas analisadas neste estudo. Isto demonstra que mais do que dinheiro em caixa, as empresas analisadas precisam de profissionais especializados e equipamentos adequados para o desenvolvimento e escalonamento de uma tecnologia nova. 
O cenário identificado corrobora com a hipótese formulada de que os custos inerentes à obtenção e manutenção de uma infraestrutura PDI é fator relevante para o abandono de pesquisas de novas tecnologias nas MPEs do setor químico analisadas neste estudo. Assim, como reforçam a ideia de que através do compartilhamento de uma infraestrutura PDI, MPEs poderiam usufruir de uma maior eficiência na conversão de pesquisas básicas em novas tecnologias para o mercado, pois esta alternativa aborda diretamente os três principais gargalos levantados pelos micro e pequenos empresários.

No tocante à falta de mão de obra especializada, através do compartilhamento de infraestruturas por ICTs, as MPE's contariam com o apoio de especialistas técnicos em cada equipamento. A gestão do projeto em si continua a cargo da empresa, porém a operacionalização das atividades contará com o apoio e conhecimento de um técnico de laboratório ou pesquisador de uma ICT parceira. Questões sobre patentes, sigilo da pesquisa e propriedade intelectual devem estar bem delimitadas e estabelecidas para sucesso desta iniciativa.

Dando continuidade à análise dos fatores relevantes para a interrupção de projetos de pesquisa, a segunda variável mais mencionada pelos empresários foi a própria falta de infraestrutura de pesquisa em si, o que demonstra uma carência no segmento de infraestrutura adequada para o desenvolvimento de novas tecnologias. Ainda que existam algumas linhas de financiamento governamental para obtenção de equipamentos, o risco associado ao desenvolvimento de produtos inovadores pode inibir a conclusão de projetos com inovações disruptivas. Através do compartilhamento de infraestruturas de pesquisa e desenvolvimento, ICTs assumem parte do risco inerente a este processo, sendo responsável pelo custo da infraestrutura e do capital técnico especializado para gestão e sua manutenção.

Considerando o ponto de vista de Instituições de Ciência e Tecnologia, além dos elevados custos para aquisição de alguns equipamentos, os laboratórios de PDI enfrentam grandes desafios no que se refere ao equilíbrio e sustentabilidade financeira. As despesas com a gestão do ambiente laboratorial, incluindo custos com mão de obra técnica especializada consumíveis e manutenção do equipamento representam, uma fatia considerável de seus custos operacionais. Através da dissolução destes custos em projetos de desenvolvimento variados, as ICTs podem usufruir de uma maior eficiência na gestão das operações e do seu negócio principal.

Quanto ao terceiro aspecto relevante para o insucesso das pesquisas nas empresas analisadas, foi verificado que a falta de recursos financeiros pode impactar diretamente no abandono destas pesquisas, evidenciando a necessidade de uma análise do papel dos agentes da hélice tríplice neste cenário. 0 governo está envolvido através da criação de políticas de fomento à inovação, disponibilização de créditos e incentivos para o desenvolvimento de novos produtos e fortalecimento das MPEs; Da mesma forma, as ICTs incluindo universidades possuem um papel de extrema relevância no fortalecimento deste mercado, não apenas pela pesquisa básica e fornecimento de capital intelectual para o mercado, mas também promovendo práticas de otimização dos recursos e processos disponíveis. 0 compartilhamento de infraestruturas de pesquisa por Instituições de Ciência e Tecnologia pode em conjunto com políticas governamentais reduzir o custo com: a) aquisições de equipamentos; b) adequações físicas e estruturais; c) treinamentos e gestão do capital técnico intelectual; d) manutenções preventivas e corretivas; e) obsolescência técnica; f) gastos estruturais não previstos.

Sendo assim através da utilização de uma infraestrutura PDI compartilhada a empresa pode se beneficiar de uma redução nos seus custos operacionais, focando em sua atividade fim e otimizando seus resultados através de uma maior eficiência em sua taxa de conversão de pesquisas básicas para tecnologias inovadoras no mercado.

As demais variáveis levantadas: falta de conhecimento nos processos, falta de conhecimento teórico, problemas com prazos curtos e dificuldade em manter a produtividade, problemas com obsolescência tecnológica e mutação de mercado (necessidade de atualização constante dos equipamentos e atualização do capital humano - conhecimento técnico) e localização de parte da estrutura de PD fora do território nacional. também podem apresentar benefícios através da alternativa formulada nesta pesquisa.

Em continuidade, a análise dos dados levantados verificou-se que 46,16\% das empresas de nossa amostra já desenvolveram patentes, sendo que metade deste total utilizou-se de parceria com alguma ICT ou empresa parceira para tal. Tal fato demonstra uma maturidade e perfil inovador das empresas analisadas no tocante ao desenvolvimento de novas tecnologias para o mercado. 
Por outro lado, quando o assunto é interação com o governo e programas de financiamento, apoio e fomento, 76,92\% da amostra pesquisada afirmou nunca ter participado de programas governamentais ou recebido incentivos fiscais ou financiamentos específicos. Dentre as empresas que obtiveram tal interação existiu a participação em projetos de incubadoras de empresas regionais, utilização de recursos de agências financiadoras como CNPq e FAPESP e participação no programa de inovação tecnológica conforme decreto no 5.798 de 7 de junho de 2006 e lei no 11.196, de 21 de novembro de 2005.

Analisando mais diretamente a disponibilidade de infraestrutura própria para o escalonamento de novas tecnologias, 76,92\% das empresas analisadas afirmaram não possuir infraestrutura própria para PDI que atenda de forma total suas necessidades, sendo que deste total 15,38\% das empresas afirma não possuir infraestrutura PDI. Este fato demonstra uma carência estrutural nas empresas analisadas e corrobora com a hipótese de que o compartilhamento de uma infraestrutura de pesquisa poderia resultar em ganho de desempenho na conversão de pesquisas básicas em tecnologias para o mercado, aumentando assim a competitividade e fomentando a inovação.

No que se refere à necessidade de compra de equipamentos para o desenvolvimento de uma nova tecnologia, 85\% das empresas analisadas informaram que necessitaram realizar a compra de equipamento novo nos últimos 5 anos, sendo que 23\% dessas empresas não pôde concluir a compra do equipamento por falta de recursos. Isto demonstra que quase $1 / 4$ (um quarto) das empresas analisadas interrompeu projetos de pesquisa devido aos altos custos envolvidos no escalonamento de uma nova tecnologia.

Sendo assim, foi possível através da análise dos dados obtidos com a presente pesquisa verificar a existência de abandono de projetos de pesquisa nas micro e pequenas empresas do segmento químico do $\mathrm{ABC}$ paulista, confirmando-se o custo de uma infraestrutura de pesquisa como fator relevante para a conclusão de novos projetos e desenvolvimento de novos produtos nas empresas avaliadas. A hipótese de que por meio de um compartilhamento dos riscos associados e dos custos de aquisição de equipamentos e gestão da infraestrutura, estas empresas podem usufruir de maior eficiência na conversão de pesquisas básicas em novas tecnologias para o mercado também se mostrou válida, abrindo espaço para maiores estudos sobre o tema visando o levantamento de modelos eficientes para o compartilhamento de infraestrutura entre os agentes tríplice Hélice.

\section{REFERÊNCIAS}

[1] ABIQUIM - Associação Brasileira da Indústria Química. O desempenho da industria química, 2017.

[2] ALTUNOK, T.; CAKMAK, T. A Technology Readiness Levels (TRLs) calculator software for systems engineering and technology management tool. Advances in Engineering Software, v. 41, n. 5, p.9, 2010.

[3] BRUNEEL, J; D'ESTE, P; NEELY, A; SALTER, A. The search for talent and technology: Examining the Attitudes of EPSRC Industrial Collaborators towards Universities. Londres: Advanced Institute of Management Research, 2009.

[4] ETZKOWITZ, H.; ZHOU, C. Hélice Tríplice: inovação e empreendedorismo universidade-indústria-governo. Estud. av. [online]. 2017, vol.31, n.90, pp.23-48.

[5] ETZKOWITZ, H., \& LEYDESDORFF, L. The Dynamics of Innovation: From National Systems and 'Mode 2' to a Triple Helix of University-Industry-Government Relations. Research Policy, 29(2), 109-123, 2000.

[6] HOUSE OF COMMONS SCIENCE AND TECHNOLOGY COMMITTEE. Bridging the valley of death: improving the commercialisation of research. United Kingdom, 2013.

[7] IBGE - Instituto Brasileiro de Geografia e Estatística. PIA Empresas unidade de investigação: Unidade local industrial, 2015.

[8] PERKMANN, Markus et al. Academic engagement and commercialisation: A review of the literature on university-industry relations. Research Policy, v. 42, n. 2, p.423-442, mar. 2013. Elsevier BV.

[9] RABELO, R. J.; KLEN, A. A. P. Escalonamento cooperativo interorganizacional. Gest. Prod., São Carlos , v. 7, n. 3, p. 226-246, Dec. 2000.

[10] SADIN, S. R.; POVINELLI, F. P.; ROSEN, R. The NASA technology push towards future space mission systems. Acta Astronautica, v. 20, n. 0, p. 4, 1989.

[11] SEBRAE - Serviço Brasileiro de Apoio às Micro e Pequenas Empresas. Análise do CAGED, 2017.

[12] ZILBER, M. A.; PEREZ, G.; LEX, S. Inovação tecnológica e obtenção de vantagens competitivas: um estudo duplo qualitativo na indústria brasileira de equipamentos eletromédicos. Organ. Soc., Salvador , v. 16, n. 51, p. $707-$ 723, Dec. 2009. 


\section{Capítulo 5}

\section{Desenvolvimento de modelos de apresentação de conteúdo baseados em estilos de aprendizagem}

\section{Brunno José Fagundes}

Rejane Frozza

Liane Mahlmann Kipper

Thaisi dos Santos Fagundes

Danielli Cossul

Resumo: Em ambientes virtuais de aprendizagem (AVA) os usuários interagem com o conteúdo apresentado e constroem seu conhecimento. Porém, diferentes usuários interagem com um mesmo ambiente. Tais usuários possuem uma forma particular de manipular as informações para construir seu conhecimento. Esta particularidade é denominada Estilo de Aprendizagem (EA) e é abordada por diferentes autores, os quais classificam indivíduos de acordo com as suas preferências e características de manusear as informações. Além disso, para cada EA é possível adotar uma estratégia de ensino diferente, potencializando a formação de conhecimento. Este trabalho apresenta uma proposta de metodologia para o desenvolvimento de modelos estudados que favoreçam a construção do conhecimento de usuários de um AVA e que considera os EA para apresentação dos conteúdos. Ainda, apresenta-se a abordagem de classificação dos usuários, de acordo com os EA definidos por Felder e Silvermann (1988), por um grupo de especialistas da Psicologia e uma proposta de avaliação dos resultados da interação dos usuários com o AVA utilizando o software Face Reader.

Palavras-chave: Ambiente Virtual de Aprendizagem, Estilo Cognitivo de Aprendizagem, Estratégia de Ensino, Face Reader. 


\section{INTRODUÇÃO}

Em Ambientes Virtuais de Aprendizagem (AVA) o usuário interage com o conteúdo apresentado e a partir desta interação, constrói seu conhecimento. Estes ambientes são utilizados nos mais diferentes cenários, sejam eles corporativos, acadêmicos ou institucionais (FAGUNDES, FROZZA e KIPPER, 2016). Porém, os usuários que interagem com um mesmo ambiente virtual de aprendizagem possuem características particulares, isto é, cada indivíduo possui uma forma ou método de construir seu próprio conhecimento. Estas características particulares são chamadas de Estilos de Aprendizagem (EA) (FELDER e SILVERMAN, 1988). Tais estilos são abordados por diferentes autores, como, por exemplo, Kolb (1999), Muhlbeier e Mozzaquatro (2012) e Felder e Silverman (1988) que classificam os indivíduos em grupos de acordo com suas características e preferências para organizar as informações. Dentre os autores que abordam essa classificação dos EAs, destaca-se Felder e Silverman (1988), um dos autores mais referenciados na literatura, que classificam os indivíduos em oito grupos de acordo com suas preferências e melhores práticas de organização de conteúdo durante o processo de aprendizagem.

Através da utilização de ferramentas que possibilitem a identificação destes EAs é possível ajustar o conteúdo de um ambiente virtual de aprendizagem de acordo com o estilo do usuário, potencializando o processo de ensino-aprendizagem. Para se obter mais eficiência neste processo, pode-se utilizar diferentes estratégias de ensino. As estratégias de ensino contemplam a forma e o conjunto de ações que buscam facilitar o processo de aprendizagem por meio de uma metodologia. Esta metodologia deve favorecer o desenvolvimento de ações cognitivas como, por exemplo, a observação, a confrontação, a elaboração de hipóteses, a análise e a sintetização, realizadas pelo estudante ao aprender. Assim, para cada EA, é pertinente considerar a utilização de diferentes estratégias de ensino que favorecem a formação de conhecimento dos usuários (ANASTASIOU, 2003).

O Ambiente Virtual de Aprendizagem (AVA) contemplado nesse capítulo, foi desenvolvido pelo grupo de pesquisa composto por professores e estudantes do Departamento de Computação e do Programa de PósGraduação em Sistemas e Processos Industriais de uma instituição de ensino superior do Estado do Rio Grande do Sul e vem ao longo dos anos aperfeiçoando-o constantemente, desde seus primeiros trabalhos realizados até o presente momento (SANTOS et al., 2001), (SILVA, 2002), (MAINIERI et al., 2005), (FROZZA et al., 2011), (FROZZA, et al., 2009), (BORIN et al., 2012), (GRIESANG; FROZZA, 2013), (HOMRICH, FROZZA e SCHREIBER, 2013), (SCHAEFER, FROZZA, SILVEIRA, RUTSATZ, 2015).

Várias pesquisas estão sendo realizadas na área da educação a distância e sobre a utilização de AVAs, cujo objetivo principal é proporcionar um melhor aprendizado aos estudantes que utilizam estes ambientes. Neste sentido, a Tabela 1 apresenta a evolução deste projeto e as etapas alcançadas até a presente data.

Tabela 1 - Evolução do AVA no decorrer dos anos

\begin{tabular}{|c|c|c|c|c|c|c|c|c|c|}
\hline Etapas & 2000 & 2002 & 2005 & 2007 & 2009 & 2010 & 2011 & 2012 & Ano \\
\hline Agente Dóris & Sim & Sim & Sim & Sim & Sim & Sim & Sim & Sim & \\
\hline Agente Dimi & - & Sim & Sim & Sim & Sim & Sim & Sim & Sim & \\
\hline Guiar Aluno & Sim & Sim & Sim & Sim & Sim & Sim & Sim & Sim & \\
\hline Coletar Informações & - & Sim & Sim & Sim & Sim & Sim & Sim & Sim & \\
\hline Rede Bayesiana & - & - & Sim & Sim & Sim & Sim & Sim & Sim & \\
\hline Teste de Ross & - & - & - & Sim & Sim & Sim & Sim & Sim & \\
\hline Emoções Dóris & 3 & 3 & 3 & 3 & 7 & 7 & 7 & 7 & \\
\hline Emoções Dimi & - & Fixa & Fixa & Fixa & Fixa & 2 & 2 & 2 & \\
\hline $\begin{array}{l}\text { Domínio de } \\
\text { Conhecimento Dóris }\end{array}$ & Geral & Geral & Geral & Geral & Geral & Geral & $\begin{array}{c}\text { Geral e } \\
\text { específi } \\
\text { co }\end{array}$ & $\begin{array}{c}\text { Geral e } \\
\text { específico }\end{array}$ & \\
\hline $\begin{array}{l}\text { Domínio de } \\
\text { Conhecimento Dimi }\end{array}$ & - & Geral & Geral & Geral & Geral & Geral & Geral & Geral & \\
\hline Aparência Dóris & $2 \mathrm{D}$ & $2 \mathrm{D}$ & 2D & $2 \mathrm{D}$ & $3 \mathrm{D}$ & $3 \mathrm{D}$ & $3 \mathrm{D}$ & $3 \mathrm{D}$ & \\
\hline Aparência Dimi & - & $2 \mathrm{D}$ & $2 \mathrm{D}$ & $2 \mathrm{D}$ & $2 \mathrm{D}$ & $3 \mathrm{D}$ & $3 \mathrm{D}$ & $3 \mathrm{D}$ & \\
\hline $\begin{array}{l}\text { Interação entre } \\
\text { agentes pedagógicos }\end{array}$ & - & - & - & - & - & - & - & Sim & \\
\hline
\end{tabular}


Tabela 1 - Evolução do AVA no decorrer dos anos

\begin{tabular}{|l|l|}
\hline Inferência do estilo de aprendizagem do estudante com o uso de Redes Neurais Artificiais & 2013 \\
\hline $\begin{array}{l}\text { Definição dos momentos em que a emoção e o estilo de aprendizagem são inferidos através das regras } \\
\text { de interação e determinação da relação entre a emoção e a cognição }\end{array}$ & 2014 \\
\hline $\begin{array}{l}\text { Estudo sobre as características dos estilos de aprendizagem e elaboração das duas táticas pedagógicas } \\
\text { utilizadas (com animação e sem animação) para promover a adaptação do AVA e produção de material } \\
\text { didático. Integração ao AVA utilizando métodos de animação }\end{array}$ & 2015 \\
\hline Interação com o agente pedagógico Dóris através de linguagem natural & 2016 \\
\hline $\begin{array}{l}\text { Proposta de Modelos de apresentação de conteúdo em um AVA, considerando as Táticas de ensino e os } \\
\text { Estilos Cognitivo de Aprendizagem dos usuários }\end{array}$ & 2016 \\
\hline $\begin{array}{l}\text { Avaliação de Modelos de Conteúdo Orientados aos Estilos de Aprendizagem em Ambientes Virtuais de } \\
\text { Aprendizagem }\end{array}$ & 2019 \\
\hline
\end{tabular}

É possível identificar a partir da Tabela 1, que o projeto iniciou com o agente Dóris em 2000. Dóris é um agente pedagógico tutor que tem a função de guiar o usuário dentro do ambiente virtual a fim de auxiliá-lo no processo de aprendizagem. Este agente expressava apenas três emoções e sua função era guiar o estudante dentro do ambiente. Neste período o agente foi desenvolvido em duas dimensões (2D). Somente após 2 anos, em 2002 foi criado o agente Dimi, companheiro do agente Dóris. Ambos agentes possuíam conhecimentos de domínio geral. Nos anos de 2005 e 2007, o ambiente passou a utilizar redes bayesianas e testes de Ross, para coleta de informações, e estilo cognitivo do estudante. Três anos depois os agentes passaram a ser programados em três dimensões (3D) e em 2012 foi estabelecido um protocolo de comunicação entre os agentes, que modelou e padronizou a comunicação entre eles. 0 passo seguinte foi possibilitar que o ambiente utilizasse animação como tática de ensino mantendo a identificação do EA. Já em 2016, foram propostos modelos de apresentação de conteúdos para os diferentes EAs, buscando melhorar as experiências de utilização do usuário no AVA e viabilizando a sua formação de conhecimento.

Este trabalho insere-se no projeto deste AVA considerando as preferências individuais dos usuários. 0 objetivo desta pesquisa é propor uma metodologia para desenvolvimento da etapa do projeto responsável pela apresentação de conteúdos de forma personalizada, de acordo com o EA do usuário. Nessa metodologia, apresenta-se uma abordagem para a aferição e validação da identificação dos EAs com o auxílio de um grupo especialista da área da Psicologia, bem como uma validação dos modelos de apresentação de conteúdo propostos para cada EA do usuário.

Este capítulo está organizado nas seguintes seções. Apresenta na Seção 2 a metodologia utilizada para elaboração deste estudo. Na Seção 3, é descrito o desenvolvimento do conteúdo dos AVA. Por fim, na Seção 4 é apresentada a conclusão.

\section{METODOLOGIA}

Para desenvolver este trabalho foi realizada, inicialmente, uma pesquisa nas bases de dados Web of Science, Scopus e Scielo, na data 05 de agosto de 2020, através do portal de pesquisa da CAPES, para identificar trabalhos (artigos) desenvolvidos relacionados ao tema principal deste trabalho nos últimos 5 anos (2015-2019) em todas as áreas do conhecimento para elaboração de uma bibliometria sobre o tema. A bibliometria consiste em "uma técnica quantitativa e estatística de medição dos índices de produção e disseminação do conhecimento científico" (ARAÚJO, 2006). A pesquisa iniciou com uma análise bibliométrica (quantitativa e qualitativa), a fim de conhecer os termos relacionados à pesquisa e os trabalhos sendo publicados na área de interesse.

$\mathrm{Na}$ pesquisa realizada foram utilizados os termos tanto em idioma nativo como em idioma estrangeiro (inglês), buscando assim maior número possível de trabalhos. No idioma nativo, foram utilizados os termos "Estilo de Aprendizagem", "Estratégia de Ensino", "Ambiente Virtual de Aprendizagem" e "Face Reader". Já no idioma inglês foram utilizados os termos "Learning Style", "Teaching Strategy", "Virtual Learning Environment" e "Face Reader". Os resultados desta pesquisa no idioma nativo são apresentados pela Tabela 2 . 
Tabela 2: Resultados da bibliometria em idioma nativo

\begin{tabular}{|c|c|c|c|c|}
\hline SCIELO & \begin{tabular}{|l|} 
Estilo de \\
Aprendizagem
\end{tabular} & $\begin{array}{l}\text { Estratégia de } \\
\text { Ensino }\end{array}$ & $\begin{array}{l}\text { Ambiente Virtual de } \\
\text { Aprendizagem }\end{array}$ & Face Reader \\
\hline $\begin{array}{l}\text { Estilo de } \\
\text { Aprendizagem }\end{array}$ & 19 & 0 & 0 & 0 \\
\hline Estratégia de Ensino & & 51 & 0 & 0 \\
\hline $\begin{array}{l}\text { Ambiente Virtual de } \\
\text { Aprendizagem }\end{array}$ & & & 43 & 0 \\
\hline Face Reader & & & & 2 \\
\hline SCOPUS & $\begin{array}{l}\text { Estilo de } \\
\text { Aprendizagem }\end{array}$ & $\begin{array}{l}\text { Estratégia de } \\
\text { Ensino }\end{array}$ & $\begin{array}{l}\text { Ambiente Virtual de } \\
\text { Aprendizagem }\end{array}$ & Face Reader \\
\hline $\begin{array}{l}\text { Estilo de } \\
\text { Aprendizagem }\end{array}$ & 0 & 0 & 0 & 0 \\
\hline Estratégia de Ensino & & 2 & 0 & 0 \\
\hline $\begin{array}{l}\text { Ambiente Virtual de } \\
\text { Aprendizagem }\end{array}$ & & & 9 & 0 \\
\hline Face Reader & & & & 14 \\
\hline WEB OF SCIENCE & $\begin{array}{c}\text { Estilo de } \\
\text { Aprendizagem }\end{array}$ & $\begin{array}{l}\text { Estratégia de } \\
\text { Ensino }\end{array}$ & $\begin{array}{c}\text { Ambiente Virtual de } \\
\text { Aprendizagem }\end{array}$ & Face Reader \\
\hline $\begin{array}{l}\text { Estilo de } \\
\text { Aprendizagem }\end{array}$ & 0 & 0 & 0 & 0 \\
\hline Estratégia de Ensino & & 0 & 0 & 0 \\
\hline $\begin{array}{l}\text { Ambiente Virtual de } \\
\text { Aprendizagem }\end{array}$ & & & 1 & 0 \\
\hline Face Reader & & & & 9 \\
\hline
\end{tabular}

Fonte: Pesquisa realizada em agosto de 2020

Conforme apresenta a Tabela 2, os resultados mais expressivos dizem respeito aos termos "Estilo de Aprendizagem", "Estratégia de Ensino" e "Ambientes Virtuais de Aprendizagem". Contudo, ao combinar apenas os dois primeiros termos a pesquisa no idioma nativo não retornou resultados. No caso do idioma inglês, os resultados foram mais expressivos, apresentando uma quantidade maior de trabalhos, conforme apresenta a Tabela 3 .

Tabela3: Resultados da bibliometria em idioma inglês

\begin{tabular}{|c|c|c|c|c|}
\hline SCIELO & Learning Style & $\begin{array}{l}\text { Teaching } \\
\text { Strategy }\end{array}$ & $\begin{array}{c}\text { Virtual Learning } \\
\text { Environment }\end{array}$ & Face Reader \\
\hline Learning Style & 55 & 0 & 0 & 0 \\
\hline Teaching Strategy & & 120 & 0 & 0 \\
\hline $\begin{array}{l}\text { Virtual Leaning } \\
\text { Environment }\end{array}$ & & & 78 & 0 \\
\hline Face Reader & & & & 2 \\
\hline SCOPUS & Learning Style & $\begin{array}{l}\text { Teaching } \\
\text { Strategy }\end{array}$ & $\begin{array}{c}\text { Virtual Learning } \\
\text { Environment }\end{array}$ & Face Reader \\
\hline Learning Style & 1.933 & 175 & 7 & 0 \\
\hline Teaching Strategy & & 2.479 & 28 & 0 \\
\hline $\begin{array}{l}\text { Virtual Learning } \\
\text { Environment }\end{array}$ & & & 587 & 0 \\
\hline Face Reader & & & & 14 \\
\hline WEB OF SCIENCE & Learning Style & $\begin{array}{l}\text { Teaching } \\
\text { Strategy }\end{array}$ & $\begin{array}{c}\text { Virtual Learning } \\
\text { Environment }\end{array}$ & Face Reader \\
\hline Learning Style & 856 & 9 & 0 & 0 \\
\hline Teaching Strategy & & 643 & 1 & 0 \\
\hline $\begin{array}{c}\text { Virtual Learning } \\
\text { Environment }\end{array}$ & & & 417 & 0 \\
\hline Face Reader & & & & 9 \\
\hline
\end{tabular}

Fonte: Pesquisa realizada em agosto de 2020 
Na Tabela 3, é possível observar que há maior incidência de resultados referentes aos termos "Teaching Strategy" seguido de "Learning Style", nesta ordem. A medida em que são correlacionados os termos "Learning Styel" AND "Teaching Strategy" AND "Virtual Leaning Environment", são rastreados 7 documentos, apenas na base de dados Scopus, evidenciando pesquisas que abordam soluções para Ambientes Virtuais de Aprendizagem.

No entanto, cabe destacar que se trata de um tema de estudo de baixa incidência, isto é, apesar de vagarosa, encontra-se em fase emergencial. Até o presente momento, tendo em vista o período investigado (2015-2019), os resultados apresentados pouco abordam o tema principal deste trabalho, que se trata da personalização de AVA a partir da utilização de Estilos de Aprendizagem (EA) e do software Face Reader. Em relação a esta ferramenta, não foram identificados trabalhos que o utilizam para esta finalidade. A maioria dos resultados apresenta propostas aplicadas aos ambientes presenciais, desconsiderando os ambientes virtuais de aprendizagem ou, ainda, apenas citam a utilização de ambientes virtuais.

\subsection{REVISÃO BIBLIOGRÁFICA E TRABALHOS RELACIONADOS}

Após a realização desta bibliometria, identificou-se uma lacuna de pesquisa envolvendo os ambientes virtuais de aprendizagem que levem em consideração os estilos cognitivos de aprendizagem dos usuários. Neste sentido destaca-se o trabalho relacionado a este projeto, desenvolvido por Fagundes, Frozza e Kipper (2016), que apresenta um estudo sobre diferentes autores que abordam a identificação e classificação de EAs. Como resultado deste trabalho, as autoras propõem alguns modelos de exibição de conteúdo em um AVA para os diferentes EAs, com ênfase no modelo de Felder e Silverman (1988). A Figura 1 ilustra um exemplo dos modelos propostos por Fagundes, Frozza e Kipper (2016).

Figura 1: Exemplo dos modelos de apresentação de conteúdo

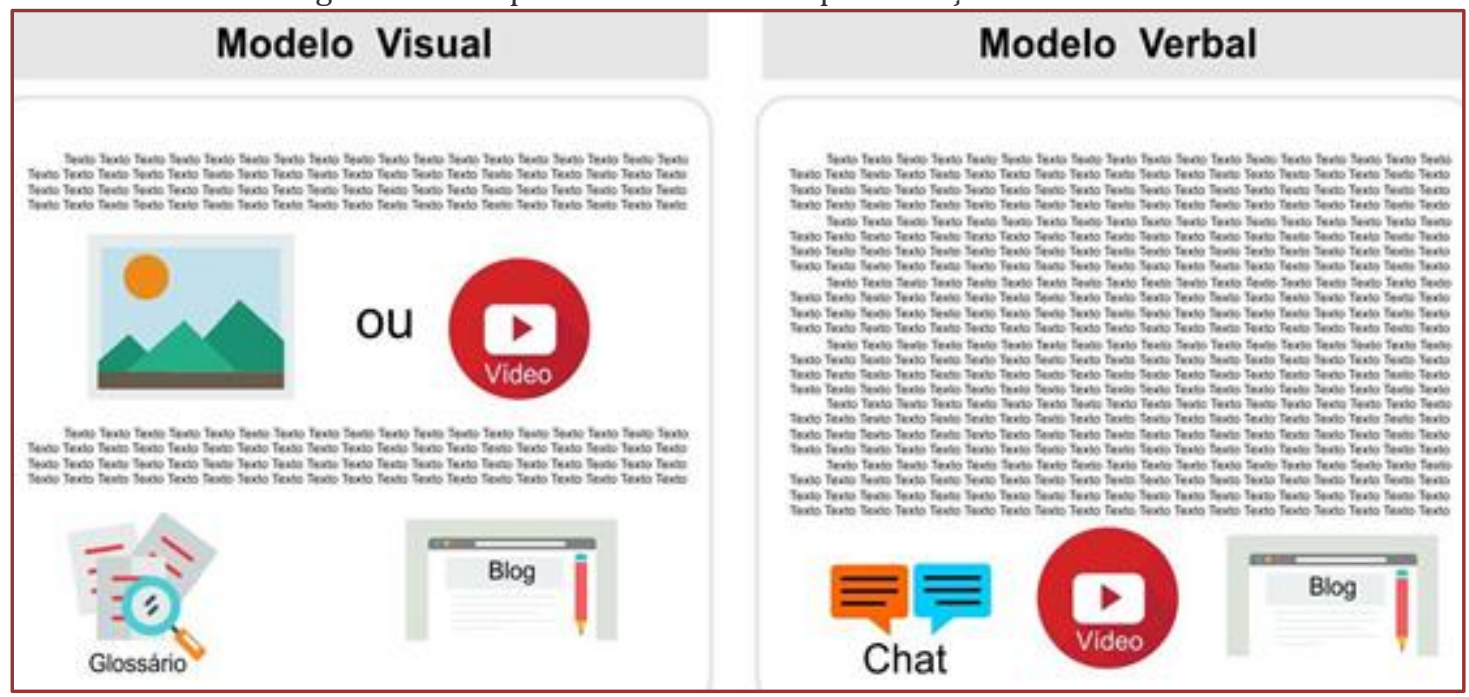

Fonte: Adaptado de Fagundes, Frozza e Kipper (2016)

A Figura 1 apresenta a proposta de composição dos modelos referentes aos estilos cognitivos definido por Felder e Silverman (1988) como "visual" e "verbal". É possível identificar a distribuição de diferentes tipos conteúdos que compõem diferentes estratégias de ensino, considerando o EA do usuário. No modelo proposto para o estilo verbal, a sugestão é usar conteúdos com mais áudio, a possibilidade de um botão de leitor de tela ao lado dos textos, para que o usuário possa optar por ouvir ao invés de ler e uso vídeos com legendas. A assimilação no processo de aprendizagem é maior ao ler ou escutar algo, por isso, a sugestão é, ao usar vídeos, que estes contenham áudio. Para o estilo visual, a proposta é utilizar imagens, ilustrações, mapas mentais e conceituais, fluxos, desenhos, vídeos, animações. Contudo, apesar de apresentar um amplo estudo sobre o tema e propor modelos de apresentação dos conteúdos de acordo com o EA de cada usuário, não foi realizada a implementação destes modelos em um AVA. Tal etapa é proposta como um trabalho futuro, bem como a validação destes modelos. 
Ainda sobre estudos envolvendo modelos de apresentação de conteúdo para AVA alinhados ao EA dos usuários relata-se o trabalho apresentado por Silva, Ferreira e Pimentel (2016), que propõe outra forma de apresentação de conteúdos de acordo com o EA dos usuários. Neste trabalho também são adotados os EAs definidos por Felder e Silverman (1988). Este trabalho considera a aplicação da Teoria Cognitiva de Aprendizagem Multimídia de Mayer (MAYER, 2005) que busca evitar a utilização inadequada de recursos em diferentes formatos, causando desinteresse e/ou distração do usuário. Ainda, Silva, Ferreira e Pimentel (2016) apresenta uma abordagem referente à prática de estudo dos EAs, considerando modelos que permitem um estudo sequencial e aleatório.

Neste contexto, uma nova proposta é combinar os modelos propostos por Fagundes, Frozza e Kipper (2016) levando em consideração a utilização da aplicação da Teoria Cognitiva de Aprendizagem Multimídia de Mayer (MAYER, 2005) e exibição de diferentes formas de navegação entre as aulas, de acordo com o EA do usuário, conforme proposto por Silva, Ferreira e Pimentel (2016) para então, desenvolver os conteúdos e disponibilizar em um AVA.

No que diz respeito à validação dos modelos, o trabalho apresentado por Liaw, Chiu e Choub (2014) apresenta o software Face Reader (software de reconhecimento facial) como uma ferramenta apropriada para esta finalidade. Neste trabalho, os autores utilizaram a ferramenta para avaliar o comportamento de estudantes durante a apresentação de um experimento de química. Através deste trabalho foi possível observar que o Face Reader é uma ferramenta capaz de gerar resultados no que diz respeito à reação dos usuários diante de uma situação. Para avaliar a satisfação dos usuários durante a utilização dos modelos implementados, pretende-se utilizar o Face Reader, dada a sua aplicabilidade ao caso.

\section{DESENVOLVIMENTO DE CONTEÚDOS PARA AVAS}

Com base nos trabalhos estudados e com o objetivo de dar continuidade a mais uma etapa do projeto, elaborou-se uma proposta para o desenvolvimento de uma versão do AVA que contemplasse a criação de diferentes formas de apresentação de conteúdo conforme os EAs definidos por Felder e Silvermam (1988), utilizando os modelos propostos por Fagundes, Frozza e Kipper (2016). Desta forma, quando o usuário acessar o AVA, realizará um teste para identificar o seu EA e após, o sistema automaticamente irá selecionar o conteúdo, apresentando-o de acordo com os modelos propostos e conforme o EA identificado pelo sistema.

Conforme o usuário realiza atividades disponibilizadas no AVA o sistema interage com o usuário através de um agente inteligente e realiza reavaliações para manter atualizado o EA do usuário. Desta forma, caso um usuário, com o passar do tempo altere seu EA, o sistema automaticamente passa a apresentar o conteúdo da forma mais adequada ao novo EA, potencializando a formação e aquisição de conhecimento do usuário. Com esta abordagem, pretende-se obter um AVA que favoreça a exploração dos EAs de seus usuários no que diz respeito à apresentação de informações e transformação destas informações em conhecimentos. É pertinente mencionar que a nova versão proposta utiliza outra tecnologia e linguagem de programação, possibilitando que os usuários utilizem o mesmo AVA em diferentes plataformas, isto é, independente de sistema operacional e de dispositivo (computadores, tablets ou smartphones, por exemplo).

Pretende-se utilizar como ferramenta de avaliação da satisfação do usuário o software Face Reader, o qual se apresentou adequado para tal finalidade, conforme o estudo de Liaw, Chiu e Choub (2014). Ainda, para reforçar a precisão do sistema, o grupo de especialistas da área da Psicologia realizará um processo de pesquisa do tipo survey, utilizando o questionário proposto por Felder e Soloman (2006) traduzidos para o português, para identificar os EAs definidos na comunidade acadêmica de uma Instituição de Ensino Superior do Estado do Rio Grande do Sul, independente da área de conhecimento. Após os usuários terem seus EAS identificados pelos especialistas e classificados conforme Felder e Silvermam (1988), estes mesmos participantes da survey utilizarão o AVA. No ambiente, estes usuários serão reavaliados pelo AVA. Com isso, busca-se a validação da precisão do AVA no processo de detecção de EA dos usuários, frente ao resultado obtido pelos especialistas. A partir disso, pretende-se concluir com uma dupla validação, tanto no que diz respeito ao processo de identificação dos EAs, quanto no que diz respeito ao conteúdo apresentado. Todos os processos descritos são representados pela Figura 2. 
Figura 2: Fluxo de processos do modelo proposto.

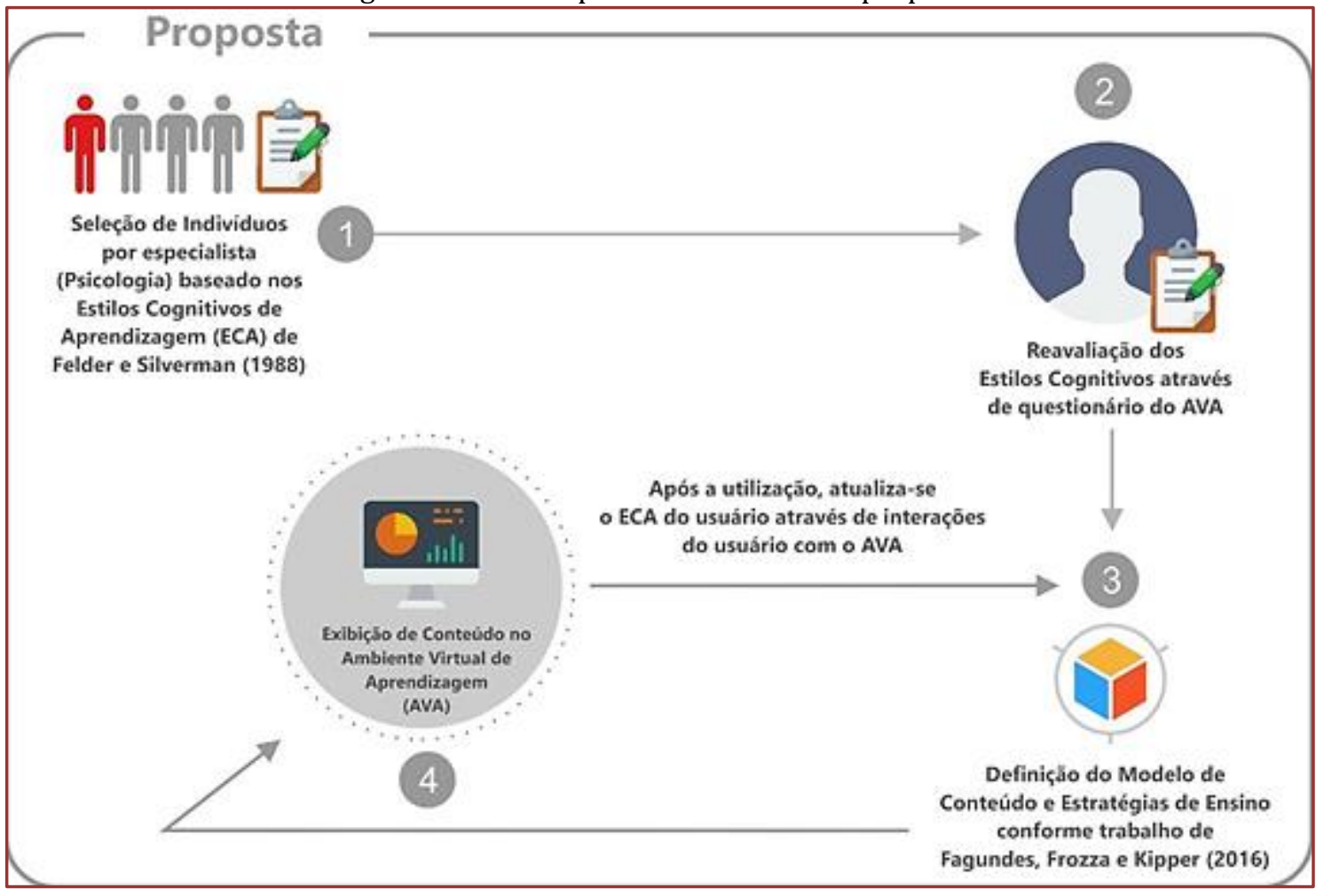

A Figura 2 ilustra a proposta de modo geral, apresentando (1) a identificação dos usuários por parte do grupo de especialistas da Psicologia e em (2) a reavaliação destes usuários pelo AVA através de um questionário. Nesta primeira etapa pretende-se validar a precisão do AVA na detecção dos EAs dos usuários. Após identificado os EAs destes usuários, o AVA seleciona o conteúdo a ser apresentado de acordo com os modelos implementados (3). Feito isso, o AVA apresenta o conteúdo ao usuário (4). Por fim, o AVA novamente reavalia o usuário com o objetivo de manter o EA do usuário atualizado e o conteúdo sendo apresentado da forma mais adequada, isso em um processo cíclico e continuado.

Paralelo a isso, será utilizada a ferramenta Face Reader para realizar a avaliação da satisfação do usuário durante a utilização do AVA. Desta forma, espera-se obter a validação dos EAs identificados pelos especialistas em relação à identificação do AVA e também a validação dos modelos desenvolvidos referente às estratégias de ensino de cada EA.

\section{CONCLUSÃO}

Com o estudo realizado e a metodologia proposta, este trabalho pretende desenvolver os modelos propostos por Fagundes, Frozza e Kipper (2016) e disponibilizá-los para os usuários que interagem com o AVA já desenvolvido pelo projeto, de acordo com os seus EA. Com a utilização da survey aplicada em colaboração com o grupo de especialistas da área da Psicologia pretende-se identificar previamente indivíduos que atendam aos EA definido por Felder e Silverman (1988) para que seja possível validar todos os modelos. Por fim, através da utilização do AVA com a utilização dos modelos de apresentação de conteúdo, busca-se identificar e validar os modelos desenvolvidos durante a interação dos usuários com o AVA. Por fim, com a utilização da ferramenta Face Reader pretende-se avaliar a satisfação dos usuários ao utilizar o AVA diante dos modelos propostos.

\section{REFERÊNCIAS}

[1] ANASTASIOU, L. D. G. C. Processos de ensinagem na universidade: pressupostos para as estratégias de trabalho em aula. Ensinar, aprender, apreender e processos de ensinagem, v. 7, p. 15-43, 2003.

[2] ARAÚJO, C. A. Bibliometria: evolução histórica e questões atuais. Em Questão, Porto Alegre, v. 12, n. 1, p. 11$32,2006$. 
[3] BORIN, M; FROZZA, R.; KIPPER, L.; SCHREIBER, J. N. C. Virtual Learning Environments with Emotional Pedagogical Agents for Training in Organizations. In: International Conference on Industrial Engineering and Operations Management (ICIEOM), Guimarães, Portugal, 2012.

[4] FAGUNDES, T. D. S.; FROZZA, R.; KIPPER, L. M. Modelo para elaboração de conteúdos em ambientes virtuais de aprendizagem baseados na relação entre táticas de ensino e estilos cognitivos de aprendizagem. Dissertação do Curso de Pós Graduação em Sistemas e Processos Industrias - Mestrado. Universidade de Santa Cruz do Sul, Santa Cruz do Sul, 2016.

[5] FELDER, R. M.; SILVERMAN, L. K. Learning and teaching styles in engineering education. Engineering education, 1988. 674-681.

[6] FELDER, R. M.; SOLOMAN, B. A. Index of Learning Styles Questionnaire. North Carolina State University, 2016. Disponivel em: <https://www.webtools.ncsu.edu/learningstyles/>. Acesso em: 20 Abril 2016.

[7] FROZZA, R.; KONZEN, A., MAINIERI, A. G., SCHREIBER, J., MOLZ, K., TAUTZ, J., PEDÓ, R., DRESCH, j.; Agentes tutor e companheiro em um ambiente educacional baseado em estilos cognitivos. In: Workshop - Escola de Sistemas de Agentes para ambientes Colaborativos - WESAAC 2007. UCPEL, Pelotas, 2007.

[8] FROZZA, R.; SILVA, A. A. K. da; SCHREIBER, J. N. C.; LUX, B.; MOLZ, K. W.; KIPPER, L. M.; BORIN, M. P.; CARVALHO, A. B. de; BAIERLE, J. L.; SAMPAIO, L. Agentes Pedagógicos Emocionais atuando em um Ambiente Virtual de Aprendizagem. Centro Interdisciplinar de Tecnologia Educacional da Universidade Federal do Rio Grande do Sul (CINTED-UFRGS). RENOTE - Revista Novas Tecnologias na Educação, 2011.

[9] FROZZA, R.; SILVA, A. K. da; LUX, B.; CRUZ, M. E. J. K da; BORIN, M. Dóris 3D: Agente Pedagógico baseado em Emoções. In: XX SBIE - Simpósio Brasileiro de Informática na Educação, 2009.

[10] GRIESANG, G.; FROZZA, R. Desenvolvimento de um Mecanismo de Comunicação entre Agentes Pedagógicos em um Ambiente Virtual de Aprendizagem. Dissertação de mestrado. Universidade de Santa Cruz Sul - UNISC, 2013.

[11] HOMRICH, N. C.; FROZZA, R.; SCHREIBER, Jacques Nelson Corleta. The use of emotions in student assessment in a virtual learning environment. In: International XIX International Conference on Industrial Engineering and Operations Management, ICIEOM 2013. Rio de Janeiro: ABEPRO, v. único, 2013. p. 1-10.

[12] KOLB, D. A. Experiential Learning Theory: Previous Research and New Directions. 1999.

[13] LIAW, H. L.; CHIU, M.-H.; CHOUB, C.-C. Using facial recognition technology in the exploration of student responses to conceptual conflict phenomenon. Chemistry Education Research and Practice, v. 15, n. 4, p. 824-834, Agosto 2014.

[14] MAINIERI, A. G.; FROZZA, R.; Schreiber, J.; Molz, K.; Educational System based on Cognitive styles and/or Learning styles. In: XXVII Annual Conference of the Cognitive Science Society. Stresa, 2005.

[15] MAYER, R. E. Principles for managing essential processing in multimedia learning: Segmenting, pretraining, and modality principles. The Cambridge handbook of multimedia learning, 2005. 169-182.

[16] MUHLBEIER, A. R. K.; MOZZAQUATRO, P. M. Estilos e Estratégias de Aprendizagem Personalizadas a Alunos das Modalidades Presenciais e a Distância. Revista Brasileira de Informática, Vol 20, N¹, 2012.

[17] SANTOS, C. T. dos; FROZZA, R.; DAHMER A.; GASPARY, L. P.; Dóris - Um Agente de Acompanhamento Pedagógico em Sistemas Tutores Inteligentes. In: XII Simpósio Brasileiro de Informática na Educação - SBIE - UFES, 2001.

[18] SCHAEFER, M.; FROZZA, REJANE; SILVEIRA, R. A.; RUTSATZ, R. F. Treinamentos E-Learning com estratégia de ensino baseada em animações. In: XX Congreso Internacional de Informática Eduactiva - TISE. Santiago: Universidad de Chile, v. 11, 2015. p. 786-791.

[19] SILVA, A. K.; Frozza, R; Borin, M. P.; Molz, K.; Schreiber, J.; Lux, B.; Carvalho, A. B.; Baierle, J.; Kipper, L.; O Método Clínico de Piaget como forma de Avaliação da Aprendizagem em um Sistema Tutor Inteligente com Agente Pedagógico. XXI Brazilian Symposium on Computer in Education (SBIE). João Pessoa/PB, 2010.

[20] SILVA, L. F. R. da; DIMI: um agente selecionador de estratégias de ensino para sistemas tutores inteligentes. Monografia (graduação) - Universidade de Santa Cruz do Sul, 2002.

[21] SIlVA, Z. C. D.; FERREIRA, L. R.; PIMENTEL, A. R. Modelo de Apresentação Adaptativa de Objeto de Aprendizagem baseada em Estilos de Aprendizagem. Anais do XXVII Simpósio Brasileiro de Informática na Educação, 2016. 717-726. 


\section{Capítulo 6}

Melhoria da qualidade e produtividade na linha de produção de uma empresa de ar-condicionado do Pólo Industrial de Manaus

\section{Luciana Oliveira do Valle Carminé \\ Adriano Franco da Silva \\ Michelle Teles de Abreu}

Luiz. Vitor de Oliveira Gonzaga

Resumo: No contexto atual, a gestão da qualidade foi desenvolvida para padronizar serviços ou produtos. Por meio da padronização, as instituições conquistam agilidade em seu processo de produção, conseguem, assim, gerar mais valor e satisfação aos clientes e assim obter uma melhor execução de todas as tarefas e procedimentos. Por essa razão, uma empresa de ar-condicionado instalada em Manaus resolveu modificar a gestão da qualidade, colocando em prática uma das 7 ferramentas da qualidade para investigar a causa do problema no processo produtivo no setor de montagem do sistema elétrico para assim tomar as providências em relação ao problema. A empresa segue os critérios de padronização da ISO 9001 para atender as expectativas dos clientes que irão usufruir do serviço ou produto oferecido pela organização. 0 Japão foi o primeiro país a adotar a gerência de qualidade dos seus produtos e serviços com o nome, em inglês, de “Total Quality Management” (TMQ), que significa Gestão da Qualidade Total (GQT). No Japão, o Toyotismo aplicou a nova técnica organizacional e conseguiu melhorar o processo organizacional no pós segunda guerra. Para a realização do estudo utilizou-se pesquisa bibliográfica, artigos científicos, diagramas e estudo in loco.

Palavras-chave: Qualidade, Produtividade, Ar-condicionado. 


\section{INTRODUÇÃO}

SLACK (1997) afirma que "programar e monitorar a fabricação consiste essencialmente em conciliar o fornecimento de mercadorias e atividades com a demanda de pedidos". Para o autor a principal área da administração de empresas é o planejamento e controle da produção, com isso quando se efetua por lotes ou em pequenas series adquiridas, seja para estoque, a programação da produção obtém como propósito fazer o planejamento e controle dos recursos produtivos. Esse sistema atende às demandas conflitantes, recebendo informações sobre estoque, linha de produção, capacidade e modo de produzir para distribuir todo processo produtivo no prazo certo ao mesmo tempo que consiga colocar as máquinas e os homens ao nível da capacidade esperada e diminuir os estoques de matérias em fase de produção.

Para GHINATO (2008), o produto com defeito significa retrabalho e materiais perdidos, tempo livre de colaboradores, quantidades de equipamentos, deslocação de materiais irregulares, estocagem de materiais irregulares, examinação de produto, entre muitos.

Foram realizados nos últimos anos processos teóricos com a intenção de solucionar os vários problemas no sistema elétrico das empresas, com destaque para as ferramentas da qualidade no qual as organizações diminuíram as perdas nessa área de atuação, por darem custos elevados e atrasos nos processos.

Segundo JURAN (1990), "a qualidade é adequação ao uso." o sistema elétrico é uma das áreas que precisam de cuidados redobrados, fazendo uso de modelos de quantidade e formas de alto padrão de gestão, além de montar uma variedade de informações traduzidas em numerosos setores da organização, como por exemplo, engenharia de processos e materiais.

MARINO (2006) destaca que "a gestão da qualidade cuida do processo de manufatura como um potencialidade estimulante de competividade e com pedaço dessas estratégias está à obtenção de produtos de modo correto, entregas veloz para o cliente, feita no prazo predeterminado, com variedade de produtos amplos e conforme demanda de mercado, técnica adequadas para produzir a baixo custo." Por isso, o projeto em questão tende a melhorar a fabricação de ar-condicionado na montagem do aparelho, onde certifica que a mercadoria seja produzida de maneira certo e com qualidade garantida.

DEMING (1990) afirma que "qualidade é tudo aquilo que melhora o produto do ponto de vista do cliente." Ou seja, os clientes exigem qualidade dos aparelhos, como características principais. querendo cumprir esses atributos de qualidade na empresa de ar-condicionado, é imprescindível um olhar ordenado de melhoria, como aparência, designer, linha de produção, produtividade e qualidade do produto.

No contexto da aparência não adianta ter embalagens fantásticas e sedutoras, mas sendo um produto ou aparelho de qualidade discutível. Por isso que as empresas estão investindo tanto em qualidade quanto em aparência dos produtos. Dessa forma ativando as três principais questões da aparência que são: foco no cliente, nivelamento e orientação.

O designer talvez seja a parte mais importante da fabricação de um aparelho ou produto, por ter uma aproximação muito grande com a engenharia, imagem do produto e embalagem. Sendo assim, o designer industrial, também denomina designer de produto, trabalha com criação e produção de objetos e produtos tridimensionais com foco em usufruto humano.

Uma linha de produção pode ser entendida como parte operacional onde são produzidos em series. Encontra-se presença humana lado a lado e/ou em frente diante do posto automatizado para que o produto possa ser fabricado por todos no processo produtivo. Os trabalhadores tem ajuda de máquinas automatizadas para que se trabalhe continuamente. De acordo com DUARTE (2009), na linha de produção também são constituídas cadeia de produtividade, formando-se um integrado de pessoas, máquinas, equipamentos, acessórios e matérias primas para o fundamento do sistema.

Já a produtividade de acordo com CONTADOR (1994), "a produtividade é a relação entre os resultados da produção e os recursos produtivo que são aplicadas sobre elas" com a existência de três níveis da operação, da empresa e da supervisão. No nível da operação, são usados pensamentos do Taylorismo como aumento da produtividade e elevação dos recursos realizados na atividade. No nível da empresa, busca um interesse no faturamento e nos custos. E a supervisão são controles da produtividade na organização, controlado por um software.

A qualidade do produto permite satisfazer necessidades. Segundo MIRANDA (1994), "as organizações necessitam gerar produtos e serviços em condições de atender as demandas dos usuários finalconsumidores sob todos os aspectos." Na atividade de produção é importante ratificar que o nível de qualidade seja bastante elevado para garantir o prazer do fornecedor e do consumidor final, deste modo a qualidade de produtos são bastante importantes para diminuição de defeitos, ou seja, estará com a 
provação garantida dos mesmos. Segundo OLIVEIRA (2010), "é difícil vender produtos de baixa qualidade, produtos de qualidade aceitável precisam conquistar clientes." No momento que a qualidade está instalada no processo, do início da verificação da conformidade das matérias-primas até sua destinação, uma má qualidade pode ser evitada no início ou final das operações nas instituições, nessa situação, pode alinha adversidade e evitar o retrabalho.

Para CORRÊA (2009) “a perda por defeitos é o resultado da geração de produtos que apresentem alguma de suas características de qualidade fora de sua especificação ou padrão estabelecido que possa não satisfazer de requisito de aplicação de uso"

É correto que as instituições podem comportar-se de forma técnica em relação à qualidade, para que as mesmas possam se preservar de modo aceitável no mercado pretendendo alcançar à qualidade para se diferenciar das outras organizações, visto que reduzir os defeitos como também os retrabalhos pode elevar o processo. De acordo com MARTINS etal.,(2002, p.57), "a definição de qualidade focada no produto e é constituída de variáveis e atributos que podem ser medidos e controlados" Para assegurar um auto padrão de qualidade as instituições e colaboradores devem ser orientados e preparados para que possam trabalhar na função corretamente, já que os mesmos são parte importante para a atividade de produção.

As sete ferramentas da qualidade são métodos utilizados nas empresas com intenção de mensurar, definir, analisar e propor soluções ou melhorias para parar as causas que interferem na produtividade dos processos das organizações. Permitindo maior controle dos processos e melhoria na tomada de decisões. Para CERQUEIRA NETO (1993), a função da qualidade tem com princípios básicos organização de problemas, e que cada um deles é uma oportunidade de melhoria para pessoas, processos, produtos e sistemas. em cada problema tem como objetivo de identifica-lo em função de risco, custo e benefícios para negócios, para assim estabelecer um projeto de análise e solução.

A partir da aplicação das sete ferramentas da Qualidade: Diagrama de Pareto, Diagrama de Causa e Efeito; Histogramas; Folhas de Verificação; Gráficos de Dispersão; Fluxograma; Cartas de Controle, no processo produtivo pode-se reduzir o índice de falhas e defeitos.

Diagrama de Ishikawa: o diagrama de causa e feito é usado para identificar falhas. É um processo que permite analisar e identificar as principais causas de variações do processo ou da ocorrência de um problema. Segundo CARPINETTI (2016), foi criada essa ferramenta para identificar a existência do problema para auxiliar no resultado do processo.

Fluxograma: De acordo com CHIROLI (2016), faz uma representação esquemática de um processo, permitindo um conhecimento sobre a atividade em questão. Muitas vezes ilustradas com símbolo e modelo de atividade que apresentam informações entre os elementos operacionais, identificando uma sequência do processo para os colaboradores, permite também melhorar o ritmo das necessidades dos clientes.

Cartas de Controle: Para MONTGOMERY (2006), o controle estatístico do processo tem o objetivo de eliminar a variação no processo. As ocorrências podem ser divididas em duas etapas: causa comum ou aleatórias e causas comuns aleatórias e causas assinável ou especial. As causas comuns ou aleatórias são tipos de variações que ocorrem de forma aleatórias no processo, atuando normalmente na sua forma, já as causas assináveis ou especiais, são operações que tem falhas e fazem alterações na qualidade do produto final, quando são representadas fora do padrão estabelecido.

Histograma: Para WERKEMA (2006), "é conjunto de dados para a representação do gráfico com colunas e barra, com divisão de classe no intervalo pequeno e subdividido no eixo horizontal do gráfico, representam valores para localizar uma variação de interesse numérico". Os histogramas podem ser aproveitados para representação de números quantitativos, para identificar os pontos central e a variação da produção. 0 histograma é classificado em 6 formas: são eles, histograma de simétrico, assimétrico, despenhadeira, dois picos, achatado e ilha isolada, essa ferramenta de qualidade pode ser aplicada em situações normais e básicas. Segundo TRIVELLATO (2010), as barras são formadas por intervalos de curta duração e com relação em que se ocorre intervalos, com isso fica visível os valores centrais como também a representação do formato da classificação de dados numéricos.

Diagrama de Dispersão: são responsáveis por localizar duas variáveis de defeitos e causa, a dispersão pode ser utilizada em variáveis positivas, negativas ou inexistente. São exibidos valores em cartesianos para que seja usado um conjunto de dados numéricos. CARPINETTI (2010), MONTGOMERY (2009).

Complementado com WERKEMA (2006) o Diagrama de Dispersão faz uma demonstração entre duas variáveis ou mais. A propensão de variação é capaz de melhorar a competência de métodos de controle do 
processo facilitando o reconhecimento de prováveis dificuldades para a elaboração de atividades que permitem conforme a análise de algumas dessa relações.

Folha de Verificação: para WERKEMA (2006) são usadas tabelas ou planilhas para coletar dados da empresa que possa ser analisado o escopo, com intensão de manter organizado informação útil. A coleta de dados serve do ponto de partida para análise estatística de forma que apresente informações em formato gráfico. De acordo com VIEIRA (1999), a forma de folha de verificação dependerá muito da instituição, ou seja, podendo identificar qual será seu objetivo, fazendo os seguintes levantamento de itens como por exemplos, levantar causas; as causas dos defeitos; classificação de medidas; não conformes; causas efeitos; medir a distribuição de um conjunto de medições; contagem e classificação de defeitos em vários tipos e monitorar um contagem de quantidade.

Gráfico de Pareto: são utilizados para observar problemas e produtos de uma instituição. São importantes para focar na distribuição de dados priorizando a frequência que terá um ótimo resultado, localizando falhas que ocorrem com maior taxa tendo capacidade de ter uma ordem percentual ou de ordem real. Recordando que uma falha ou defeito não significa que pode ser o principal ou mais críticos dos problemas do processo. CARPINETTI (2010), MONTGOMERY (2009).

VIEIRA (1999), diz que o gráfico de Pareto é usado para localizar problemas como produto fabricados que necessitam de retrabalho, quebra de produto, falhas e atrasos de entregas, entre muitos.

\subsection{CERTIFICAÇÃO ISO 9001}

A certificação do sistema de gestão da qualidade foi implantada em conformidade com a norma NBR ISO 9001 para que a empresa busque benefícios como a melhoria nos processos de fabricação dos produtos e serviços. A ISO 9001 foi implantada nas organizações para atender aos requisitos de qualidade, a implementação é realizada com auditoria de certificação por um organismo credenciado por uma empresa, são realizadas em duas etapas. Primeiramente, o organismo certificador revisa a preparação de sua organização para a auditoria, verificando se os procedimentos e controles da ISO 9001 foram desenvolvidos corretamente pela empresa. Normalmente, esta primeira etapa é realizada na sede do organismo certificador agenda a auditoria de implementação dos procedimentos e controles de empresa para certificar que eles estão funcionando efetivamente conforme a certificação exigida.

As motivações para ISO 9001 podem ser classificadas em duas categorias: motivação internas e motivação externas. As internas estão relacionadas com objetivo de alcançar a melhoria da organização, enquanto as externas estão relacionadas ao marketing e pressões do cliente.

Os benefícios internos podem ser relacionados às questões de eficiência e gerencias. Os relacionados à eficiência são redução de custo; aumento da produtividade; redução dos tempos de entrega e de taxas de defeitos, diminuição de etapas desnecessária de processos, eliminação de movimentações desnecessária de produtos e/ou pessoas.

CHOW-CHUA (2003), "a certificação ISO 9001 não garante automaticamente um seguro de qualidade, mas sim consiste de procedimentos para se ajustar na direção de uma mentalidade de comando e controle" ou seja, a certificação não garante uma qualidade, mas sim uma aplicação corretamente da mesma.

\section{METODOLOGIA}

A pesquisa tem seu embasamento em um estudo de caso, no qual foram detectadas ocorrências de falhas, na linha de montagem de ar-condicionado de uma empresa do Polo Industrial de Manaus. A pesquisa formou-se por ser qualitativa, feita através de observação no ambiente corporativo, além do balanço da produtividade da empresa.

Através da coleta dados foram analisadas as possíveis causas da adversidade, sendo de carácter descritivo e aplicada, descrevendo e mensurando as falhas na montagem produtiva, com a aplicabilidade da ferramenta da qualidade diagrama de Ishikawa na ação sobre o problema e eliminação das possíveis causas. Foram utilizadas pesquisas bibliográficas, diagramas, artigos científicos e estudo in loco, RAMPAZZO (2005), a aplicação de autores se caracteriza por usar dados originados de publicações, ou seja, são realizadas com pesquisas de referências conceituais já existente como artigos teóricos que possam ser reutilizados no contexto correto. 
Os dados obtidos foram analisados indutivamente, com o objetivo de propor mudanças para empresa visando melhor produtividade e qualidade no processo e produto, com a finalidade de garantir a confiabilidade e fidelidade de seus clientes e a valorização da sua marca no mercado competitivo.

\section{RESULTADOS E DISCUSSÃO}

Fundada em 1970 no Japão, a empresa de ar-condicionado começou sua produção na área de evaporadoras e condensadoras, com o passar dos anos a empresa se tornou responsável pela produção de refrigerados para o governo Japonês. Ao longo de sua história seus negócios foram se expandindo, e assim conseguindo parceiros com outras empresas levando sua produção para outros países, chegando ao Brasil em 1992 fazendo parte do polo industrial de Manaus. Com objetivo de contribuir para novos avanços tecnológicos a empresa visa a inovação, criatividade, agilidade, sinceridade e ser reconhecida como referência empresarial para soluções no setor de manufatura, por sua qualidade e excelência nos seus produtos e serviços.

A empresa de ar-condicionado também tem seus princípios e valores, buscando de maneira sustentável valorizar seus clientes, colaboradores, acionista e parceiros de negócios, garantindo um ambiente de trabalho agradável, respeitando a todos de forma justa e honesta.

Ao analisar uma linha de refrigeração da empresa em Manaus que produz aparelhos de ar-condicionado, foi feito um estudo, em que determinado posto apresentava problema na parte elétrica da evaporadora onde o operador iniciava o teste, porém o aparelho testado desligava no meio da atividade apresentando defeito de hipot, que é o teste que consiste em aplicar alta tensão na evaporadora, a fim de testar a capacidade de isolamento elétrico. Quando o produto apresentava esse problema era levado para reparo técnico. Com base nesses acontecimentos, percebeu-se que o teste apresentava variações de resultados onde causava falsos defeitos no processo. Por conta disso, o processo acabava perdendo produtividade, e assim não alcançava as metas estabelecidas ocasionando atrasos na produção.

Foi feita a análise no processo em que o posto 4 da linha de produção em estudo ao realizar o teste de hipot apresentou problemas nas evaporadoras que eram levadas para reparo. Com a produção mensal de 6.400 onde 640 apresentavam falsos defeitos. A partir desses defeitos no processo foi analisado onde poderia ser o problema. Através do estudo realizado, foi utilizado uma das 7 ferramentas da qualidade chamada diagrama de Ishikawa, onde pode-se encontrar possíveis problemas e suas causas-raízes. observou-se que os cabos utilizados para realizar o teste do hipot na evaporadora apresentavam um problema quando eram conectados ao aparelho, pois os cabos estavam com cabeçote menor, e assim terminava-se que o operador não fazia o encaixe correto nas evaporadoras causando algumas falhas no teste.

\subsection{DIAGRAMA DE ISHIKAWA}

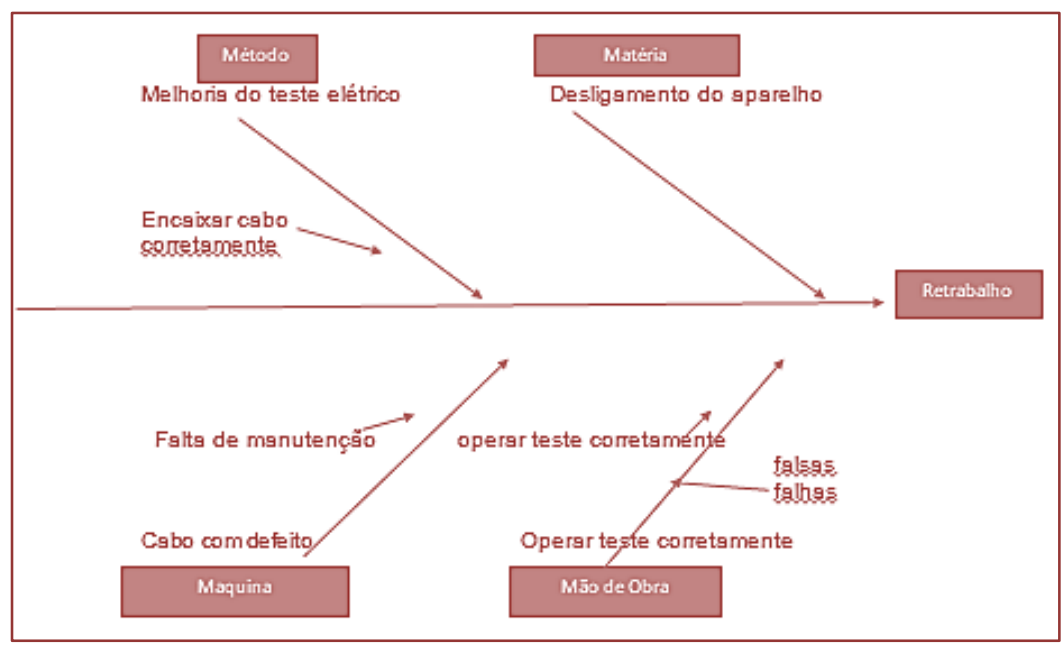

Considerando os fatos ocorridos e visando a qualidade do produto, foi realizado uma melhoria nos cabos do teste elétrico, onde foram trocados todos os cabos de energia e seus cabeçotes, com isso o operador não encontraria dificuldade para fazer o encaixe correto dos cabos na evaporadora, pois o cabeçote só 
encaixaria de um único jeito levando o operador a fazer a conexão correta. Feita a melhoria, o processo irá conseguir alcançar a meta estabelecida de 6.400 evaporadoras por mês sem apresentar falsas falhas, assim garantindo o prazo de entrega planejado e a qualidade no produto.

\section{CONCLUSÕES}

O desenvolvimento do presente estudo de caso em uma empresa de ar condicionado no Polo Industrial de Manaus possibilitou detectar os problemas pertinentes na linha de montagem da unidade evaporadora, mais precisamente na realização do teste elétrico hipot. Com a aplicabilidade de uma das ferramentas da qualidade, o diagrama de Ishikawa, observou-se que o cabo utilizado no teste elétrico estava com o cabeçote menor que o especificado, com isso o operador fazia o encaixe incorreto do cabo na evaporadora ocasionando falsas falhas no processo. A produção mensal durante a ocorrência dessas falhas era de 5.760 evaporadoras. Após a implementação da melhoria no processo, onde foram trocados os cabos de energia e seus cabeçotes, o operador não terá dificuldade ao fazer o encaixe correto do cabo na evaporadora e realizar o teste adequadamente. Verificou-se que as 640 falsas falhas, identificadas no teste elétrico, foram totalmente corrigidas do processo, devido a análise e solução do problema, atingindo o objetivo esperado. Utilizando o diagrama de Ishikawa foi possível estabelecer um procedimento para reparar as variações ocorridas, permitindo melhorias no controle do processo, na qualidade do produto, na produtividade e no alcance da meta estabelecida pelo planejamento de produção de 6.400 evaporadoras produzidas mensalmente, garantindo a satisfação de seus clientes, aumentando a confiabilidade e a fidelidade dos mesmo, tornando-se referência no segmento em que atua, valorizando sua marca no mercado competitivo.

\section{REFERÊNCIAS}

[1] CARPINETT, L. C. R. gestão da qualidade: conceitos e técnicas. São Paulo; Atlas, 2010.

[2] CARPINETTI, Luiz Cesar Ribeiro; Gestão Qualidade: conceitos e técnicas. 3 ed-são Paulo: Atlas, 2016.

[3] CERQUEIRA NETO, Edgard Pereira. Gestão da qualidade: princípios e métodos. 3. ed. São Paulo: pioneira, 1993

[4] CHIROLL, Daiane Maria de Genaro. Sistema de avaliação da qualidade. In: avaliação de sistema. Cap. 6, p. 218273 Curitiba: interSaberes, 2016.

[5] CHOW-CHUA, clare, GOH, Mark, and WAN, Tan b. v.20, no. 8, 2003.

[6] CONTADOR. J.C. produtividade fabril - método para rápido aumento da produtividade fabril. Gestão \& produção, v.1, n.3, p.217-238, de 1994.

[7] CORRÊA, H, L, (2009). Uma abordagem de defeitos. São Paulo: Atlas.

[8] DUARTE, G, dicionário da administração e negócios. Rio de Janeiro do: saraiva, 2009.

[9] GUINATO. P. produção \& competividade: aplicações e inovações, 2008.

[10] JURAN, J. M. Juran planejamento para a qualidade. São Paulo: pioneira, 1990.

[11] MARINO, H. F. de c. gestão da qualidade do conhecimento: fatores - chaves para a produtividade e competividade empresarial. SIMPER - BAURU, SP Brasil, 2006.

[12] MARTINS. P. G: laugenif. P. administração da produção. Saraiva 2002.

[13] MIRANDA, R. 1. Qualidade total: rompendo as barreiras entre a teoria e a prática. 2 ed. São Paulo: 1994.

[14] MONTGMERY, D C. introdução ao controle estatístico da qualidade. Rio de Janeiro: L T C, 2009.

[15] MONTGOMERY, Douglas c; introdução ao controle. Tradução e revisão técnicas: FARIAS, Ana Maria Lima de, flores, Vera Regina Lima de Farias e.7.LTC 2016.

[16] OLIVEIRA. O. gestão da qualidade tópicos avançados: São Paulo. Tampson, 2010.

[17] RAMPAZZO, Lino. Metodologia científica para alunos dos cursos de graduação e pós-graduação. 3 ed. São Paulo: Atlas, 1995.

[18] SLACK, Nígel et al. Administração da produção. São Paulo: Atlas, 1997.

[19] VIEIRA. S. 15, ed. Rio de Janeiro: Elsevier, 1999.

[20] WERKEMA, M, C.C gerenciamento de processos. 1. Ed. Belo Horizonte: 2006. 


\section{Capítulo 7}

Melhoria no controle de estoque: Estudo de caso em uma empresa no Pólo Industrial de Manaus - AM

\section{Luciana Oliveira do Valle Carminé \\ Carlos Alberto Santos Nascimento \\ Claudemir Moraes de Sá \\ Daniel Maciel de Menezes}

Resumo: Este artigo tem como problemática a avaliação de um registro não confiável de saídas de materiais avaliando se este parâmetro pode influenciar na eficiência do processo produtivo. Desta forma o objetivo é avaliar se o método atual de gerenciamento de materiais é eficiente a ponto de garantir o controle das operações inerentes ao almoxarifado da empresa alvo do estudo em questão bem como analisar os parâmetros de gerenciamento, analisar o desempenho operacional assim como sugerir melhorias visando garantir maior agilidade e controle das operações. Utilizou-se a observação direta para a análise dos procedimentos adotados pela empresa. Este estudo de caso visa sugerir um método de gerenciamento do estoque que atenda a demanda da empresa garantindo assim maior eficiência para o processo produtivo.

Palavras-chave: Gestão de operações, estoque, eficiência. 


\section{INTRODUÇÃO}

Segundo Moreira (2012), os estoques são quantidades de bens físicos que ficam armazenados de forma improdutiva por algum intervalo de tempo; constituem estoques tanto aos produtos acabados que aguardam a venda ou despacho, como matérias primas e componentes que aguardam utilização a produção.

De acordo com Ballou (2006), estoques são pilhas de matérias-primas, insumos, componentes, produtos em processo e produtos acabados que aparecem em numerosos pontos por todos os canais logísticos e de produção da empresa. Já Martins e Campos Alt(2009), afirmam que estoque é o acúmulo armazenado de recursos materiais em um sistema de produção e/ou operações.

0 excesso de estoque é frequentemente a maior ameaça à liquidez do caixa. Para uma empresa ter sucesso e sobreviver, destinar de maneira errada os recursos leva a riscos desnecessários e desperdiça as oportunidades produtivas, portanto deve encontrar um equilíbrio ideal para cada produto que tiver que ser mantido, porém acima do nível o estoque torna-se excessivo e abaixo dele a empresa estará correndo risco de ficar com faltas antes de fazer outra encomenda (RESNIK, 1990, p. 189-190).

"O controle de estoques é necessário para que o processo de produção/vendas da empresa atue com um número mínimo de preocupações e desníveis. O setor de controle de estoque acompanha o nível de estoque e o investimento financeiro envolvido" (DIAS, 2011).

Para Martins e Alt (2009), manter altos níveis de estoque pode ser sinônimo de custos desnecessários, seja pelo custo de seu manuseio, produção ou administração. Por isso é importante que o administrador tenha um controle de gestão dos estoques eficaz para que possa verificar a correta utilização dos estoques, se são bem manuseados e controlado.

Para Chopra e Meindl (2003), o papel do estoque numa empresa é estratégico para torná-la mais competitiva, pois se a estratégia competitiva da empresa é manter estoques altos isso exige dos gerentes maior grau de responsabilidade. Contrariamente, a empresa pode se tornar mais eficiente reduzindo seus níveis de estoques. A escolha da empresa referente a manter estoques ou não está entre a responsabilidade pela manutenção de estoques maiores, e a eficiência resultante de estoques menores, a empresa precisa saber o que é mais vantajoso manter estoques altos ou reduzir os estoques.

Segundo Stockton (1976/16), "Os estoques constituem um ativo da firma e, como tal, comparecem em valor monetário no balanço da empresa. Do ponto de vista financeiro, os estoques representam um investimento de capital e devem, por conseguinte, competir com os demais ativos da firma".

Para Borges et al (2010), um bom gerenciamento de estoques ajuda na redução dos valores monetários envolvidos, de forma a mantê-los os mais baixos possíveis, mas dentro dos níveis de segurança e dos volumes para o atendimento da demanda.

A gestão de operações tem se tornado cada vez mais relevante devido aos inúmeros processos envolvidos associados aos altos índices de liquidez o qual o mesmo precisa evidenciar para mostrar sua eficiência. Ao contrário, sua ineficiência pode gerar custos inesperados de natureza diversa tais como excesso de custo no processo e ao produto, impactos ambientais, interrupção das operações, perda de certificações. Assim, desenvolver métodos de gerenciamento envolvendo o controle do estoque para melhoria da performance industrial, da empresa alvo do estudo em questão, justifica a relevância do projeto.

Um dos principais motivos para se ter um bom planejamento e controle de estoques é o grande impacto financeiro que é possível alcançar através do aumento da eficácia e eficiência das operações da Organização (BORGES et al, 2010)

Bowersox et al (2006), dizem que o gerenciamento de estoque é o processo integrado pelo qual são obedecidas às políticas da empresa com relação aos estoques. A abordagem usa a demanda dos clientes para deslocar os produtos para a distribuição.

Na visão de Beulke e Bertó (2001), o acompanhamento do fluxo de entrada, estocagem e consumo/saída dos estoques é algo básico e de suma importância, pois a falta desse controle pode ocasionar ociosidade dos estoques, desperdícios, maus usos, desvios, etc. Consequentemente isso se reflete em prejuízos para a organização, tais como o desembolso desnecessário de recursos financeiros para manutenção dos estoques, assim como possível perda de competitividade no mercado devido à influência direta nos custos dos produtos e mercadorias. 
Ao buscarem melhores condições de competitividade, as organizações necessitam de ferramentas e processos que lhes permitam eliminar os desperdícios, resultando na sustentabilidade e continuidade de seus negócios no cenário em que estão inseridas. Indiferentemente do sistema produtivo, a busca pela melhoria das técnicas e procedimentos, bem como as alternativas que mensurem seu desempenho e elimine as perdas, devem estar inseridas em qualquer tipo de empresa, fazendo parte de seus processos de produção (DONADEL et al., 2007).

Chiavenato (2014) enfatiza que a gestão das operações é um processo que utiliza recursos físicos e materiais da empresa tais como máquinas, matérias-primas, equipamento, tecnologias e que, estes são indispensáveis para que todos esses ativos tangíveis possam ser integrados em uma atividade conjunta e coordenada.

Da mesma forma, Batalha (2008 pag. 41) sustenta que "no que diz respeito a produtos, a gestão de operações compreende o planejamento e a gerência da manufatura de bens de capital e de consumo". Assim, torna-se evidente que o gerenciamento dos bens de capital usados nas atividades produtivas leva em consideração as necessidades de seu controle, visando à minimização dos impactos causados por atividades não gerenciadas.

Corrêa (2004 pag. 58) sustenta ainda que a gestão de operações é a atividade de gerenciamento dos recursos e processos produtivos que produzem o pacote de serviços entregue ao cliente. Desta forma a grande maioria das organizações possui uma função (e processos) que tem este papel, embora muitas vezes não sejam chamados por esse nome (operações). Essas funções, em geral, processam insumos clientes, materiais, informações, energia e outros - e usam, para isso, recursos de transformação: máquinas, equipamentos, terreno, pessoas, sistemas de informação e outros. As saídas dos processos produtivos das operações são um composto de serviços e bens físicos, que compõem o "pacote de valor" entregue ao cliente, no sentido de criar nele uma percepção favorável de satisfação em relação a suas expectativas.

Os custos inerentes às atividades de uma organização são determinantes para uma maior ou menor lucratividade. Isso se explica porque o preço final para o consumidor é estabelecido em grande parte, pelo mercado, e não de acordo com os custos agregados as atividades acessórias daquela organização. Nessas atividades estão incluídos os serviços logísticos (LAVIE, 2006).

De acordo com Dutra (2003), entende-se como custo, o gasto que aplica-se no processo da produção ou ainda, em qualquer outra operação que gere gasto, esse sendo pago ou não. Para que as empresas atinjam o objetivo de se manterem competitivas no mercado é necessário conhecer e implantar um sistema de levantamento de custos que lhes dê suporte. Na opinião de Pompermayer e Lima (2002), faz necessário que a empresa venha ter uma visão gerencial de custos em que leve em consideração alguns aspectos como: a intensa concorrência a que estiver submetida a empresa, e, a implantação de um método que lhe permita conhecer seus custos.

\section{MATERIAL E MÉTODOS}

Dentro do contexto, efetuou-se uma análise qualitativa entre diferentes referenciais bibliográficos incluindo livros e artigos científicos já publicados sobre o processo de controle de estoque nas organizações. Para Beuren et al. (2004, p.86) a pesquisa bibliográfica "objetiva recolher informações e conhecimentos prévios acerca de um problema para o qual se procura resposta ou acerca de uma hipótese que se quer experimentar".

Foi realizada uma análise "in loco" (no próprio local) na empresa.

Por se tratar de uma pesquisa ação, salienta-se que a participação dos pesquisadores e gestores da empresa em foco ocorreu de forma conjunta em todas as etapas da pesquisa, pois houve uma produção cooperativa de conhecimentos sobre a realidade pesquisada, no qual a participação de todos os envolvidos pactuou desde a formulação dos objetivos até o desenvolvimento dos resultados. Ademais, a pesquisa possui caráter descritivo e observatório, no qual tornou-se necessário o entendimento do ambiente situacional da empresa, que atrelado a necessidade de redução de custos oportunizaram o enlace entre a teoria e prática na busca por soluções do problema levantado. 


\section{RESULTADOS E DISCUSSÃO}

0 presente artigo foi elaborado a partir de um estudo realizado numa indústria do polo de duas rodas atuante no ramo de motocicletas, localizada na região norte do Brasil. A empresa foi a primeira fábrica da organização, no Brasil. Construída em uma área de 489.560 m2, no Polo Industrial de Manaus, a unidade representa o segundo maior investimento da organização fora do Japão, no setor de duas rodas.

Tratou-se inicialmente de quatro situações inerentes ao processo onde a falha poderia estar ocorrendo.

Foi utilizada a ferramenta matriz GUT(ferramenta da qualidade utilizada para a priorização de tomadas de decisões), com o intuito de priorizar problemas e consequentemente tratá-los, levando em consideração suas gravidades, urgências e tendências.

Assim, para cada característica citada aplicou-se notas que posteriormente foram somadas para se chegar à priorização dos problemas elencados em um processo. Quanto maior o somatório, mais grave é a deficiência apontada (PEIXOTO; TRABASSO, 2010). Para Behr et al. (2008), cada problema deve ser ponderado de 1 a 5 em cada critério, tendo como base para ponderação a tabela 1 abaixo:

Figura 1 - Matriz GUT - Priorização

\begin{tabular}{c|l|l|l|} 
Nota & \multicolumn{2}{c}{ Gravidade } & \multicolumn{1}{c|}{ Urgência } \\
\hline 5 & Extremamente grave & Precisa de ação imediata & Irá piorar rapidamente \\
\hline 4 & Muito grave & Muito urgente & Irá pioroar a longo prazo \\
\hline 3 & Grave & Urgente, merece atenção no curto prazo & Irá piorar e médio prazo \\
\hline 2 & Pouco grave & Pouco urgente & Irá piorar a curto prazo \\
\hline 1 & Sem gravidade & Pode esperar & não irá mudar \\
\hline
\end{tabular}

Fonte: Behr et. al. (2008).

Assim, para cada impossibilidade deve-se indicar qual sua Gravidade, Urgência e Tendência, e posteriormente realizar a multiplicação desses elementos. Posteriormente, deve se elencar as impossibilidades em ordem decrescente, para que sejam tomadas medidas com o intuito de eliminar ou amenizar as impossibilidades.

Assim por meio da matriz GUT evidenciou-se as características abaixo conforme a figura 2:

Figura 2 - Matriz GUT

\begin{tabular}{lllll|}
\hline TEMAS SUGERIDOS & G & U & T & TLL \\
\hline 1. AQUISIÇÃO DE MATERIAL ERRADO & 3 & 2 & 2 & 12 \\
\hline 2. FALHA NO CONTROLE DO ESTOQUE & 3 & 3 & 2 & 18 \\
\hline $\begin{array}{l}\text { 3. ATRASO NO RECEBIMENTO DOS MATERIAIS } \\
\text { (LOCAL E NACIONAL) }\end{array}$ & 3 & 2 & 1 & 6 \\
$\begin{array}{l}\text { 4. FALHA NO DESENVOLVIMENTO DE NOVOS } \\
\text { FORNECEDORES }\end{array}$ & 2 & 1 & 1 & 2 \\
\hline
\end{tabular}

Fonte: Dados da pesquisa.

Avalia-se, desta forma, que o item 2 apresentado na tabela acima destaca-se frente aos demais quanto à sua gravidade, urgência e tendências logo, devendo o mesmo, ser a prioridade quanto a tratativa da solução do problema.

Visando a solução do problema apontado pela matriz GUT, a figura abaixo retrata algumas soluções realizadas no processo visando o aumento da eficiência das operações de almoxarifado na área de solda, pintura e montagem bem como suas consequências ao processo.

Percebe-se que na figura 3, os setores em estudo: (solda, pintura e montagem), todos têm o seu almoxarifado, caracterizando uma descentralização dos insumos relacionados ao estoque. Foi detectada como principal evidência a inexistência de mistura de materiais entre os setores em estudo, um controle manual eficiente, porém um custo de manutenção alto para suportar tal estratégia. 
Figura 3 - Análise de descentralização do almoxarifado 'antes'

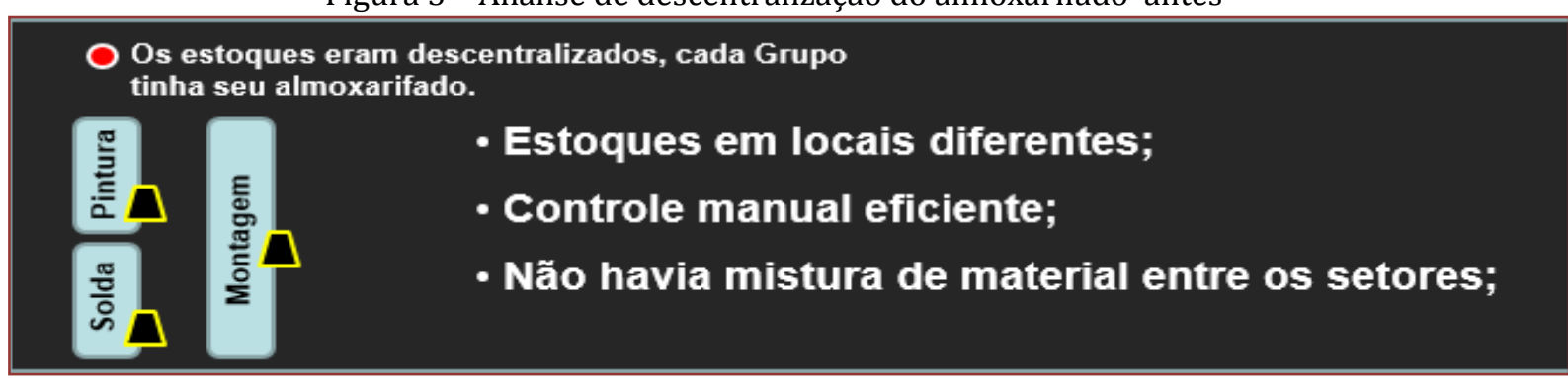

Fonte: Dados da pesquisa.

A empresa com intuito de redução de custo, conforme figura 4 realizou a centralização do almoxarifado onde todos os setores em estudo: solda, pintura e montagem tiveram os seus insumos centralizados em apenas um estoque. Isso ocasionou controle manual deficiente e uma excessiva mistura de material entre os setores.

Figura 4 - Análise da centralização do almoxarifado 'depois'

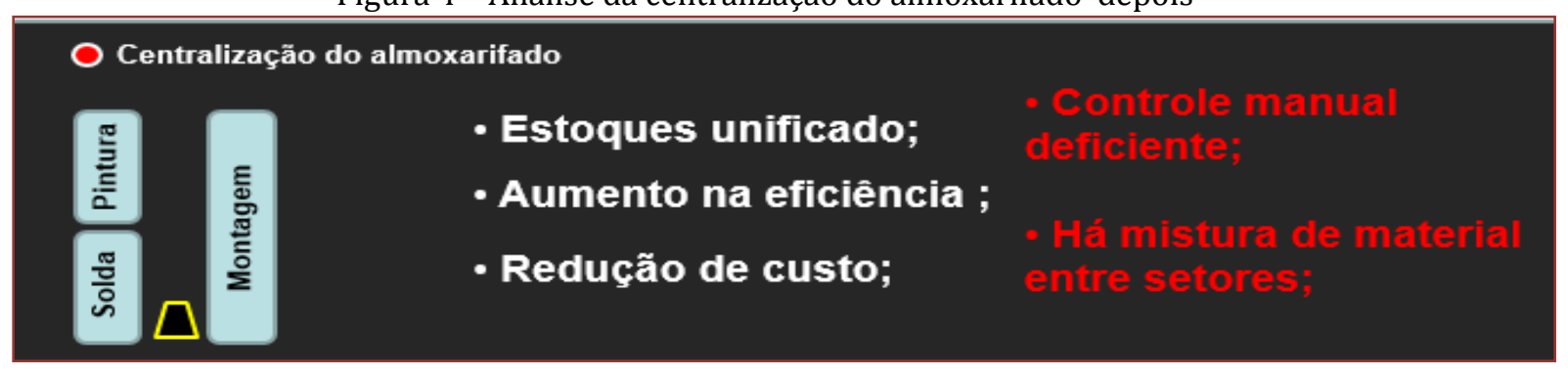

Fonte: Dados da pesquisa.

A seguir, para melhor entendimento do processo, o fluxograma das atividades foco do estudo em questão representado pela figura 5 .

Ainda com base na análise da situação atual, o posto entrega para produção, conforme figura abaixo, demonstra desordem tendo em vista que todo material que é destinado para produção é controlado de forma manual, acarretando ineficiência no processo bem como confusão no pagamento dos materiais, quando solicitados de forma rápida e em grandes volumes.

Assim, não havendo um registro confiável das saídas dos materiais, o estudo em questão se sustenta tendo em vista uma ineficiência ocorrida pela deficiência no controle do estoque na empresa alvo do estudo.

Figura 5 - Fluxograma das Atividades

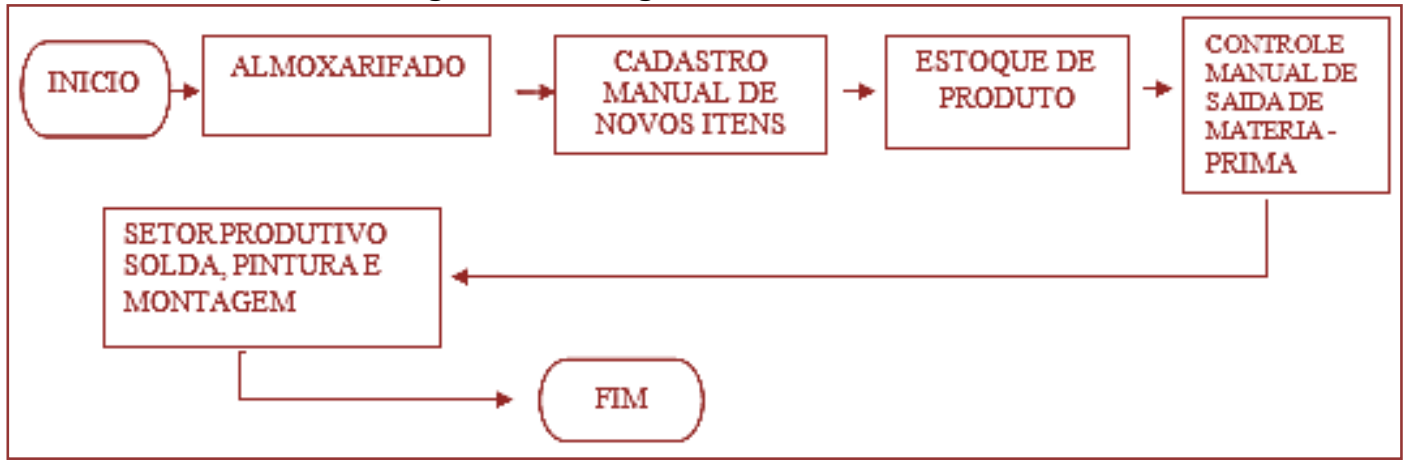


Após elucidação do funcionamento do processo, vide figura 5, permeia a análise se o método atual de gerenciamento de materiais é eficiente ou não para o controle dos processos e sucesso da operação em função de uma problemática relacionada ao registro não confiável de saídas de materiais salientando se a mesma condição de tal registro pode influenciar a eficiência do processo produtivo.

Conforme observação na empresa (in loco) demonstrou que apenas $20 \%$ do estoque transferido para a produção era controlado. Isso em função de todos os controles partirem da premissa de controles manuais.

Tendo em vista que os controles dos materiais transferidos à produção são de extrema importância, a figura 5 .

O desenvolvimento de um BI (Business Intelligent) ou sistema próprio em VBA além de atender todas as demandas relacionadas à solução do problema, ainda tem força de viabilização conforme figura 6 - 4M.

A figura 6 demonstra que, após avaliação, os itens Método e Material demonstram ineficiência quanto sua avaliação, pois não atendem as expectativas do controle de estoque. No Método identificou-se a entrega do material com seu controle manual e no item material em função da inexistência de um software de controle dos materiais.

Assim, em resumo, identificou-se que a implantação de um sistema de controle em VBA era de suma importância para a persecução dos objetivos da empresa. Desta forma conforme as figuras abaixo o processo de criação foi desenvolvido.

Figura 6-4M's

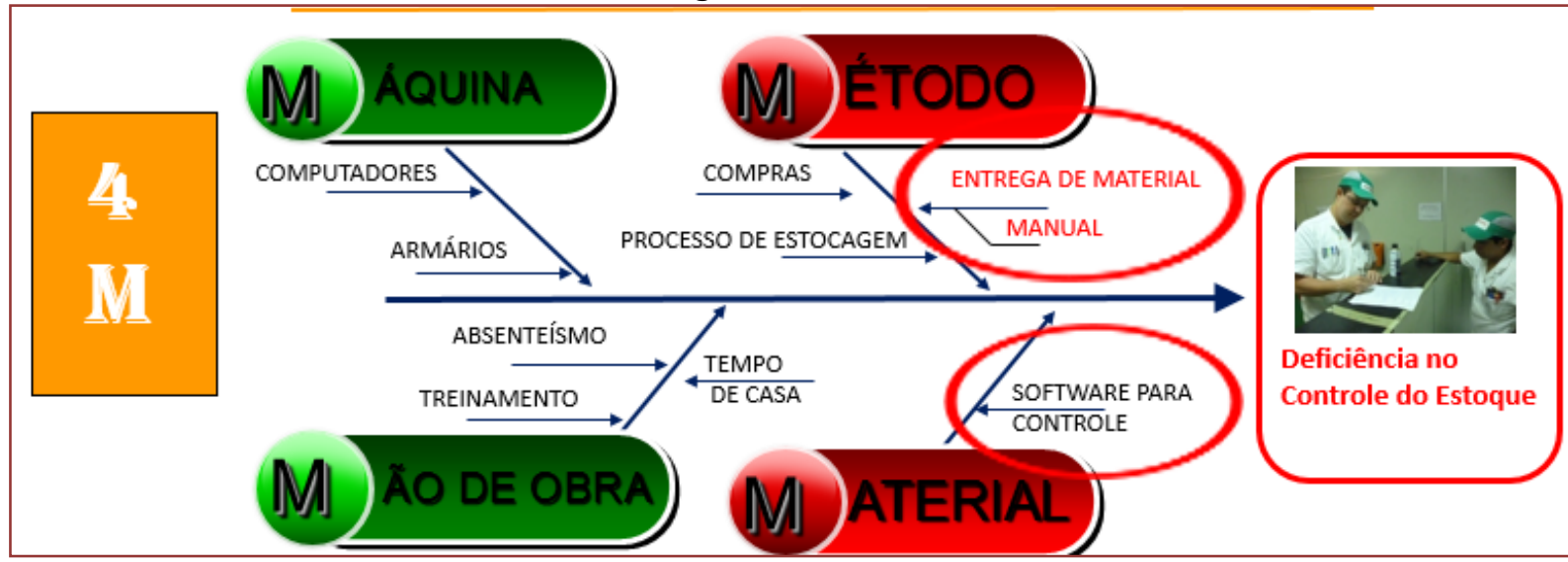

Assim, visando eliminar tal anomalia de ineficiência no processo da empresa, foram realizados estudos para implantação da solução.

A figura 7 refere-se ao sistema SAP, e após avaliação do time de melhorias, chegou-se à conclusão de que em função do custo a viabilidade não poderia ser efetivada.

Figura 7 - Estudo de implantação de soluções.

\begin{tabular}{|c|c|c|c|c|c|}
\hline \multicolumn{6}{|c|}{ Tlabilidade de implantação da proposta } \\
\hline Foto & Q-Quafidade & C-Custo & D-Atendimento & $M-M a \tilde{o}-d \varepsilon-o b r a$ & S-Seguranca \\
\hline & $\begin{array}{l}\text { Atende com } \\
\text { satisfação }\end{array}$ & $\begin{array}{l}\text { MC } \\
\text { Não está orçado. } \\
\text { Custo elevado. }\end{array}$ & $\begin{array}{l}\text { OX } \\
\text { Atende com } \\
\text { satisfação }\end{array}$ & $\begin{array}{l}\text { On } \\
\text { Operador não teria } \\
\text { dificuldade }\end{array}$ & $\begin{array}{l}\text { OXI } \\
\text { Não houve } \\
\text { alteracõos }\end{array}$ \\
\hline
\end{tabular}

Fonte: Dados da pesquisa. 
A figura 8 demostra o pacote office, utilizando o programa Excel, e após avaliação do time de melhorias, chegou-se à conclusão de que em função da qualidade não atende todas as necessidades por se tratar de sistema muito.

Figura 8 - Estudo de implantação dissoluções.

\begin{tabular}{|c|c|c|c|c|c|}
\hline \multicolumn{6}{|c|}{ Viabilidade de implantação da proposta } \\
\hline Foto & Q- Quafidade & C-Custo & (D-Atendimento & $M-M a \tilde{o}-d_{\varepsilon}-o b r a$ & S-Segurança \\
\hline$=$ & $\begin{array}{l}\text { NC } \\
\text { Não atende todas as } \\
\text { necessidades muito } \\
\quad \text { manual. }\end{array}$ & $\begin{array}{l}\text { Não houve } \\
\text { alteracõos }\end{array}$ & $\begin{array}{l}\text { MC } \\
\text { Demora no } \\
\text { atendimento }\end{array}$ & $\begin{array}{l}\text { Ox } \\
\text { Demora na } \\
\text { digitafáa. }\end{array}$ & $\begin{array}{l}\text { OX } \\
\text { Não houve } \\
\text { alteracões }\end{array}$ \\
\hline
\end{tabular}

Fonte: Dados da pesquisa.

A figura 9 apresenta um sistema próprio em VBA(atua como uma linguagem de programação à serviço do usuário, permitindo a criação de macros e a automatização de diversos processos dentro das planilhas e tabelas desenvolvidas no Excel). E após todas as avaliações pelo time de melhorias, chegou-se à conclusão de que esta é a melhor solução para implantação. Logo sua viabilidade foi eminente partindo-se para o plano de desenvolvimento da proposta.

Figura 9 - Estudo de implantação de soluções

\begin{tabular}{|c|c|c|c|c|c|}
\hline \multicolumn{6}{|c|}{ Viabilidade de implantação da proposta } \\
\hline Foto & Q-Qualidade & C-Custo & D - Atendimento & $M-M \tilde{a} o-d \varepsilon-o b r a$ & S-Segurança \\
\hline 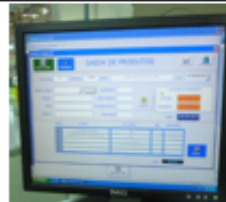 & $\begin{array}{l}\text { OX } \\
\text { Atende com } \\
\text { satisfação }\end{array}$ & $\begin{array}{l}\text { OX. } \\
\text { Custo zero. }\end{array}$ & OX & $\begin{array}{l}\text { OX } \\
\text { Aumento na } \\
\text { satisfacaão do } \\
\text { colaborador }\end{array}$ & $\begin{array}{l}\text { OX } \\
\text { Jão houve } \\
\text { alteracões }\end{array}$ \\
\hline
\end{tabular}

Fonte: Dados da pesquisa.

Conforme as figuras 7, 8 e 9 acima, evidenciam-se três propostas para solução do problema de registro não confiável de saídas de materiais e a hipótese é se tal registro não confiável pode influenciar na eficiência do processo produtivo.

Todo o sistema implantado contribuiu de forma extremamente positiva para o gerenciamento da empresa. 0 sistema possibilitou à empresa o controle e a organização que ela precisava.

Figura 10 - Implantação do sistema de controle de estoques

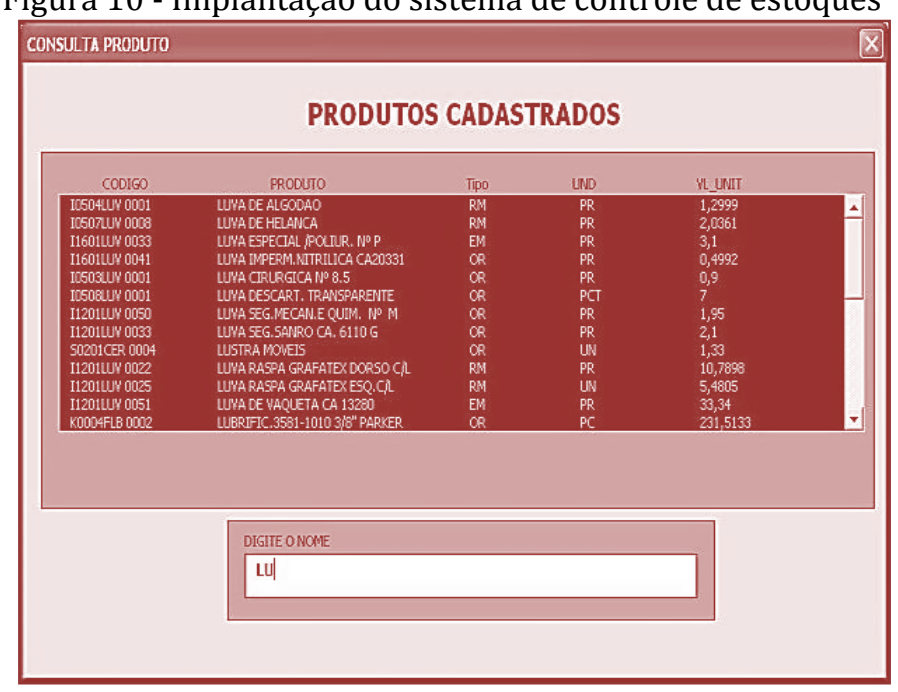

Fonte: Dados da pesquisa. 
É importante salientar que, para que o sistema de controle de estoque tenha funcionamento eficiente, são necessários o treinamento e orientação dos funcionários, de modo a evitar omissão de registros de saída, que ocasiona divergência entre os dados do software e a real situação do estoque.

Figura 11 - Implantação do sistema de controle de estoques

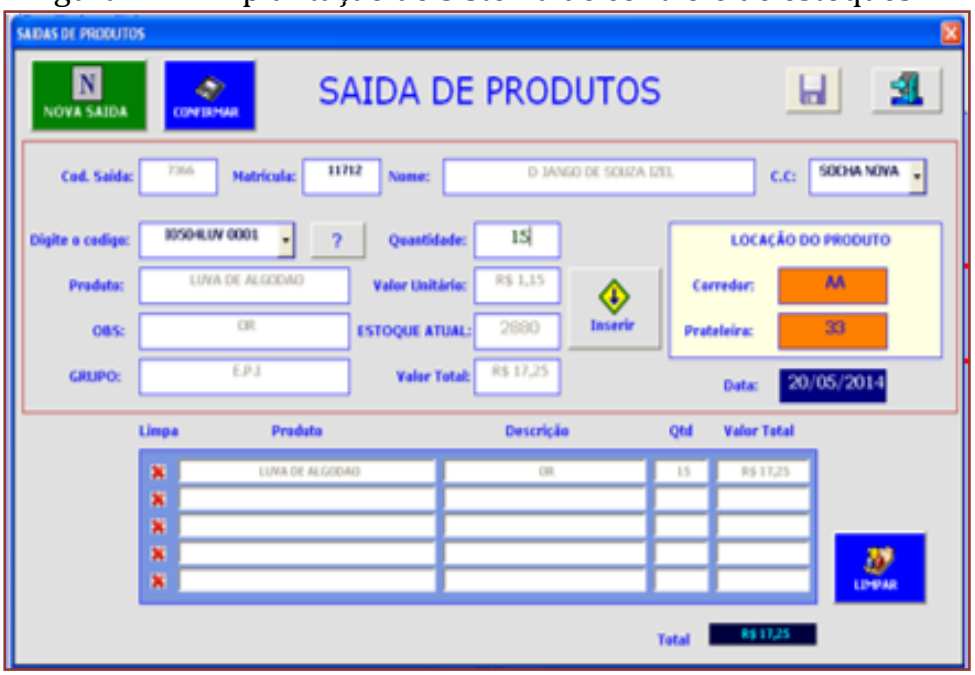

Fonte: Dados da pesquisa.

De forma geral a Gestão de estoque é um mecanismo fundamental para uma empresa, considerando que influencia diretamente no ativo da empresa. Caso ocorram falhas, pode deixar de gerar lucros.

A empresa, após as investigações realizadas bem como a implantação do novo sistema visando o aumento da eficiência do processo em todos os seus sentidos, porém focadas no controle de estoque e na gestão das operações atenderam os seguintes resultados após sua implantação.

Após as avaliações preliminares estima-se que 96,47\% está com a cobertura acerca do controle de estoques na empresa, percebe-se que a implantação do BI em VBA foi de extrema importância e obviamente que, para uma cobertura ainda maior, serão realizadas avaliações no sistema, e atualização no programa.

Figura 12 - Registro de saídas do almoxarifado

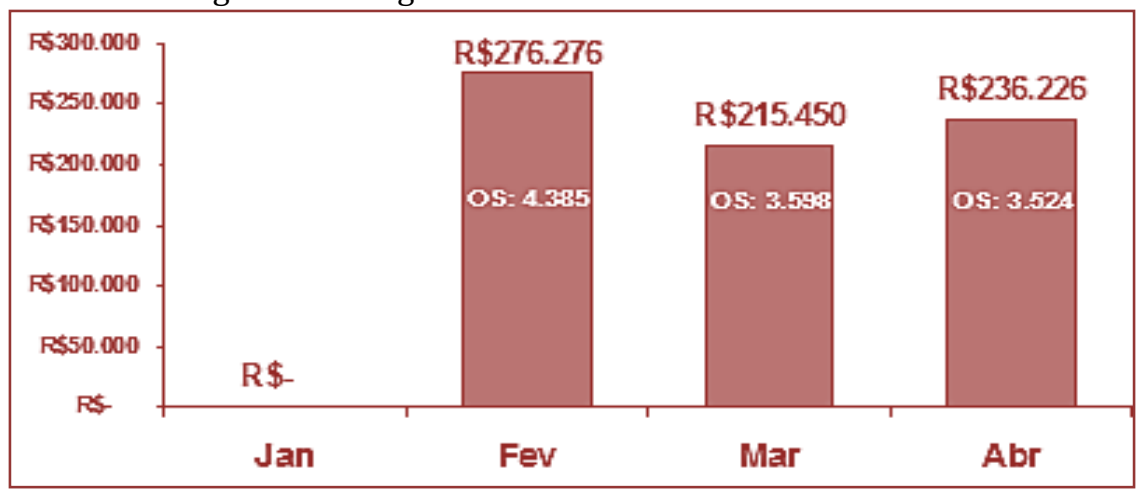

Fonte: Dados da pesquisa.

\section{CONCLUSÕES}

Mediante a inovação do novo sistema implementado, percebeu-se uma melhora na eficiência de controle, uma vez que, apenas $20 \%$ do estoque transferido para a produção era controlado, com a implantação do BI em VBA notou-se a maior eficiência no controle de estoque que após avaliações aumentou sua cobertura de $20 \%$ para $96,47 \%$ visando garantir um melhor gerenciamento e maior agilidade e controle das operações. 
Estudos de caso, além de explorar os modelos de apoio à decisão, permitem discutir aspectos da implantação dos sistemas de controle (gerencial e da tecnologia de informação) que são de grande importância para aplicação prática dos desenvolvimentos acadêmicos.

Como sugestões para estudos futuros, devido à abrangência das mudanças dentro da organização, pode ser feita uma pesquisa acerca do processo de inovação, por meio do conhecimento dos colaboradores, bem como o controle de custo neste processo. Outra sugestão seria analisar a relação entre as estratégias de produção no desempenho da competitividade organizacional, tendo como base a inovação no setor de estoque da empresa.

\section{REFERÊNCIA}

[1] ANTUNES, Junico. et al. Sistemas de Produção: Conceitos e Práticas para projeto e gestão da produção enxuta. Porto Alegre: Bookman, 2008

[2] BALLESTERO-ALVAREZ, Maria Esmeralda. Administração da qualidade e da produtividade: abordagens do processo administrativo, São Paulo: Atlas, 2001.

[3] BALlESTERO-ALVAREZ, Maria Esmeralda. Gestão da Qualidade, Produção e Operações. São Paulo: Atlas, 2010.

[4] BATALHA, Mário Otávio et al. Introdução a engenharia de produção. Rio de Janeiro: Elsevier, 2008.

[5] BEHR, A.; MORO E.L.S.; ESTABEL, L.B. 2008. Gestão da biblioteca escolar: Metodologias, enfoques e aplicação de ferramentas de gestão e serviços de biblioteca. Ciência da Informação, v. 37, n.2, p. 32-42.

[6] CAMPOS, Vicente Falloni. TQC - Controle da Qualidade Total, (no estilo japonês). Fundação Christiano Ottoni, 1992

[7] CORRÊA, Henrique Luiz; CORRÊA, Carlos A. Administração estratégica de serviços. Compacta ed. São Paulo: Atlas, 2005.

[8] CRUZ, Tadeu. Sistemas, Organizações \& Métodos: estudo integrado das novas tecnologias de informação. 3a Ed. São Paulo: Atlas, 2002.

[9] DAMAZIO, Alex, Administrando pela gestão da qualidade total. Rio de Janeiro: Interciência, 1998

[10] DAVIS, M.; AQUILANO, N. \& CHASE, R. Fundamentos da Administração da Produção. Porto Alegre: Bookman, 2001.

[11] DAYCHOUW, M. 40 ferramentas e técnicas de gerenciamento. Rio de Janeiro: Brasport, 2007.

[12] FILHO, Gonçalves. Sistemas de Manufatura: Projeto do arranjo físico. Notas de aula. E. V., 2005.

[13] GAITHER, N. Production and operations management. 5th ed. Orlando, FL: Harcourt Brace Jovanovitch Publishers, 1992, p. 133. - Petrônio G. Martins e Fernando Piero Laugeni, Administração da Produção - 2ª ed. pág. 484.

[14] GODOY, M. H. C. Brainstorming. Belo Horizonte: Editora de Desenvolvimento Gerencial, 1997.

[15] GONZALEZ, R. V. D.; MARTINS, M. F. Melhoria contínua no ambiente ISO 9001:2000: estudo de caso em duas empresas do setor automobilístico. Revista Produção, v. 17, n. 3, p. 592-603, 2007.

[16] IDALBERTO, Chiavenato. Gestão da Produção: Uma abordagem introdutória. 3 ed. - Barueri, SP: Manole, 2014.

[17] MARSHALL, Island Junior (org). Gestão da Qualidade. Rio de Janeiro: Editora FGV, 2003.

[18] MAXIMIANO, Antonio Cesar Amaru. Introdução à administração. 4⿳a Ed. São Paulo: Atlas, 1995.

[19] OHNO, T. O Sistema Toyota de Produção. Além da Produção em Larga Escala. 1o Edição. Porto Alegre. Editora Bookman, 1997.

[20] PALADINI, Edson Pacheco, Qualidade total na prática - implantação e avaliação de sistema de qualidade total. 2. ed. São Paulo: Atlas, 1997.

[21] PAULA PESSOA, P. F. A. de. Gestão Agroindustrial. Fortaleza: Embrapa Agroindústria Tropical, 2003.

[22] PEIXOTO, Y.M.; TRABASSO, L.G. 2010. Otimização de processo via simulação Engenharia de Interiores e Placares. ENCONTRO NACIONAL DE ENGENHARIA DE PRODUÇÃO, 30, 2010. São Carlos. Anais... São Paulo.

[23] RODRIGUES, J. R. 50 gurus da gestão para o século XXI. Lisboa: Centro Atlântico, 2005,519 
[24] SLACK, Nigel; CHAMBERS, Stuart; JOHNSTON, Robert. Administração da Produção. São Paulo, 2o ed. Atlas, 2009

[25] VERGUEIRO, Waldomiro. Qualidade em Serviços de Informação. $2002 . \quad$ Disponível em:<http://books.google.com.br/books?id=pOhOtn8HOiUC\&pg=PA52\&dq

Ferramentas + da + Qualidade\&hl $=$ ptR\&sa $=X \&$ ei $=9$ QhUKiOoua8gSypYHwAw\&ved $=0$

CEkQ6AEwBQ\#v=onepage\&q=Ferramentas\%20da\%20Qualidade\&f=false>Acesso em: 21 Out. 2020.

[26] WERKEMA, Cristina. Ferramentas estatísticas básicas para o gerenciamento de processos. Belo Horizonte: Werkema Editora, 1995.

[27] WOMACK, J.P.; JONES, D.T. A mentalidade enxuta nas empresas: elimine o desperdício e crie riqueza. 6aㅡ Ed. Rio de Janeiro: Elsevier Editora Ltda, 2004.3p.

[28] TERZIOVSKI, M. Achieving performance excellence through an integrated strategy of radical and continuous improvement. Measuring Business Excellence, v. 6, n. 2, p. 5-14, 2002. Disponível em:< http://dx.doi. org/10.1108/13683040210431419>Acesso em: 15 de Out. 2020. 


\section{Capítulo 8}

Aplicabilidade da ferramenta kaizen em uma empresa de ar-condicionado em Manaus

\section{Luciana Oliveira do Valle Carminé}

Clayberson Alves Carvalho

Paulo Christian Bezerra Pastor

Kennedy França Kramer

Resumo: Este trabalho constituiu em um estudo de caso em uma empresa de arcondicionado do polo industrial de Manaus que visou a aplicabilidade da ferramenta kaizen no processo produtivo da empresa. Tal aplicação objetivava a redução de custo, desperdícios e melhoria do processo de teste na empresa em questão. 0 foco principal é uma melhor compreensão da filosofia japonesa de melhoria continua do kaizen e como ela é aplicada. Os métodos e instrumentos para fazer a coleta de dados foram as fontes secundárias, com informações a partir da análise de documentos fornecidos pela própria empresa. Foi realizado um estudo de caso e as conclusões obtidas foram a constatação de que no método kaizen é aplicado com sucesso pela empresa e os colaboradores que dele participam, se empenham em manter as mudanças realizadas. Esta conscientização deve ser mais divulgada entre todos os afetados pelas modificações, para que estes também façam parte do processo e procurem complementar e fortalecer este pensamento de contínua busca pelo melhoramento de suas atividades.

A ferramenta Kaizen significa melhoramento nas operações, sendo muito utilizada em empresas ao redor do mundo. A metodologia existe com princípios do Sistema Toyota de Produção - TPS tendo como significado fazer melhor. 0 processo ajuda a aumentar a produtividade através de padrões em cada etapa do processo de produção.

Palavras-chave: Melhoria contínua, Otimização, Qualidade e Redução de custo. 


\section{INTRODUÇÃO}

A gestão de produção possibilita habilidades especificas para realizar comportamento e ações ao longo do processo. As experiências da produção adaptada com novas ideias de melhoria dentro das operações fazem com que a otimização utilizada na ferramenta Kaizen, invista no processo de melhoria contínua nos processos de produção. A análise exige leitura do mercado empresarial, acompanhar demandas com auxílio da implantação de sistemas de produção mais integrados.

Para Tanaka et al. (2012), a diferença da melhoria contínua e as novas ideias estão em busca constante da perfeição trazendo evolução e desenvolvimento rápido na qualidade do processo e na melhoria dos produtos.

Segundo Taiichi Ohno, o sucesso permanece com propósito de oferecer produtos e serviços de qualidade com menor custo. Atualmente as empresas se espelham no Sistema Toyota de Produção - STP, um sistema que aderi a melhoria dos seus processos, melhoria do clima organizacional e crescimento das pessoas. acreditando na política e na cultura organizacional, considerando filosofia de vida. De origem japonesa conhecida como Kaizen, pode ser aplicada em qualquer atividade produtiva, pois tem como domínio melhorar processo produtivo reduzindo desperdícios e eliminando atividades que não agrega valores.

Segundo Marino Kishida (2015), Kaizen é reconhecida como "a filosofia mais poderosa da administração", pois, detém ferramentas que envolvem todos dentro da empresa, com isso, ele incentiva os funcionários a remover as barreiras e desafios que surgem e atingir as metas propostas para a melhoria de processos e do ambiente organizacional. A implantação da metodologia da ferramenta Kaizen é para a otimizar a redução de custo, a melhoria contínua na segurança e redução dos riscos na área, minimizando a movimentação desnecessária e espera, aproveitando ao máximo de operadores e seu desenvolvimento de performance profissional. Deste modo as chances na redução dos defeitos e a melhor qualidade nos produtos aumento da velocidade dos processos e a redução da espera do transporte, consequentemente, levando obter menor tempo de fabricação e entrega.

Segundo Chambers e Johnston (2009) Kaizen tem como origem japonesa que significa mudança para melhor, usada para transmitir melhoria contínua na vida em geral, seja ela pessoal, familiar, social e no trabalho. Sua essência é simples e direta: Hoje melhor que ontem, amanhã melhor do que hoje, tendo como reflexo o bem da empresa, com todos os envolvidos nos processos. A filosofia afirma que o nosso modo de vida - seja no trabalho, na vida social ou em casa - merece ser continuamente melhorado. As empresas competitivas têm como fator determinante reduzir ao máximo seus custos, sem deixar de oferecer produto com qualidade e no tempo que o cliente deseja. As filosofias e metodologias do Kaizen vem como ferramentas para auxiliar a gestão.

Segundo Maike Cardoso (2015), o Kaizen é organizado de três formas: Pré-kaizen; Kaizen e Pós-kaizen. A primeira fase acontece na análise geral do processo, focando na busca dos pontos de melhoria, fazendo cotações, observando layout com o intuito de elaborar um plano de ação para a realização das atividades definindo metas e prazo. A segunda é a fase é a execução, o momento em que cada colaborador executa a tarefa que foi determinada. Nesta etapa segue-se o cronograma elaborado no Pré-kaizen e após o término é realizada uma auditoria que mostra o desenvolvimento dos trabalhos, na terceira fase, será o acompanhamento, analisando os trabalhos realizados e se estão trazendo os resultados que foram estabelecidos como meta. De acordo com a metodologia aplicada da ferramenta Kaizen, requer mudanças diárias resultando ao longo do prazo a melhoria do que almeja ser otimizado, valorizar o trabalho. A melhoria pode ser dividida por Kaizen ou por Inovação. Se for por Kaizen significa melhorias contínuas, caso seja a Inovação significa melhorias drásticas que estão normalmente relacionadas com grandes investimentos nas novas tecnologias ou em novos equipamentos. Alcançar o estado atual e o estado desejável, é necessário alcançar o estado ideal e o monitoramento constante dos dados e resultados adquiridos. Resultando estabilidade financeira e emocional dos funcionários, clima organizacional agradável, um ambiente de trabalho simples, organizado e funcional.

Afirma Ballestero-Alvarez (2012), que o Kaizen oferece muitos pontos fortes para uma aplicação dentro da organização de trabalho. Sua adoção tem um custo baixo por não envolver "novas" tecnologias e utilizar fundamentalmente a participação e a criatividade de todos os envolvidos. Contando com a participação de todos dentro da empresa, o Kaizen promove o aproveitamento de ideias e a valorização do talento assim, elevando a moral e promovendo um clima organizacional mais participativo, e isto beneficia a todos. A sustentabilidade da ferramenta exige treinamentos contínuos para nivelar o conhecimento e conscientizar a todos sobre a importância da eliminação de desperdícios, embora isso seja necessário mudanças no layout do processo e até mesmo movimentação de operadores entre postos de trabalho, desta forma torna-se eficaz a implementação da ferramenta bem como sua sustentabilidade no processo envolvido. 
É importante saber que o Kaizen começa após a identificação de uma oportunidade no processo produtivo e não tem fim, uma vez que sua premissa é promover a melhoria contínua e para isso é muito importante a coleta de dados bem como a gestão sobre tais informações afim de definir ações eficazes no processo de forma continua, verificando de forma linear sua aplicação através do método PDCA (Plan - Planejar, Executar, Controlar, Acti). Este método tem se destacado no ambiente organizacional como um método gerencial para melhoria de processos e soluções de problemas. Seja ela em uma empresa privada, ou organização sem fins lucrativos ou até mesmo em um setor público. Segundo Vieira Filho (2010, p. 24) o PDCA é um método que gerencia as tomadas de decisões melhorando as atividades de uma organização. Desta forma a ferramenta PDCA tem um papel de fundamental importância para a obtenção de melhores resultados. Pois, através do gerenciamento dos processos pode-se identificar e melhorar o desempenhe estabelecidos. Assim, a utilização do método PDCA vem sendo cada vez utilizado para alcançar a excelência operacional e a melhoria contínua, além de fomentar nas organizações uma cultura voltada à eliminação de falhas e busca por resultados cada vez melhores.

0 termo " $\mathrm{P}$ ", do ciclo, significa planejamento e estabelece metas sobre os itens de controle. 0 processo de planejamento define-se da seguinte forma:

Identificação do problema: Neste caso é necessário definir de maneira clara o problema e a sua importância, através de diretrizes gerais como qualidade, custos, atendimento etc.

Posteriormente verifica-se o histórico do problema através de sua frequência e modo de ocorrência. Após esta etapa verifica-se as perdas atuais e os ganhos viáveis, seguida da análise de Pareto para priorizar os temas e estabelecer as responsabilidades por indivíduo ou departamento e propor uma data limite para ter a solução do problema. Segundo Robson Camargo (2018), o diagrama de Pareto é um recurso gráfico utilizado para estabelecer uma ordenação nas causas de perdas que devem ser sanadas. Observação: A investigação de forma específica do problema com uma visão geral e sob vários pontos de vista, tais como, linhas de manufatura, tipo de problema, indivíduos envolvidos etc. 0 objetivo é identificaras características do problema através de observação no local para coletar informações que não podem ser obtidas somente através de dados numéricos. Consequentemente um cronograma deverá ser elaborado e que pode ser utilizado em cada processo para estimar um orçamento e definir uma meta a ser atingida. Análise: Nesta fase o objetivo é descobrir as causas fundamentais, que pode ser feito através do diagrama de causa e efeito. Deve-se escolher por meio do diagrama de causa e efeito as causas mais prováveis, para em seguida serem analisadas e testadas. 0 resultado da análise confirmará ou não a existência de relação entre o problema (efeito) e as causas (hipóteses). Em seguida, é necessário realizar o teste de consistência da causa fundamental, verificar se é possível bloquear essa causa, ou se o bloqueio não causará efeito colateral.

Plano de Ação: elaborar uma estratégia de ação para bloquear as causas fundamentais. As ações devem ser tomadas sobre as causas fundamentais e não devem produzir efeitos colaterais. 0 plano de ação deve ser pautado no bloqueio e revisão do orçamento final, deve-se utilizar o cronograma de custo 5W2H.

0 termo " $\mathrm{D}$ ", do ciclo, tem como significado execução e está relacionado ao cumprimento das as tarefas exatamente como prescritas no plano e coletar dados para verificação e validação do processo. Este processo poderá ser utilizado da seguinte forma: Ação: Avaliar ações necessitam de a cooperação divulgar o plano de ação para todos em reuniões participativas. Em seguida, deve-se executar a ação com foco no plano e no cronograma. É muto importante que todas as ações e resultados sejam registrados com a data que foram tomadas.

0 termo "C", do ciclo, significa verificação: Nesta etapa os dados devem ser coletados durante o processo e comparados a meta planejada. Esta etapa da seguinte forma: Verificação: comparação dos resultados; devem-se utilizar os dados coletados antes e após a ação do bloqueio para verificar a efetividade da ação e o grau de redução dos resultados indesejáveis

A ferramenta $5 \mathrm{~W} 2 \mathrm{H}$ também tem grande eficiência no processo de análise dos processos, segundo Rabelo (2014) e Nakagawa (2013) afirmam que a ferramenta é simples e ágil e que não há concordância sobre quem a desenvolveu. Todavia Sasdelli e Kaminski (2013) alegam que a ferramenta foi atribuída a Marcus Fabius Quintilianus no tratado oratório do ano de 30 e 100 D.C, pois algumas literaturas faziam menção ao seu nome. 
No mesmo tratado os autores afirmam que para garantir a compreensão foi gerado um conjunto de perguntas em inglês que por sua vês serias abreviadas. Sendo elas:

1 - What (o que) - A resposta é o que será feito para alcançar os objetivos de melhorias.

2 - Who (quem) - define responsáveis

3 - When (quando)- Definição de tempo para as ações.

4 - Where (onde)- Onde será feita tal ação

5 - Why (por que)- Por que será feito

6 - How (como)- Detalhamento das atividades a serem executadas, como a ação será realizada, qual a lista de ações.

7 - How Much (quanto)- Definição do custo-benefício e quanto de recurso será destinado a cada atividade.

\section{MATERIAL E MÉTODOS}

O procedimento metodológico aplicado para a formação deste trabalho tem como enfoque qualitativo, utilizando a análise de pesquisa bibliográfica, desenvolvido ao longo de uma série de etapas, tais como a temática e o levantamento de pesquisa de campo, mapeando os registros de defeitos diários. Propor melhoria e implantação dos planos de ação com as ferramentas da qualidade 5W2H e PDCA.

Houve também a pesquisa de campo, com a finalidade de examinar e compreender as atividades desenvolvidas no processo de manufatura da empresa, buscando otimização para o processo produtivos.

\section{RESULTADOS E DISCUSSÃO}

A pesquisa foi realizada em uma empresa do polo industrial de Manaus com cerca de 200 funcionários, especializada na produção de aparelhos de Ar-condicionado. Apresentava altos índices de defeitos/hora, em duas de suas linhas de manufatura. Os aparelhos de refrigeração não energizavam (ligavam).

Este problema era apresentado no momento da entrada do aparelho na cabine de teste de funcionamento, onde especificamente os condensadores apresentavam falhas de funcionamento, não ligavam.

No desenvolvimento do plano de ação utiliza-se a pesquisa de campo através da ferramenta 5W2H sendo possível detectar que acontecia desgaste das agulhas até que elas fossem isoladas completamente ao ponto de não fazer contato elétrico, com o aparelho, gerando defeito e aumento do índice de defeitos/hora no processo produtivo. Após análise pôde-se afirmar o excesso de produtos defeituoso, movimentos repetitivos com cabos de alimentação anteriores.

Conforme a Tabela 1 abaixo: 0 plano de ação utilizando a ferramenta $5 \mathrm{~W} 2 \mathrm{H}$ para resolução, definindo datas prévias e responsáveis, por cada ação.

Tabela 1: Proposta por meio da ferramenta 5W2H

\begin{tabular}{|c|c|c||}
\hline \multicolumn{3}{|c|}{5 W2H } \\
\hline What & o que? & $\begin{array}{c}\text { Checagem da periodicidade de vida útil das } \\
\text { agulhas de testes }\end{array}$ \\
\hline Who & Quem? & Gerente da Manutenção e engenharia \\
\hline Where & Onde? & Área de Produção \\
\hline When & Quando? & 10/09/2020 \\
\hline Why & Por que? & \begin{tabular}{c} 
Garantir a qualidade do Produto \\
\hline How
\end{tabular} \\
\hline How & Como? & $\begin{array}{c}\text { Seguir Roteiro de checagem da vida util da } \\
\text { agulhas de teste }\end{array}$ \\
\hline Quanto? & R\$ 600,00 \\
\hline
\end{tabular}

Fonte: Elaborado pelos autores (2020) 
No processo produtivo foi detectada uma sobrecarga no produto a ser testado por conta da alta corrente elétrica aplicada. Assim gerando derretimento da borneira: sistema de ligações elétricas, e com isso repelindo resíduo plástico na agulha de contato do cabo de alimentação de teste, conforme Figura 1. Fazendo com que as agulhas fiquem isoladas bloqueando o contato elétrico, conforme Figura 2

Figura 1. Borneira queimada Sobrecarga elétrica.

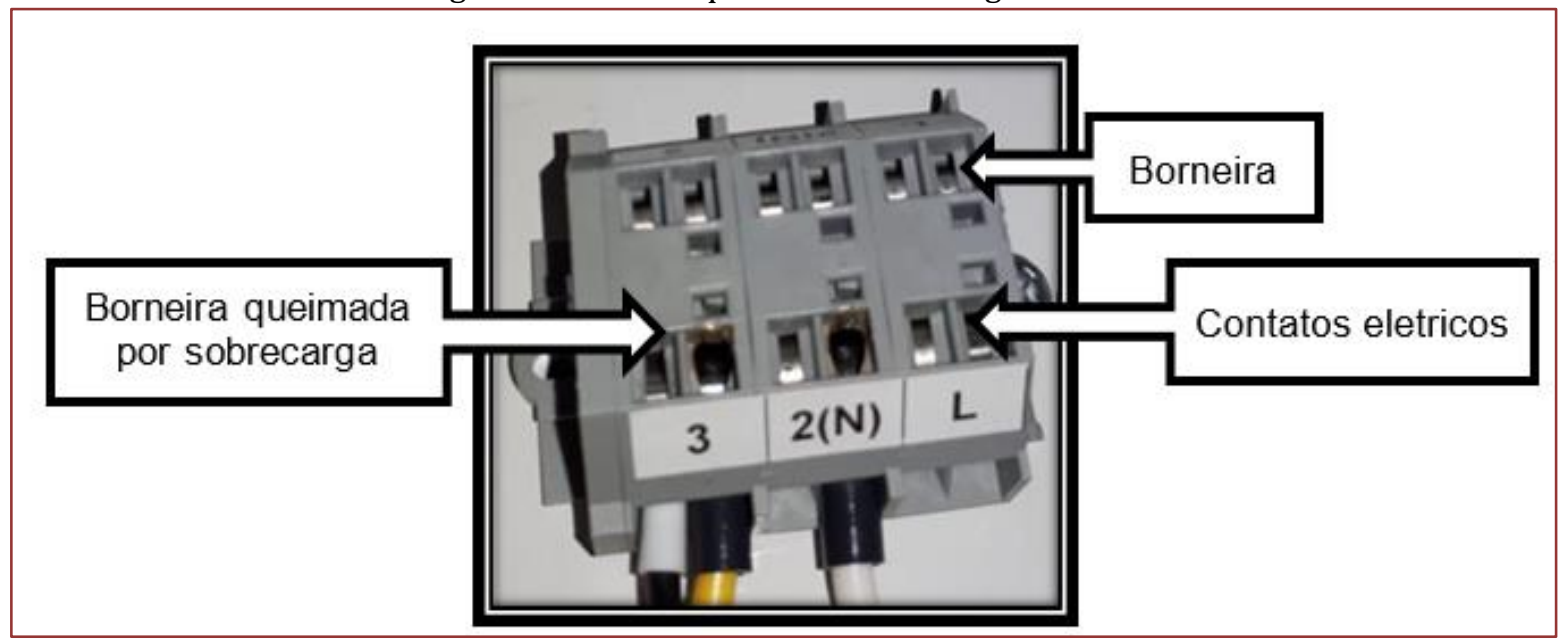

Fonte Própria em 10/2020

Figura 2. Teste de continuidade dos contatos queimados e isolados por conta do derretimento da borneira no momento de teste do produto.

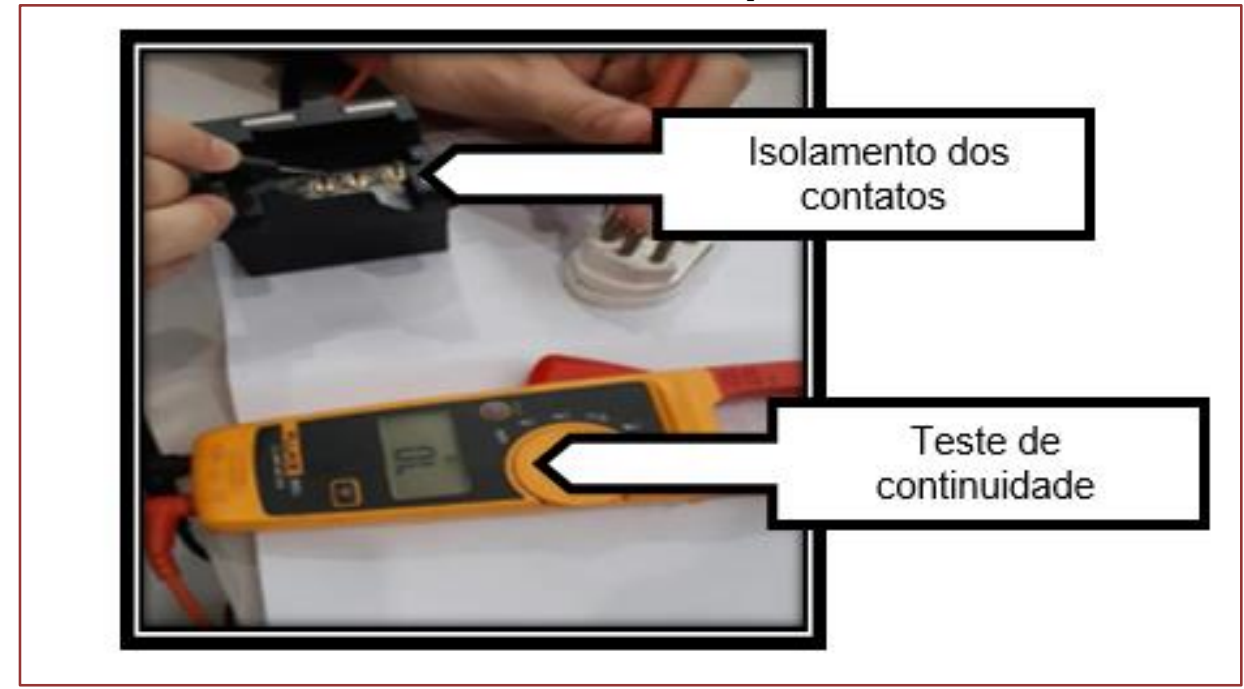

Fonte Própria em 10/2020

$\mathrm{Na}$ análise do problema foi necessário coletar dados no processo de manufatura na empresa de Arcondicionado conforme Figura 3 gráficos estratificado dos maiores defeitos diários identificando o não liga como maior. Por meio deste levantamento utilizando a ferramenta PDCA, foram evidenciados vários pontos nas negativos principalmente no dispositivo de teste do produto. Estabelecendo o paralelo entre o ciclo PDCA e o 5W2H listou todos os principais pontos correlacionados ao problema. 
Figura 3 - Gráfico estratificado dos três maiores defeitos diários mensurando o produto não liga como maior causa.

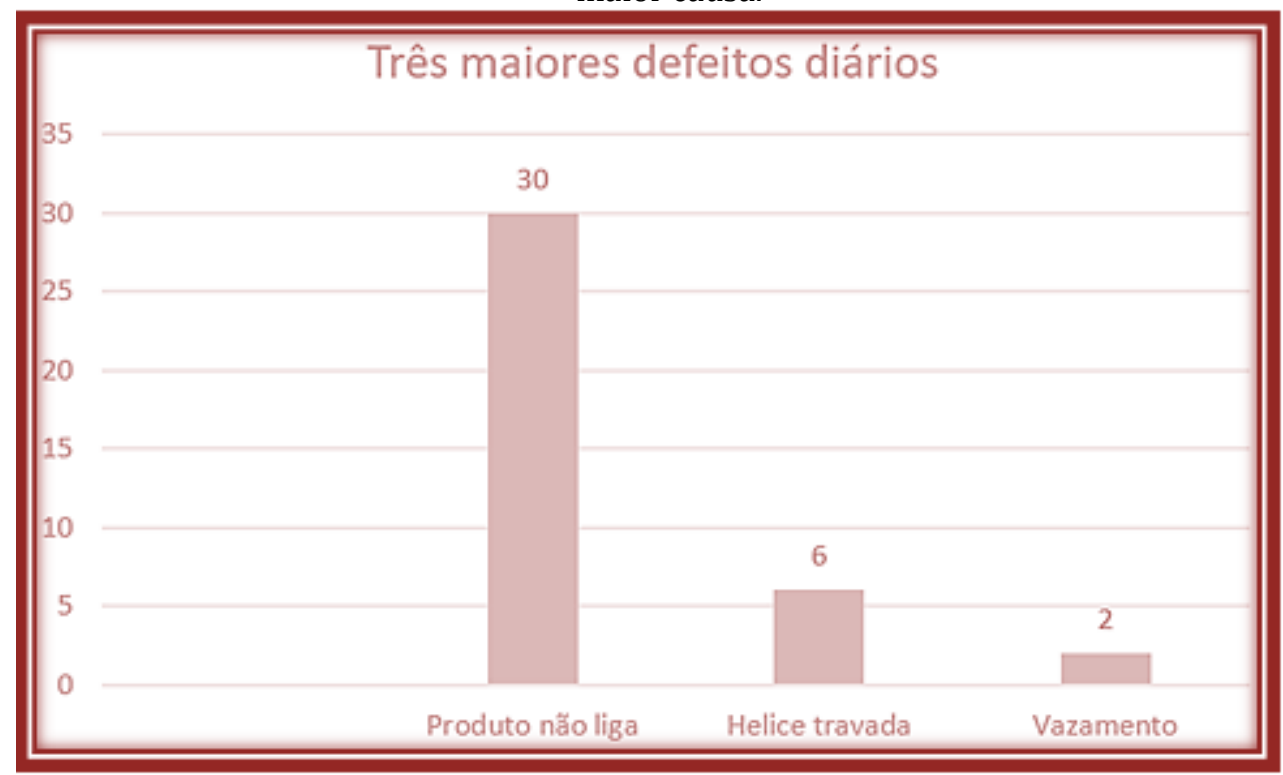

Fonte Própria em 10/2020

Figura 4 - Ciclo PDCA e o A3.

\begin{tabular}{|c|c|c|c|c|}
\hline PLACA & ETAPAS & FASE & OBJETIVO & SOLUCÃO \\
\hline \multirow{4}{*}{ A } & 1 & $\begin{array}{l}\text { IOENTFICACĀÁODO } \\
\text { PROBLEMA }\end{array}$ & $\begin{array}{l}\text { SOBRE CARGA ELETRICA NA } \\
\text { BOTOEIRA }\end{array}$ & $\begin{array}{l}\text { DESENVOLVER OUTRO TIPO DE AGULHA DE } \\
\text { TESTE COM MATERIAL RESISTENTE E } \\
\text { CONCEITO MELHOR PARA ABSOVICAOA E } \\
\text { DISSIPACCAO DA CORRENTE ELETRICA AO } \\
\text { PRODUTO }\end{array}$ \\
\hline & 2 & OBSERVAÇÃO & $\begin{array}{l}\text { 1.CHECAGEM DA PERIOCIDADE DE } \\
\text { VIDA UTL DAS AGULHAS DE TESTE. } \\
\text { 2. CHECAR TPO DE MATERIAL } \\
\text { CONDUTIVO DAS AGULHAS DE } \\
\text { TESTES. } \\
\text { 3. LEVANTAR CUSTOS DE } \\
\text { MANUTENCYAO DOS CABOS DE } \\
\text { ALIMENTACAO }\end{array}$ & $\begin{array}{l}\text { PLANEJAMENTO DA PROPOSTA DE } \\
\text { IMPLANTAÇAKO }\end{array}$ \\
\hline & 3 & ANÁLISE & - & $\begin{array}{l}\text { LEVANTAR CUSTOS DE MANUTENÇÁO DOS } \\
\text { CABOS DE ALIMENTAÇAO }\end{array}$ \\
\hline & 4 & PLANO DE ACĂO & $\begin{array}{l}\text { 1. REDESENVOLVER CABO DE TESTE } \\
\text { ROBUSTO E DE FACIL ACESSO PARA } \\
\text { MANUTENÇAO AUTOMATIIA } \\
\text { 2. DESENVOLVER OUTRO TIPO DE } \\
\text { AGULHA DE TESTE COM MATERIAL } \\
\text { RESISTENTEE CONCEITO MELHOR } \\
\text { PARA ABSOVICAO DA CORRENTE } \\
\text { ELETRICA DO PRODUTO. }\end{array}$ & $\begin{array}{l}\text { IMPLANTACEAOO DA METODOLOGIA DA } \\
\text { FERRAMENTA KAIZEN }\end{array}$ \\
\hline $\mathbf{B}$ & 5 & AÇĀOO & $\begin{array}{l}\text { PONTOS POSITIVOS E NEGATIVOS DO } \\
\text { DESENVOLVMENTO DO NOVO CABO }\end{array}$ & APLICACCÁO DA MELHORIA \\
\hline \multirow{2}{*}{ c } & 6 & VERIFICACĂO & . & $\begin{array}{l}\text { REALIZAR ACOMPANHAMENTO NO PROCESSO, } \\
\text { CHECANDO CADA ETAPA AFETADA. }\end{array}$ \\
\hline & ? & $\begin{array}{l}\text { PROBLEMA FOI } \\
\text { RESOLVIDO }\end{array}$ & * & $\begin{array}{l}\text { ANALISE E IMPLEMENTACĂO DO KAIZEN: BEM } \\
\text { SUCEDIDO. }\end{array}$ \\
\hline \multirow[b]{2}{*}{ E } & 7 & PADRONIZAÇĀO & - & $\begin{array}{l}\text { REALIZAR ACCAO CORRE TIVA E PREVENTIVA. } \\
\text { GERANDO MELHORIA CONTINUA NO } \\
\text { PROCESSO. }\end{array}$ \\
\hline & 8 & CONCLUSAO & - & $\begin{array}{l}\text { REALIZAR TREINAMENTO CONSTANTE, PARA } \\
\text { ATINGIR MELHORIA CONINUAA NO PROCESSO, } \\
\text { ESTABELECENDO A IMPLANTACÁO DO KAIZEN } \\
\text { COM EFICIENCIA E EFICACIA }\end{array}$ \\
\hline
\end{tabular}

Fonte Própria em 10/2020

\section{RESULTADO DA MELHORIA}

Tem-se como ação a implantação no plano de ação 5W2H a confecção de um protótipo de um novo cabo de alimentação com a mecânica interna desenvolvida do zero, conforme Figura 5 
Figura 5 - Cabo de alimentação construído do zero.

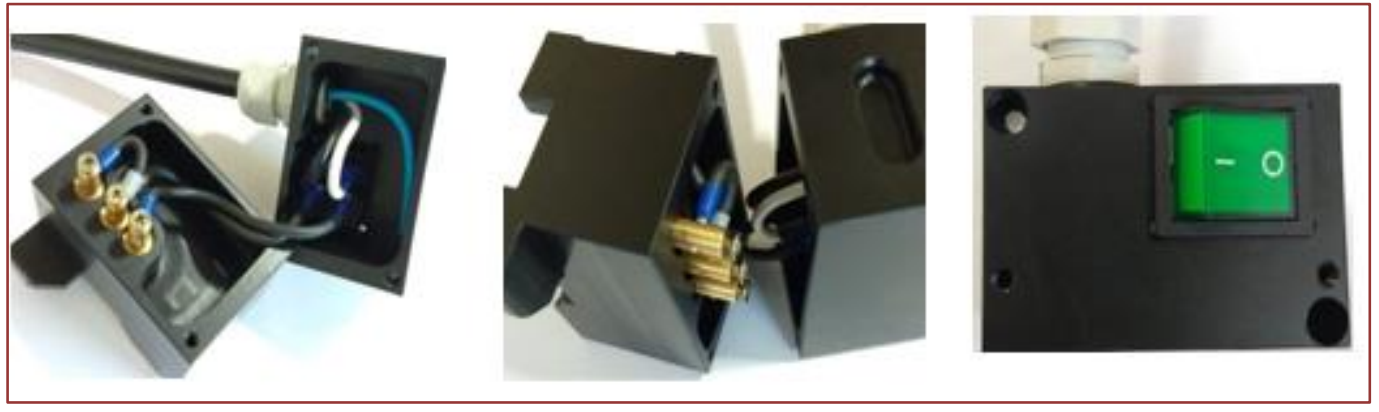

Fonte Própria em 10/2020

2 - Foram desenvolvidas novas pontas de teste com abrangência da área de teste dissipando em mais áreas o calor da corrente elétrica aplicada no produto, levando em conta o menor aquecimento para borneira, conforme Figura 6

Figura 6 - Novas pontas de teste desenvolvidas.

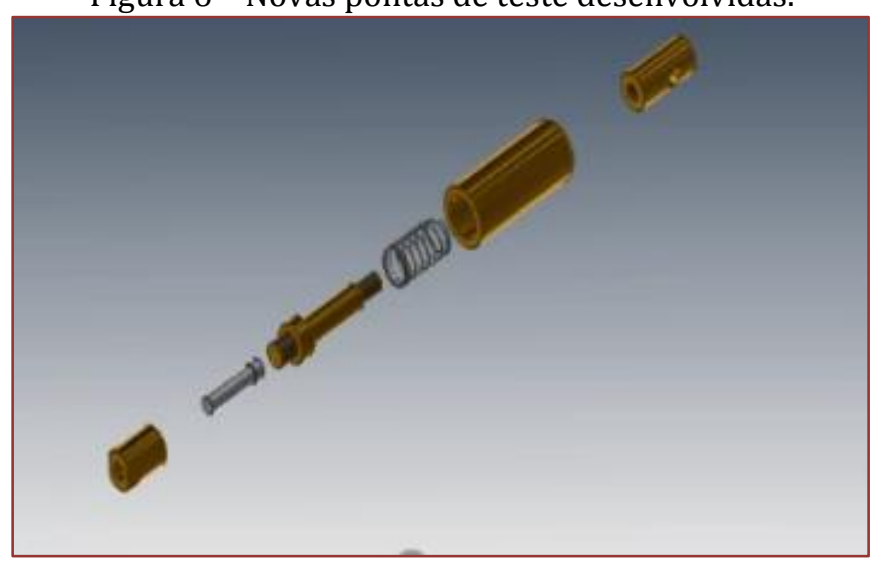

Fonte Própria em 10/20.

3 - Após implantação da melhoria foi feito acompanhamento hora/hora no período de uma semana e pode-se estratificar dados de eficácia na implantação da melhoria. Conforme Figura 7

Figura 7 - Gráfico de acompanhamento da melhoria estratificando os três maiores defeitos diários.

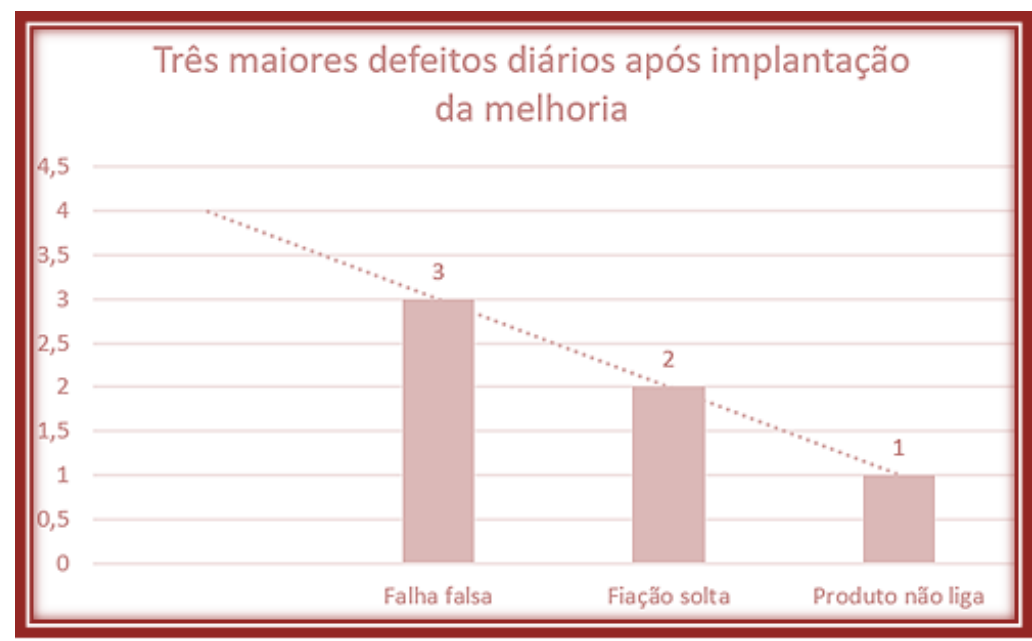

Fonte Própria em 10/20. 
4 - Foram identificado uma otimização no custo de manutenção do dispositivo, levando em conta que, no dispositivo anterior ao da melhoria tinha um custo relativo de $\mathrm{R} \$ 11.000,00$ ao mês por manutenção, e ao cabo atual o custo de manutenção é de R\$2. 400,00 por mês. Conforme Figura 8

Figura 8 - Gráfico de acompanhamento da melhoria estratificando eficácia da melhoria em custo de manutenção.

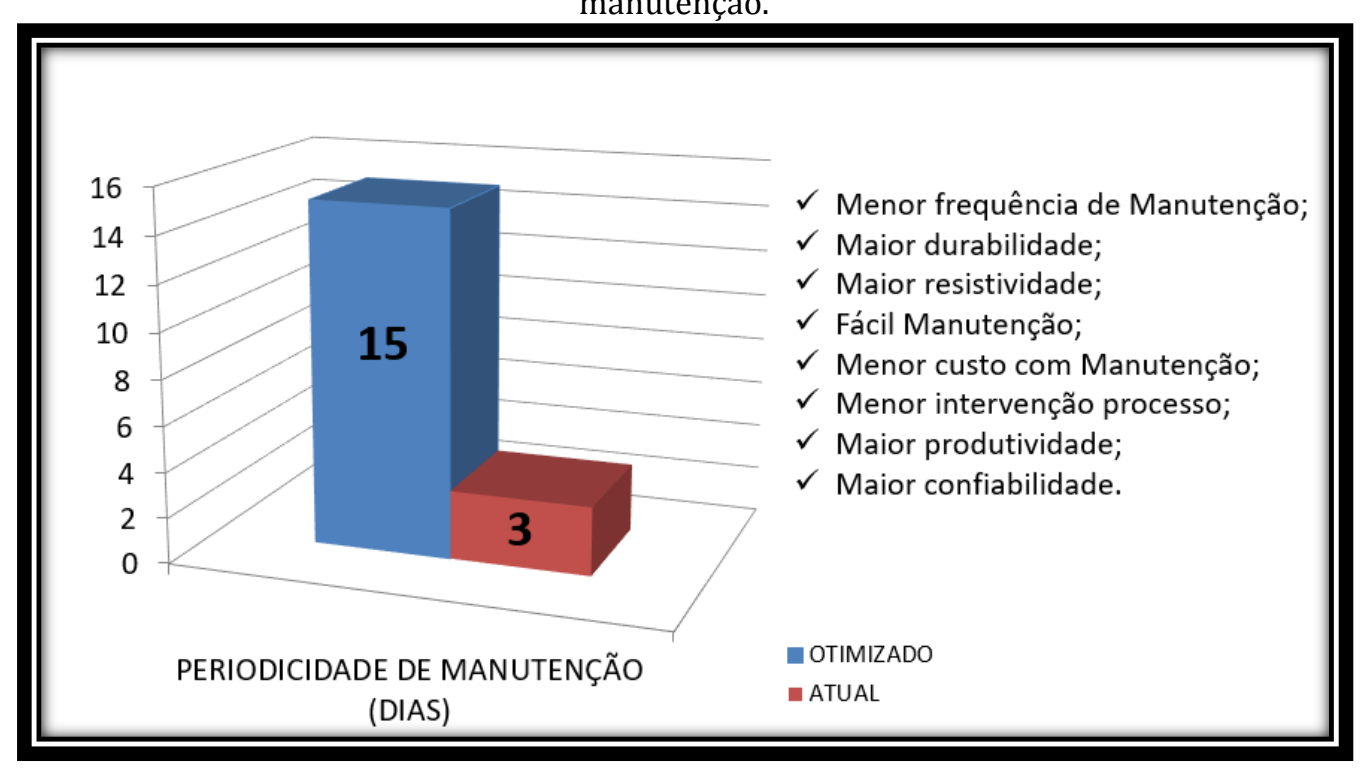

Fonte Própria em 10/20

\section{CONCLUSÕES}

Um dos principais focos de uma empresa é a manutenção e o desenvolvimento de seu portifólio dentro do mercado ao qual está inserida. Diante deste quadro foram utilizadas algumas ferramentas de qualidade dentre elas o Kaizen, 5W2H e PDCA. Avaliando a real necessidade das empresas em buscar a melhoria contínua em seus processos de manufatura, o presente trabalho contribui positivamente para que elas adotem esta metodologia com a finalidade de resolver seus problemas, conforme estudo de caso foi apresentado uma problemática real, trabalhando a aplicabilidade da ferramenta pode-se mensurar os principais pontos a serem corrigidos e após sua implantação acompanhar a eficácia da melhoria através da ferramenta kaizen no qual proporcionou uma visão mais ampla e real de solução de problema seguindo sua metodologia conceitual. Pois, é evidente que a filosofia Kaizen auxilia de forma eficiente a busca do cumprimento de metas, sem necessariamente de altos investimentos. Após a implementação da ferramenta, nota-se a mudança que ela produz sobre os processos de manufatura, evidenciando a importância e eficiência desse modelo para um melhor funcionamento do sistema.

A procura pela melhoria contínua tem como foco promover vantagens competitivas no mercado ao qual a empresa está inserida, promovendo a integração, criatividade, e o bem-estar de seus funcionários e da empresa em geral. Torna-se evidente que o sucesso e o retorno da aplicação do Kaizen se relacionam ao comprometimento, disposição e empenho dos funcionários de os níveis da organização. Funcionários de outros departamentos contribuem com ideias e pontos de vista diferentes, mas em conjunto apresentam soluções para os problemas de forma efetiva.

Pode-se também reportar como ponto positivo do Kaizen a valorização dos funcionários em geral. Considerando que, suas ideias tornam possíveis a implementação da metodologia Kaizen no dia a dia de seus processos operacionais. Sendo assim o senso de valor ao processo é fundamental para o sucesso da organização bem como contribui de forma direta na busca da melhoria contínua dos seus processos. 


\section{REFERÊNCIAS}

[1] AGOSTINETTO, J. S. - Sistematização do processo de desenvolvimento de produtos, melhoria contínua e desempenho: o caso de uma empresa de autopeças. Tese de Mestrado, USP. São Carlos, 2006

[2] AL-SMADI, S. (2009). A estratégia Kaizen e o impulso para a competitividade: desafios e oportunidades. Revisão da Competitividade: Um Jornal Internacional de Negócios, 19 (3), 203-211.

[3] ALUKAL, G. e MANOS, A. (2006). Lean Kaizen: uma abordagem simplificada para melhorias de processo. Milwaukee: Asq Press.

[4] ARAUJO, C. A. C.; RENTES, A. F. A Metodologia Kaizen na Condução de Processos de Mudança em Sistemas de Produção Enxuta. Revista Gestão Industrial. Universidade de São Paulo - Escola de Engenharia de São Carlos - São Paulo. V.02, n.02, p.133-142. 2006.

[5] BASTOS, B.; CHAVES, C. (2012). Aplicação de Lean Manufacturing em uma Linha de Produção de uma Empresa do Setor Automotivo.

[6] BESSANT, J; CAFFYN, S.; GALLAGHER, M. An evolutionary model of continuous improvement behavior. Technovation, vol. 21, pp67-77, 2001

[7] BRIALES, J. A.; FERRAS, F. T. Melhoria contínua através do Kaizen. 2005. Disponível em: http://intranet.viannajr.edu.br/revista/eco/doc/artigo_70002.pdf. Acesso em: 21 de julho, 2017

[8] BRIALES, J. A. Melhoria contínua através do kaizen: Estudo de caso daimlerchrysler do Brasil. Niterói: 2005.

[9] BALLESTERO-ALVAREZ, Maria Esmeralda. Gestão da Qualidade, Produção e Operações. São Paulo: Editora Atlas, 2012

[10] BRIALES, J.; FERRAZ, F. (2005). Melhoria Contínua Através do Kaizen.

[11] OHNO, Taiichi. O Sistema Toyota de Produção. Porto Alegre: Bookman, 1997

[12] TANAKA, W. Y. Fatores Críticos para Implantação de Projetos de Melhoria Contínua Segundo Líderes e Consultores Industriais. 2012.

[13] KISHIDA, Marino. O Círculo Kaizen para a sustentação do Lean. Instituto Lean, 2009.

[14] IMAI, M. Gemba kaizen: estratégias e técnicas do kaizen no piso de fábrica. São Paulo: IMAM, 2004.

[15] IMAI, M. Kaizen: a estratégia para o sucesso competitivo. a estratégia para o sucesso competitivo. A estratégia para o sucesso competitivo. 5. ed. São Paulo: IMAM, 1994.

[16] JUNIOR, Isnard Marshall; et al. Gestão da Qualidade. 10ª ed. Rio de Janeiro: Editora FGV, 2010. 


\section{Capítulo 9}

\section{Análise de capacidade produtiva baseada na simulação de processos}

\section{Reginaldo Otto Nau}

Silvio Luiz dos Santos Alvim

\section{Ottomar Antônio Galizio de Oliveira}

Resumo: 0 objetivo desta pesquisa é analisar, por meio de simulação computacional de processos, a capacidade produtiva de determinada linha de produtos, buscando determinar a produtividade do fluxo de fabricação. A pesquisa foi desenvolvida em uma empresa do ramo de fabricação de geladeiras para o setor automotivo que não adota a filosofia Lean Manufacturing e tem a característica de não possuir produtos padronizados, o que torna o processo produtivo complexo e de baixa eficiência. Como ponto de partida, foi elaborado o VSM (Value Stream Map) para identificar o estado atual e o fluxo do processo. A avaliação inicial demonstrou um OEE (Overall Equipament Effectivences) de $76 \%$ na empresa, considerado baixo se comparado com o padrão mundial, que é de 85\%, gerando a necessidade de turnos adicionais e horas extras para atender à demanda de produção. Os resultados da simulação apontaram a necessidade da adoção de duas estratégias de decisão: alteração nos turnos de trabalho e a aquisição de mais uma máquina puncionadeira. Os resultados também demonstraram que é necessário realizar uma análise mais detalhada dos custos envolvidos no processo. Por fim, foi constatado que a simulação de processos tem a vantagem de permitir simular e comparar diferentes cenários produtivos para a escolha de estratégias de mudança com mais assertividade.

Palavras-chave: Abordagem de simulação. Fluxo de fabricação. Produção enxuta. Processos. VSM. 


\section{INTRODUÇÃO}

Mudanças geradas pela globalização econômica estão ocorrendo a um ritmo acelerado, proporcionando às empresas novas oportunidades e, com isto, também maiores desafios para elas se manterem no mercado (RAMOS et al., 2013). Para acompanhar este ritmo de mudança, as empresas estão adotando diversos métodos e técnicas que podem ser utilizados para melhorar a eficiência e a produtividade de suas linhas de produção e para auxiliar na tomada de decisões, tais como análise estatística, ferramentas enxutas e simulação por computador (ROHANI; ZAHRAEE, 2015). A simulação computacional vem sendo utilizada como ferramenta de auxílio para estudar o comportamento de processos produtivos das indústrias (RYAN; HEAVEY, 2006). Um modelo de simulação procura prever ou reproduzir em um software computacional o comportamento de um sistema, quando submetido a certas condições ou variáveis (CHWIF; MEDINA, 2006) dentro de um ambiente controlado, sem oferecer riscos ou gerar custos financeiros (MONTEVECHI et al., 2007).

Ainda, para sistematizar a melhoria de seus produtos e processos, as organizações vêm adotando também novas abordagens de gestão, tal como a Produção Enxuta (PE) (FAÉ; RIBEIRO, 2005). Princípios, conceitos e práticas da PE têm sido considerados como diferencial para melhoria do desempenho das empresas, conferindo a elas maior destaque (CONGER; MILLER, 2014; KANIGOLLA et al., 2014). Várias práticas da PE aliadas são capazes de otimizar os processos da empresa, como por exemplo, Kanban, 5S e Mapeamento de Fluxo de Valor (ALVES et al., 2014).

Dentro deste contexto, este artigo apresenta um estudo de caso onde o objetivo é fazer uma análise da capacidade produtiva de um processo fabril em uma empresa fabricante de geladeiras para o setor automotivo, utilizando como ferramenta de simulação o software Anylogic. Para apresentar o fluxo produtivo de forma estruturada e visando promover a simples compreensão do fluxo da manufatura associa-se a este estudo a prática de PE denominada Value Stream Mapping - VSM (Mapeamento do Fluxo de Valor).

A relevância deste artigo está em demonstrar a contribuição das ferramentas VSM e simulação utilizadas em conjunto, sendo que, neste estudo de caso, é explanada a existência da evidência empírica para a aplicação de conceitos vigentes na literatura. Além desta seção introdutória, este artigo está estruturado do seguinte modo: a seção 2 relata uma revisão das literaturas mais recentes sobre os principais temas abordados; a seção 3 descreve o modelo conceitual; a seção 4 apresenta o estudo de caso do sistema para análise, o modelo de simulação e os resultados; por fim, a seção 5 traz as considerações finais da pesquisa.

\section{REVISÃO DE LITERATURA}

\subsection{VALUE STREAM MAPPING - VSM}

Por meio da redução dos desperdícios, as empresas vêm conseguindo diminuir seus custos e enxugar seus processos, conceito utilizado pela Produção Enxuta ou Lean Manufacturing (OHNO, 1997). A PE é uma abordagem voltada à eliminação de atividades que não agregam valor sob a perspectiva dos clientes, aos produtos e processos, e seus benefícios têm sido observados em diversos segmentos da indústria (WOMACK; JONES, 2004). Dentre as diversas ferramentas que fazem parte da filosofia da PE está o Value Stream Mapping - VSM (Mapeamento do Fluxo de Valor), proposta por Rother e Shook (2003).

o VSM é uma ferramenta que apresenta de forma estruturada o fluxo produtivo, auxiliando na compreensão de forma simples do fluxo da manufatura, demonstrando também operações que agregam e não agregam valor dentro do processo, desde a matéria prima até o cliente, sendo que o principal objetivo do VSM é identificar diferentes tipos de desperdícios e tentar eliminá-los (ROTHER; SHOOK, 2003; ROHANI; ZAHRAEE, 2015). O fluxo de valor é um processo mais amplo e não se pode considerar apenas os processos individuais, mas deve-se melhorar o processo como um todo, não tornando ótimas apenas algumas de suas partes (VIEIRA et al., 2014).

O VSM é uma ferramenta simples que utiliza um conjunto de ícones padronizados para ser desenhado manualmente com lápis e papel ou com o auxílio de sistemas computacionais (ROTHER; SHOOK, 2003). Para a construção do VSM existem algumas etapas que devem ser seguidas, a saber:

a) 0 primeiro passo é escolher uma família de produtos ou um produto específico como alvo de melhoria; 
b) $\quad 0$ segundo passo é desenhar um mapa do fluxo do processo atual. É importante nesta fase que a equipe responsável por elaborar o mapa tenha um conhecimento detalhado do processo, que seja visitado o chão de fábrica regularmente para captura de informações importantes, que seja analisado o sistema e que sejam verificados seus pontos fracos;

c) 0 próximo passo é desenhar o novo e melhorado processo, ou seja, o mapa do fluxo do processo produtivo do futuro, com as ineficiências do processo identificadas, eliminadas ou reduzidas, onde seja possível analisar atividades que agregam ou não valor ao produto e à família de produtos estudados (ABDULMALEK; RAJGOPAL, 2007; ROHANI; ZAHRAEE, 2015).

O mapa do fluxo do processo futuro tornar-se-á a base para implementação das mudanças necessárias no sistema do processo melhorado, por meio dos desperdícios eliminados ou reduzidos. O VSM cria um embasamento comum do processo produtivo, promovendo decisões mais assertivas para melhorar o fluxo de valor (ABDULMALEK; RAJGOPAL, 2007).

\subsection{ABORDAGEM DE SIMULAÇÃO}

Muitas empresas se baseiam em abordagens tradicionais em seus sistemas de fabricação e relutam em implementar novas ideias ou ferramentas de gestão, por não enxergarem os ganhos que podem ser alcançados com novas mudanças (ABDULMALEK; RAJGOPAL, 2007). No mercado, há inúmeras ferramentas e softwares de modelagem e simulação de processos disponíveis para auxiliar no entendimento de diversos sistemas e processos fabris (KETTINGER et al., 1997; RYAN; HEAVEY, 2006). 0 Quadro 1 demonstra alguns dos principais softwares utilizados para a simulação.

Quadro 2 - Softwares de simulação

\begin{tabular}{|c|c|c|c|}
\hline Software & Abordagem & Autor (es) & Link \\
\hline Anylogic & $\begin{array}{l}\text { Utilizado para a simulação de } \\
\text { sistemas dinâmicos, eventos } \\
\text { discretos e simulação baseada } \\
\text { em agentes. }\end{array}$ & $\begin{array}{l}\text { (GRIGORYEV, 2015; The } \\
\text { Anylogic Company, 2018) }\end{array}$ & www.anylogic.com \\
\hline Anylogistix & $\begin{array}{l}\text { Mais utilizado para simulação } \\
\text { relacionada a problemas de } \\
\text { gerenciamento da cadeia de } \\
\text { suprimentos. }\end{array}$ & (IVANOV, 2017) & www.anylogistix.com \\
\hline Arena $®$ & $\begin{array}{l}\text { Software mais utilizado para } \\
\text { simulação de eventos } \\
\text { discretos. }\end{array}$ & $\begin{array}{l}\text { (KELTON et al., 2010; } \\
\text { TAYFUR et al., 2007) }\end{array}$ & www.arenasimulation.com \\
\hline Simio & $\begin{array}{l}\text { Software de simulação 2D e } \\
\text { 3D. }\end{array}$ & (KELTON et al., 2010) & www.simio.com \\
\hline Promodel & $\begin{array}{l}\text { Software de simulação que } \\
\text { possui abordagem gráfica } \\
\text { intuitiva e que dispensa a } \\
\text { necessidade de programação. }\end{array}$ & (SHARMA, 2018) & www.promodel.com \\
\hline
\end{tabular}

Fonte: Elaborado pelos autores (2020).

A simulação procura repetir em um computador a modelagem de um sistema real, reproduzindo seu comportamento quando submetido às mesmas condições da realidade em seu entorno (CHWIF; MEDINA, 2010). O propósito da simulação é entender o comportamento do sistema real quando submetido a diversas condições, sem riscos ou envolvimento de custos (MONTEVECHI et al., 2007), e também avaliar estratégicas envolvidas, ajudando as empresas a resolver problemas do mundo real (GRIGORYEV, 2015).

Cada software de simulação possui características específicas e, dependendo das especificidades de cada um, pode-se construir modelos de simulação baseados em eventos discretos, em sistemas dinâmicos ou em agentes que podem ser aplicados nas mais diversas áreas, tais como: cadeia de suprimentos, logística, produção, transporte, militar e saúde (GRIGORVEY, 2015; IVANOV, 2017). 
Diferentes autores incluem em suas pesquisas as vantagens oferecidas pelo uso da simulação, o que contribui para o aumento crescente da utilização dessas ferramentas nos mais variados setores do mercado (CARSON et al., 1996; MONTEVECHI et al., 2007; IVANOV, 2017; BURCH; SMITH, 2017). Dentre as vantagens da simulação, destacam-se:

a) Melhor compreensão de um sistema real sem a intervenção no sistema real;

b) Ganho de tempo com o processo de simulação;

c) Estudo de sistemas que não existem ou de situações improváveis;

d) Análise de cenários alternativos;

e) Visualização do resultado a cada variável envolvido.

A simulação computacional, no âmbito dos processos produtivos, vem sendo utilizada com maior frequência por oferecer inúmeras vantagens, sendo uma delas a possibilidade de antever resultados de processos sem que haja uma intervenção física no ambiente produtivo (GERÔNIMO et al., 2018). A simulação também possui algumas desvantagens, como: o processo requerer um treinamento especial do software (o que pode demandar certo tempo); a análise de modelos requer conhecimento profundo do sistema envolvido; e a simulação de resultados pode ser de difícil compreensão (CARSON et al., 1996; TORGA, 2007). Vale ressaltar que os modelos de simulação servem apenas para análise de comportamento de um sistema sob a variação de determinadas condições (MONTEVECHI et al., 2007).

\section{METODOLOGIA DE PESQUISA E MÉTODO DE TRABALHO}

No intuito de identificar as atividades que não agregam valor ao processo produtivo, ferramentas de simulação vêm sendo utilizadas para contrastar diferentes cenários e entender o impacto da PE antes e depois de sua implementação. Tais mudanças, quando aplicadas diretamente no chão de fábrica, podem implicar em custos elevados e em um tempo de mudança considerável, caso sejam feitas de forma ineficiente, por isso, a principal vantagem de realizar simulações em um ambiente controlado é ver imediatamente os efeitos de tais mudanças.

De acordo ao exposto, a metodologia adotada para a pesquisa é a modelagem e simulação, definida como a abordagem centrada na construção de um modelo quantitativo para descrever o funcionamento de um sistema ou parte desse sistema ou ainda simular a operação, (CAUCHIK, 2017). A aplicação da metodologia é suportada por um estudo de caso com dados reais, combinado à técnica de Mapa do Fluxo de Valor, em uma proposta integrada, visando atender o objetivo da pesquisa: análise da capacidade produtiva de um processo fabril em uma empresa fabricante de geladeiras para o setor automotivo.

De forma genérica, nos estudos de cenários produtivos se tem, nas várias fases dos processos, certas variáveis que diferem em algum aspecto produtivo, influenciam no tempo de produção e devem ser consideradas como aspectos importantes, a saber: volume, variedade, variação e grau de visibilidade da produção do ponto de vista do cliente (SLACK et al., 2009). Um exemplo desse cenário genérico é apresentado na Figura 1.

Figura 1 - Exemplo de um cenário produtivo

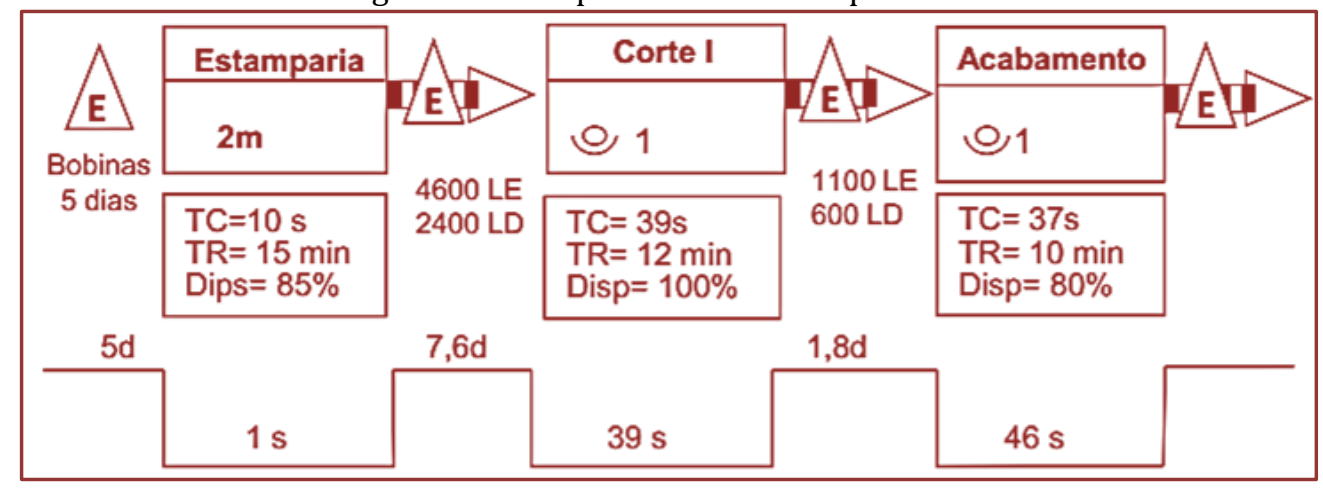

Fonte: Elaborado pelos autores (2020). 
No estudo de caso deste artigo, o cenário a ser investigado é baseado no efeito da capacidade de produção versus o tempo disponível. Os dois indicadores principais serão o tempo médio por produto e o volume de produção. A simulação do desempenho dos diferentes cenários deverá fornecer resultados para o apoio ao processo de tomada decisão mais efetivo e para uma melhor compreensão das diferentes estratégias de produção que podem ser seguidas.

\subsection{ESTUDO DE CASO}

A empresa selecionada para o estudo de caso deste artigo é fabricante de geladeiras para todos os tipos de veículos automotores, está localizada no estado de Santa Catarina e tem a característica de não utilizar nenhuma ferramenta de Lean Manufacturing. A empresa é uma fábrica de geladeiras de 12 e 24 volts para aplicações automotivas e desenvolve também equipamentos para conservação de refrigerados em transporte, conservadoras de vacina para linha veterinária destinadas ao transporte e conservação de medicamentos e vacinas. Suas principais linhas de produtos são linha ônibus, linha caminhão, linha hospitalar, linha cafeteria, linha motor e linha compressor. A empresa tem a característica de não possuir produtos padronizados, o que torna seu processo complicado e demanda certo tempo e custo de produção. No entanto, este é um diferencial competitivo no mercado atualmente, pois seus produtos são produzidos de acordo com o pedido do cliente, ou seja, sob encomenda.

Nas primeiras visitas ao chão de fábrica, foi realizada uma análise geral do processo para conhecer todas as etapas de fabricação, desde a chegada de matéria prima até a entrega do produto à expedição. No Quadro 2 são demonstradas as linhas de produtos e os passos do processo de fabricação.

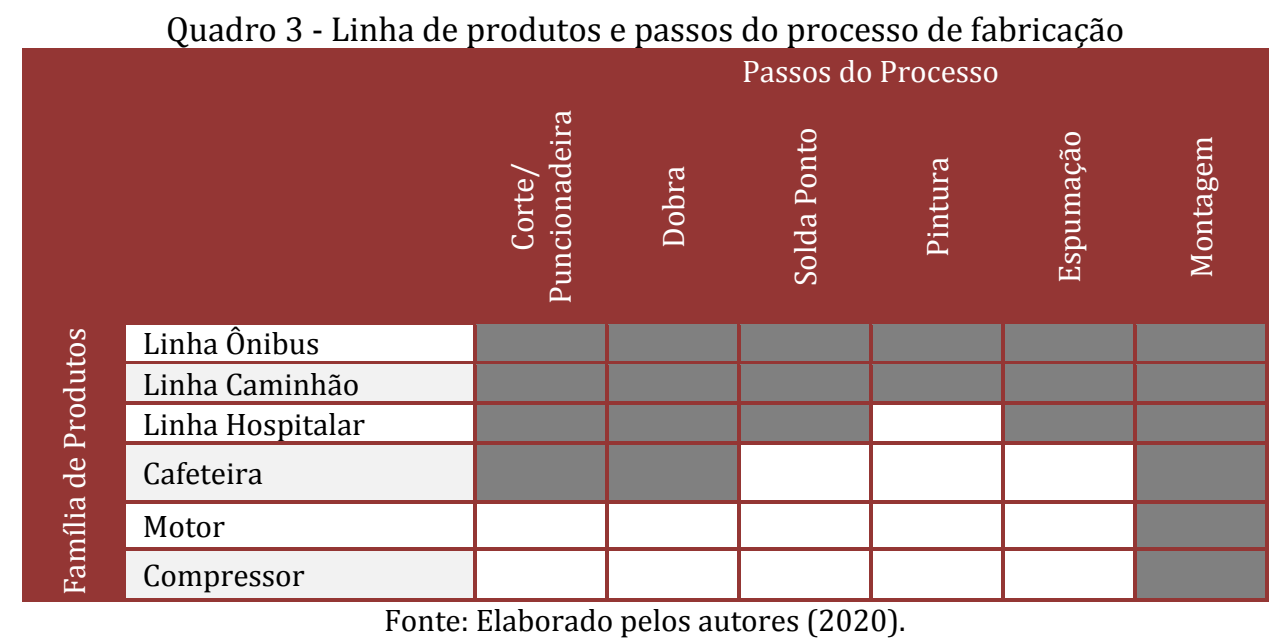

A produção é programada sob encomenda e voltada ao atendimento das necessidades específicas de cada cliente. Atualmente, a empresa tem uma demanda de 84 geladeiras por dia, dentre as linhas ônibus, caminhão e hospitalar, foco deste estudo, por serem estes processos os mais similares dentro da cadeia produtiva interna. Devido ao fato de a empresa possuir característica de produção sob encomenda, exigese que a montagem do plano de produção tenha alta flexibilidade, o que gera um custo elevado, por haver certa ociosidade quando a demanda não ocorre. Esta característica faz com que o OEE - Overall Equipament Effectivences (Eficiência Geral de Equipamento) calculado seja de aproximadamente de $76 \%$. Na Figura 2 podemos visualizar o mapa do fluxo de valor (VSM) da situação atual da empresa, onde sua capacidade é para 65 geladeiras por dia no primeiro estágio do processamento, onde temos também o Tempo de Ciclo (TC) e o Tempo de Troca (TC) para cada estágio do processo. 
Figura 2 - Mapa do fluxo de valor (atual)

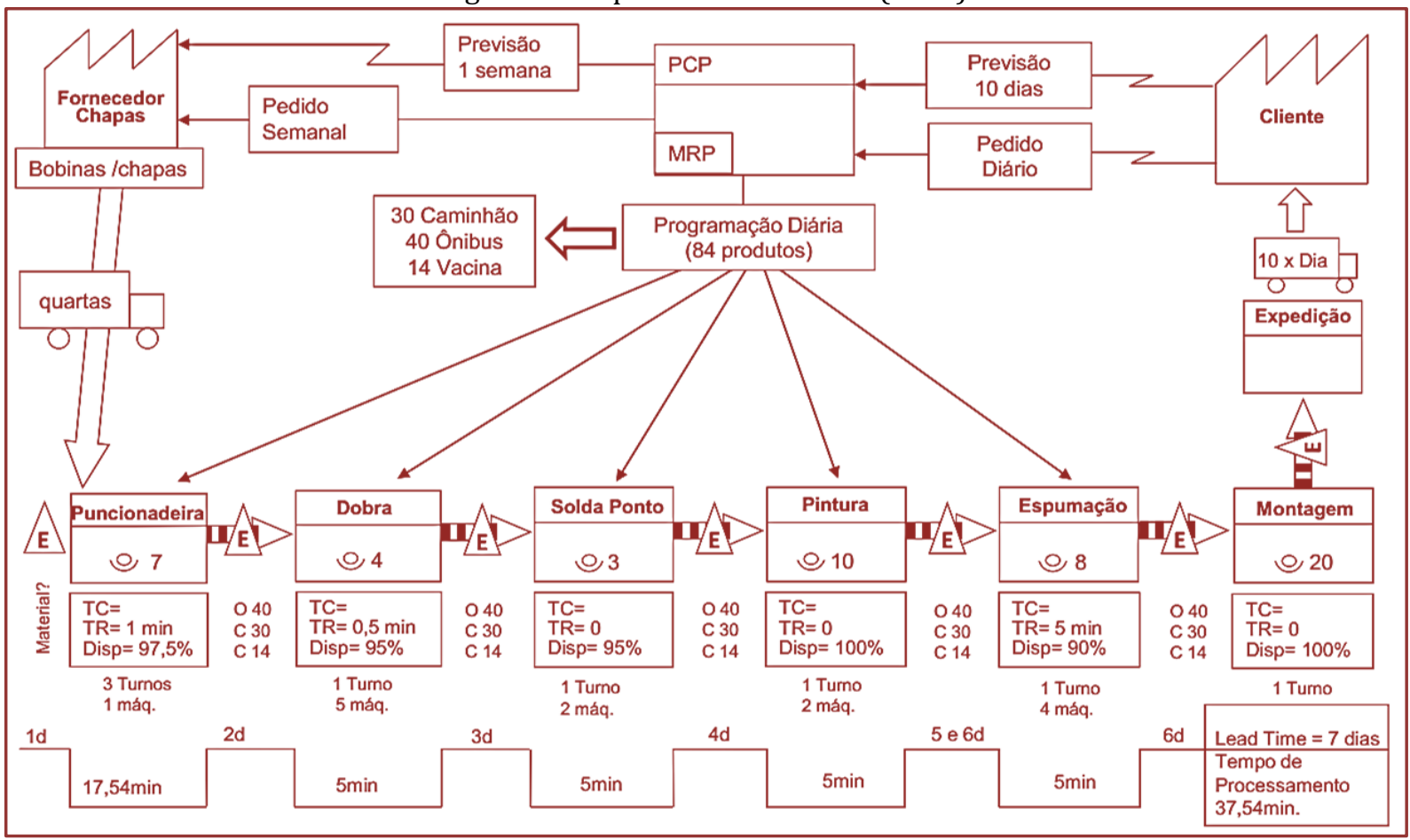

Fonte: Elaborado pelos autores (2020).

A análise do VSM demonstra que o Lead Time de produção é de 7 dias e o tempo de processamento total é 37,54 minutos. 0 tempo de processamento do primeiro estágio na máquina Puncionadeira é o gargalo, pois não há a capacidade para tal demanda solicitada de 84 geladeiras por dia, o que causa atraso nas entregas, gerando hora extra e ociosidade nos processos subsequentes, onde o trabalho é de apenas 1 turno, em contrapartida ao primeiro estágio, em que o trabalho é de 3 turnos.

O fluxo de produção no primeiro estágio tem também as seguintes características:

a) Tempo disponível: 24 horas;

b) Paradas programadas nos 3 turnos: 3 horas;

c) Paradas não programadas (exceto setup): 2 horas somente no segundo turno;

d) Paradas por setup: 30 minutos por turno.

O primeiro passo para o presente estudo foi calcular o Takt Time (ritmo de produção) com base na relação entre o tempo disponível e a demanda. Para este caso, o cálculo demonstra que são necessários 17,54 minutos para produzir cada geladeira, com base na capacidade de produção de 65 geladeiras por dia e no tempo disponível de 19 horas.

Outra característica importante detectada na análise do processo é que $10 \%$ dos produtos fabricados no primeiro estágio passam por um retrabalho, devido a falhas no processo. Este tempo de retrabalho varia entre 10 e 12 minutos.

\section{RESULTADO E ANÁLISE}

Levando em consideração as diferentes opções dentre os softwares estudados, no presente estudo optouse pelo uso do software Anylogic para simulação do estudo de caso. 0 Anylogic é um dos pacotes comerciais desenvolvidos pela empresa russa The Anylogic Company e possui um ambiente de programação e simulação que permite a modelagem de sistemas híbridos (EMRICH et al., 2007).

Para a simulação foram utilizadas diversas variáveis (tempo início, tempo final normal e tempo final com retrabalho) para armazenar o resultado da simulação e verificar quanto tempo um produto permanece no sistema. Por meio da utilização da ferramenta Statistics do software para calcular as informações 
estatísticas do processo, chegou-se à indicação de que ele possui a característica de um processo discreto, onde o tempo estudado ocorre em pontos isolados do sistema.

O gargalo de produção é o primeiro estágio do processo na máquina chamada Puncionadeira. Esta máquina produz 1 geladeira a cada 17,54 minutos, conforme estudo do VSM inicial, tendo ainda, em média, $10 \%$ desta produção um retrabalho que dura 10 a 12 minutos

No software Anylogic foram elaborados três cenários para estudo, levando em consideração a capacidade atual no cenário 1 , a necessidade no cenário 2 e a produção ideal com a determinada capacidade requerida no cenário 3, como demonstrado na Tabela 1.

Tabela 2 - Cenários simulados

\begin{tabular}{|l|c|c|c|}
\multicolumn{1}{|c|}{ Contexto de Produção } & $\begin{array}{c}\text { Cenário 1 } \\
\text { (Capacidade) }\end{array}$ & $\begin{array}{c}\text { Cenário 2 } \\
\text { (Necessidade) }\end{array}$ & $\begin{array}{c}\text { Cenário 3 } \\
\text { (Ideal) }\end{array}$ \\
\hline Produção por dia & 65 & 84 & 84 \\
\hline Tempo total no processo normal por dia (horas) & 18,34 & 23,70 & 18,10 \\
\hline Tempo total no processo com retrabalho por dia (horas) & 18,44 & 23,75 & 18,16 \\
\hline Tempo médio de processamento por geladeira (min.) & 16,93 & 16,93 & 12,93 \\
\hline Tempo médio de retrabalho (min.) & 10,22 & 11,56 & 11,55 \\
\hline
\end{tabular}

Fonte: Elaborado pelos autores por meio do software Anylogic (2020).

Para esta análise, a simulação abrangeu 10 dias de produção para cada cenário nas 3 diferentes configurações, levando em consideração a demanda e o tempo total de processamento com retrabalho. No primeiro cenário analisado, foi levada em consideração a produção de 65 geladeiras por dia em uma variação uniforme no tempo de processamento de 16 a 18 minutos. Também a uma taxa de $10 \%$ de retrabalho com variação uniforme do tempo de 10 a 12 minutos.

É interessante analisar o resultado no primeiro cenário, quando o tempo em que os 65 produtos permanecem no sistema foi de, em média, 18,44 horas com retrabalho durante o dia, como já esperado, o que está dentro da capacidade da fábrica de 19 horas. 0 tempo médio de processamento por geladeira neste cenário ficou em 16,93 minutos, um pouco abaixo do Takt Time calculado, de 17,54 minutos.

Já no cenário 2, em que foi simulada a produção de 84 geladeiras por dia, obteve-se como resultado 23,75 horas de tempo necessário de produção, apesar de que o tempo médio de processamento por geladeira ficou também em torno de 16,93 min. Esta simulação confirma que a fábrica não tem capacidade diária para tal demanda, com base no tempo disponível, e levando em consideração as paradas programadas, não programadas e o setup de máquina.

O cenário 3 simulado é o ideal, no qual foi encontrado o tempo ideal para o processamento das 84 geladeiras por dia. Nesta simulação foi encontrado um tempo médio de 12,93 minutos por geladeira, o que ocuparia a capacidade da fábrica em 18,16 hora por dia. Um comparativo dos 3 cenários, levando em consideração o tempo total necessário por dia para processamento das geladeiras, pode ser visualizado no Gráfico 1.

Gráfico 1 - Comparativo do tempo total requerido dia para processamento

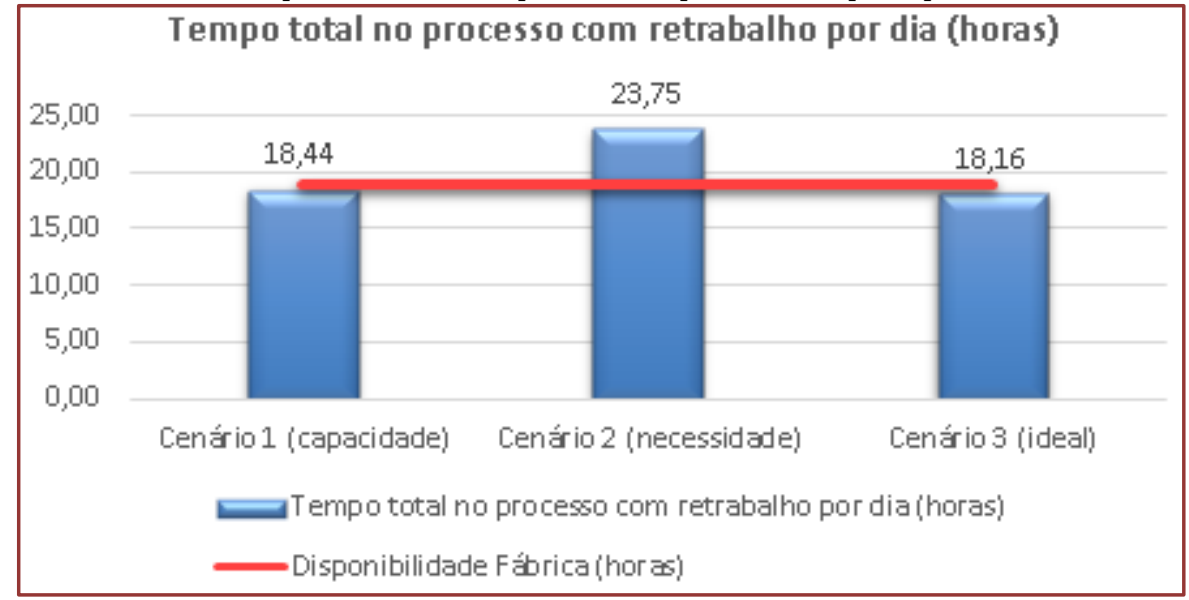


Destaca-se a característica do tempo de processamento por geladeira neste comparativo, onde o tempo encontrado no cenário 3 é menor do que no cenário 1. O Takt Time calculado para o cenário 3 é 13,57 minutos por geladeira.

\section{CONSIDERAÇÕES FINAIS}

O objetivo principal deste trabalho foi realizar um estudo de caso para investigar a capacidade produtiva de determinada linha de produtos em uma empresa de fabricação de geladeiras. 0 resultado demonstra que a simulação computacional, combinada com outras ferramentas de análise de processos, como o VSM, pode ser utilizada para observar a capacidade produtiva, avaliando diferentes cenários como experiência.

Os resultados obtidos nos cenários simulados na Tabela 1 podem levar à decisão de tomar a estratégia do segundo ou terceiro cenário. No segundo cenário, exige-se um tempo de produção diário de quase 24 horas ininterruptas. A diferença para o primeiro cenário é de 5,31 horas diárias, totalizando quase 27 horas semanais a mais de trabalho. Uma recomendação seria adotar turnos de 12x36 horas, pois atualmente a empresa não trabalha nos finais de semana, compensando, assim, as horas faltantes para que a produção de 420 geladeiras por semana fosse atingida. Esta estratégia poderia ser tomada para um resultado mais rápido na produção, mas implicaria em um estudo maior dos custos envolvidos nesta decisão para avaliar sua viabilidade.

Já no cenário 3, as 19 horas disponíveis de trabalho exigiram um tempo médio de processamento de 12,93 minutos por geladeira, ante os 16,93 minutos do cenário 1 e 2, ou seja, cerca de 3 minutos por geladeira, o que deve ser reduzido para que o objetivo de 84 geladeiras por dia, com a mesma máquina, seja atingido. Recomenda-se investigar o volume, a variedade e a variabilidade dos pedidos, além das variáveis da empresa envolvidas em toda a cadeia produtiva destes produtos, para verificar se o processo produtivo pode ser melhorado, principalmente no ponto onde é o gargalo de produção, para se chegar a esta redução de tempo por produto.

Outra estratégia que poderia ser seguida analisando todos os cenários é a compra de mais uma máquina Puncionadeira, similar à atual, que proporcionaria ganhos de produtividade e maior flexibilidade de produção, garantindo a entrega dos pedidos aos clientes, não comprometendo a reputação da empresa e evitando pesadas multas contratuais, algo que é comum neste segmento. É importante ressaltar que os custos de compra e os ganhos envolvidos na produção devem ser avaliados com uma criticidade maior, já que uma nova máquina custaria em torno de $\mathrm{R} \$ 1.000 .000,00$.

Para dar continuidade a este estudo é recomendado realizar uma análise mais detalhada, incluindo os custos envolvidos no processo, bem como simular outros cenários para investigar a influência de todas as variáveis envolvidas e onde estas poderão auxiliar na tomada de novas estratégias para o processo.

Por fim, é possível dizer que as informações fornecidas pela simulação de processo em softwares específicos, como o Anylogic, podem permitir a comparação do desempenho de diferentes cenários produtivos de uma empresa em relação ao sistema existente, auxiliando na aplicação de estratégias de mudança com mais assertividade.

\section{REFERÊNCIAS}

[1] ABDULMALEK, F. A., \& RAJGOPAL, J. (2007). Analyzing the benefits of lean manufacturing and value stream mapping via simulation: A process sector case study. International Journal of Production Economics, 107(1), 223-236.

[2] AlVES, A. C., KAHLEN, F. J., FlumERfELT, S., \& MANALANG, A. B. S. (2014). The lean production multidisciplinary: from operations to education. Proceedings of the International Conference on Production Research/Americas, Lima, Peru, 7.

[3] BURCH V. R. F., \& SMITH, B. (2017). Using simulation to teach lean methodologies and the benefits for Millennials. Total Quality Management \& Business Excellence, 30(3-4), 320-334.

[4] CARSON, J. S., BANKS, J., \& NELSON, B. L. (1996). Discrete-event system simulation. Upper Saddle River: Prentice- Hall.

[5] CAUCHICK-MIGUEL...[et.al], ( 2017), Elaboração de artigos acadêmicos: estrutura, métodos e técnicas -1.ed.Rio de Janeiro:Elsevier. 
[6] CHWIF, L., \& MEDINA, A. C. (2010). Modelagem e simulação de eventos discretos: teoria e aplicações (2a ed.). São Paulo: Editora dos Autores.

[7] CONGER, S., \& MILLER, R. (2014). Problem-based learning applied to student consulting in a lean production course. Journal of Higher Education Theory and Practice, 14(1), 81.

[8] EMRICH, S., SUSLOV, S., \& JUDEX, F. (2007). Fully Agent Based. Modellings of Epidemic Spread Using Anylogic. Proceedings of the EUROSIM Congress on Modelling and Simulation, Ljubljana, Slovenia, 6.

[9] FAÉ, C. S., \& RIBEIRO, J. L. D. (2005). Um retrato da engenharia de produção no Brasil. Revista Gestão Industrial, 1(3), 315-316.

[10] GERÔNIMO, M. S. et al. (2018). O uso da simulação computacional para melhoria nos processos produtivos: uma aplicação da teoria de filas com o uso de simuladores. Exacta, 16(3), 167-180.

[11] GRIGORYEV, I. (2015). AnyLogic 7 in three days: a quick course in simulation modeling. CreateSpace Independent Publishing Platform.

[12] IVANOV, D. (2017). Supply chain simulation and optimization with anyLogistix: teaching notes. Berlin: Berlin School of Economics and Law.

[13] KANIGOLLA, D., CUDNEY, E. \& CORNS, S. (2014). Enhancing engineering education using project-based learning for lean and six sigma. International Journal of Lean Six Sigma, 5(1), 45-61.

[14] KELTON, D., SADOWSKI, D. A., \& SADOWSKI, R. P. (2010). Simulation with ARENA. New York: McGraw-Hill.

[15] KETTINGER, W. J., TENG, J. T., \& GUHA, S. (1997). Business process change: a study of methodologies, techniques, and tools. MIS Quarterly, 21(1), 55-80.

[16] MESQUITA, D. C. V., MESQUITA, W. G., \& SOUZA, L. R. S. (2014). Implementação do mapeamento de fluxo de valor de uma montadora de veículos, denominada empresa Beta. Exacta, 12(2), 197-208.

[17] MONTEVECHI, J. A. B., de PINHO, A. F., LEAL, F., \& MARINS, F. A. S. (2007). Application of design of experiments on the simulation of a process in an automotive industry. Proceedings of the 39th Conference on Winter Simulation: 40 years! The best is yet to come, Washington, DC, USA, 39.

[18] OHNO, T. (1997). O sistema Toyota de produção. Porto Alegre: Bookman.

[19] RAMOS, A. G., LOPES, M. P., \& AVILA, P. S. (2013). Development of a platform for lean manufacturing simulation games. IEEE Revista Iberoamericana de Tecnologias del Aprendizaje, 8(4), 184-190.

[20] ROHANI, J. M., \& ZAHRAEE, S. M. (2015). Production line analysis via value stream mapping: a lean manufacturing process of color industry. Procedia Manufacturing, 2, 6-10.

[21] ROTHER, M., \& SHOOK, J. (2003). Learning to see: value stream mapping to create value and eliminate muda (3a ed.). Cambridge. The Lean Enterprise Institute.

[22] RYAN, J., \& HEAVEY, C. (2006). Process modeling for simulation. Computers in Industry, 57(5), 437-450.

[23] SHARMA, P. (2018). Implementation of simulation for the analysis of available layout alternatives of manufacturing plant. International Journal of Advanced Operations Management, 10(1)19-31.

[24] SLACK, N., CHAMBERS S., \& JOHNSTON, R. (2009). Administração da produção (3a ed.). São Paulo: Atlas.

[25] TAYFUR, A., \& MELAMED, B. (2007). Simulation modeling and analysis with ARENA. New York: Elsevier.

[26] THE ANYLOGIC COMPANY. (2018). AnyLogic help. Recuperado em 20 novembro, 2018, de http://www.anylogic.com/anylogic/help/

[27] TORGA, B. L. M. (2007). Modelagem, simulação e otimização em sistemas puxados de manufatura. Dissertação de Mestrado, Universidade Federal de Itajubá, Itajubá, MG, Brasil.

[28] WOMACK, J. P., JONES, D. T., \& ROOS, D. (1990). Machine that changed the world. New York: Simon and Schuster.

[29] WOMACK, J. P., \& JONES, D. T. (2004). A mentalidade enxuta nas empresas (6a ed.). Rio de Janeiro: Campus.

[30] WOMACK, J. P., \& JONES, D. T. (2010). Lean thinking: banish waste and create wealth in your corporation. New York: Simon and Schuster. 


\section{Capítulo 10}

\section{Análise da capacidade em uma empresa no setor de confecções: Um estudo de caso acerca de fatores que causam perdas produtivas}

Rafael de Azevedo Palhares

Jedson Oriel de Melo Nogueira

Denyeivisson da Silva Freire

Joel da Costa Câmara Neto Segundo

Marcos Antônio Araújo da Costa

Resumo: 0 presente artigo busca realizar um estudo de caso no setor de moda íntima, propondo uma comparação entre o comportamento da capacidade efetiva e da capacidade realizada de produção. 0 conhecimento acerca da capacidade produtiva de uma empresa é algo importante, pois significa conhecer o processo de operações como também ter a percepção de que os retrabalhos e/ou refugos devem ser calculados, pois são fatores que consomem também recursos e tempo da capacidade produtiva. A capacidade pode ser dividida em quatro categorias: capacidade instalada, capacidade disponível, capacidade efetiva e capacidade realizada. Nesse contexto, o planejamento e controle da capacidade auxiliam as decisões estratégicas em longo prazo, pois levam em consideração aspectos operacionais, financeiros, entre outros pontos quantificáveis, com extrema relevância quando se trata de grandes indústrias, devendo considerar também o impacto social e relacionamento com concorrentes e governo. A gestão da capacidade efetiva e da capacidade realizada de uma empresa requer considerar horas por paradas planejadas e horas por paradas não planejadas, respectivamente. Para isso, foram analisadas tendências de acordo com o aglutinamento de dados de quatro células observadas durante cinco dias durante a jornada de trabalho. Após análise foram observadas várias causas de impacto à produção, tais como paradas para amamentação, falta de treinamento, paradas por setup, etc. Dessa forma, o trabalho teve o intuito de investigar outras causas que paravam a produção além da falta de desempenho dos funcionários, causando diferenças entre a capacidade efetiva e a capacidade realizada.

Palavras chave: Capacidade de Produção, Tendência, Célula. 


\section{INTRODUÇÃO}

Conhecer e elaborar a capacidade produtiva de uma organização são fatores de importância para um bom planejamento estratégico e programação da produção de uma empresa. Dessa forma um bom planejamento da gestão da capacidade é indispensável para que uma organização consiga estabelecer metas e manter seu controle produtivo.

Estabelecendo um cenário de uma demanda que se apresente inferior que a capacidade disponível pela empresa, pode-se perceber uma ociosidade entre os recursos disponíveis como instalações, máquinas e equipes de trabalho. Em contra-partida, ao surgir uma demanda significativamente maior que a capacidade produtiva oferecida, é coerente afirmar que há surgimento de filas. (ANTUNES, 2008).

De acordo com o SEBRAE (Serviço Brasileiro de Apoio ás Micro e Pequenas Empresas), empresas caracterizadas no ramo de confecções estabelecem uma produção anual de $R \$ 1,6$ bilhão de peças, demostrando um mercado que possui uma movimentação financeira de 3,6 bilhões de peças (NEVES; BRIGATTO; PASCHOARELLI, 2015).

O IEMI (Instituto de Estudos e Marketing Industrial) estimou no ano de 2014 um crescimento de 33\% no setor de moda íntima, prevendo um crescimento de ate 7,9\% do mesmo ano. (NEVES; BRIGATTO; PASCHOARELLI, 2015).

Destacando o estudo realizado no setor de moda íntima, percebe-se a importância de sua gestão da capacidade produtiva, uma vez que com uma boa gestão da capacidade produtiva, é possível planejar os recursos disponíveis de acordo com as solicitações de pedidos ofertados para a empresa, de modo a atendê-las dentro de suas limitações de chão de fábrica, maquinários e colaboradores disponíveis.

A problemática é desenvolvida devido a empresa apresentar índices de deficiência produtiva ao longo dos últimos meses, não conseguindo assim, suprir com a necessidade ofertadas por clientes que compram seus produtos no atacado.

Neste contexto, o objetivo da pesquisa consiste em auxiliar a empresa de modo a estabelecer uma compreensão sobre as principais causas do problema, com o objetivo de manter a produção dentro dos padrões normais de acordo com as demandas do mercado. Além disso, ofertar uma análise comparativa entre a capacidade efetiva demonstrada pela empresa e a capacidade realizada no seu dia a dia apontará possíveis problemas que causam a diferença potencial entre as duas capacidades.

Em análise do potencial de crescimento do setor de moda íntima nos últimos anos, a relevância da proposta apresentada pelo presente artigo é aplicada a gestão da capacidade já implementada em um setor de moda íntima localizado no interior do estado do Ceará.

\section{REFERENCIAL TEÓRICO}

\subsection{CAPACIDADE PRODUTIVA}

Analisando a capacidade de forma isolada, pode associa-la a um conceito de competência, volume máximo e quantidade máxima de algum bem ou serviço. Entretanto ao ser conceituado a capacidade de produção, deve se levar em consideração seu dinamismo em determinado volume em um determinado tempo. (PEINADO; GRAEML, 2007).

Para Motta e Gomes, (2016), apud Moreira (2008), a capacidade produtiva é caracterizada como a quantidade máxima de produtos e serviços que conseguem ser manufaturados em um intervalo de tempo pré estabelecido.

Antunes (2008) destaca três possíveis situações relacionadas a capacidade produtiva. A primeira corresponde a quando a capacidade produtiva é superior à demanda (recurso com capacidade), a segunda acontece quando a capacidade produtiva é igual à demanda (recurso com restrição de capacidade) e a terceira situação acontece quando a capacidade produtiva é menor que a demanda (recurso sem capacidade).

Martins Junior (2009) analisa a primeira situação como favorável à empresa, pois a empresa se mantém preparada em relação a imporevistos. Em relação a segunda situação, é considerada razoável, pois em caso de imprevistos a empresa pode não ter como suprir a demanda de produtos e por fim, a terceira situação é considerada negativa para a empresa, pois a mesma não está ganhando clientes por não ter capacidade de suprir a demana. 
Staudt (2011) afirma que conhcecer a capacidade atual da empresa requer conhecer o processo de operações como também ter a percepção de que os retrabalhos e/ou refugos devem ser calculados, pois são fatores que consomem também recursos e tempo da capacidade produtiva. 0 autor propõe que a capacidade pode ser dividida em quatro categorias: capacidade instalada, capacidade disponível, capacidade efetiva e capacidade realizada.

\subsection{TIPOS DE CAPACIDADE PRODUTIVA}

Pode-se atribuir a Capacidade Produtiva, 4 formas de capacidade que, são classificadas de acordo com seu índice e grau. (MOTTA; GOMES, 2016).

O Quadro 1 apresenta os tipos de capacidade produtiva existentes e suas principais características.

Quadro 1 - Tipos de Capacidade

\begin{tabular}{|l|l|}
\multicolumn{1}{|c|}{ TIPO } & $\begin{array}{l}\text { CARACTERÍSTICAS } \\
\text { Capacidade } \\
\text { Instalada }\end{array}$ \\
\hline $\begin{array}{l}\text { Capacidade } \\
\text { que a produção trabalhe 24 horas por dia durante um mes inteiro. }\end{array}$ \\
\hline Capacidade & $\begin{array}{l}\text { Capacidade Máxima de produção de um sistema, dentro de uma jornada de trabalho } \\
\text { fornecida por seus colaboradores. Neste modelo as perdas também são levadas em } \\
\text { consideração. }\end{array}$ \\
\hline $\begin{array}{l}\text { Capacidade } \\
\text { Realizada }\end{array}$ & $\begin{array}{l}\text { Capacidade Calculada em uma jornada de trabalho com a diminuição de } \\
\text { suas perdas ja planejadas previamente. }\end{array}$ \\
\hline
\end{tabular}
Fonte: Adaptado de Motta e Gomes(2016)

Staudt (2011) discerne que a capacidade efetiva é representada pela capacidade disponível subtraída das perdas planejadas como: manutenção preventiva e paradas de setup. A subtração da carga horária de trabalho $(\mathrm{CH})$ pelo tempo das paradas planejadas resulta nas horas disponíveis para produção (HD) como segue adiante:

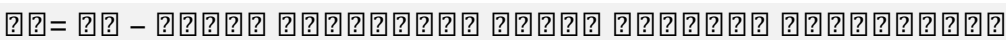

Com esse resultado das horas disponíveis, possibilata o cálculo da capacidade efetiva, que se dá pela divisão das horas disponíveis (HD) pelo tempo padrão de produção de determinado produto (TP), como segue: Capaciadade efetiva $=\frac{\mathrm{HD}}{\mathrm{TP}}$

0 autor segue explicando como calcular a capacidade realizada, que em suma, provém da capacidade efetiva, considerando a subtração das perdas não planejadas. As paradas não planejadas são aquelas causadas por imprevistos, como quebra de maquinários, quedas de energia, absenteísmo, falta de matéria prima, etc. Staudt et al. (2011) pressupõe que essas paradas não planejadas são consideradas pela empresa como uma ineficiência na produção .

E dessa forma, o cálculo da capacidade realizada se dá pela subtração das horas disponíveis (HD) das horas paradas não planejadas, divididas pelo tempo padrão, como segue:

\section{Capacidade realizada $=$ HD- Horas paradas não planejadas $/$ Tempo Padrão.}

\subsection{PLANEJAMENTO E CONTROLE DA CAPACIDADE}

Planejamento e controle da capacidade correspondem a determinar a capacidade efetiva da operação de modo que ela possa responder a demanda, ou seja, calcula a capacidade que a empresa deve ter diante de flutuações da demanda (SLACK, 2009).

Proto e Mesquita (2003) correspondem afirmando que as decisões estratégicas em longo prazo levam em consideração aspectos operacionais, financeiros, entre outros pontos quantificáveis, com extrema 
relevância quando trata-se de grandes indústrias, devendo considerar também o impacto social e relacionamento com concorrentes e governo.

Os autores complementam que decisões de expansão de capacidade tem impacto positivo em relação à quantidade de capital envolvido e, se forem tomadas em momentos errados, podem colocar em risco a situação financeira da empresa, pois decisões inoportunas de redução de capacidade podem gerar um cenário de grande impacto social e risco de perda na participação frente à concorrência, caso o mercado volte a apresentar crescimento.

Dentro desse enfoque, as atividades de planejamento da capacidade são:

1. Levantamento da capacidade produtiva e de sua distribuição geográfica;

2. Previsão da demanda futura dos produtos e serviços e avaliação do seu impacto na demanda por capacidade;

3. Avaliar as alternativas futuras de gestão da capacidade;

4. Análise das Alternativas (PROTO E MESQUITA, 2003).

\subsection{TIPOS DE PERDA}

As perdas por espera podem ser descritas como os recursos que ficam aguardando a realização de determinadas atividades. Segundo Antunes (2008), as causas centrais que levam ao incremento das perdas por espera, conforme exposto no quadro 1, são as seguintes: o tempo de setup, falta de sincronização e falhas não previstas.

\section{METODOLOGIA}

\subsection{CARACTERIZAÇÃO DA PESQUISA}

0 presente estudo é caracterizado em relação a sua natureza como uma pesquisa aplicada, pois, segundo Appolinário (2011) é uma pesquisa que procura promover soluções para a uma realidade de uma instituição financeira.

Referente ao seu objetivo a pesquisa se classifica como exploratória, Severino (2007) afirma que a pesquisa exploratória busca alcançar dados sobre um determino tema, restringindo assim a área a ser trabalhada. Torna aos autores maior familiaridade com o problema tratado no desenvolvimento do referido trabalho.

No que se refere à abordagem, a pesquisa é considerada como qualitativa e quantitativa, tornando-se uma pesquisa combinada. Segundo Rodrigues e Limena (2006), a pesquisa quantitativa é assimilada quando a abordagem está relacionada à quantificação, analise e interpretação das informações alcançadas na busca, utilizando-se da estatística. Já na abordagem qualitativa, o investigador tenta representar a dificuldade de uma determinada hipótese, investigando a interação entre as variáveis e também esclarecendo os dados e teorias.

0 Quadro 2 apresenta as características relatadas:

Quadro 2 - Classificação da Pesquisa

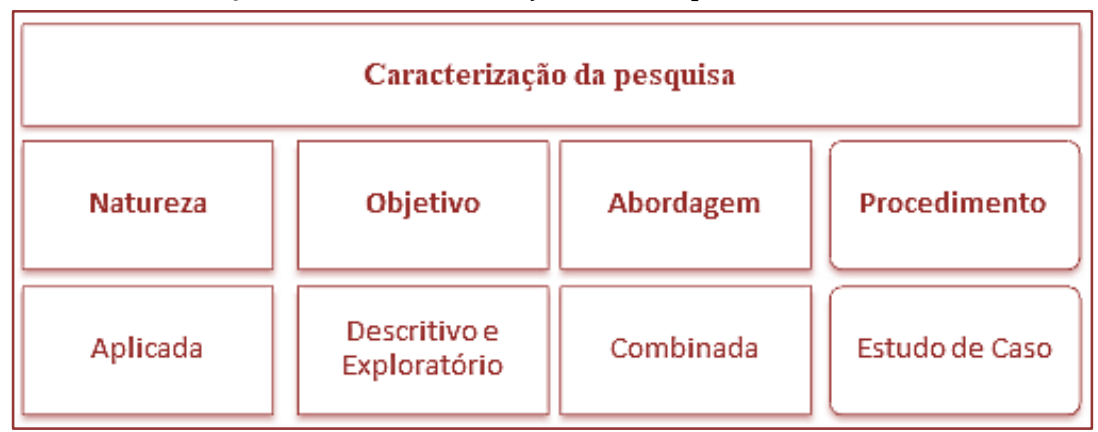

Fonte: Dados da Pesquisa (2019) 


\subsection{ESTUDO DE CASO}

A presente pesquisa estabelecida no trabalho busca efetuar uma análise comparativa entre as metas de produção estabelecidas no chão de fábrica, teoricamente conceituadas como capacidade efetiva e sua real aplicação demonstrada pela capacidade realizada e suas percas não planejadas que influenciam na diminuição de ritmo produtivo da empresa.

0 estudo proposto demostrará as principais tendências demonstradas de forma gráfica entre as capacidades, com o objetivo de analisar o comportamento das retas descrevendo seu padrão de desempenho.

Contemplando o estudo, os pontos que apresentarem discrepancia entre as solicitações produtivas da capacidade efetiva e produção real produzida, serão identificados graficamente e registrados com qual o fator que resultou na diferênça das capacidades de acordo com o período de tempo solicitado.

A identificação resultará em medidas de melhoramento, onde serão propostas melhorias para tentar solucionar o problema, fazendo então o extreitamento entre as duas capacidades, como forma de modelo perfeito de produção, onde o que se é socilitado, é produzido.

Os dados foram coletados pelos autores em um período total de 5 dias úteis, onde foram observadas 4 células diferentes todos os dias. As análises foram feitas em peças de sutiãs e calças de forma aleatória e casual, para que gerasse um gráfico espontáneo e realista.

A análise e coleta de dados foram efetuadas em um período diário onde, as células produtivas recebem inspeção e visita a cada meia hora, com o objetivo de analisar a relação da meta com a produção real, entre 17 horários distribuídos diariamente, que se dividem entre 07:00 horas as 11:08 horas no turno da manhã e 13:00 as 17:40 no turno da tarde.

\section{ANÁLISE DOS RESULTADOS}

Para análise dos resultados, foi feita uma distribuição da base de dados separada por célula, dando a origem a 4 tabelas que irão apresentar os dados das capacidades durante os 5 dias, mostrando sua meta em comparativo com sua produção a cada dia.

Os horários de observação considerou um intervalo de 30 em 30 minutos, indo de 07h00min as $11 \mathrm{~h} 00 \mathrm{~min}$ no período da manhã e de $13 \mathrm{~h} 00 \mathrm{~min}$ às $17 \mathrm{~h} 30 \mathrm{~min}$ no período da tarde, numerados respectivamente de 1 a 17, nomeados de verificação, com objetivo de reduzir o dimensionamento da tabela, melhorando o entendimento e compreensão dos dados plotados.

A Tabela 1 apresentada a seguir sugere o aglutinamento de dados oferecido durante os 5 dias de análise na denominada célula 1.

Tabela 3 - Aglutinamento de Dados da Célula 1 de Produção

\begin{tabular}{|c|c|c|c|c|c|c|c|c|c|c|}
\hline \multirow[b]{3}{*}{ Verificação } & \multicolumn{8}{|c|}{ Célula 01} & \multirow{2}{*}{\multicolumn{2}{|c|}{ Dia 05}} \\
\hline & \multicolumn{2}{|c|}{ Dia 01} & \multicolumn{2}{|c|}{ Dia 02} & \multicolumn{2}{|c|}{ Dia 03} & \multicolumn{2}{|c|}{ Dia 04} & & \\
\hline & Meta & Prod & Meta & Prod & Meta & Prod & Meta & Prod & Meta & Prod \\
\hline 1 & 14 & 5 & 14 & 5 & 14 & 12 & 19 & 10 & 17 & 17 \\
\hline 2 & 17 & 10 & 17 & 15 & 17 & 15 & 23 & 10 & 20 & 20 \\
\hline 3 & 17 & 17 & 17 & 15 & 17 & 15 & 23 & 10 & 20 & 20 \\
\hline 4 & 17 & 17 & 17 & 15 & 17 & 15 & 23 & 23 & 20 & 20 \\
\hline 5 & 17 & 17 & 17 & 10 & 17 & 15 & 23 & 15 & 20 & 20 \\
\hline 6 & 17 & 16 & 17 & 15 & 17 & 10 & 23 & 9 & 20 & 20 \\
\hline 7 & 17 & 16 & 17 & 15 & 17 & 15 & 23 & 23 & 20 & 20 \\
\hline 8 & 22 & 17 & 22 & 10 & 20 & 17 & 29 & 25 & 25 & 25 \\
\hline 9 & 17 & 17 & 17 & 15 & 20 & 20 & 23 & 16 & 20 & 20 \\
\hline 10 & 17 & 17 & 17 & 15 & 20 & 25 & 23 & 23 & 20 & 18 \\
\hline 11 & 17 & 15 & 17 & 15 & 20 & 25 & 23 & 9 & 20 & 19 \\
\hline 12 & 17 & 16 & 17 & 10 & 20 & 25 & 23 & 10 & 20 & 20 \\
\hline 13 & 17 & 16 & 17 & 10 & 20 & 20 & 23 & 23 & 20 & 20 \\
\hline 14 & 17 & 16 & 17 & 10 & 20 & 20 & 23 & 23 & 20 & 20 \\
\hline 15 & 17 & 15 & 17 & 10 & 20 & 20 & 23 & 23 & 20 & 20 \\
\hline 16 & 17 & 17 & 17 & 10 & 20 & 20 & 23 & 20 & 20 & 20 \\
\hline 17 & 23 & 21 & 23 & 15 & 27 & 27 & 31 & 15 & 29 & 29 \\
\hline
\end{tabular}

Fonte: Dados da Pesquisa (2019). 
A Tabela 2 demonstra o aglutinamento de dados produtivos disponibilizado para a célula 2 de produção.

Tabela 2 - Aglutinamento de dados da Célula 2 de Produção

\begin{tabular}{|c|c|c|c|c|c|c|c|c|c|c|}
\hline \multirow[b]{3}{*}{ Verificação } & \multicolumn{8}{|c|}{ Célula 02} & \multirow{2}{*}{\multicolumn{2}{|c|}{ Dia 05}} \\
\hline & \multicolumn{2}{|c|}{ Dia 01} & \multicolumn{2}{|c|}{ Dia 02} & \multicolumn{2}{|c|}{ Dia 03} & \multicolumn{2}{|c|}{ Dia 04} & & \\
\hline & Meta & Prod & Meta & Prod & Meta & Prod & Meta & Prod & Meta & Prod \\
\hline 1 & 14 & 6 & 14 & 5 & 17 & 7 & 18 & 5 & 17 & 20 \\
\hline 2 & 17 & 15 & 17 & 12 & 20 & 12 & 22 & 23 & 20 & 25 \\
\hline 3 & 17 & 15 & 17 & 0 & 20 & 12 & 22 & 23 & 20 & 25 \\
\hline 4 & 17 & 15 & 17 & 10 & 20 & 12 & 22 & 12 & 20 & 25 \\
\hline 5 & 17 & 10 & 17 & 10 & 20 & 13 & 22 & 23 & 20 & 25 \\
\hline 6 & 17 & 15 & 17 & 10 & 20 & 13 & 22 & 20 & 20 & 25 \\
\hline 7 & 17 & 15 & 17 & 13 & 19 & 13 & 22 & 0 & 20 & 25 \\
\hline 8 & 22 & 15 & 22 & 14 & 20 & 10 & 28 & 24 & 25 & 20 \\
\hline 9 & 17 & 17 & 17 & 14 & 23 & 25 & 22 & 22 & 23 & 25 \\
\hline 10 & 17 & 15 & 17 & 14 & 23 & 25 & 22 & 22 & 23 & 6 \\
\hline 11 & 17 & 15 & 17 & 14 & 23 & 25 & 22 & 22 & 23 & 15 \\
\hline 12 & 17 & 15 & 17 & 14 & 23 & 25 & 22 & 22 & 23 & 25 \\
\hline 13 & 17 & 12 & 17 & 14 & 23 & 25 & 22 & 15 & 23 & 25 \\
\hline 14 & 17 & 16 & 17 & 14 & 23 & 25 & 22 & 22 & 23 & 25 \\
\hline 15 & 17 & 16 & 17 & 14 & 23 & 25 & 22 & 22 & 23 & 25 \\
\hline 16 & 17 & 16 & 14 & 23 & 23 & 25 & 22 & 22 & 23 & 25 \\
\hline 17 & 23 & 16 & 14 & 17 & 30 & 31 & 30 & 30 & 29 & 31 \\
\hline
\end{tabular}

A Tabela 3 faz referência ao agrupamento de dados fornecidos durante o período de 5 dias de análise para a Célula 3.

Tabela 3 - Aglutinamento De Dados Da Célula 3 de Produção

\begin{tabular}{|c|c|c|c|c|c|c|c|c|c|c|}
\hline \multirow[b]{3}{*}{ Verificação } & \multicolumn{8}{|c|}{ Célula 03} & \multirow{2}{*}{\multicolumn{2}{|c|}{ Dia 05}} \\
\hline & \multicolumn{2}{|c|}{ Dia 01} & \multicolumn{2}{|c|}{ Dia 02} & \multicolumn{2}{|c|}{ Dia 03} & \multicolumn{2}{|c|}{ Dia 04} & & \\
\hline & Meta & Prod & Meta & Prod & Meta & Prod & Meta & Prod & Meta & Prod \\
\hline 1 & 14 & 5 & 18 & 10 & 17 & 20 & 20 & 20 & 19 & 19 \\
\hline 2 & 17 & 10 & 21 & 22 & 20 & 25 & 24 & 24 & 23 & 19 \\
\hline 3 & 20 & 15 & 21 & 22 & 20 & 25 & 24 & 24 & 23 & 19 \\
\hline 4 & 20 & 15 & 21 & 22 & 20 & 27 & 24 & 24 & 15 & 19 \\
\hline 5 & 20 & 15 & 21 & 22 & 19 & 23 & 24 & 24 & 18 & 19 \\
\hline 6 & 20 & 10 & 21 & 17 & 23 & 23 & 24 & 24 & 18 & 19 \\
\hline 7 & 20 & 15 & 21 & 17 & 23 & 23 & 24 & 24 & 18 & 19 \\
\hline 8 & 25 & 10 & 27 & 17 & 29 & 30 & 30 & 30 & 23 & 19 \\
\hline 9 & 20 & 14 & 17 & 9 & 23 & 25 & 24 & 24 & 18 & 19 \\
\hline 10 & 17 & 12 & 20 & 3 & 23 & 25 & 24 & 24 & 18 & 20 \\
\hline 11 & 17 & 15 & 20 & 5 & 23 & 25 & 24 & 24 & 18 & 20 \\
\hline 12 & 17 & 15 & 20 & 10 & 23 & 25 & 24 & 24 & 18 & 20 \\
\hline 13 & 17 & 15 & 20 & 10 & 23 & 25 & 24 & 24 & 18 & 20 \\
\hline 14 & 17 & 15 & 20 & 15 & 23 & 25 & 24 & 24 & 18 & 20 \\
\hline 15 & 17 & 16 & 20 & 15 & 23 & 25 & 24 & 24 & 18 & 24 \\
\hline 16 & 17 & 16 & 20 & 15 & 23 & 25 & 24 & 24 & 18 & 24 \\
\hline 17 & 23 & 16 & 27 & 12 & 31 & 31 & 32 & 32 & 25 & 27 \\
\hline
\end{tabular}

Fonte: Dados da Pesquisa (2019).

A Tabela 4 faz referência ao agrupamento de dados fornecidos durante o período de 5 dias de análise para a Célula 4. 
Tabela 4 - Aglutinamento de Dados da Célula 4 de Produção

\begin{tabular}{|c|c|c|c|c|c|c|c|c|c|c|}
\hline \multirow[b]{3}{*}{ Verificação } & \multicolumn{8}{|c|}{ Célula 04} & \multirow{2}{*}{\multicolumn{2}{|c|}{ Dia 05}} \\
\hline & \multicolumn{2}{|c|}{ Dia 01} & \multicolumn{2}{|c|}{ Dia 02} & \multicolumn{2}{|c|}{ Dia 03} & \multicolumn{2}{|c|}{ Dia 04} & & \\
\hline & Meta & Prod & Meta & Prod & Meta & Prod & Meta & Prod & Meta & Prod \\
\hline 1 & 14 & 7 & 14 & 6 & 14 & 5 & 19 & 15 & 19 & 7 \\
\hline 2 & 17 & 17 & 17 & 15 & 17 & 14 & 23 & 23 & 23 & 25 \\
\hline 3 & 17 & 17 & 17 & 15 & 17 & 10 & 26 & 19 & 23 & 18 \\
\hline 4 & 17 & 17 & 17 & 10 & 17 & 15 & 26 & 23 & 16 & 0 \\
\hline 5 & 17 & 17 & 17 & 10 & 17 & 7 & 26 & 26 & 16 & 12 \\
\hline 6 & 17 & 17 & 17 & 15 & 19 & 19 & 26 & 26 & 16 & 12 \\
\hline 7 & 17 & 17 & 17 & 13 & 23 & 23 & 26 & 26 & 16 & 10 \\
\hline 8 & 22 & 17 & 22 & 14 & 29 & 30 & 33 & 33 & 20 & 16 \\
\hline 9 & 17 & 17 & 17 & 14 & 23 & 23 & 26 & 26 & 16 & 19 \\
\hline 10 & 17 & 17 & 17 & 14 & 23 & 24 & 26 & 26 & 16 & 16 \\
\hline 11 & 17 & 17 & 17 & 14 & 23 & 24 & 26 & 26 & 16 & 16 \\
\hline 12 & 17 & 17 & 17 & 14 & 23 & 24 & 26 & 26 & 16 & 16 \\
\hline 13 & 17 & 17 & 17 & 14 & 23 & 24 & 26 & 26 & 16 & 16 \\
\hline 14 & 17 & 17 & 17 & 14 & 23 & 24 & 26 & 26 & 16 & 12 \\
\hline 15 & 17 & 17 & 17 & 14 & 23 & 24 & 26 & 26 & 16 & 12 \\
\hline 16 & 17 & 17 & 17 & 14 & 23 & 24 & 26 & 26 & 16 & 12 \\
\hline 17 & 23 & 17 & 25 & 2 & 31 & 31 & 35 & 35 & 22 & 20 \\
\hline
\end{tabular}

\subsection{ANÁLISE DE TENDÊNCIAS GRÁFICAS}

Como forma de análise de tendências, foi possível analisar todo o conjunto de dados e gerar gráficos que demonstrem os principais comportamentos descritos para as 4 células. 0 objetivo dos gráficos não está inserido nos valores numéricos apresentados, mas sim no comportamento da associação entre as duas retas fornecidas: Capacidade efetiva ou meta e Capacidade Realizada ou produção real.

A análise é feita entre uma reta de representação de cor azul utilizada para as metas produtivas e uma reta de representação de cor laranja para a real capacidade produzida em um período de tempo.

A Figura 1 descreve o primeiro comportamento apresentado pelas células demonstrando pontos em que a produção realizada se apresenta com picos produtivos a baixo e a cima das metas solicitadas.

Figura 3 - Tendência com Oscilação de Picos

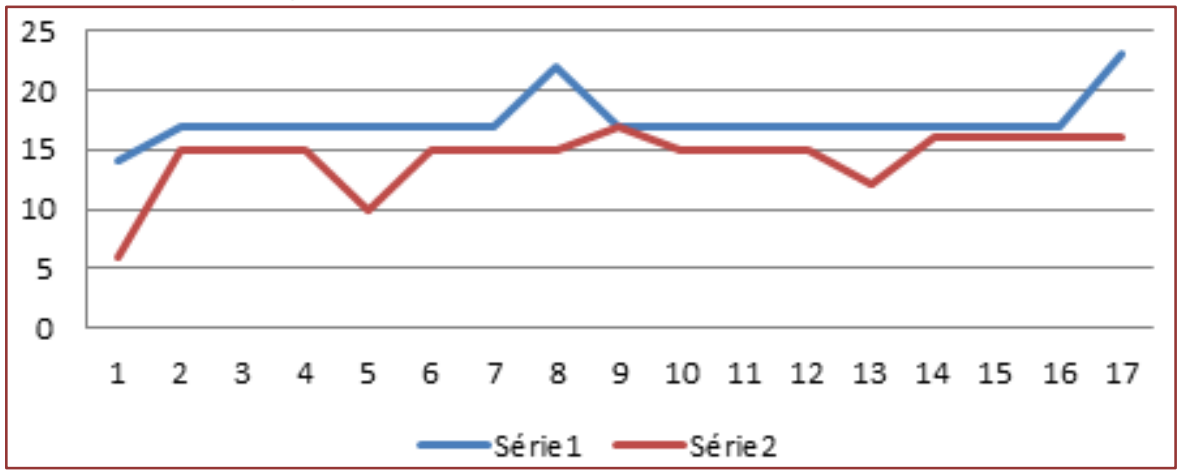

Fonte: Dados da Pesquisa (2019).

Com a primeira tendência, é possível constatar que a produção é consciderada normal, porém recebe perdas não planejadas em determinados horários que causam diferença entre o que é solicitado e o que é produzido. Da mesma forma a produção recebe picos positivos em sua linha temporal, devido a fatores de motivação nas células.

Como a produção consegue se estabelecer em períodos posteriores, pode-se considerar que o sistema é capaz se recuperar sozinho sem a necessidade de um replanejamento celular. 
A Figura 2 descreve o segundo comportamento, onde de acordo com o gráfico sugerido, a célula perde capacidade produtiva diante a produção diária. A análise gráfica sugere quedas de produção em vários horários de forma sequêncial.

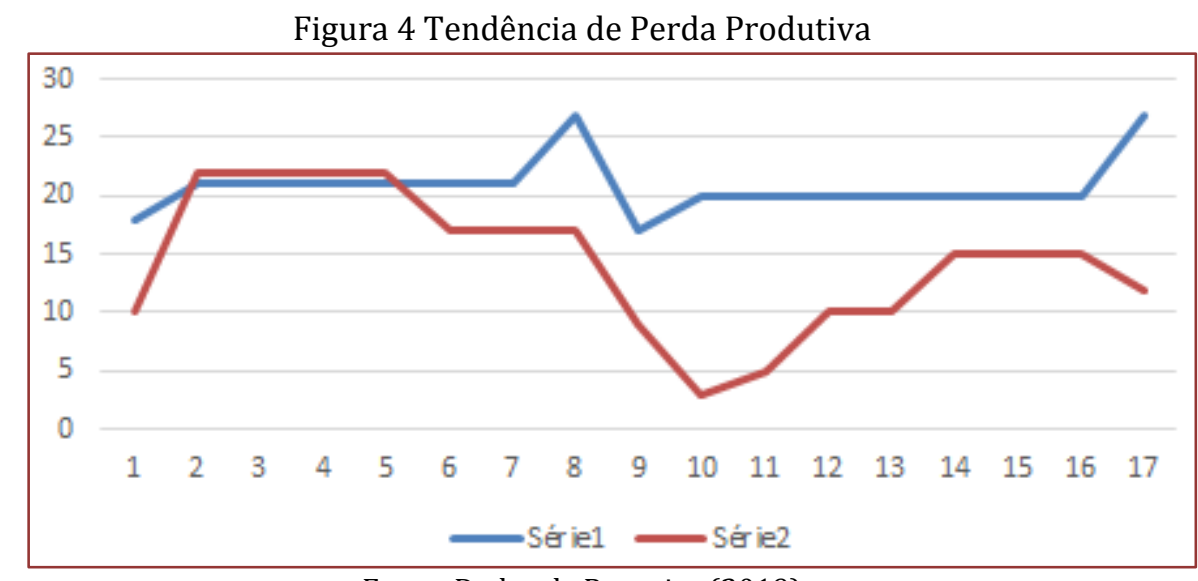

Fonte: Dados da Pesquisa (2019)

Com a análise é possível classificar a produção com presença de anormalidades, onde a produção realizada esta sendo influênciada diretamente por fatores externos que causam a diferença produtiva. Nesse modelo os fatores externos causam perdas produtivas por vários períodos diários, sendo necessário intervir e corrigir os fatores causadores da falta de desempenho.

A Figura 3 descreve um comportamento onde a produção é caracterizada por ter uma capacidade produtiva acima do desejado, marcando um terceiro comportamento de tendência.

Figura 5 - Superação da Capacidade Efetiva

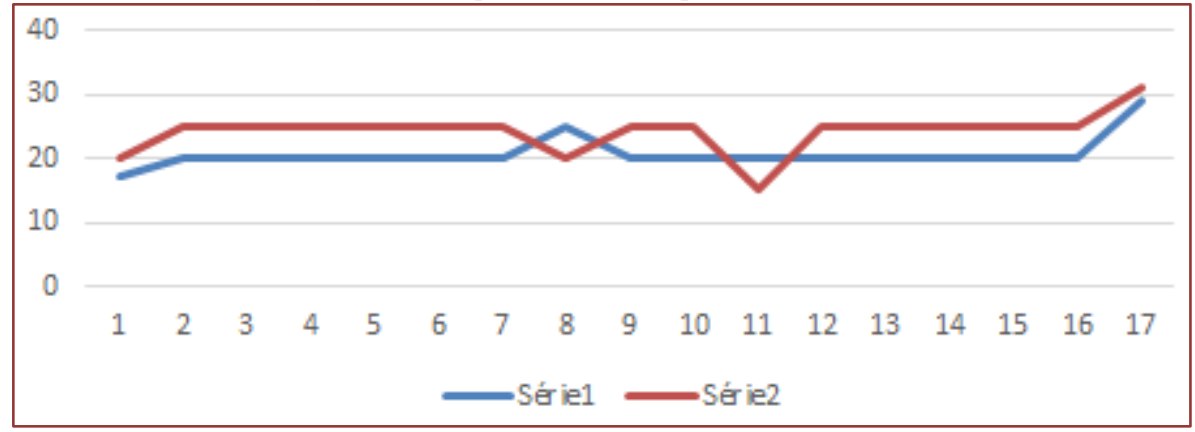

Fonte: Dados da Pesquisa (2019)

De acordo com o gráfico proposto, a capacidade realizada consegue superar as metas de produção. 0 fenômeno embora seja classificado como de alto valor, por se apresentar com ótima eficiencia produtiva, pode ser justificado devido ao fato de uma cronoanálise ser feita de forma errada, calculando o tempo padrão das peças de forma inadequada.

Esse efeito resulta em um mau planejamento efetuado pelo PCP, que fez sua programação de acordo com a capacidade produtiva efetiva das células.

A figura 4 faz a demostração gráfica onde o sistema produtivo é cassificado como ótimo fazendo o extreitamento entre a capacidade produtiva efetiva e a capacidade produtiva real. 
Figura 6 - Capacidade Ótima de Produção

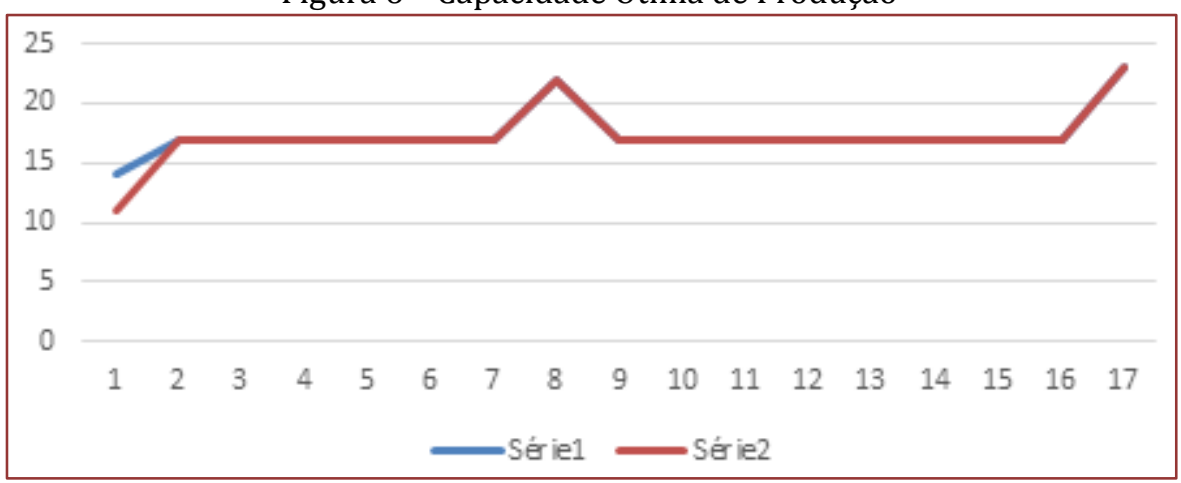

Fonte: Dados da Pesquisa (2019)

Com a análise desse gráfico pode-se classificar a produção como uma produção normal, onde foi percebido que a cronoanálise foi feita de forma correta e a produção não possui a presença de perdas não planejadas, se tornando um sistema produtivo classificado como perfeito, atendendo as solicitações de demanda.

\subsection{SOLUÇÕES E PROPOSTAS DE MELHORIAS}

Para tratar os pontos gráficos que se apresentaram em padrões anormais de produção, foi poposto um diagnóstico sobre os fatores externos que causavam a diferença produtiva entre as capacidades.

O Quadro 2 sugere as possíveis causas listadas na análise, justificadas por colaboradores presentes nas células e as possíveis soluções com objetivo de tentar aumentar a produtividade da célula, afim de manter a produção sobre controle de acordo com a tendência 4 demonstrada na Figura 4.

Quadro 2 - Causas e Soluções da Deficiência Produtiva

\begin{tabular}{|l|l|}
\hline \multicolumn{2}{|c|}{ Causa } \\
Quebra da Máquina & $\begin{array}{l}\text { Deve-se efetuar manutenção preventiva em todo o maquinário, para que o } \\
\text { processo não seja interrompido. }\end{array}$ \\
\hline Amamentação & $\begin{array}{l}\text { Deve-se fazer o planejamento e controle prevendo os períodos de } \\
\text { amamentação da colaboradora. }\end{array}$ \\
\hline Início de Referência & $\begin{array}{l}\text { Deve-se efetuar um treinamento prévio relacionado ao setup dos lotes } \\
\text { produtivos, com objetivo de diminuir o tempo de setup. }\end{array}$ \\
\hline Erro no Corte & $\begin{array}{l}\text { Deve-se efetuar a integração entre os departamentos de modo a não haver } \\
\text { erros entre um departamento e outro. }\end{array}$ \\
\hline $\begin{array}{l}\text { Má Eficiência das } \\
\text { Colaboradoras }\end{array}$ & $\begin{array}{l}\text { Treinamento para aumentar a polivalência de colaboradoras que tem seu } \\
\text { desempenho limitado. }\end{array}$ \\
\hline Produção Extra & $\begin{array}{l}\text { Deve-se tratar o ponto de venda da empresa como cliente externo da empresa, } \\
\text { não incluindo suas peças entre os pedidos de outros clientes. }\end{array}$ \\
\hline
\end{tabular}

Fonte: Dados da Pesquisa (2019).

\section{CONSIDERAÇÕES FINAIS}

Considerando a análise e os conceitos trabalhados pelos autores diante de planejamento da capacidade produtiva e tipos de perdas na produção, é possível percerber a importância de estabelecer a análise correta da capacidade produtiva da empresa em prol de um planejamento correto, levantado considerando perdas por falhas planejadas e não planejadas. 


\section{REFERÊNCIAS}

[1] APPOLINÁRIO, Fabio. Dicionário de Metodologia Científica. 2. ed. São Paulo: Atlas, 2011.

[2] ANTUNES, J. et al. Sistemas de produção: conceitos e práticas para projeto e gestão da produção enxuta. Porto Alegre: Bookman, 2008.

[3] CORRÊA, H. L.; GIANESI, I. G.; CAON, M. Planejamento, Programação e Controle de Produção MRP II / ERP Conceitos, Uso e Implantação. 5.ed. Editora Atlas. 2007.

[4] NEVES, E, P; BRIGATTO; A, C; PASChOARELLI, L, C. Moda Intima: Uma Abordagem Acerca dos Aspectos de Usabilidade. MARTINS JUNIOR, José Carlos. Método estruturado para aplicação das técnicas de aumento da capacidade de produção de recursos gargalo em células de manufatura. 2009.

[5] Dissertação (Mestrado em Engenharia de Produção) - Escola de Engenharia de São Carlos, Universidade de São Paulo, São Carlos, 2009. Disponível em: <http://www.teses.usp.br/teses/disponiveis/18/18140/tde-23102009080447 />. Acesso em: 20 out. 2012.

[6] MARTINS, P. G.; LAUGENI, F. P. Administração da produção. Saraiva, São Paulo. 1998. 173 p.

[7] MOTTA, M, PO; GOMES, J, P, H. Capacidade Produtiva e Eficiencia de Processo: Um Estudo de Caso em uma Confecção de Moda Fitness. 2016.

[8] RODRIGUES, Maria Lucia; LIMENA, Maria Margarida Cavalcanti (Orgs.). Metodologias multidimensionais em Ciências Humanas. Brasília: Líber Livros Editora, 2006.

[9] PEINADO, J.; GRAEML, A. R. Administração da produção: operações industriais e de serviços. Curitiba: Unicenp, 2007.

[10] PROTO, L. O. Z; MESQUITA, M. A.Previsão de demanda para planejamento da capacidade de empresa do setor cimenteiro. In: Encontro Nacional de Engenharia de Produção,23,2003.0uro Preto.

[11] SEVERINO, Antonio Joaquim. Metodologia do Trabalho Científico. São Paulo: Cortez, 2007.

[12] SLACK, N.; CHAMBERS, S. \& JOHNSTON, R. Administração da Produção. 3a Ed. São Paulo: Atlas, 2009.

[13] STAUDT, Francielly Hedler; COELHO, Antonio Sérgio and GONCALVES, Mirian Buss. Determinação da capacidade real necessária de um processo produtivo utilizando cadeia de Markov. Prod. [online]. 2011, vol.21, n.4, pp. 634-644. Epub Nov 08, 2011. ISSN 0103-6513. http://dx.doi.org/10.1590/S0103-65132011005000058.

[14] TUBINO, D. F. Manual de Planejamento e Controle da Produção. Atlas, São Paulo. 2000. 15- 194 p. 


\section{Capítulo 11}

Aplicação do MASP: Um estudo de caso de pizzaria em Belo Horizonte

\section{Bárbara Gabrielle Silva \\ Ana Luiza Figueiredo Viegas \\ Paulo Fernandes Sanches Junior \\ Luciano dos Santos Diniz}

Resumo: 0 atual mercado competitivo, onde a concorrência está constantemente aperfeiçoando seus processos, produtos e serviços e buscando fatias cada vez maiores no mercado, exige que as empresas busquem cada vez mais a melhoria contínua em seus processos produtivos por meio da eliminação de falhas e gargalos produtivos. Assim, identificar atividades que não agreguem valor ao produto ou serviço ofertado e extinguilas é de grande relevância para promover reduções de custos organizacionais. Neste contexto, o presente trabalho configura-se como um estudo de caso realizado na pizzaria $\mathrm{X}$ que tem como objetivo identificar causas no processo produtivo da empresa que têm ocasionado o atraso na entrega das pizzas aos seus clientes por meio da aplicação da etapa PLAN do Método de Análise e Solução de Problemas. Após a observação e análise do problema com a utilização das ferramentas da qualidade, foi elaborado um plano de ação - 5W1H.

Palavras-chave: Masp, Ferramentas da Qualidade, Qualidade em serviços 


\section{INTRODUÇÃO}

Em meio a globalização e a nova realidade competitiva do mercado, as organizações estão sendo forçadas cada vez mais a se adaptarem através da melhoria contínua e eficiente para sobreviver no mercado e se destacar frente a seus concorrentes. Desta forma, a produção da empresa moderna não pode tolerar qualquer tipo de gargalos produtivos ou desperdícios, devendo evitar ineficiências e eliminar atividades que não agregam valor ao produto ou serviço ofertado (MARTINELLI, 2009).

Neste contexto, o presente trabalho configura-se como um estudo de caso realizado na pizzaria X que tem como objetivo identificar causas no processo produtivo da empresa que têm ocasionado o atraso na entrega das pizzas aos seus clientes por meio da aplicação da etapa PLAN do Método de Análise e Solução de Problemas.

A estrutura do trabalho traz a fundamentação teórica sobre a gestão da qualidade, o método MASP e as ferramentas de qualidade. Posteriormente são apresentados os dados obtidos com a pesquisa e a análise e discussão dos resultados, bem como a apresentação de propostas de melhoria, seguidas das considerações finais do estudo.

\section{GESTÃO DA QUALIDADE}

A preocupação com a qualidade se faz presente desde as sociedades mais antigas. Carpinetti (2012) relata que, a partir de meados da década de 1950, o tema passou a integrar programas de rádio e televisão no Japão. Tal preocupação adveio da influência das ideias trazidas pelos norte-americanos no pós Segunda Guerra Mundial (CAMPOS, 2004).

Ishikawa foi o responsável por disseminar a ideia de controle de qualidade no Japão. Para ele, era de extrema importância encontrar o sistema mais adequado para a indústria japonesa (JUSE, 2018). No cenário japonês da época, a concepção estatística da qualidade defendida por Deming ganhou força (CARPINETTI, 2012). Werkema (2006) explica que, inicialmente, o controle era feito por meio do uso intensivo de técnicas estatísticas, como a inspeção por amostragem e os gráficos de controle.

No entanto, o sistema proposto passou por dificuldades. Visando solucioná-las, o Grupo de Pesquisa do Controle de Qualidade da JUSE (Union of Japanese Scientists and Engineers) convidou Juran para proferir seminários nas empresas japonesas sobre suas ideias. Em sua concepção, Juran acreditava que "o conceito de qualidade devia ser incorporado a todos os processos da organização, desde o planejamento do produto, passando pelo projeto e desenvolvimento, aquisição, produção, comercialização e pós-venda" (CARPINETTI, 2012,p. 15). Por meio dessa concepção, o controle de qualidade passou a ser visto como uma ferramenta administrativa (WERKEMA, 2006). 0 controle de qualidade estatístico estava evoluindo para o controle de qualidade total (TQC).

Assim como Deming e Juran, as contribuições de Feigebaum foram essenciais para o desenvolvimento do sistema de controle de qualidade total. Feigebaum definiu as atividades do controle de qualidade como: (a) controle de projeto; (b) controle dos materiais recebidos;

(c) controle dos produtos; e (d) estudo de processos especiais (CARPINETTI, 2012).

A Gestão da Qualidade Total deve cumprir com o objetivo de maximizar a competitividade da empresa com a aplicação de métodos de gestão (CARPINETTI, 2012). Para Campos (2004), os métodos necessários devem ser elegidos de forma a alcançar os objetivos da empresa e devem, também, ser aprendidos e praticados por todos. Os métodos devem ser aplicados nas empresas juntamente com as ferramentas da qualidade. Em sua reflexão sobre a gestão da qualidade na realidade brasileira, Campos (2004) explica que o país se tornou uma vitrine de decisões erradas. Isso se dá pelo fato de que, no país, as ferramentas são aplicadas sozinhas sem o amparo do método por trás do processo decisório.

\section{METODOLOGIA DE ANÁLISE E SOLUÇÃO DE PROBLEMAS (MASP)}

O QC Story é, segundo Hitoshi Kume (1993), um procedimento utilizado para resolução de problemas. 0 método foi aplicado inicialmente no Japão e constituía-se de um roteiro para documentação e apresentação do histórico do trabalho de melhoria realizado. Kume (1993) explica que o procedimento é semelhante a uma estória ou enredo das atividades aplicadas para monitoramento da qualidade, daí a denominação "the quality control story" ou QC Story. 
No Brasil, a metodologia foi apresentada por Campos (2004), que a denominou Método de Análise e Solução de Problemas (MASP).

O MASP é considerado por Campos (2004) como peça fundamental para que se desempenhe o controle da qualidade. Menezes (2013) explica que o MASP é um processo dinâmico, que tem como objetivo elevar a probabilidade de resolução satisfatória de um problema. A solução desse problema segue uma sequência lógica, que envolve a identificação, análise e plano de ação para eliminação do problema. O MASP é composto por 8 fases e sua aplicação se dá via PDCA.

O Ciclo PDCA é a sigla em inglês para Plan, Do, Check, Action. É definido como "um método gerencial de tomada de decisões para garantir o alcance das metas necessárias à sobrevivência de uma organização" (WERKEMA, 2006, p. 24). Segundo Menezes (2013), o ciclo é uma abordagem sistemática que previne equívocos de conclusão e conduz a soluções ótimas. É possível perceber como o MASP e o PDCA estão relacionados na figura 1 .

Figura 1 - Relação entre o MASP e o Ciclo PDCA

\begin{tabular}{|c|c|c|c|}
\hline PDCA & Fluxograma & Fase & Objetivo \\
\hline \multirow{4}{*}{ P } & $\Gamma 1$ & Identificaçăo do Problema & $\begin{array}{l}\text { Definir claramente o problema } \\
\text { Reconhecer sua importäncia }\end{array}$ \\
\hline & 2 & Observaçāo & $\begin{array}{l}\text { Investigar as caracteristicas especificas do } \\
\text { problema com uma visão ampla e sob } \\
\text { vários pontos de vista }\end{array}$ \\
\hline & 3 & Análise & Descobrir as causas fundamentais \\
\hline & 4 & Plano de Açăo & $\begin{array}{l}\text { Elaborar um plano para bloquear as causas } \\
\text { fundamentais }\end{array}$ \\
\hline D & 5 & Açăo & Bloquear as causas fundamentais \\
\hline \multirow{2}{*}{ C } & 6 & Verificação & Verificar se o bloqueio foi efetivo \\
\hline & & (Bloqueio foi efetivo?) & \\
\hline \multirow{2}{*}{$A$} & 74 & Padronizaçäo & Prevenir contra a reincidència do problema \\
\hline & 8 & Concusão & $\begin{array}{l}\text { Recapitular todo o processo de solução do } \\
\text { problema para trabalho futuro }\end{array}$ \\
\hline
\end{tabular}

Fonte: Menezes, 2013

\section{FERRAMENTAS DE QUALIDADE}

As ferramentas de qualidade, segundo Roth (2011), são instrumentos facilitadores para a execução de um determinado método e auxiliam na resolução de problemas que possam interferir no bom desempenho de um processo, produto ou serviço. É a partir da aplicação dessas ferramentas que, segundo Pacheco et al. (2011), uma organização consegue identificar as causas de um problema e buscar soluções para resolvêlo. Se adequadamente aplicadas, as ferramentas de qualidade agregam valor para a organização e tornamse diferenciais competitivos, permitindo sua sobrevivência e destaque no mercado, (SELEME; STADLER, 2010). As ferramentas utilizadas neste trabalho estão descritas a seguir.

\subsection{ESTRATIFICAÇÃO}

A estratificação consiste, segundo Werkema (1995), no agrupamento da informação (dados) em grupos menores sob vários pontos de vista, de modo a focalizar a investigação. Portanto, trata-se de segregar um amplo conjunto de informações heterogêneas em subgrupos que compartilhem informações homogêneas. 


\subsection{FOLHA DE VERIFICAÇÃO}

A folha de verificação consiste, segundo Roth (2011), em um formulário para tabular dados resultantes de uma técnica de observação e identificar a frequência de determinadas ocorrências durante o período pesquisado. Sua elaboração deve partir dos resultados obtidos no processo de estratificação, (VIEIRA, 1999).

\subsection{DIAGRAMA DE PARETO}

A maioria dos problemas relativos à qualidade nas organizações, para Kume (1993), são provenientes de um número muito restrito de defeitos, que são atribuídos a um pequeno número de causas. Diante disso, ainda segundo o autor, o princípio de Pareto afirma que se as causas desses pontuais defeitos forem identificadas, torna-se possível a eliminação de quase todos os problemas de qualidade da organização.

\subsection{BRAINSTORMING}

A técnica de dinâmica de grupo brainstorming consiste em uma reunião para o levantamento de causas potenciais que serão estruturadas em um diagrama de causa e efeito, (WERKEMA, 1995). 0 objetivo dessa técnica compreende auxiliar um grupo de pessoas a produzir o máximo de ideias possível em um tempo reduzido para se obter opiniões relevantes que serão posteriormente estudadas.

\subsection{DIAGRAMA DE ISHIKAWA}

Também conhecido como espinha de peixe ou diagrama de causa e efeito, é uma ferramenta utilizada para investigar as causas prováveis de um determinado problema de qualidade. 0 problema deve ser descrito dentro de um retângulo ao lado direito do diagrama e as possíveis causas são listadas à esquerda, (VIEIRA, 1999).

\section{METODOLOGIA}

$\mathrm{O}$ presente trabalho configura-se como um estudo de caso realizado na pizzaria $\mathrm{X}$ que tem como objetivo identificar onde estão as falhas e/ou gargalos no processo produtivo da empresa que têm ocasionado o atraso na entrega das pizzas aos seus clientes através da aplicação da etapa PLAN do MASP. Para isso, a metodologia empregada será de abordagem quantitativa que, para Lakatos e Marconi (2009), tem como principal objetivo quantificar um problema e entender sua dimensão.

A partir da identificação do problema, o levantamento de dados será feito por meio de técnicas de observação em campo com a aplicação de folhas de verificação, a fim de se identificar as principais causas do problema em questão. Posteriormente, os dados serão analisados através do Diagrama de Pareto para que as principais causas identificadas sejam ordenadas conforme sua ocorrência.

Em seguida, será realizado um brainstorming com os proprietários da Pizzaria para verificar suas opiniões sobre as causas raiz dos problemas que serão aplicadas em um Diagrama de Ishikawa. Com todas as causas primárias e secundárias identificadas, os planos de ação serão elaborados com a ferramenta 5W1H.

\section{IDENTIFICAÇ̃̃O DO PROBLEMA}

Criada em 2013, a Pizzaria X é um tele entrega de pizzas de pequeno porte localizado em um bairro comercial da cidade de Belo Horizonte (Minas Gerais) que produz e entrega pizzas na região, não sendo possível que os clientes façam refeições no local. Com uma produção total de aproximadamente 30 pizzas de terça a quinta e 130 pizzas de sexta a domingo, a pizzaria produz uma média de 10 pizzas por dia (de terça a quinta) e 43 pizzas por dia (de sexta a domingo) e conta com apenas 03 funcionários: o dono W., seu irmão G. e um motoboy contratado para as entregas.

Segundo W., dono da pizzaria X, as pizzas devem ser produzidas e entregues aos clientes em, no máximo, 40 minutos após a realização do pedido, sendo 30 minutos o cenário ideal. Há alguns meses, no entanto, a pizzaria vem recebendo queixas de demora na entrega de seus pedidos, tendo alguns destes demorado até 60 minutos para chegar até a casa dos clientes. 
Esse cenário tem despertado a atenção dos proprietários, já que os atrasos recorrentes nas entregas das pizzas têm impacto direto no faturamento da pizzaria devido à perda da fidelização de seus clientes. Além disso, a reputação da pizzaria é afetada negativamente frente a seus concorrentes, já que se coloca à prova sua relação de confiança com os clientes. Desta forma, um modelo de melhoria no processo com o objetivo de reduzir tais atrasos, traria mais satisfação aos clientes da pizzaria e, consequentemente, um impacto positivo em seu faturamento.

\section{OBSERVAÇÃO}

A primeira etapa para construção do modelo de melhoria de qualidade da pizzaria foi a estratificação dos dados para a elaboração da folha de verificação. Nesta etapa, segundo Machado, Helleno e Lima (2016), são agrupados os elementos com as mesmas características e detectados padrões que futuramente irão auxiliar na compreensão dos mecanismos causais.

Desta maneira, foram identificadas possíveis causas para os atrasos, tais como: falta de mão de obra na pizzaria, atraso na preparação da massa das pizzas, entre outros, que seriam observados e comprovados (ou não) durante a etapa de observação.

Com os dados já estratificados, elaborou-se então uma folha de verificação com as principais causas identificadas na etapa anterior. A lista foi aplicada na pizzaria no prazo de uma semana de serviço (terça a domingo) e os dados foram coletados através do método de observação, que possibilitou gerar informações claras e consistentes que serão futuramente aplicadas nas das demais ferramentas de qualidade, conforme figura abaixo.

Figura 2 - Folha de verificação (motivos de atrasos nos pedidos)

\begin{tabular}{|c|c|c|}
\hline \multicolumn{3}{|c|}{ FOLHA DE VERIFICAÇÃO } \\
\hline \multicolumn{3}{|c|}{$\begin{array}{l}\text { Local da inspeção: Pizzaria X (Bairro Castelo) } \\
\text { Data da inspeção: 20/03/2018 a 25/03/2018 (terça a domingo) } \\
\text { Total pedidos inspecionados: } 144 \text { pedidos / Total pedidos em atraso: } 70 \text { pedidos }\end{array}$} \\
\hline MOTIVO DO ATRASO & FREQUÊNCIA (SEMANAL) & FREQUÊNCIA PERCENTUAL \\
\hline Falta de ingredientes & 8 & $11 \%$ \\
\hline $\begin{array}{l}\text { Demora na seleção dos alimentos } \\
\text { (exceder } 02 \text { min) }\end{array}$ & 2 & $3 \%$ \\
\hline $\begin{array}{l}\text { Demora no corte dos alimentos } \\
\text { (exceder } 05 \mathrm{~min} \text { ) }\end{array}$ & 3 & $4 \%$ \\
\hline $\begin{array}{l}\text { Demora na preparação da massa } \\
\text { (exceder } 10 \mathrm{~min} \text { ) }\end{array}$ & 7 & $10 \%$ \\
\hline $\begin{array}{l}\text { Demora na preparação do recheio } \\
\text { (exceder } 10 \mathrm{~min} \text { ) }\end{array}$ & 5 & $7 \%$ \\
\hline Forno não estar pré-aquecido & 4 & $6 \%$ \\
\hline Sobrecarga dos pizzaiolos & 8 & $11 \%$ \\
\hline Demora entre um cliente e outro & 29 & $41 \%$ \\
\hline $\begin{array}{l}\begin{array}{l}\text { Engarrafamento (trânsito) para a } \\
\text { entrega }\end{array} \\
\text { en }\end{array}$ & 4 & $6 \%$ \\
\hline TOTAL & 70 & $100 \%$ \\
\hline
\end{tabular}

Durante a semana analisada, foram investigados 144 pedidos da Pizzaria X e foram identificados 70 pedidos com tempo de entrega superior a $40 \mathrm{~min}$. (limite estabelecido pelo dono da Pizzaria), ou seja, 48\% dos pedidos realizados na semana analisada foram entregues com atraso.

Com os dados obtidos pela técnica de observação, foi então elaborado o Gráfico de Pareto que, segundo Martinelli (2009), é um método que visa identificar as principais causas de um determinado problema, atribuindo prioridades e orientando os esforços da empresa para atuar nas causas apontadas como mais urgentes. Para facilitar essa interpretação, o gráfico pode apresentar a curva de soma acumulada dos valores em porcentagem, que sinaliza quais problemas deverão ser tratados em primeiro lugar, conforme a figura 3 . 
Figura 3 - Diagrama de Pareto (motivos de atrasos nos pedidos)

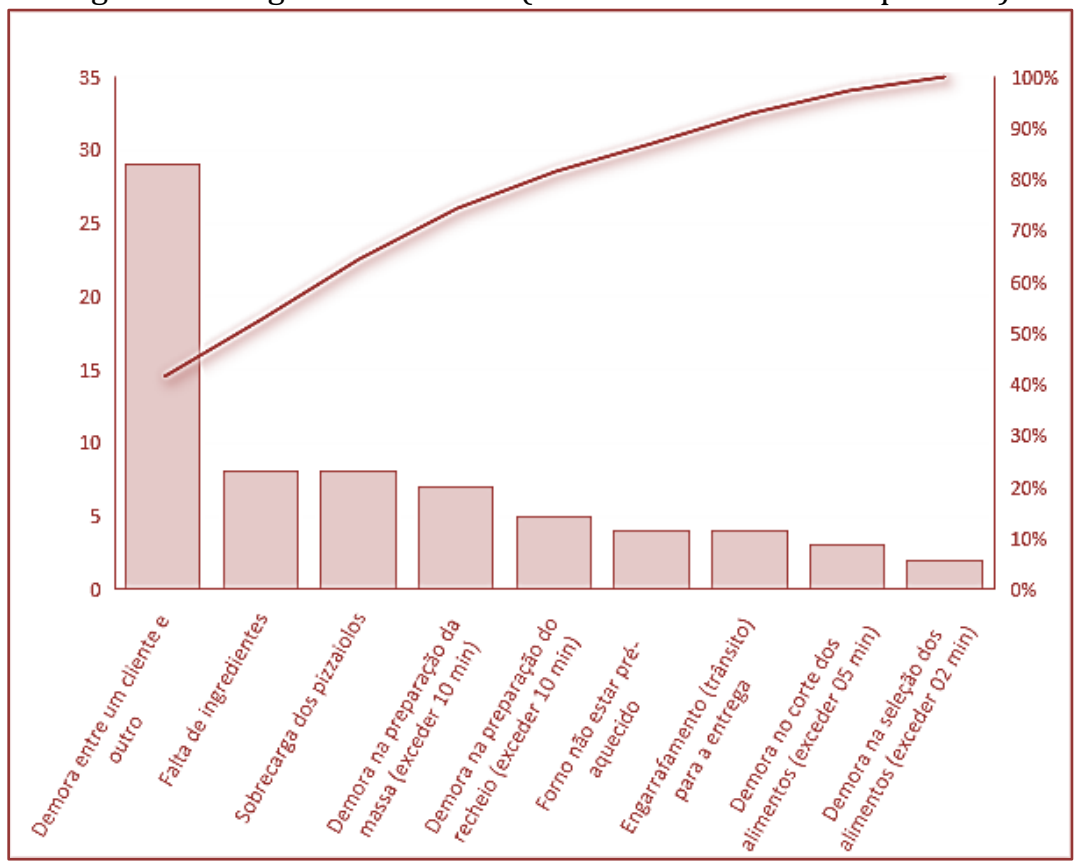

Fonte: Elaborado pelo autor (2018)

Os resultados demonstrados no Diagrama de Pareto revelam que, em geral, $80 \%$ dos problemas de atraso na entrega dos pedidos da Pizzaria X ocorrem devido a cerca de $45 \%$ das causas, ou seja, para se obter uma redução em mais de $80 \%$ dos atrasos será necessário atuar em cerca de 4 causas principais: (1) demora entre um cliente e outro; (2) falta de ingredientes; (3) sobrecarga dos pizzaiolos e (4) demora na preparação da massa.

\section{ANÁLISE}

Identificadas as causas de maior prioridade, faz-se necessário investigar as causas secundárias de tais circunstâncias, ou seja, descobrir quais razões contribuem para que esses problemas ocorram. Para isso, foi aplicada a técnica de brainstorming com os proprietários da empresa e as opiniões sobre as possíveis causas dos problemas constituíram o Diagrama da figura 4.

Figura 4 - Diagrama de Ishikawa (Atraso na entrega dos pedidos)

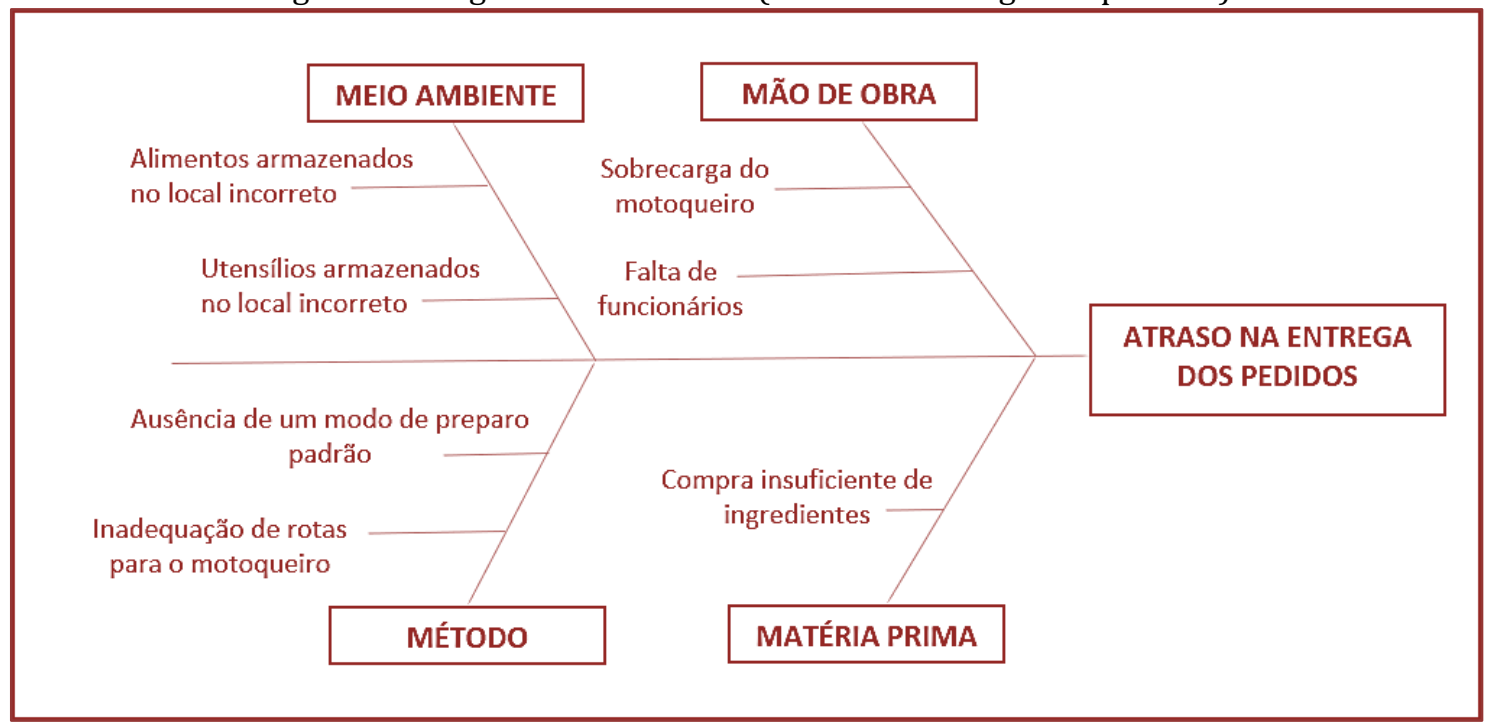

Fonte: Elaborado pelo autor (2018) 
A aplicação da ferramenta identificou as seguintes causas raiz para os 04 problemas mais agravantes da

Pizzaria X:

\begin{tabular}{|c|c|}
\hline & Sobrecarga do motoqueiro; \\
\hline & Falta de funcionários; \\
\hline & Alimentos armazenados no local incorreto; \\
\hline & Utensílios armazenados no local incorreto; \\
\hline & Ausência de um modo de preparo padrão; \\
\hline & Inadequação das rotas para o motoqueiro; e \\
\hline & Compra insuficiente de ingredientes. \\
\hline
\end{tabular}

Com as causas secundarias dos problemas identificadas, deu-se início a fase de propostas de melhorias, com o desenvolvimento de planos de ação baseados na ferramenta 5W1H.

\section{PLANO DE AÇÃO}

A partir da identificação das causas raízes dos problemas deu-se início a fase de proposta de soluções e melhorias que, para Oliveira (2009), é um momento que exige elevada criatividade e amplos conhecimentos sobre a empresa.

Neste sentido, utilizou-se da ferramenta 5W1H que busca orientar a elaboração de planos de ação através da resposta de 6 perguntas básicas que retratam as iniciais das expressões da língua inglesa: what (o quê), why (por quê), where (onde), when (quando), who (quem) e how (como), conforme figura 5.

Figura 5 - Aplicação da ferramenta 5W1H

\begin{tabular}{|c|c|c|c|c|c|}
\hline \multicolumn{6}{|c|}{$5 \mathrm{~W} 1 \mathrm{H}$} \\
\hline O que? & Por quê? & Onde? & Quando? & Quem? & Como? \\
\hline $\begin{array}{l}\text { Adequação das } \\
\text { rotas do } \\
\text { entregador às } \\
\text { distâncias dos } \\
\text { clientes }\end{array}$ & $\begin{array}{l}\text { Evitar que o entregador } \\
\text { fique indo e vindo } \\
\text { fazendo rotas não } \\
\text { estratégicas }\end{array}$ & Administrativo & Imediato & $\begin{array}{l}\text { Proprietários } \\
\text { da Pizzaria }\end{array}$ & $\begin{array}{l}\text { Segregando os clientes } \\
\text { em subgrupos de acordo } \\
\text { com a distância e } \\
\text { elaborando rotas } \\
\text { estratégicas para cada } \\
\text { grupo }\end{array}$ \\
\hline $\begin{array}{l}\text { Adequação dos } \\
\text { prazo de entrega } \\
\text { às distâncias dos } \\
\text { clientes }\end{array}$ & $\begin{array}{l}\text { Conscientizar clientes } \\
\text { mais distantes de um } \\
\text { prazo de entrega mais } \\
\text { longo }\end{array}$ & Administrativo & Imediato & $\begin{array}{l}\text { Proprietários } \\
\text { da Pizzaria }\end{array}$ & $\begin{array}{l}\text { Segregando os clientes em } \\
\text { subgrupos de acordo com } \\
\text { a distância e estipulando } \\
\text { tempos de entrega } \\
\text { diferentes para cada } \\
\text { grupo }\end{array}$ \\
\hline $\begin{array}{l}\text { Contratação de } \\
\text { mais um } \\
\text { entregador } \\
\text { terceirizado }\end{array}$ & $\begin{array}{l}\text { Descentralizar as } \\
\text { entregas de um único } \\
\text { motoqueiro }\end{array}$ & Administrativo & Imediato & $\begin{array}{l}\text { Proprietários } \\
\text { da Pizzaria }\end{array}$ & $\begin{array}{l}\text { Colocação de cartazes de } \\
\text { contratação e divulgando } \\
\text { avaga para conhecidos }\end{array}$ \\
\hline $\begin{array}{l}\text { Projeção de } \\
\text { necessidade de } \\
\text { matéria prima } \\
\text { futura }\end{array}$ & $\begin{array}{l}\text { Evitar compras de } \\
\text { quantidades } \\
\text { insuficientes de insumo }\end{array}$ & $\begin{array}{l}\text { Setor de } \\
\text { produção }\end{array}$ & Semanalmente & $\begin{array}{l}\text { Proprietários } \\
\text { da Pizzaria }\end{array}$ & $\begin{array}{l}\text { Elaborar uma projeção } \\
\text { semanal da quantidade } \\
\text { de insumo necessária } \\
\text { com base no histórico de } \\
\text { gastos }\end{array}$ \\
\hline $\begin{array}{l}\text { Controle e } \\
\text { organização dos } \\
\text { estoques de } \\
\text { matéria prima } \\
\end{array}$ & $\begin{array}{l}\text { Evitar atrasos por não } \\
\text { encontrar a matéria } \\
\text { prima em local de fácil } \\
\text { acesso }\end{array}$ & Cozinha & Diariamente & $\begin{array}{l}\text { Proprietários } \\
\text { da Pizzaria }\end{array}$ & $\begin{array}{l}\text { Conferência e } \\
\text { organização dos estoques }\end{array}$ \\
\hline $\begin{array}{l}\text { Controle e } \\
\text { organização da } \\
\text { armazenagem dos } \\
\text { utensílios }\end{array}$ & $\begin{array}{l}\text { Evitar atrasos por não } \\
\text { encontrar os utensílios } \\
\text { em local de fácil acesso }\end{array}$ & Almoxarifado & Diariamente & $\begin{array}{l}\text { Proprietários } \\
\text { da Pizzaria }\end{array}$ & $\begin{array}{l}\text { Conferência e } \\
\text { organização do } \\
\text { almoxarifado }\end{array}$ \\
\hline
\end{tabular}


(Continuação)

Figura 5 - Aplicação da ferramenta 5W1H

\begin{tabular}{|c|c|c|c|c|c|}
\hline \multicolumn{6}{|c|}{$5 W 1 H$} \\
\hline O que? & Por quê? & Onde? & Quando? & Quem? & Como? \\
\hline $\begin{array}{c}\text { Preparação de } \\
\text { massas congeladas } \\
\text { semi-prontas para o } \\
\text { final de semana }\end{array}$ & $\begin{array}{l}\text { Reduzir a sobrecarga dos } \\
\text { pizzaiolos durante o final } \\
\text { de semana }\end{array}$ & $\begin{array}{c}\text { Setor de } \\
\text { produção }\end{array}$ & Imediato & $\begin{array}{c}\text { Proprietários } \\
\text { da Pizzaria }\end{array}$ & $\begin{array}{l}\text { Preparação e } \\
\text { congelamento de } 15 \\
\text { massas por dia (terça a } \\
\text { quinta) para serem } \\
\text { utilizadas no final de } \\
\text { semana }\end{array}$ \\
\hline $\begin{array}{c}\text { Elaboração de um } \\
\text { procedimento/receit } \\
\text { a padrão para } \\
\text { confecç̧ão das pizzas }\end{array}$ & $\begin{array}{c}\text { Evitar o uso de } \\
\text { quantidades diferentes de } \\
\text { insumo em cada pizza }\end{array}$ & $\begin{array}{c}\text { Setor de } \\
\text { produção }\end{array}$ & Imediato & $\begin{array}{c}\text { Proprietários } \\
\text { da Pizzaria }\end{array}$ & $\begin{array}{l}\text { Elaborar um manual de } \\
\text { instruções para a } \\
\text { elaboração de cada sabor } \\
\text { de pizza, contendo } \\
\text { ingredientes e modo de } \\
\text { preparo }\end{array}$ \\
\hline
\end{tabular}

Fonte: Elaborado pelo autor (2018)

A aplicação das ferramentas da qualidade mostrou que a maior parcela do atraso nas entregas da Pizzaria $\mathrm{X}$ é causado pela sobrecarga do motoqueiro; inadequação das rotas para o motoqueiro; sobrecarga dos pizzaiolos aos finais de semana; alimentos armazenados no local incorreto; utensílios armazenados no local incorreto; ausência de um modo de preparo padrão; e compra insuficiente de ingredientes.

Em relação à dificuldade ocasionada pela inadequação das rotas, para encontrar a solução mais adequada é preciso, primeiramente, identificar a distância dos principais bairros clientes da Pizzaria e os tempos de entrega para tais clientes. Para isso, foi feito um levantamento dos clientes da Pizzaria X, por meio da técnica de observação, durante os dias 20/03/2018 a 25/03/2018 e os dados encontrados estão dispostos na figura 6.

Esse levantamento considerou a média de tempo de entrega e distância aproximada apenas para os bairros clientes durante a semana investigada e, tendo em vista que o cenário ideal para a empresa seria aquele no qual a entrega dos pedidos ocorra em até 30 minutos, percebe- se que a realidade se destoa do esperado em, praticamente, todas as regiões e, ao analisar o prazo de entrega de 40 minutos (o qual a pizzaria realmente se compromete a cumprir) nota-se que há atraso em $60 \%$ das regiões atendidas.

Figura 6 - Distância entre os clientes da Pizzaria e Tempo de entrega

\begin{tabular}{|l|c|c|}
\multicolumn{2}{|c}{$\begin{array}{c}\text { LOCAL CLIENTE (BAIRR0) } \\
\text { TEMPO TOTAL } \\
\text { (PREPARAÇÃO + } \\
\text { ENTREGA) }\end{array}$} & $\begin{array}{c}\text { DISTÂNCIA APROX } \\
\text { (CLIENTE E } \\
\text { PIZZARIA) }\end{array}$ \\
\hline Serrano & $00: 37$ & 2,00 \\
\hline Jaraguá & $00: 53$ & 6,00 \\
\hline Manacás & $00: 48$ & 2,50 \\
\hline Glória & $00: 44$ & 3,40 \\
\hline Caiçara & $00: 46$ & 3,00 \\
\hline Novo Ouro Preto & $00: 32$ & 1,30 \\
\hline Ouro Preto & $00: 34$ & 1,10 \\
\hline Castelo & $00: 27$ & 1,00 \\
\hline Engenho Nogueira & $00: 42$ & 2,00 \\
\hline Bandeirantes & $00: 46$ & 5,30 \\
\hline
\end{tabular}

Para entender mais claramente como os atrasos na entrega dos pedidos têm se relacionado com a localização dos clientes, foi elaborado um Gráfico Radar que demonstra o percentual de pedidos em atraso e a distância dos bairros atendidos na semana analisada (figura 7). Nota- se que os atrasos acontecem até mesmo nos bairros próximos em função do efeito cascata no processo de entrega das pizzas. 
Figura 7 - Gráfico Radar (Porcentagem de atraso por bairros)

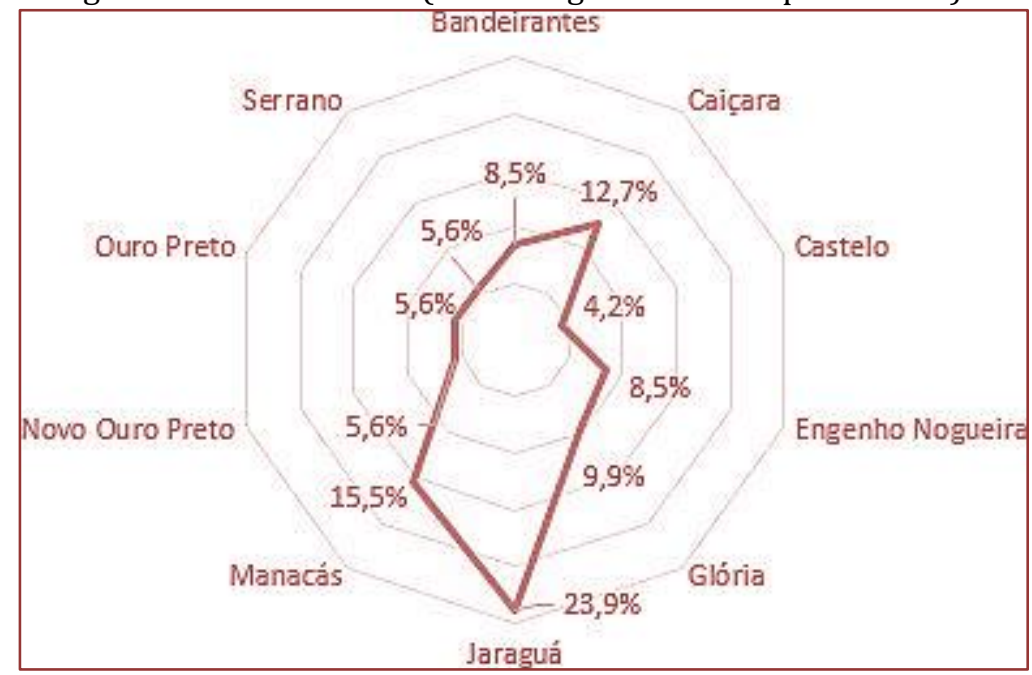

Fonte: Elaborado pelo autor (2018)

A aplicação do Gráfico Radar corrobora a hipótese de que os bairros mais distantes da pizzaria demandam maior tempo de entrega. Assim, para encontrar a solução mais adequada para o problema de roteirização é preciso, primeiramente, identificar as distancias extremas, ou seja, a menor e a maior distância entre os clientes da Pizzaria. Feito isso, identificam-se, em seguida, as demais distâncias que se encaixam entre esses valores.

As distâncias podem ser agrupadas em 3 grupos: inferior ou igual à $2 \mathrm{~km}$; superior à $2 \mathrm{~km}$ e inferior ou igual à $5 \mathrm{~km}$; e superior à $5 \mathrm{~km}$ e inferior à $7 \mathrm{~km}$. Diante disso, a primeira medida a ser implementada para solucionar essa questão é a adequação do prazo de entrega proposto considerando esses 3 grupos de distância. Para os bairros que se enquadram no primeiro grupo e, portanto, estão mais próximos da pizzaria, o prazo de entrega deverá ser de 40 minutos. 0 segundo grupo, por sua vez, contará com um prazo de entrega de 45 minutos. 0 maior prazo, 50 minutos, será oferecido para os bairros cujas distâncias até a pizzaria são maiores $5 \mathrm{~km}$ e menores que $7 \mathrm{~km}$.

A roteirização também deverá ser realizada de acordo com os grupos de distância estipulados, ou seja, as entregas realizadas pelo entregador 1 serão apenas para clientes com distância inferior ou igual à $2 \mathrm{~km}$, já que estes são a maior demanda. Enquanto o entregador contratado será responsável pelas entregas das regiões com distância superior à $2 \mathrm{~km}$ e inferior ou igual à $5 \mathrm{~km}$ e superior à $5 \mathrm{~km}$ e inferior à $7 \mathrm{~km}$. Assim, com um raio menor de entregas, serão elaboradas rotas mais estratégicas para cada motoqueiro e os entregadores darão menos voltas.

Para que essa medida seja aplicada satisfatoriamente, ela deve ser implementada juntamente à outra melhoria, que solucionará também a questão de sobrecarga do entregador: a contratação de mais um motoqueiro terceirizado, já que o entregador atual encontra-se extremamente sobrecarregado e, dessa forma, a Pizzaria X solucionará ambos os problemas de uma só vez.

Para solucionar o problema de compras inadequadas matérias prima, a primeira ação corretiva é análise das quantidades utilizadas anteriormente. Os proprietários da pizzaria devem buscar o histórico de vendas dos últimos meses e elencar os principais sabores de pizza vendidos, dessa forma, eles saberão quais são os sabores mais vendidos e poderão priorizar os pedidos de matéria-prima e realizar projeções semanais de demanda.

Assim, o pedido semanal de novos ingredientes deve sempre considerar o histórico de demanda, a situação atual da pizzaria, além do estoque de segurança que deve corresponder $10 \%$ da demanda total projetada, servindo de garantia para a empresa em caso de aumento inesperado de pedidos de clientes ou demais eventualidades referentes aos ingredientes em estoque.

Para o bom funcionamento do negócio é imprescindível que seja feito também o controle diários do estoque e almoxarifado. Todos os dias, ao início do expediente, os ingredientes disponíveis no estoque e os utensílios do almoxarifado devem ser contados e avaliados em relação ao bom estado e condições de armazenamento, assim, previne-se problemas relacionados aos ingredientes e utensílios durante o processo de preparação das pizzas. 
Essa proposta de organização do espaço do estoque, identificação, separação dos ingredientes em estoque e definição dos seus locais reflete a metodologia dos 5S que, segundo Lapa (1997), deriva de 5 palavras japonesas: Seiri (Utilização), Seiton (arrumação), Seiso (limpeza), Seiketsu (higiene), Shitsuke (Disciplina) e tem como objetivo mobilizar, motivar e conscientizar a organização para a Qualidade Total, através da organização e da disciplina no local de trabalho.

Para solucionar o problema de sobrecarga dos pizzaiolos durante os finais de semana, uma proposta corretiva eficaz seria a confecção de massas semi-prontas durante a semana, que seriam congeladas e utilizadas nos finais de semana. Essa medida é considerada viável ao passo que durante a semana (terça a quinta) a Pizzaria possui mão de obra ociosa enquanto aos finais de semana existe uma sobrecarga dos pizzaiolos, conforme figura 8.

Figura 8 - Folha de verificação do expediente dos pizzaiolos

\section{FOLHA DE VERIFICAÇÃO}

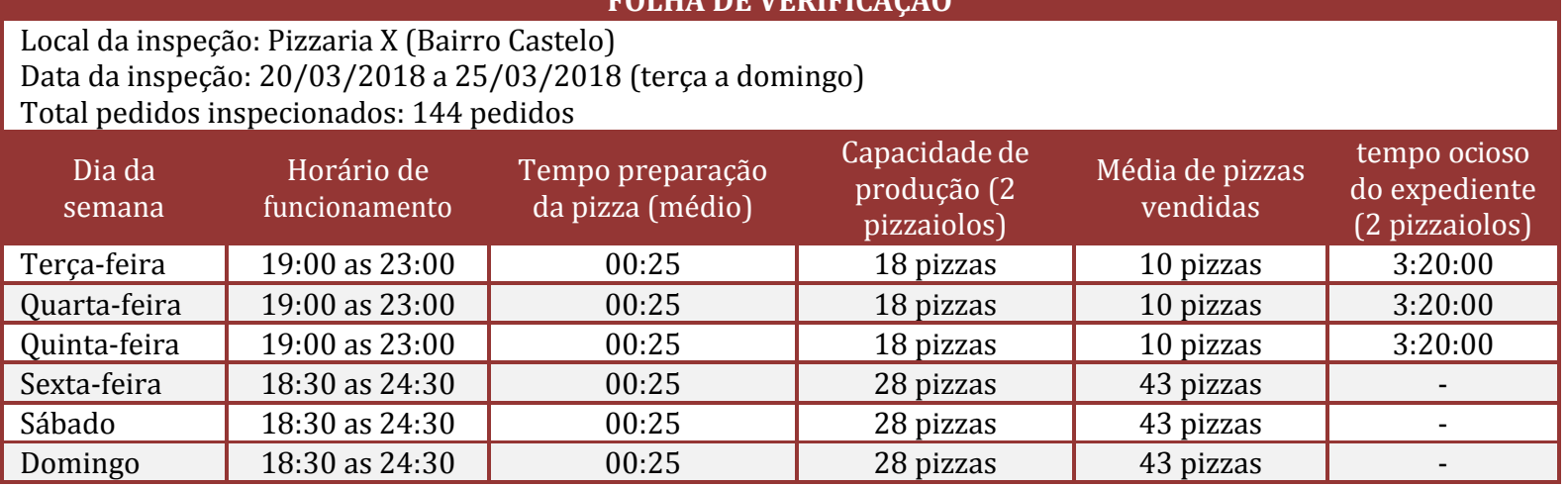

Fonte: Elaborado pelo autor (2018)

Aproveitando o tempo ocioso de 3 horas e 20 minutos (terça, quarta e quinta-feira), os pizzaiolos, juntos, conseguiriam preparar cerca de 15 massas por dia, totalizando 45 massas prontas ao final da semana e, assim, agilizar o processo de produção das pizzas nos dias de alta demanda (sexta, sábado e domingo). Como as massas podem permanecer congeladas, sem perder a qualidade e sabor, por até nove dias no freezer, a produção e congelamento semanal das massas é o mais indicado para a Pizzaria X.

Outra medida corretiva recomendada é que a cronometragem de todo o processo produtivo das pizzas e registro dos os resultados obtidos para posterior análise. Isso seria positivo para os pizzaiolos, pois os permitirá enxergar qual etapa da sua produção dispende mais tempo e, então, serem ainda mais atenciosos nesses momentos, para evitar erros e atrasos.

Por fim, os proprietários devem elaborar um manual de instruções para cada um contendo o modo padrão de preparo das pizzas e também fazer pequenos pacotes com as quantidades de ingredientes utilizada para evitar a produção de pizzas com massas e recheios diferentes e gastos exagerados (ou insuficientes) de insumos. Assim, todas as pizzas teriam o mesmo aspecto, tamanho, quantidade de ingredientes e modo de preparo.

\section{CONSIDERAÇÕES FINAIS}

A gestão da qualidade como uma ferramenta estratégica é necessária para manter a sobrevivência da empresa em um cenário mercadológico cada vez mais globalizado e competitivo. Diante disso, o presente estudo orientou-se pelo Método de Solução e Análise de Problemas (MASP) e buscou identificar as falhas de processo e gargalos de produção que vinham ocasionando atrasos nas entregas da Pizzaria X. As principais causas encontradas foram analisadas e solucionadas com a aplicação das ferramentas da qualidade que objetivaram as causas-raiz e, então, propor melhorias e ações corretivas eficazes.

A aplicação do Diagrama de Pareto auxiliou na ordenação das principais causas para orientar as próximas etapas da pesquisa, enquanto a execução do brainstorming permitiu obter as possíveis causas na elaboração do diagrama de Ishikawa. Feito isso, foram elaboradas as propostas de melhoras e planos de ação baseados na ferramenta $5 \mathrm{~W} 1 \mathrm{H}$. 
As próximas etapas do processo consistem em executar o plano de ação proposto e avaliar a sua efetividade para certificar se o bloqueio das causas foi efetivo. Efetivado o bloqueio, segue-se a padronização e monitoramento contínuo do processo. Com o monitoramento, será possível verificar novas oportunidades de melhoria e planejar a solução dos problemas remanescentes.

\section{REFERÊNCIAS}

[1] CAMPOS, V. TQC Controle da Qualidade Total - no estilo japonês. 9 ed. Nova Lima: Editora Falconi, 2004.

[2] CARPINETTI, L. Gestão da Qualidade Conceitos e Técnicas. São Paulo: Atlas, 2012.

[3] KUME, H. Métodos Estatísticos para Melhoria da Qualidade. São Paulo: Editora Gente, 1993.

[4] LAKATOS, E. M; MARCONI, M. A. Técnicas de pesquisa: planejamento e execução de pesquisas, amostragens e técnicas de pesquisa, elaboração, análise e interpretação de dados. 7. ed. São Paulo: Atlas, 2009.

[5] JUSE UNION OF JAPANESE SCIENTISTS AND ENGINEERS. Chapter 8 prof. ishikawa and quality control. Disponível em: <https://www.juse.or.jp/english/archives/pdf/ch08_ver2a_150803.pdf>. Acesso em: 15 mai. 2018.

[6] LAPA, Reginaldo. Praticando os 5 S e Programa 5S. São Paulo: Qualitymark, 1997.

[7] MACHADO, R. H. C.; HELLENO, A. L.; LIMA, C. R. C. Análise da eficiência operacional de uma linha de produção da indústria de laticínios por meio do indicador de Eficiência Global de Equipamentos (Overall Equipment Effectiveness). Exacta - EP, São Paulo, v. 14, n. 4, p. 635-644, 2016.

[8] MARTINELLI, F. Gestão da qualidade total. São Paulo: Iesde, 2009.

[9] MENEZES, F. M. MASP: Metodologia de Análise e Solução de Problemas. Porto Alegre, Produttare, 2013.

[10] OLIVEIRA, D. P. R. Planejamento Estratégico: Conceitos, metodologias e práticas. 26. ed. São Paulo: Atlas, 2009.

[11] ROTH, C. W. Qualidade e Produtividade. 3. ed. Rio Grande do Sul: Colégio Técnico Industrial e UFSM, 2011.

[12] SELEME, R.; STADLER, H. Controle da qualidade: As ferramentas essenciais. Curitiba: 2. ed Ibpex, p.27- 56, 2010.

[13] VIEIRA, S. Estatística para qualidade: como avaliar com precisão a qualidade em produtos e serviços.

[14] 10.ed. Rio de Janeiro: Elsevier, 1999.

[15] WERKEMA, M. Ferramentas estatísticas básicas para o gerenciamento de processos. Minas Gerais: Fundação Christiano Ottoni, Escola de Engenharia da UFMG, 1995.

[16] WERKEMA, M. Ferramentas estáticas básicas para gerenciamento de processos. Belo Horizonte: Werkema, 2006. 


\section{Capitulo 12}

Melhoria do processo produtivo de uma pequena empresa através da análise do mapeamento de fluxo e valor

\section{Luiz Claudio Lopes Pinheiro}

Carlo Rossano Manica

Resumo: 0 propósito desta pesquisa é mapear os processos produtivos de uma pequena empresa identificando os desperdícios ao longo da cadeia produtiva com o intuito de proporcionar maior competividade para empresa em estudo. Assim, tem-se como objetivos específicos identificar os processos produtivos da empresa e propor uma novo Mapa de Fluxo de Valor. Para tal, após realizada revisão da literatura com os principais autores que estudam a produção enxuta e o mapa de fluxo de valor foi possível iniciar o estudo de caso na empresa em questão com a aplicação da ferramenta Mapeamento de Fluxo e Valor. A coleta de dados deu-se com base nos documentos disponibilizados pela empresa e nas observações do pesquisador quanto aos tempos de ciclo. Feito isso, os resultados demonstraram que a empresa tem muitas atividades que não agregavam valor; altos estoques de matéria prima, de processos e de produtos acabados e, ainda, que o tempo de lead time poderia ser reduzido.

\section{Implicações práticas:}

Palavras-chave: Mapeamento de Fluxo de Valor, Desperdício, Produção Enxuta. 


\section{INTRODUÇÃO}

As práticas da produção enxuta podem contribuir para o desempenho das Micro e Pequenas Empresas (MPEs). Uma das ferramentas mais importantes para iniciar a avaliação do processo produtivo é o Mapeamento de Fluxo e Valor, uma vez que se trata de uma forma de identificar os processos da empresa, desde a entrada do pedido, o processamento até a saída do produto acabado. Conforme Rother e Shook (2003), o Mapeamento de Fluxo e Valor pode ser instrumento de planejamento, instrumento de comunicação e também um instrumento para gerenciar a mudança.

Uma maneira de diminuir custos e otimizar recursos é evitar ao máximo os desperdícios, que devem ser identificados em toda a cadeia de valor de cada produto para posterior eliminação. Segundo Martins e Laugeni (2005), a cadeia de valor abrange a definição do produto, o gerenciamento de informações, desde o aceite do pedido até o planejamento detalhado da entrega e a transformação física dos materiais. 0 processo deve ser desenhado de modo a atingir um fluxo contínuo e, assim, produzir e entregar o produto na hora certa.

É importante que os proprietários de micro e pequenas empresas repensem seus processos de produção para evitar desperdícios, quebrando paradigmas que acreditam que basta produzir bastante para a empresa estar bem. É necessário propor estratégias para a melhoria do processo produtivo. Nessa perspectiva, o presente artigo propõe refletir como o Mapeamento de Fluxo e Valor pode ajudar na melhoria do processo produtivo de uma pequena empresa, baseando-se no sistema de produção enxuta.

\section{REVISÃO BIBLIOGRÁFICA}

\subsection{PRODUÇÃO ENXUTA}

Produção enxuta, termo cunhado no livro A máquina que mudou o mundo, de James Womack, Daniel Jones e Daniel Roos (1992), consiste em um sistema de produção baseado na concepção do Sistema Toyota de Produção (STP), que teve início logo após a Segunda Guerra Mundial (SHIMOKAWA; FUJIMOTO, 2011).

Na produção enxuta, costuma-se usar uma casa como uma metáfora que facilita o entendimento do sistema STP (LIKER, 2005). Como um sistema estrutural, a casa precisa de telhado, colunas e bases fortes, pois se qualquer uma de suas partes estiver fragilizada, será comprometido todo o sistema. Na Figura 1, está a ilustração do diagrama de casa STP:

Figura 1 - 0 diagrama da Casa do STP

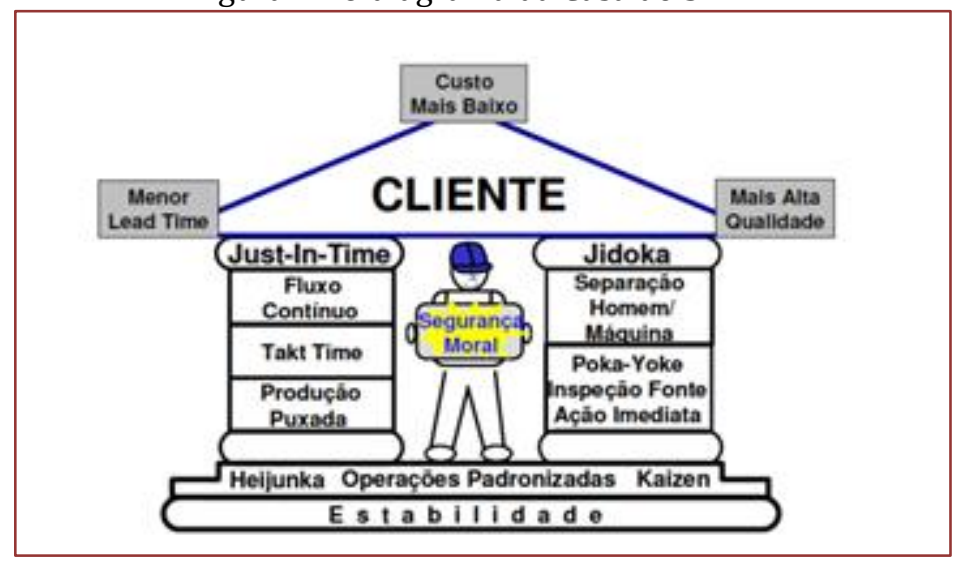

Fonte: Ghinato (2000).

Para manter a estrutura, os pilares (Just-in-time e Jidoka) são apoiados na base, onde estão a estabilidade e a padronização. 0 telhado simboliza o cliente. No centro da casa, encontram-se as pessoas (colaboradores), que são o coração do sistema, pois garantem a estabilidade necessária para a operação e terão a capacidade de identificar as perdas e eliminar as causas dos problemas (LIKER, 2005). 


\subsubsection{JUST-IN-TIME}

O Just-in-time ou JIT é o conjunto de conceitos, ferramentas e técnicas que permite que a empresa atenda à demanda do cliente, produzindo e entregando produtos em pequenas quantidades, ou seja, os itens corretos na hora certa (LIKER, 2005).

Desse modo, o objetivo do JIT é identificar, localizar e eliminar as perdas, garantindo um fluxo contínuo de produção. A eficácia do JIT depende de três fatores, que estão diretamente relacionados: Takt time, fluxo contínuo e produção puxada.

O Takt time é utilizado para dar o ritmo da produção, conforme o andamento das vendas. Fornece um número de referência, que dá a noção do ritmo em que cada processo deve estar produzindo e, assim, ajuda a visualizar como as coisas estão indo e quais iniciativas tomar para melhorar (ROTHER; SHOOK, 2003).

Por sua vez, o fluxo contínuo, conforme Ghinato (2000), surge como solução à necessidade de reduzir o lead time de produção. A aplicação de um fluxo contínuo na cadeia produtiva, em geral, exige a reorganização e o rearranjo do layout da empresa, transformando os tradicionais layouts funcionais (ou layouts por processos), em que as máquinas e os recursos agrupam-se de acordo com seus processos, em células de manufatura, compostas das diferentes etapas da fabricação de uma família de produtos.

Quanto a "produção puxada", o termo é empregado de forma intercambiável com o conceito de "fluxo". 0 fluxo indica o estado do material à medida que passa de um processo a outro. 0 sistema puxado, por sua vez, indica o momento em que o material é movimentado e quem determina esse movimento, que é o cliente (LIKER; MEIER, 2007).

Rother e Shook (2003) lembram que na produção onde não é possível ter um fluxo contínuo se pode usar o estoque de supermercado para interligar o processo cliente com o processo fornecedor. Aqui, a produção será puxada através de um cartão Kanban.

\subsubsection{JIDOKA}

0 pilar da autonomação ou Jidoka permite à máquina ou ao operador a autonomia de parar a máquina sempre que detectar algo anormal, ou quando a quantidade planejada foi atingida. Com esse recurso, a qualidade na estação de trabalho aumenta, impedindo que os problemas passem adiante (LIKER, 2005).

Isso possibilitou a operação simultânea de várias máquinas e, mais tarde, a implementação nas máquinas da capacidade de detectar anormalidades.

\subsection{AS PERDAS DO PROCESSO PRODUTIVO}

Segundo Shingo (1996), o Sistema Toyota de Produção tem como principal propósito a eliminação de perdas, sendo fundamental a organização identificar essas perdas em seus processos produtivos, para iniciar uma jornada de produção enxuta.

A Toyota identificou sete desperdícios ao longo do processo administrativo ou produtivo. Liker (2005) descreveu os sete desperdícios que são as perdas ao longo do processo que não agregam valor ao produto ou serviço, e ainda acrescentou um oitavo desperdício. Então, conforme Liker (2005), os desperdícios são por:

a) superprodução: consiste em produzir a mais do que a demanda;

b) espera (tempo sem trabalho): ocorre quando os funcionários ficam com tempo ocioso;

c) transporte: são os movimentos desnecessários de operadores e transporte ineficientes de produtos;

d) superprocessamento: trata-se de etapas desnecessárias para processar produtos devido a um projeto de baixa qualidade;

e) excesso de estoque: produtos ou materiais estocados desnecessariamente;

f) movimentação: movimento inútil de funcionários;

g) defeito: consertos que geram retrabalhos; 
h) desperdício da criatividade dos funcionários: perda de tempo, ideias, habilidades, melhorias e oportunidades de aprendizagem.

\subsection{KAIZEN}

Uma das formas de reduzir desperdícios é com a utilização do Kaizen. Esse é uma metodologia útil tanto, para melhorar o fluxo de valor completo quanto para melhorar um processo pontual de forma específica.

Rother e Shook (2003), descreve dois tipos de Kaizen, que são:

a) Kaizen de processo: concentra-se em processos individuas, eliminando os desperdícios nas operações.

b) Kaizen de fluxo: consiste na melhora do fluxo de valor, sendo de responsabilidade da gerência.

\subsection{MAPEAMENTO DO FLUXO DE VALOR (MFV)}

Segundo Rother e Shook (2003), o método MFV, que é usado na manufatura enxuta, foi adaptado por Rother e John, a partir do diagrama de fluxo de material e informação. De acordo com os autores, o MFV é uma ferramenta valiosa que nos auxilia a enxergar e compreender o fluxo de informação e o material na medida em que o produto ou serviço segue o fluxo de valor.

Rother e Shook (2003) propõem alguns símbolos a serem considerados na representação do mapa do estado atual e futuro, conforme a Figura 2.

Figura 2 - Figuras para utilizar no mapeamento de fluxo

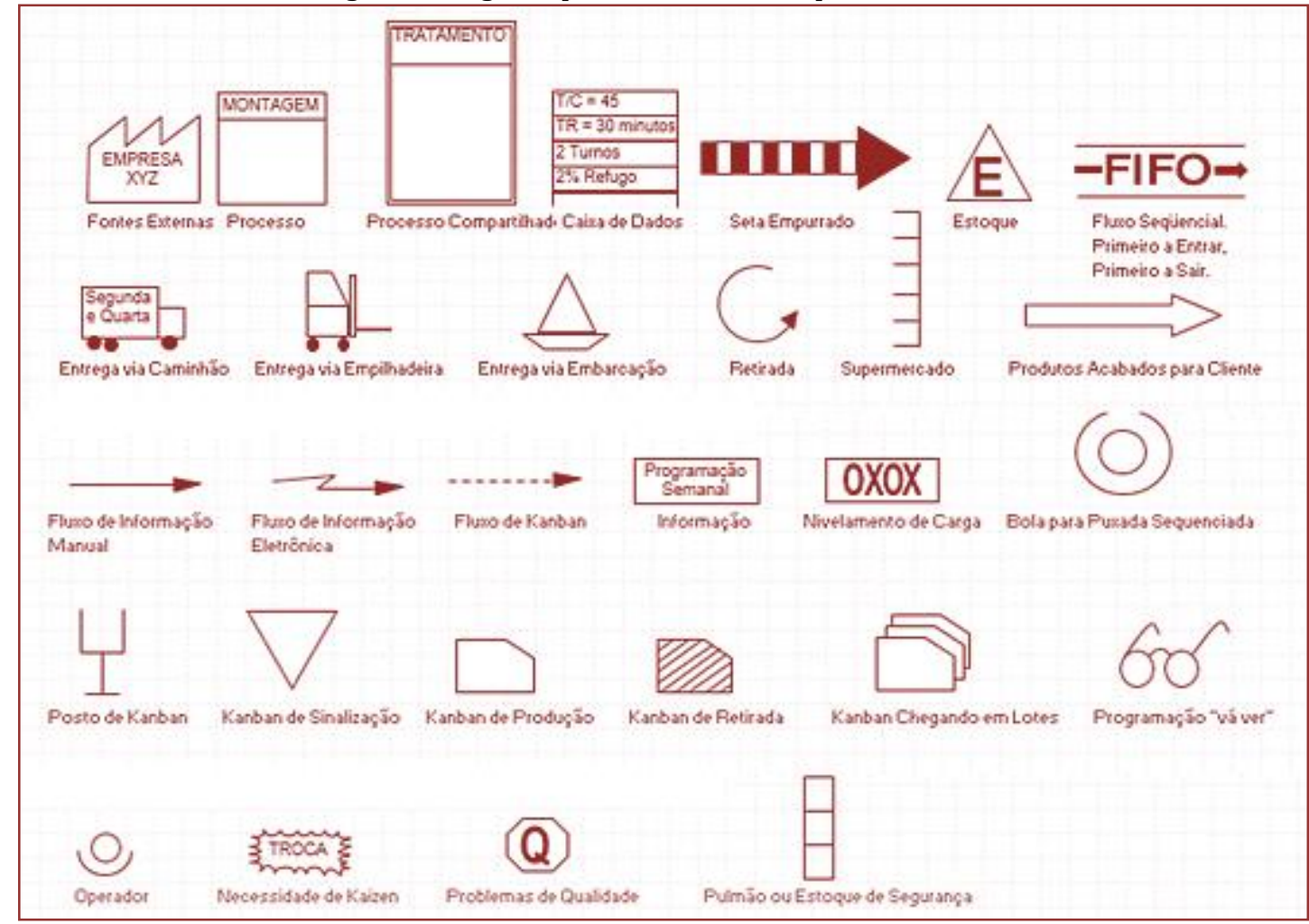

Fonte: Rother e Shook (2003).

Conforme Rother e Shook (2003), o Mapeamento de Fluxo e Valor pode ser instrumento de planejamento, instrumento de comunicação e também um instrumento para gerenciar a mudança. Os autores ainda ressaltam que para aprender a mapear deve-se praticar até que a aplicação do MFV se torne intuitiva. Na Figura 3, define-se o escopo para realizar o mapeamento. 
Figura 3 - Etapas para criar o Fluxo de valor

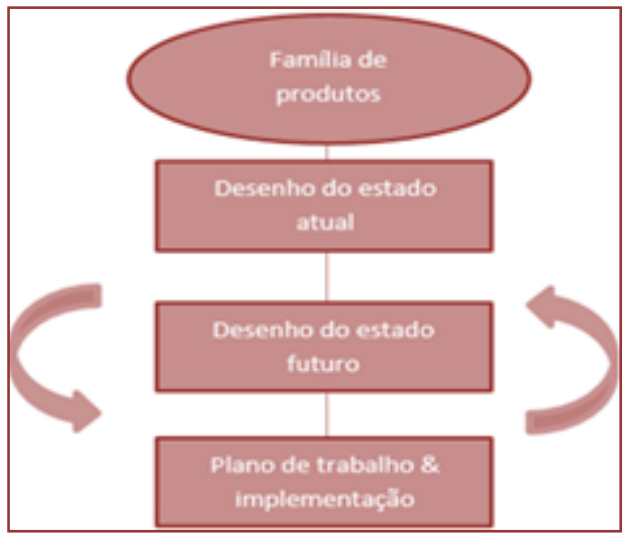

Fonte: Rother e Shook (2003)

\subsubsection{IDENTIFICAÇÃO DA FAMÍLIA DE PRODUTOS}

Para Rother e Shook (2003), a seleção da família de produtos inicia-se a partir do cliente no fluxo de valor. Os autores ainda esclarecem que, para identificar esse grupo de família, é necessário analisar os produtos que passam por etapas de transformação semelhantes, ou seja, que utilizam equipamentos e processos semelhantes.

Na Figura 4, são ilustrados alguns produtos, as suas etapas de montagem e quais pertencem à mesma família.

Figura 4 - Identificação da família de produtos

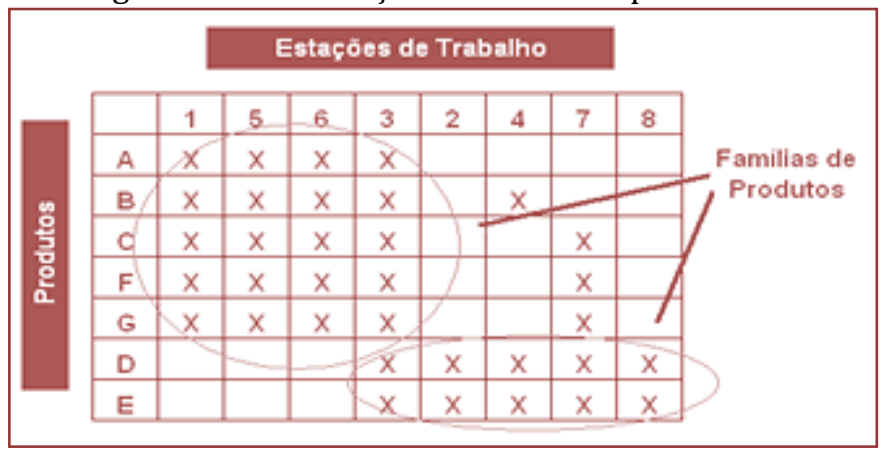

Fonte: Rother e Shook (2003).

\subsubsection{DESENHANDO O MAPA DE FLUXO DE VALOR DO ESTADO ATUAL}

Liker e Meier (2007) afirmam que o propósito do mapeamento é identificar falhas no fluxo de valor das organizações. 0 objetivo do mapa do estado atual é compreender a natureza dos processos de forma que um mapa do estado futuro possa ser criado.

Segundo Womack (2011), o mapeamento do fluxo de valor do estado atual é uma ferramenta útil para avaliar o estado de qualquer processo. Os mapas devem representar todos as fases do processo; verificando se cada etapa é válida, capaz, disponível, adequada e flexível; e evidenciando se o fluxo de valor segue de uma etapa para outra puxado pelo cliente.

\subsubsection{DESENHANDO UM NOVO MAPA DE FLUXO DE VALOR}

Ainda segundo Rother e Shook (2003), a meta do MFV futuro é alcançar uma cadeia de valor onde os processos isolados venham a se tornar fluxos contínuos ou puxados que atendam às necessidades dos clientes de forma adequada e no momento preciso para, assim, satisfazer suas expectativas em relação aos produtos ou serviços. Os autores ainda contempla que estado futuro mostra aonde você deseja chegar, e deve-se estruturar um plano de ação. 
Tubino (2009) afirma que uma forma de organizar seu plano de ação e controlar suas ações e responsabilidades sobre as tarefas a serem executadas é com a ferramenta $5 \mathrm{~W} 1 \mathrm{H}$. Sua metodologia tem origem nos termos why (por que), what (o quê), who (quem), when (quando), where (onde) e how (como), e consiste em montar uma tabela de verificação a partir dessas seis questões a serem respondidas.

\section{PROCEDIMENTOS METODOLÓGICOS}

0 estudo foi realizado em uma empresa localizada na região metropolitana de Porto Alegre-RS, fundada em 2010, especializada em soluções para gerenciamento de fiações, componentes eletroeletrônicos e armários (quadro de comando).

0 delineamento da pesquisa é de natureza aplicada, com abordagem qualitativa, sendo descritiva do ponto de vista do seu objetivo. Quanto aos procedimentos, trata-se de um estudo de caso e de aplicação da ferramenta de Mapeamento de Fluxo e Valor para análise de dados e proposta de solução de problemas. As etapas da pesquisa estão descritas na Figura 5.

Figura 5 - Identificação das etapas do estudo

\begin{tabular}{|c|c|c|c|}
\hline Etapa 1 & Etapa 2 & Etapa 3 & Etapa 4 \\
\hline Elaboração do projeto: & Coleta de dados: & Analise dos dados: & Resultados: \\
\hline $\begin{array}{l}\text { Delimitação do tema } \\
\text { Definição dos objetivos } \\
\text { Revisăo teórica }\end{array}$ & $\begin{array}{l}\text { Identificação do processo } \\
\text { Escolha da familia de produto } \\
\text { Tempo de ciclo } \\
\text { Tempo de valor nåo agregado } \\
\text { Confiabilidade } \\
\text { Número de operadores } \\
\text { Estoque }\end{array}$ & $\begin{array}{l}\text { Desenho do MFV atual } \\
\text { Análise dos desperdícios }\end{array}$ & $\begin{array}{l}\text { Desenho do MFV futuro } \\
\text { Plano de açăo }\end{array}$ \\
\hline
\end{tabular}

Fonte: Elaborado pelo autor.

A observação dessas etapas permitiu o desenho do Mapa de Fluxo de Valor futuro, a partir do qual se estabeleceu um Plano de Ação.

\section{RESULTADOS}

\subsection{DESCRIÇÃO DOS PROCESSOS DA EMPRESA}

Para identificar informações relevantes ao estudo, primeiramente identificou-se quais são os processos produtivos de modo a facilitar o entendimento e criar um fluxo básico dos processos de fabricação, conforme a Figura 6.

Figura 6 - Processos produtivos

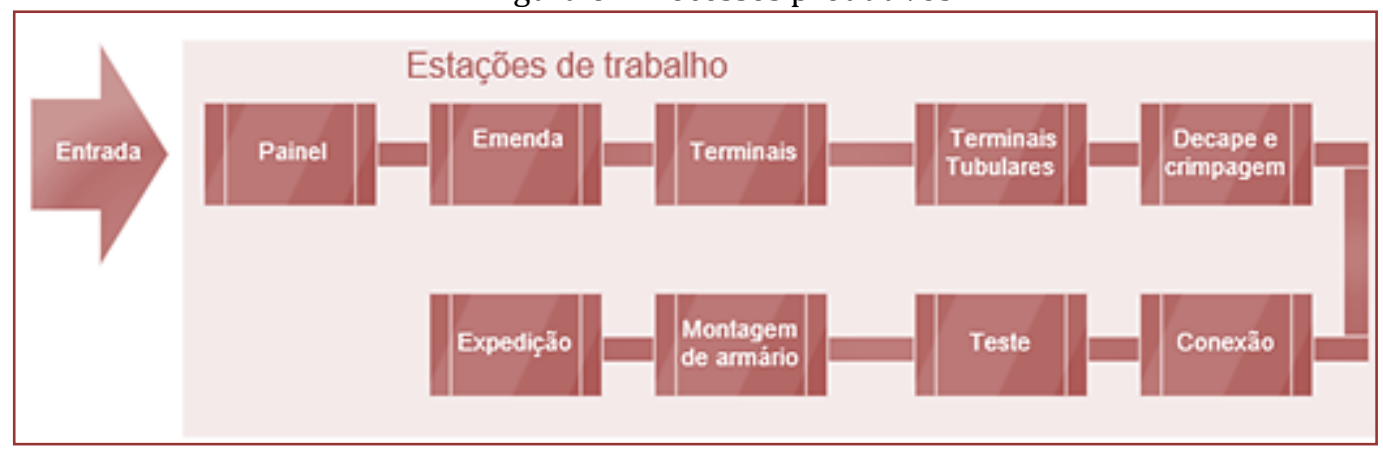

Fonte: Elaborado pelo autor. 
Uma vez identificado o fluxo dos processos de produção, observou-se as atividades de cada processo. Esta análise foi realizada através da observação de cada etapa de transformação e da indagação aos colaboradores sobre os procedimentos necessários para cada um dos processos.

É importante ressaltar que, para o entendimento do fluxo de valor, a visita na fábrica teve início na expedição, ou seja, ao contrário da ordem mais usual, que é sempre iniciar a visita no recebimento de matéria-prima, seguindo cada etapa do processo até a última. Conforme Liker e Meier (2007), a visitação do chão de fábrica (Gemba) deve iniciar no final do fluxo, e isso não se trata de um macete, mas de um modo de visualizar o processo na perspectiva do cliente, que deseja saber para onde o material vai e não de onde o material vem.

\subsection{IDENTIFICAÇÃO DA FAMÍLIA DE PRODUTOS QUE SERÁ ANALISADA NO MFV}

Realizou-se uma análise das famílias de produtos que são de maior relevância para a empresa e que representam a maior demanda, conforme Rother e Shook (2003). No Gráfico 1 da página seguinte, estão os dados obtidos entre janeiro e junho de 2017, a partir das informações fornecidas pelo Setor Comercial da empresa:

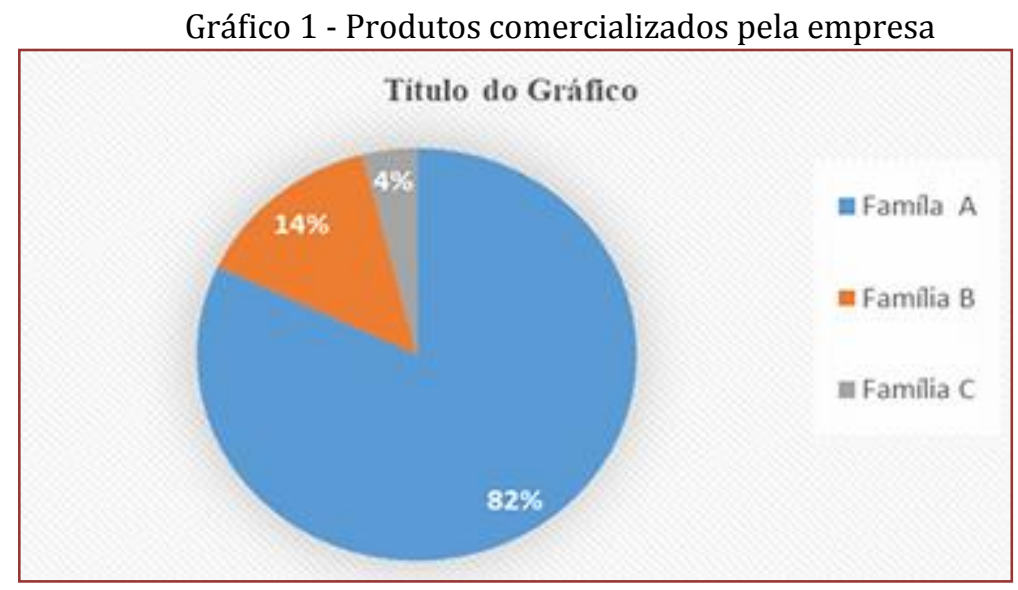

Fonte: Elaborado pelo autor.

A Família A representa $82 \%$ dos produtos comercializados pela empresa e, por isso, foi escolhida para a aplicação do MFV do estado atual. No caso desse estudo, escolheu-se um produto dessa família, que vamos chamar de produto Armário "ALFA".

\subsection{IDENTIFICAÇÃO DO MAPA DE FLUXO DE VALOR DO ESTADO ATUAL}

O MFV do estado atual da empresa foi desenhado principalmente com base nos dados e informações coletados no chão de fábrica e nas áreas de apoio, conforme já citado na metodologia.

Para a análise do mapa do estado atual, propõe-se a divisão em três loops, que são: loop 1, do cliente, loop 2, da manufatura e loop3, do fornecedor que serão apresentados na Figura 7 da página a seguir. 
Figura 7 - Mapa de Fluxo de Valor do Estado Atual

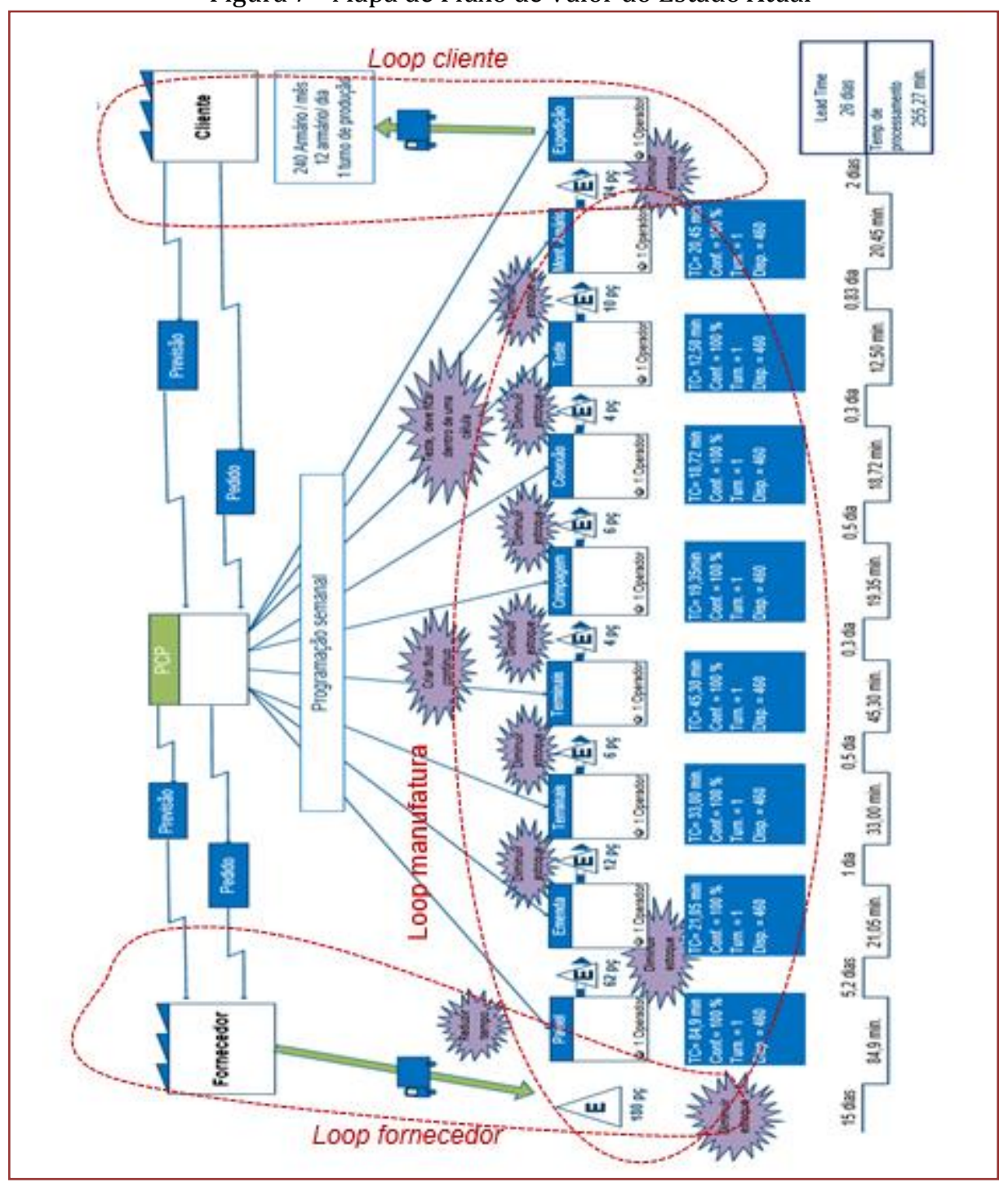

Fonte: Elaborado pelo autor.

\subsection{IDENTIFICAÇÃO DOS DESPERDÍCIOS DO MFV ATUAL}

Com a análise do mapa atual, foram identificadas as perdas no sistema produtivo. Na sequência, serão descritos os desperdícios mais relevantes no mapa atual para a proposição de um mapa futuro:

a) desperdícios de superprodução: verificou-se superprodução por antecipação em todas as etapas de fabricação, no setor de painel. Esse foi o principal desperdício devido a fabricação ser realizada bem antes da entrega para o cliente.

b) desperdício de espera: ocorreu devido ao alto volume de produtos esperando para ser processados entre os postos de trabalho.

c) desperdício em transporte: identificou-se grandes desperdícios de transporte, dos produtos em elaboração, ao longo do processo de transformação, pois não há uma sequência nas operações que leve em conta as distâncias dos postos de trabalho.

d) desperdício de processamento: não foi encontrado desperdício de processamento, pois a empresa só fabrica o produto conforme as especificações do cliente.

e) desperdício de estoque: há estoques de matéria-prima, de produtos acabados e estoques de processo, cujas respectivas quantidades estão registradas abaixo dos triângulos do mapa. 
f) desperdício de movimento: os operadores se movimentavam para buscar materiais no almoxarifado e ferramentas que estavam fora do local de trabalho, gastando tempo excessivo para procurar material no posto, gerando movimentos desnecessários que não agregam valor durante a operação;

g) desperdício por defeito: todos os defeitos que ocorrem no processo de fabricação só são percebidos na etapa de teste, havendo perda de cerca de $3 \%$ no processo produtivo por dia, sendo que o produto enviado ao cliente tem uma margem de 0,01\% de defeito;

h) desperdício da criatividade: os operadores com formação técnica são subaproveitados nas funções, executando tarefas simples para o seu grau de conhecimento. Outra forma de desperdício de criatividade diz respeito ao não aproveitamento das ideias sugeridas pelos colaboradores.

\subsection{IDENTIFICAÇÃO DO MFV FUTURO}

Conforme Rother e Shook (2003), para realização do MFV futuro, primeiramente é necessário identificar os pontos-chave para o estado futuro, que que serão descritos a seguir.

\subsubsection{O TAKT TIME: RITMO QUE O CLIENTE SOLICITA OS PRODUTOS}

Para obter o resultado do takt time, foram levantados informações junto ao departamento de PCP e comercial, sobre as quantidades de produtos solicitados pelo cliente, o tempo disponível para produção e o tempo de intervalos. De acordo com Rother e Shook (2003), o cálculo do takt time é obtido pela fórmula, conforme apresentado na figura 8 a seguir.

Figura 8 - Cálculo do takt

\begin{tabular}{|c|c|c|c|c|}
\hline \multirow{2}{*}{ Dados } & \multirow{2}{*}{ Valor } & \multicolumn{3}{|c|}{ Cálculo } \\
\hline & & \multirow{2}{*}{ Tempo takt } & \multicolumn{2}{|c|}{ tempo de trabalho disponivel por turno } \\
\hline Demanda do cliente (dia ) & 12 unidades por turno & & demanda do & por turno \\
\hline $\begin{array}{l}\text { Tempo disponivel da } \\
\text { produção }\end{array}$ & 480 minutos & & $480-20$ & 38,33 minutos \\
\hline Intervalos & 20 minutos & Tempo takt = & 12 & \\
\hline
\end{tabular}

Fonte: Elaborado pelo autor.

\subsubsection{PRODUÇÃO DIRETA PARA EXPEDIÇÃO OU PARA SUPERMERCADO DE PRODUTOS ACABADOS}

Como a empresa não tem uma previsão confiável da demanda do cliente, produzir diretamente para expedição é um risco de não atender os prazos de entrega. Dessa forma, em um primeiro momento, foi proposta no MFV futuro a implementação de um estoque supermercado de produtos acabados entre a expedição e o último processo, conforme proposto por Rother e Harris (2003).

\subsubsection{IMPLEMENTAÇÃO DO FLUXO CONTÍNUO}

Segundo Rother e Harris (2003), um dos principais objetivos do MFV é a criação do fluxo continuo, sendo que o fluxo pode ser conseguido através de linha de montagem ou de células de montagem. Verificou-se que o volume da produção não tem continuidade, acarretando em pequenas pilhas de estoque acumuladas entre as operações. Isso se dá por não haver um entendimento da importância da utilização do takt time.

Para obter o mapa futuro, primeiro foi desenvolvido um gráfico com os tempos de cada processo do produto analisado, comparado com o takt time. 0 Gráfico 2 da página a seguir apresenta os tempos de ciclos das estações de trabalho na empresa em análise. 
Gráfico 2 - Tempos de ciclos atuais

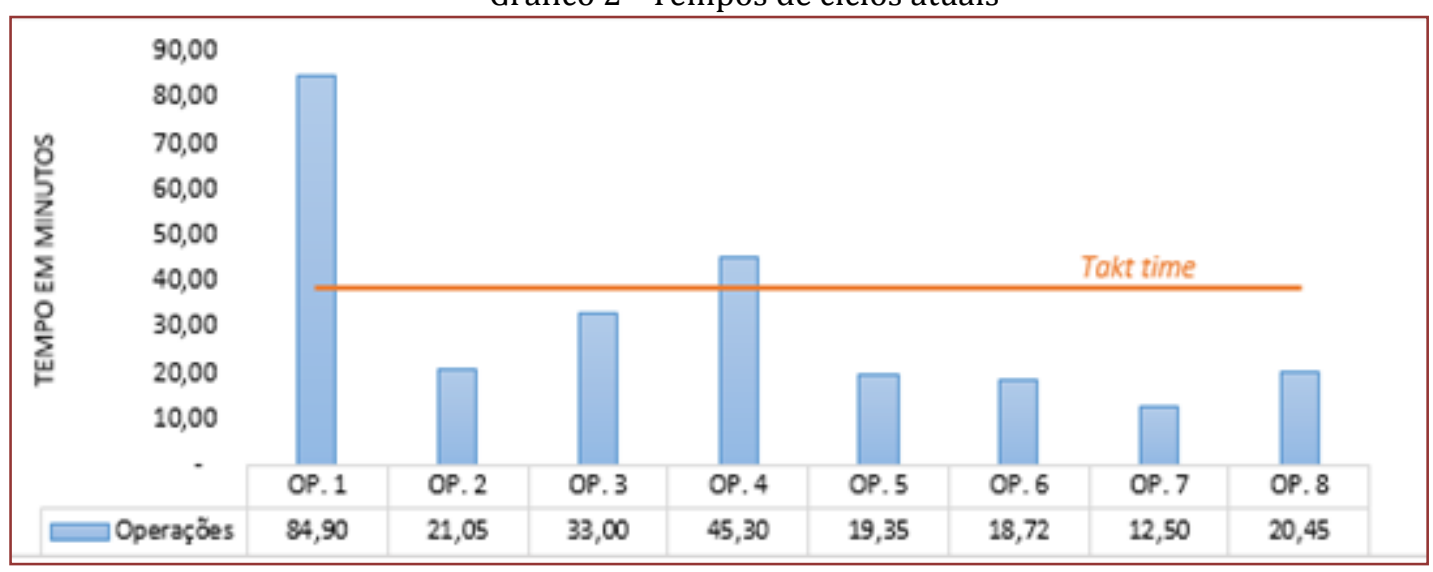

Fonte: Elaborado pelo autor.

Fazendo a análise do gráfico, começando pelos pontos críticos, é possível visualizar que os tempos de ciclos são bem diferentes uns dos outros. Algumas operações estão muito distantes do takt time, conforme pode ser visualizado na linha do gráfico acima.

A operação 1 ocorre em um tempo muito elevado e é realizada em um painel de montagem, apresentando certa complexidade e exigindo um operador exclusivo. A complexidade dessa operação demanda um treinamento de 3 meses e uma certa habilidade manual do colaborador, que é atingida apenas no quarto ou quinto mês, conforme depoimento do Gerente do RH.

Para diminuir o tempo de ciclo da operação é necessário fazer um kaizen de processos para eliminar os desperdícios que não agregam valor, como indicado nos balões do mapa atual (Figura 7). Depois, a fim de atingir o tempo de ciclo próximo ao takt time, é preciso reservar dois operadores dedicados para a família dos produtos. Como incorporar a operação a um fluxo contínuo será impossível, a melhor alternativa é fabricar em pequenos lotes e controlar a produção com o estoque supermercado.

A partir da operação 2 até a operação 7, deve haver um fluxo contínuo entre os processos, formando uma célula de montagem. Os operadores deverão seguir uma sequência de tarefas passando as peças de uma etapa do processo para outra, distribuindo os elementos de trabalho de modo que a operação fique abaixo do takt time.

A operação 8 é a da montagem final do armário, na qual pode ser implementada uma célula dedicada a essa tarefa, que poderá ser o processo puxador.

Seguindo Rother e Harris (2003), para a definição do número de operadores necessários para a célula atingir o Takt time, deve-se dividir o conteúdo total de trabalho (após o Kaizen) pelo takt time. Na célula 1, dividiu-se o total do conteúdo de trabalho de 139,50 minutos pelo takt time de 38,33 minutos, resultando em 4 operadores, conforme o Gráfico 3 da página a seguir: 
Gráfico 3 - Tempos de ciclos nas estações de trabalho da Célula 1

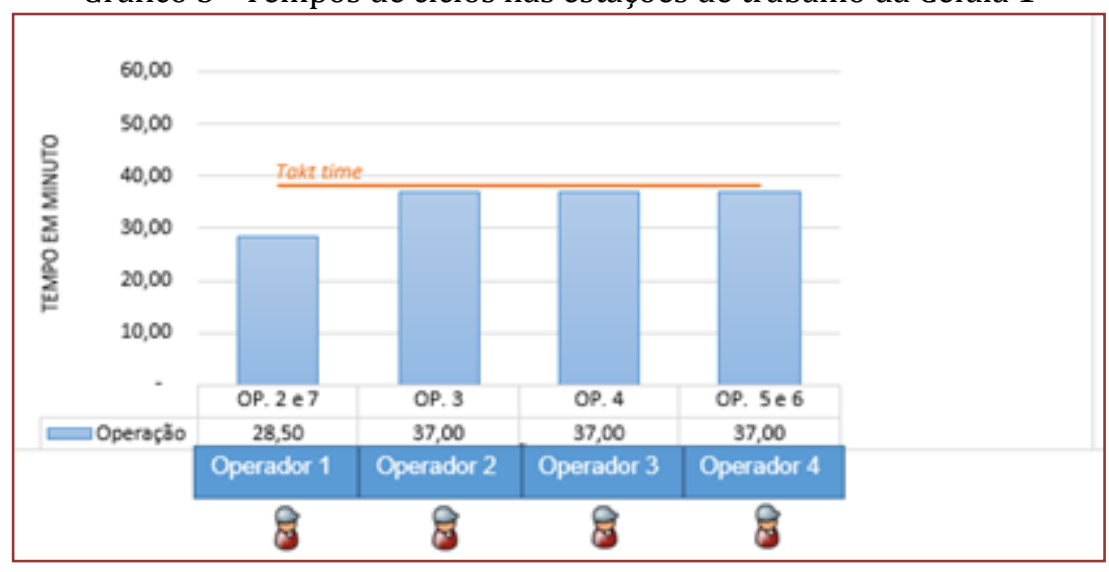

Fonte: Elaborado pelo autor.

Após a distribuição dos elementos de trabalho em cada operação com base no Kaizen, as operações ficaram balanceadas, conforme pode ser constatado no gráfico acima. Para o caso do operador 1, optou-se por deixa-lo um pouco abaixo do takt time, conforme recomenda Rother e Harris (2003), ele terá maior flexibilidade para auxiliar os demais operadores em momento de necessidade. Assim, caberá a esse operador a função de receber o material na entrada da célula e executar a primeira operação. Ele também será responsável pela última etapa, que é a de teste, e pela saída do material da célula.

Para a definição do número de operadores necessário para atingir o Takt time na célula 2, fez-se o mesmo cálculo, e verificou-se que há a necessidade de 1 operador, conforme o Gráfico 4 a seguir.

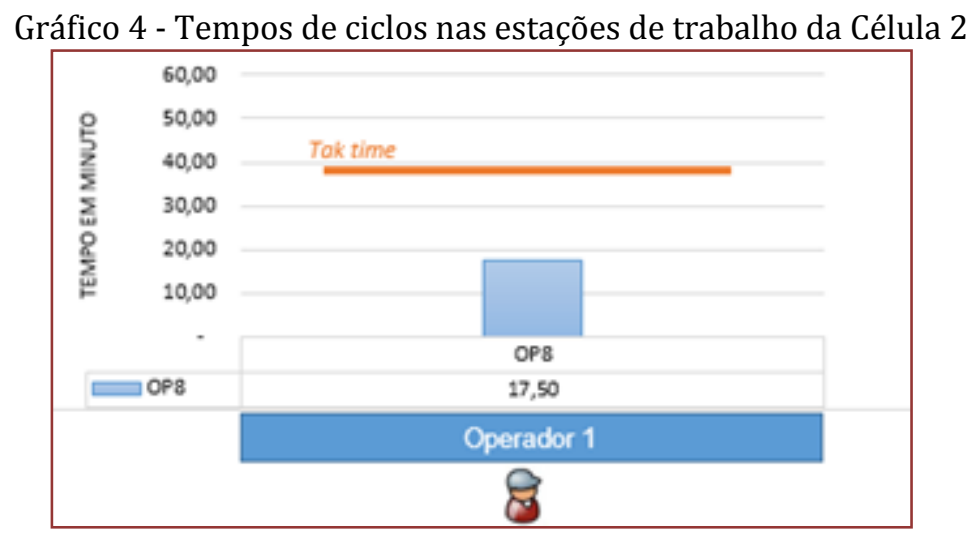

Fonte: Elaborado pelo autor.

Observa-se que operador da célula 2, está ocioso com tempo de ciclo abaixo do takt time. Desse modo, sugere-se que esse operador fique disponível a essa família de produtos somente no período da manhã e, assim, esteja liberado para outros atividades no período da tarde.

\subsubsection{DESENHO DO MAPA DE FLUXO DE VALOR FUTURO}

O MFV futuro apresenta uma diferença considerável em relação ao MFV atual. Na nova versão, observa-se um mapa mais enxuto, como resultado da aplicação de técnicas de melhorias voltadas para a produção enxuta, tais como a produção puxada pelo cliente, a criação de células de montagem para viabilizar o fluxo contínuo, o uso de estoque de supermercados onde não é possível interligar processos com o fluxo continuo e assim, ter um fluxo de informação mais objetivo, conforme a figura 9 a seguir. 
Figura 9 - Proposta de mapa de fluxo de valor futuro

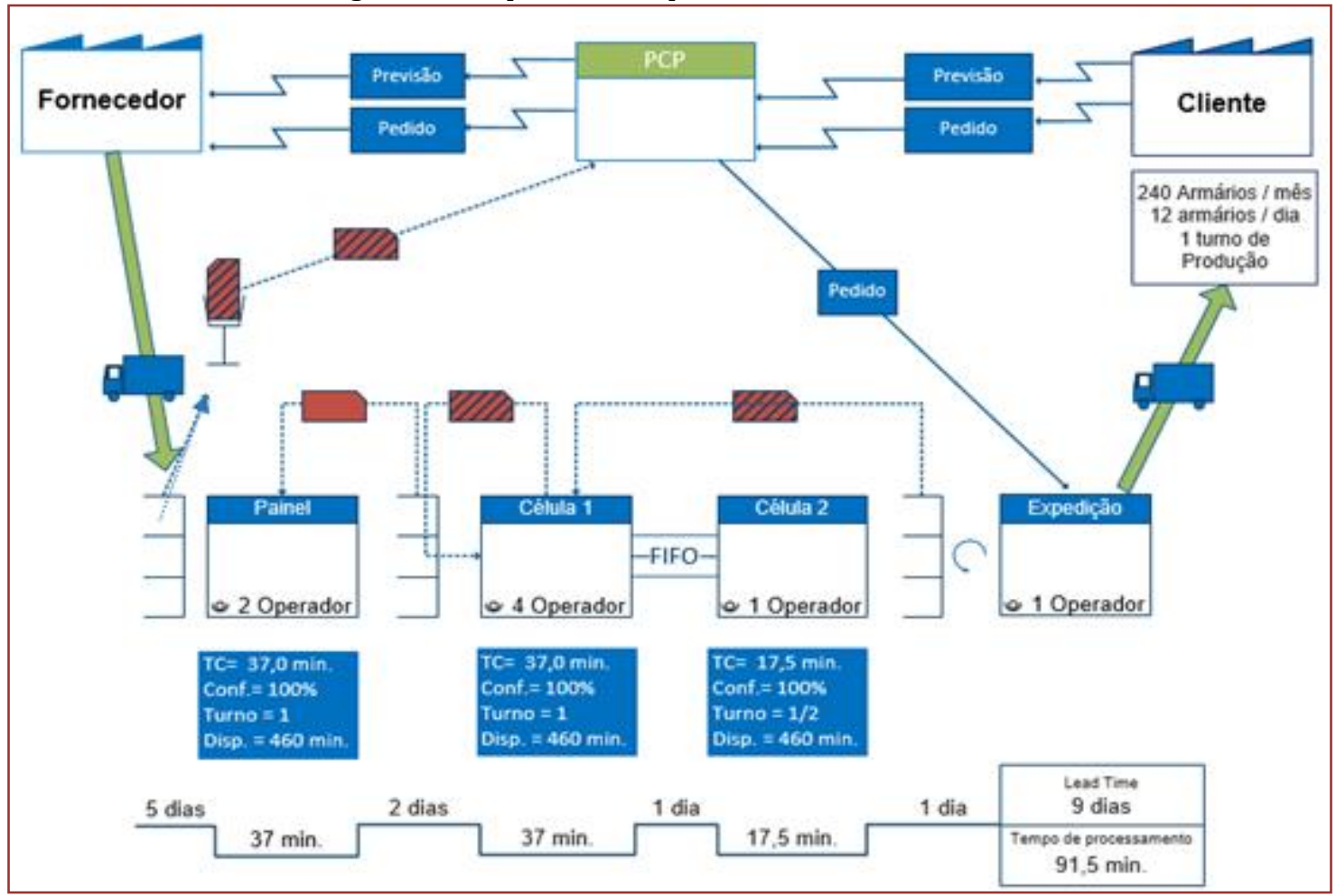

Fonte: elaborado pela autor.

As melhorias podem ser observadas no Quadro 1 que segue, que mostra os indicadores do MFV atual em comparação ao MFV futuro:

Quadro 1 - Comparação do estado atual com o futuro

\begin{tabular}{|l|c|c|c|}
\multicolumn{1}{c|}{ Indicador } & Atual & Proposto & Melhoria \\
\hline Lead Time (total) & 26 & 9 dias & Redução de $65 \%$ \\
\hline Lead Time (Manufatura) & 8 dias & 3 dias & Redução de $62,5 \%$ \\
\hline Tempo de processamento & 255,27 & 91,5 minutos & Redução de $64,15 \%$ \\
\hline Estoque de produtos acabados & 2 dias & 1 dia & Redução de $50 \%$ \\
\hline $\begin{array}{l}\text { Estoque de matéria prima } \\
\text { (Gabinete do Armário) }\end{array}$ & 15 dias & 5 dias & Redução de $66,7 \%$ \\
\hline Número de Estações de trabalho & 9 & 4 & Redução de $55 \%$ \\
\hline
\end{tabular}

Fonte: Elaborado pelo autor.

Pelo constatado, ao se utilizar a proposta do novo MFV, houve ganhos significativos (mais de 50\%) em todos os indicadores acima analisados, com destaque para a redução no tempo do estoque de matéria prima $(66,7 \%)$ e no tempo de processamento $(64,1 \%)$. Com isso tonar-se possível aumentar a capacidade produtiva, melhorar fluxo de caixa, diminuir a perda de estoques e, portanto, obter ganhos de produtividade e competitividade.

\subsection{ELABORAÇÃO DO PLANO DE AÇÃO}

Por meio do mapa do estado futuro, pode-se fazer um planejamento para possibilitar o alcance da situação desejada. A utilização da ferramenta do $5 \mathrm{~W} 1 \mathrm{H}$ auxilia neste processo na medida em que define as ações a serem tomadas, dando prazos de conclusão e direcionando as responsabilidades de cada tarefa. Assim, de acordo com as ações propostas dentro do mapa do estado futuro elaborou-se um plano de ação representado abaixo na Tabela 1. 
Tabela 1 - Plano de ação com as ações propostas dentro do mapa do estado futuro

\begin{tabular}{|c|c|c|c|c|c|}
\hline 0 que fazer ? & Por quê? & Quem fará? & Como? & Onde? & Quando? \\
\hline $\begin{array}{l}\text { Definir as equipes } \\
\text { de trabalho }\end{array}$ & $\begin{array}{l}\text { Definir as pessoas } \\
\text { responsáveis pelas } \\
\text { atividades }\end{array}$ & $\begin{array}{l}\text { Gerente da Empresa e } \\
\text { a direção }\end{array}$ & Reuniões presenciais & $\begin{array}{l}\text { Nas dependências da } \\
\text { empresa }\end{array}$ & $\begin{array}{l}\text { até a } 2^{2} \text { semana do } \\
\text { plano de ação }\end{array}$ \\
\hline $\begin{array}{l}\text { Definir o Gerente } \\
\text { do fluxo de Valor }\end{array}$ & $\begin{array}{l}\text { Para gerenciar a } \\
\text { execução do MFV }\end{array}$ & Direção da Empresa & $\begin{array}{l}\text { Avaliação de habilidades } \\
\text { e experiência }\end{array}$ & $\begin{array}{l}\text { Nas dependências da } \\
\text { empresa }\end{array}$ & $\begin{array}{l}\text { até a } 22 \text { semana do } \\
\text { plano de ação }\end{array}$ \\
\hline $\begin{array}{l}\text { Treinamentos sobre } \\
\text { produção enxuta }\end{array}$ & $\begin{array}{l}\text { Para disseminar o } \\
\text { conhecimento da } \\
\text { produção enxuta }\end{array}$ & $\begin{array}{l}\text { Equipe responsável } \\
\text { pelo treinamento }\end{array}$ & Cursos presenciais & $\begin{array}{l}\text { Nas dependências da } \\
\text { empresa }\end{array}$ & $\begin{array}{l}32 \text { semana do } \\
\text { plano de ação }\end{array}$ \\
\hline $\begin{array}{l}\text { Implentar } \\
\text { supermercado da } \\
\text { expediçăo }\end{array}$ & Controlar estoque de & Setor de produção & $\begin{array}{l}\text { Organização do setor de } \\
\text { estoque de fornecedor e } \\
\text { aquisição de estruturas } \\
\text { para estoque supercado }\end{array}$ & $\begin{array}{l}\text { Estoque de produto } \\
\text { acabado }\end{array}$ & $\begin{array}{l}\text { até a } 6 \text { t semana do } \\
\text { plano de ação }\end{array}$ \\
\hline $\begin{array}{l}\text { implementar as } \\
\text { células } 1 \text { e } 2 \text { e o } \\
\text { estoque fifo }\end{array}$ & Criar fluxo contínuo & Setor de produção & $\begin{array}{l}\text { Executando projeto MFV } \\
\text { futuro }\end{array}$ & $\begin{array}{l}\text { Setor de montagem de } \\
\text { armários e montagem de } \\
\text { fiação }\end{array}$ & $\begin{array}{l}14 \text { semana do } \\
\text { plano de ação }\end{array}$ \\
\hline $\begin{array}{l}\text { Estaçăo de trabalho } \\
\text { painel e } \\
\text { supermercado }\end{array}$ & $\begin{array}{l}\text { Para interligar o } \\
\text { setor de painel com } \\
\text { as células }\end{array}$ & Setor de produção & $\begin{array}{l}\text { Executando projeto MFV } \\
\text { futuro }\end{array}$ & Na etapa painel & $\begin{array}{l}\text { 18: semana do } \\
\text { plano de ação }\end{array}$ \\
\hline $\begin{array}{l}\text { Implentar } \\
\text { supermercado de } \\
\text { fornecedor }\end{array}$ & $\begin{array}{l}\text { Controlar estoque de } \\
\text { fornecedor }\end{array}$ & Setor de produção & $\begin{array}{l}\text { Organização do setor de } \\
\text { estoque de fornecedor e } \\
\text { aquisição de estruturas } \\
\text { para estoque supercado }\end{array}$ & $\begin{array}{l}\text { Estoque de matéria- } \\
\text { prima }\end{array}$ & $\begin{array}{l}\text { 19: semana do } \\
\text { plano de ação }\end{array}$ \\
\hline $\begin{array}{l}\text { Diminuir o prazo de } \\
\text { entregas dos } \\
\text { fornecedores }\end{array}$ & Diminuir estoques & Setor comercial & $\begin{array}{l}\text { Negociação com } \\
\text { fornecedores }\end{array}$ & $\begin{array}{l}\text { Reuniỏes na empresa ou } \\
\text { videoconferências }\end{array}$ & $\begin{array}{l}20 \text { semana do } \\
\text { plano de ação }\end{array}$ \\
\hline
\end{tabular}

Fonte: Elaborado pelo autor.

O plano de ação proposto visa auxiliar a Empresa a implementar o MFV futuro, para atingir os objetivos da Produção Enxuta.

\section{CONCLUSÕES}

Ao se objetivar identificar os desperdícios ao longo da cadeia produtiva foi possível constatar que a empresa em questão pode melhorar seus processos se ela adaptar sua cadeia produtiva de acordo com o MFV proposto, pois, por meio dele, será possível atender o tike time e, ainda, ter ganhos com a redução no tempo do Lead Time, tempo de processamento, no giro do estoque de produtos acabados e estoque de matéria prima.

O uso da ferramenta MFV ajudou a verificar que o processo produtivo da empresa caracteriza-se por ser por produção empurrada, havendo muitas interrupções no decorrer do fluxo e ausência de estabilidade na produção.

Dessa forma, eliminou-se os desperdícios, rompendo o paradigma da produção em massa, e atendendo ao objetivo da produção enxuta, que é fabricar em pequenos lotes e atender a demanda somente no momento em que o cliente solicita. 


\section{REFERÊNCIAS}

[1] ANTUNES, Junico. Sistema de Produção: Conceito e Práticas para projeto e Gestão da Produção Enxuta. Porto Alegre: Bookmam, 2008.

[2] CRESWELL, John W. Projeto de pesquisa: métodos qualitativo, quantitativo e misto. 3. ed. Porto Alegre: Bookman, 2010.

[3] GHINATO, Paulo. Sistema Toyota de Produção: mais do que simplesmente just-in-timecap. In: ALMEIDA, Adiel; SOUZA, Fernando. Produção \& competitividade: aplicações e inovações. Recife: UFPE, 2000. Cap. 2. p. 59-152.

[4] LIKER, Jeffery K.; MEIER, David. O modelo Toyota: manual de aplicação um guia prático para a implemetação dos 4PS da Toyota. São Paulo: Bookman, 2007.

[5] LIKER, Jeffrey K. O Modelo Toyota: 14 princípios de gestão do maior fabricante do mundo. Porto Alegre: Bookman, 2005.

[6] MARTINS, Petronio G.; LAUGENI, Fernando P. Administração da produção. 2. ed. São Paulo: Saraiva, 2005.

[7] OHNO, Taiichi. O Sistema Toyota de Produção: além da produção em larga escala. Porto Alegre: Bookmam, 1997.

[8] OLEIRO, Walter N.; DAMEDA, André das N.; VICTOR, Fernanda G. O uso da informação contábil na gestão das micro e pequenas empresas atendidas pelo programa de extensão empresarial NEE/FURG. Sinergia, v. 11, n. 1, p. 37 47, 2007.

[9] ROTHER, Mike; HARRIS, Rick. Criando Fluxo Contínuo: Um guia de ação para gerentes, engenheiros e associados da produção. São Paulo: Lean Institute Brasil, 2003.

[10] ROTHER, Mike; SHOOK, John. Aprendendo a enxergar: mapeando o fluxo de valor para agregar valor e eliminar o desperdício. São Paulo: Lean Institute Brasil, 2003.

[11] SHIMOKAWA, Koichi; FUJIMOTO, Takahiro. O nascimento do lean: conversas com Taiichi Ohno, Eiji Toyoda e outras pessoas que deram forma ao modelo Toyota de gestão. Porto Alegre: Bookman, 2011.

[12] SHINGO, Shigeo. O sistema Toyota de produção do ponto de vista da engenharia de produção. Porto Alegre: Bookmam, 1996.

[13] TUBINO, Dalvio F. Planejamento e Controle da Produção: Teoria e prática. São Paulo: Atlas, 2009.

[14] WOMACK, James P.; JONES, Daniel T. A mentalidade enxuta nas empresas: eliminando o desperdício e crie riqueza. Rio de Janeiro: Campus, 1998.

[15] WOMACK, James P.; JONES, Daniel; ROOS, Daniel. A máquina que mudou o mundo. Rio de Janeiro: Campus, 1992.

[16] WOMACK, Jim. Caminhadas pelo Gemba. São Paulo: Lean Institute Brasil, 2011.

[17] YIN, Roberto K. Estudo de caso: planejamentos e métodos. 4. ed. Porto Alegre: Bookmam, 2010. 


\section{Capítulo 13}

\section{Os desafios da empresa contemporânea: Lean Manufacturing \& Sustentabilidade}

\section{Antonio Carlos Freire Roboredo}

Resumo: 0 objetivo geral do presente artigo é analisar, compreender e divulgar a maneira como grandes organizações se posicionam com relação ao sistema de gestão e desenvolvimento sustentável. Para tal, será realizada uma ampla pesquisa bibliográfica em livros, revistas, artigos de periódicos e artigos de congressos acadêmicos, para referenciar Lean Manufacturing e a sustentabilidade, que tem como objetivo procurar satisfazer as necessidades presentes de produção e consumo. Para evidenciar tais conceitos, este trabalho terá abordagem de pesquisa qualitativa. Melhorando a qualidade dos produtos/serviços; o ambiente de trabalho; o atendimento ao usuário; a qualidade de vida dos funcionários; o aproveitamento dos recursos disponíveis; eliminando e prevenindo acidentes; otimizando o espaço físico; reduzindo gastos e desperdícios, as organizações contemporâneas que passam por transformações sociais e tecnológicas alcançarão o sucesso organizacional. Para se alcançar a sustentabilidade, é imprescindível conservar o meio ambiente, controlando o crescimento populacional, diminuindo o consumismo, os valores culturais. Hoje, o tema sustentabilidade, com suporte empresarial, ganha espaço internacional, porque considera fatores sociais, ambientais e econômicos. 0 conceito de desenvolvimento sustentável está interligado às dimensões ambientais, econômicas e sociais. Nessa seara ressalta-se um dos requisitos, que é adquirir líder com competências e habilidades específicas num sistema de gestão do conhecimento. Essa estratégia abrange a preocupação das empresas não só com a sua saúde como também a forma física e psicológica dos seus colaboradores para atendimento eficaz aos clientes.

Palavras-chave: Lean Manufacturing, Sustentabilidade. Sistemas de gestão, Liderança, Avaliação de Desempenho. 


\section{INTRODUÇÃO}

O mercado imensamente competitivo está a exigir melhorias na produtividade, qualidade, otimização do tempo e redução de custos, levando a análise sobre sobrevivência das organizações interligada a utilização de novas técnicas de gerenciamento. Assim, os modelos hodiernos de gestão têm como desafio promover as melhores diretrizes do sistema de gestão e o desenvolvimento sustentável das organizações, gerando valor para as empresas, para as pessoas e para o meio ambiente, harmonizando desenvolvimento econômico, ambiental, social e cultural, ou seja, conhecer e dominar os fundamentos de viabilidade econômica e financeira do que foi projetado.

Para alcançar a sustentabilidade torna-se imprescindível conservar o meio ambiente, diminuindo o consumismo e buscando os valores culturais. Hoje, o tema sustentabilidade tem suporte empresarial internacional porque empresas que contribuem para a criação de um modelo-referência de desenvolvimento sustentável considera fatores sociais, ambientais e econômicos.

Nesta seara, caberá aos dirigentes que desejem resultados satisfatórios para suas organizações ofertar bom tratamento aos que lhes são confiados para ter um trabalho com êxitos nos resultados. Sabe-se que o desenvolvimento na gestão de pessoas no âmbito de uma empresa é realizado através da avaliação de desempenho do indivíduo ou da equipe, visualizando os fatores positivos que devem ser continuados e os que deverão ser aprimorados ou retirados.

\section{Objetivos e Questão de Pesquisa}

O objetivo geral do presente trabalho é analisar, compreender e divulgar a forma como grandes organizações se posicionam frente ao sistema de gestão e com relação ao desenvolvimento sustentável e quais seus benefícios ao meio ambiente, apresentando casos reais da importância da sustentabilidade nas organizações e seus impactos em competitividade e lucros das empresas. Para tal, será realizada uma ampla pesquisa bibliográfica em livros, revistas, artigos de periódicos e artigos de congressos acadêmicos, para referenciar a sustentabilidade que tem como objetivo procurar satisfazer as necessidades presentes de produção e consumo, sem comprometer a capacidade das gerações futuras de suprir suas próprias necessidades. Para evidenciar tal conceito, o presente trabalho terá abordagem de pesquisa qualitativa e, segundo procedimento técnico, com uma pesquisa bibliográfica.

Esta pesquisa é voltada para o estudo de um sistema contemporâneo sob o foco da gestão do conhecimento nas empresas. $\mathrm{O}$ objetivo geral deste artigo é melhorar a qualidade dos produtos/serviços; melhorar o ambiente de trabalho e de atendimento ao usuário; melhorar a qualidade de vida dos funcionários; melhorar as relações humanas; maximizar o aproveitamento dos recursos disponíveis; reduzir gastos e desperdícios.

BARBIERI E CAJAZEIRA (2009), explicam que empresa sustentável é aquela que procura incorporar os conceitos e objetivos relacionados com o desenvolvimento sustentável em suas políticas e práticas de forma consistente. 0 objetivo da empresa com responsabilidade social é contribuir de forma efetiva para o desenvolvimento sustentável. Para a empresa, a incorporação desses objetivos significa obter estratégias de negócios e atividades que consigam atender às necessidades das empresas atuais, sustentando e aumentando os recursos humanos e naturais que serão necessários no futuro.

A gestão empresarial está relacionada com a preocupação maior que se relaciona com os desafios a enfrentar no futuro. Floresce desta reflexão a importância do Sistema de Gestão e as indagações mais frequentes são:

- Como melhorar a empresa, reexaminando a forma como os negócios são realizados?

- Como conseguir visualizar o negócio como um todo?

- Como fazer um planejamento estratégico eficaz observando as lideranças para compreender os ambientes de mudança?

- Como controlar a Gestão Financeira e inovar continuamente para que as empresas tenham sucesso contínuo?

- Como lidar com concorrentes?

- $\quad$ Como fazer Gestão de Marketing e Vendas? 
Enfim, como ser diferente a cada dia e inovar para competir e sobreviver?

Assim fica constatado que o conhecimento sobre Sistema de Gestão nesta fase contemporânea propicia mudanças em relação à sobrevivência e competitividade da empresa, melhorando a compreensão sobre o sistema a ser adotado e a sua evolução nos reflexos organizacionais, inclusive, com a flexibilização, inovação das técnicas e nos métodos utilizados, pois em momentos de crises econômicas, aberturas de mercado e investimentos constantes, as exigências ambientais eficazes são cada vez maiores nas organizações produtivas, sejam elas industriais ou de serviços.

Hodiernamente as empresas serão diferenciadas naquilo que sabem, embora a posse do conhecimento por parte da organização somente se torna um artigo valioso quando está acessível, e seu valor aumenta e ele se torna um ativo corporativo quando gerenciado e cercado do mesmo cuidado dedicado à obtenção de valor de outros ativos tangíveis (DAVENPORT e PRUSAK, p.14-21).

ROCHA (2011) explica que os sistemas de gestão da qualidade (SGQ) objetiva a verificação dos processos da empresa para aprimorar a qualidade dos produtos e serviços em prol da satisfação dos clientes. Os princípios e diretrizes da qualidade são aplicados no cotidiano da organização efetuando a tomada de decisões segura, a fim de facilitar a atuação do gestor nos indicadores de desempenho da empresa inclusive para obter uma melhora na imagem, no desempenho e na cultura organizacional.

Nesse processo há também uma redução dos custos e aumento da produtividade enfrentando basicamente a competitividade cada vez mais crescente no mercado. É também verdadeiro que deve haver treinamento para uma comunicação mais eficiente entre os funcionários, além do mapeamento dos processos empresariais e registros das atividades empresariais, obtendo inclusive o certificado de qualidade: de acreditação e certificação.

Seguindo os ensinamentos de LODI entre as metas a médio e em longo prazo estão:

- Aumento dos lucros;

- Atendimento satisfatório aos clientes e o novo conceito de pessoas;

- Divisão de tarefas além da diminuição dos gastos obrigatórios.

- Conhecer e dominar os fundamentos de viabilidade econômica e financeira do projeto desejado.

Se a opção for pela reengenharia, que é um sistema administrativo utilizado na competitividade das empresas baseado no repensar e reinventar os procedimentos para aumento da produtividade com redução de custos e satisfação dos clientes, enfim, num processo de redefinição de estratégia, recolhimento de informações e mapeamento dos processos para obter melhoria operacional de processos e de negócios, para reduzir custos, tempo das atividades e qualidade dos serviços prestados, as regras obsoletas poderão ser ultrapassadas na criação de uma nova e produtiva concepção (GONÇALVES, 1994). Outro ponto a considerar é a escolha do líder competente e com habilidades específicas, pois as transformações sociais e tecnológicas contemporâneas que influenciam no sucesso organizacional das empresas exigem líderes eficazes e eficientes.

STAIR E REYNOLDS (2002) explicam: “(...) um redesenho de processos, que envolve a readequação dos processos empresariais, estruturas organizacionais, sistemas de informação e valores da organização, objetivando uma guinada nos resultados dos negócios da organização".

Há, porém, especialistas que não são favoráveis a este sistema contínuo, pois adotam a conhecida parábola: "Ninguém põe remendo de pano novo em roupa velha..." (Mateus 9:16-17). Explicam que este sistema possibilita a interpretação de que as coisas não estão fluindo bem na empresa, propiciando insegurança quanto aos procedimentos e aos recursos humanos já habituais, dificultando a não consecução dos resultados positivos.

DAVENPORT \& SHORT (1990) expõem que: “Os mais bem sucedidos usuários da tecnologia da informação parecem ter criado a Reengenharia de processos sem ter necessariamente consciência disso.". 
Este sistema merece profunda análise. As empresas contemporâneas se encontram em ambientes complexos, confrontando-se com desafios e inúmeras dificuldades diárias, para os quais precisam encontrar soluções rápidas. Essa complexidade poderá propiciar prejuízos à gestão alicerçada na flexibilidade da estrutura organizacional; nas parcerias com outras organizações; no estilo participativo de trabalho em equipe e também aos clientes. Assim, tanto a informação, o conhecimento, a criatividade e a própria sustentabilidade, como também a liderança, que fazem parte do sistema de gestão de qualidade total nas organizações contemporâneas, precisam ser eficazmente utilizados.

Com base no contexto apresentado acima, tem-se a problemática neste trabalho relacionada com as seguintes indagações:

$\rightarrow$ Que sistema de gestão ajudará de maneira eficiente à empresa ultrapassando as regras obsoletas na criação de uma nova e produtiva concepção?

$\rightarrow$ E mais, existem relações ou correlações entre as mudanças na liderança e o sistema de gestão de qualidade total?

A Metodologia usada, diante destes questionamentos, foi o levantamento bibliográfico, na procura das melhores respostas, afirmativas ou não. A redação fora elaborada após análise e reflexão do conteúdo pesquisado e dos resultados obtidos no contexto. A coleta de dados deu-se numa ampla pesquisa bibliográfica em livros, revistas, artigos de periódicos e artigos de congressos acadêmicos, para referenciar o tema proposto. Para evidenciar tais conceitos, o presente trabalho terá, assim, abordagem de pesquisa qualitativa e, segundo procedimento técnico, com uma pesquisa bibliográfica.

Adotando uma perspectiva qualitativa destacam-se os principais aspectos do tema, ou seja, mudanças para alcançar com eficiência os objetivos da empresa frente às evoluções pós-industriais, tecnológicas e globalização no sistema de gestão de qualidade total e liderança. Lean Manufacturing \& Sustentabilidade embasa a combinação ideal para qualquer empresa. Com a Sustentabilidade ter-se-á o crescimento e os lucros que a empresa obterá a médio e longo prazo, sem contar o impacto positivo que advém desse posicionamento empresarial.

GIL (1996, p. 46), afirma que a pesquisa descritiva "tem como objetivo primordial a descrição das características de determinada população ou fenômeno ou, então, o estabelecimento de relações entre as variáveis". Este mesmo autor expõe que, "as pesquisas descritivas são, juntamente com as exploratórias, as que habitualmente realizam os pesquisadores sociais preocupados com a atuação prática".

Esta revisão bibliográfica traz outras reflexões acerca do tema, pois o pressuposto básico da empresa reinventada é que as pessoas são o seu bem mais escasso e precioso, que constituem a pedra angular da competitividade de qualquer organização. Neste cenário necessita-se inclusive de uma análise sobre seus impactos nas relações de poder.

O poder é visto como elemento dotado de energia capaz de moldar e transformar as organizações, sendo fundamental sua análise no processo de mudança organizacional. 0 poder é uma relação de dependência, envolvendo a habilidade para se conseguir que outra pessoa faça alguma coisa que, de outra forma, não seria feita. 0 poder ordena, na medida em que é legítimo e também porque estabelece as fronteiras, homologa os processos organizacionais e premia o que organizacionalmente é considerado bom desempenho.

Ratifica-se que o presente trabalho foi realizado com base em Pesquisa Bibliográfica elaborada a partir de material já publicado, principalmente livros, artigos de periódicos e materiais disponibilizados na Internet. Inicialmente, será utilizada a Pesquisa Exploratória para maior familiaridade com a problemática, após o levantamento bibliográfico evidentemente. A Pesquisa Descritiva também será usada para descrever melhor o assunto, além da Pesquisa Explicativa, objetivando identificar e aprofundar o conhecimento da realidade e o porquê das mudanças, pois em relação à Estrutura Organizacional a tecnologia poderá alterar profundamente a gestão, provocando transformações desde a forma de administração até o layout da empresa. A pesquisa fundamenta-se com estudiosos do assunto, como STAIR e REYNOLDS (2002); DAVENPORT \& SHORT (1990); CHIAVENATO (2004/2012); ROBBINS (1998); MAXIMINIANO (2008); ZANELLI (2008), entre outros do mesmo naipe.

Utilizar-se-á também a leitura analítica objetivando ordenar e fichar as informações e as fontes para responder as indagações da pesquisa. A leitura interpretativa propiciará a construção lógica que é a organização das ideias para atender aos objetivos formulados. 
A coleta de dados partiu da leitura histórica visando entender de que maneira o tema fora discutido no decorrer dos anos. Buscou-se analisar, sintetizar e interpretar 'de que forma o sistema de gestão de qualidade poderia alcançar êxito nas organizações contemporâneas e qual o papel do líder influenciando no processo de desempenho de seus liderados'. Após especular, questionar, avaliar, repensar e sintetizar o que foi lido elaborou-se um relato da literatura selecionada acerca das variáveis ou palavras-chave do tema.

\section{REVISÃO DE LITERATURA}

\subsection{ORGANIZAÇÕES CONTEMPORÂNEAS}

0 embasamento foi espelhado nos trabalhos que olham com mais atenção o desenvolvimento das empresas no contexto moderno. A meta preliminar foi validar a abordagem valiosa para compreender os modelos de gestão e ação gerencial apresentando, inclusive, uma reflexão crítica das proposições da Gestão da Excelência nas organizações contemporâneas, pois o desafio atual é caracterizar e organizar eficaz e efetivamente as atividades que alcançam resultados satisfatórios no mercado. No mais, a necessidade crescente de novas estruturas e processos organizacionais atendendo ao surgimento de outras demandas implicam em uma nova postura mental e um novo comportamento gerencial nas decisões sutis e integradoras que irão tomar. Floresce assim a imprescindível indagação: 'por onde começar?'.

NONAKA E TAKEUCHI (1997, p. 63), explicam que o conhecimento, ao contrário da informação, diz respeito a crenças e compromissos. 0 conhecimento é função de uma atitude, perspectiva ou intenção específica e, ao contrário da informação, o conhecimento, está relacionado à ação. É sempre o conhecimento "com algum fim". O conhecimento, como a informação, diz respeito ao significado. É específico ao contexto relacional. Os autores consideram o conhecimento como um processo humano dinâmico de justificar a crença pessoal com relação à "verdade".

A Organização humanizada precisa da humanização também do processo de trabalho. Assim, o crescimento das forças produtivas deverá estar interligado às necessidades humanas. As iniciativas inerentes às novas tecnologias de gestão organizacionais passam a pregar a flexibilização dos processos de produção, constituindo-se como a busca da qualidade total, segundo explicam MELO (1996) e ANTUNES (1995).

Ideias reforçadas com fundamentos da Gestão da Excelência, preconizada por PETERS \& WATERMAN (1982), são importantes, mas questionáveis. Estes autores apresentam um quadro de preceitos que deverão se sobrepor as crises econômicas; ao aumento da inflação; a elevação das taxas de juros; ao papel do Estado como agente econômico produtivo e a saturação de mercados de bens de consumo. Alicerçados em uma pesquisa realizada em sessenta e duas organizações nos Estados Unidos definiram vários atributos caracterizadores de empresas inovadoras:

a) Vontade de inovar;

b) Almejo da autonomia e do espírito empreendedor dos líderes e demais membros organizacionais;

c) Ganhos de produtividade através da equipe;

d) Compromisso com valores organizacionais e resultados esperados;

e) Proximidade ao cliente;

f) Equilíbrio entre centralização e descentralização nas decisões a serem tomadas.

Estes itens são importantes, mas na era da informação é preciso estar atento ao que as empresas buscam: imensa capacidade de organização e adaptação às mudanças de um mercado cada vez mais complexo, dinâmico e turbulento, cientes de que a estrutura da gestão tenha que ser flexível para melhor se integrar aos objetivos da empresa em seus bens tangíveis e intangíveis, sempre reavaliando sua estratégia. 


\section{2 - SISTEMAS DE GESTÃO}

BELLUZZO (2007) enfatiza que a sociedade contemporânea tem a informação como o principal bem de valor e o conhecimento como agregador de valor aos produtos e serviços.

TAKEUCHI E NONAKA (2008, p. 166) reiteram explicando que, “[...] o patrimônio indispensável para as empresas de hoje não é a fábrica e o equipamento, mas o conhecimento acumulado e as pessoas que o possuem.".

ALBUQUERQUE (2012 p.01) "um dos fatores impulsionadores do sucesso em nossa carreira, é a forma pelo qual relacionamos com as pessoas.".

A importância deste estudo alcança também a abrangência de seus impactos, pois o campo é muito amplo inclusive nas relações de poder (elemento envolvendo a habilidade para se conseguir que outra pessoa faça alguma coisa que, de outra forma, não seria feita) nas atividades laborais. Essa estratégia abrange a preocupação das empresas não só com a sua saúde como também a forma física e psicológica dos seus colaboradores: ser simultaneamente pró-pessoas e pró-lucros, ambos caminhando juntos para a via certa em direção a excelência.

Ratificando que as empresas de hoje têm a necessidade de vender seus serviços satisfazendo também seus consumidores, torna-se imprescindível buscar maneiras eficientes de realocar recursos e orçamento presentes nas despesas operacionais rotineiras para investi-las em ações que suportem melhores os objetivos de negócio da empresa, garantindo-lhe a infraestrutura no cumprimento das metas de disponibilidade e performance, com eficiência de custos. São ingredientes imprescindíveis: sobrevivência e competitividade.

\section{3 - LIDERANÇA}

Ratifica-se que as transformações sociais e tecnológicas contemporâneas que influenciam no sucesso organizacional das empresas requerem líder com competências e habilidades específicas, tais como: saber ouvir; estar preocupado em solução e não, em problemas; possuir empatia; comunicação clara; gerir as equipes na busca constante por conhecimento; saber compartilhar o que sabe; solucionar conflitos de forma clara e imediata.

De tal sorte que, caberá aos dirigentes a nível superior que desejam resultados satisfatórios para suas organizações, ofertar bom tratamento aos que lhes são confiados para ter um resultado eficaz e, consequentemente, atingir os êxitos nos resultados totais numa vantagem competitiva.

\subsection{1 - A LIDERANÇA E A PRODUTIVIDADE}

A liderança, que se preocupa em estabelecer altos níveis de produtividade de forma sustentável e ética, deve observar os Códigos de Conduta e Códigos de Ética. 0 líder tem que estar aberto à diversidade, aceitando todos os tipos de pessoas e não deve tolerar discriminação racial, religiosa, etnia, sexual e nem assédios. Aliás, é nesta seara que se desenvolve a teoria sobre liderança ética. (BROWN, TREVIÑO e HARRISON, 2005). As crises morais vêm despertando crescente interesse pelo estudo da ética na liderança (BROWN e TREVIÑO, 2006). A liderança ética é definida por Brown et. al. (2005, p.120) como: " $a$ demonstração de conduta apropriada através de ações pessoais e relações interpessoais, bem como a promoção de tal conduta entre os seguidores através de uma comunicação bidirecional, do reforço e da tomada de decisão".

Entende-se numa visão sintetizada de BIGNETTI (2002) que cada empresa deve identificar um conjunto de motivações próprias que propulsione a investir em inovação. Entre estas motivações particulares ressaltam-se algumas das mais frequentes:

- Inovar os processos de fabricação - modernização da tecnológica

- Melhorar a imagem no mercado; proteção contra os ciclos econômicos;

- Reforço da capacidade competitiva no mercado; redução de custos de produção; o aproveitamento de economias de escala; 
- Aproveitamento de sinergias-gama de produtos, tecnologias, estrutura comercial;

- A melhoria da qualidade dos produtos; diversificação de produtos; o aumento dos lucros com a satisfação dos consumidores.

BERGAMINI divide as variáveis que afetam o comportamento em individuais e ambientais. Explica que "toda a bagagem inata, mais as experiências adquiridas ao longo das várias fases evolutivas, tais como a infância, a adolescência e a fase adulta de cada um" e ao "grupo social, cultura e outros fatores do meio ambiente físico" e o sucesso "parece intimamente ligado a dois aspectos interdependentes: a característica de personalidade de cada um dos dois sujeitos e, consequentemente, o sistema de lentes de percepção social que cada um deles utiliza para conhecer o outro". Enfatiza ainda que "Pouco a pouco alguns fatores, tais como tipo de estrutura da empresa, sistemas de planejamento e controle, clima organizacional, canais de comunicação e muitos outros, também compõem o quadro facilitador ou impeditivo da eficácia dos líderes".

ROBBINS conceitua esta teoria como sendo: “[...] um campo de estudo que investiga o impacto que indivíduos, grupos e a estrutura têm sobre o comportamento dentro das organizações com o propósito de aplicar este conhecimento em prol do aprimoramento da eficácia de uma organização".

FREITAS, KLEIN \& FARGUNDES explicam nitidamente que as organizações contemporâneas têm que desenvolver um sistema de liderança capaz de integrar as competências pessoais com os objetivos da organização.

Já HOOVER E VALENTI afirmam que "a liderança é um círculo, não uma escada”.

Sabe-se que as teorias sobre a Liderança Situacional, isto é, a relação entre a maturidade para a realização das tarefas e os estilos utilizados, apresentam quatro características na forma de liderar: "determinar, persuadir, compartilhar e delegar".

SIQUEIRA ensina que o líder na avaliação de desempenho deve agir como num processo de aprendizagem recíproco, construído e desenvolvido por ambos os envolvidos.

BLANCHARD et. al. diz que liderança é a "capacidade de influenciar os outros a liberar seu poder e potencial de forma a impactar o bem maior". Ratifica que liderança não está relacionada a resultados, pois "[...] não deve ser exercida apenas por um ganho pessoal ou para atingir objetivos, deve ser um propósito muito maior".

ROBERT OWEN "foi provavelmente o primeiro dono de fábrica a proporcionar condições decentes de trabalho, salários suportáveis e educação para os filhos e operários".

RODRIGUES afirma que nesta visão de ROBERT OWEN há comunicação fácil entre os trabalhadores dos diversos níveis, vez que a explicitação nos grandes objetivos das estradas construídas, os salários proporcionais ao desempenho do trabalhador e um ambiente sadio, que induza liberdade e desbravamento, levam a valoração dos trabalhadores.

CHIAVENATO com toda transparência enfatiza que, a abordagem humanista da administração leva em conta o comportamento no trabalho, consequência de fatores motivacionais; que as pessoas são motivadas por necessidades humanas e alcançam sua satisfação por meio dos grupos sociais com quem interagem; que a motivação é fator preponderante sobre as necessidades dos indivíduos a fim de supri-las para atingir os objetivos pessoais e organizacionais, pois a evolução na gestão de pessoas dentro de uma empresa é realizada através da avaliação de desempenho do indivíduo ou da equipe, assim empresa e empregado, estarão conscientemente certos dos fatores que devem ser aprimorados ou retirados.

ROEDER afirma que "é compreendido como um conjunto de relações sociais, biológicas, culturais, econômicas, religiosas, políticas e ecológicas, que formam um contexto que interage com o ser humano onde, a partir desta interação (ser humano e ambiente), ambos podem ser modificados ou transformados".

SILVEIRA \& BASTIAS explicam que o acompanhamento nada mais é do que garantir que as atividades estejam sendo realizadas de acordo com o planejado, possuindo inclusive importância estratégica. Que este acompanhamento tem quatro fases distintas: estabelecimento de padrões de desempenho; mensuração do desempenho; comparação do desempenho verificado com o padrão estabelecido; e ações corretivas. 0 líder tem que estar ciente e preparado para a possibilidade de mudanças, que requer muitas habilidades e reforço nas competências, mas é por meio destas mudanças que a empresa pode evoluir. Há outros dois pontos importantes no papel da liderança que eles ressaltam: o "vinculador de dentro para fora", onde o líder manifestará internamente todas as oportunidades para o negócio afetar de forma 
positiva a sociedade. E o "vinculador de fora para dentro", que se refere à identificação de como as condições sociais influenciam a empresa, podendo assim levá-la a melhorar seus processos, produtos e parcerias.

Globalização, mercado, integração, gestão, cultura organizacional, tecnologia, transformam a sociedade industrial em sociedade do conhecimento. De tal sorte que, inovação nas empresas visa a atribuir uma função prática às novas ideias e viabilizar o resultado para o uso comercial. Inovar seria, então, ideia com um novo significado a produtos, serviços e processos - para que sejam integrados ao mercado. Neste contexto, sintetiza-se: "fazer mais com menos".

De maneira que, em relação à qualidade de vida é de bom alvitre ressaltar que a reengenharia está intimamente ligada à imagem da organização, apresentando um sentido positivo no mercado consumidor. Que o Estado Democrático de Direito se rege por normas democráticas, com eleições livres pelo povo, bem como o respeito das autoridades públicas aos direitos e garantias fundamentais e ao princípio democrático, o qual exprime a exigência da integral participação de todos na vida política e civil do país. Todas as pessoas, individualmente ou em grupos, têm o direito de influenciar no processo pelo qual se discutem, deliberam e implementam quaisquer políticas que de alguma forma afete sua vida profissional ou privada.

No Processo de reordenamento institucional: estratégia sobrevivência/competitividade) está bem explicitando a importância de que todos devem ter assegurada à possibilidade de argumentar em favor de seus interesses. Para a caracterização do modelo apresentado é indispensável antecipar que adota uma perspectiva que considera o Estado, o indivíduo e o sistema-empresa como dimensões estreitamente articuladas e reciprocamente condicionantes, objetivando ajustar-se às novas demandas e necessidades que surjam.

Numa reflexão aprofundada pode-se afirmar que, o pressuposto básico da empresa reinventada é que as 'pessoas' são o seu bem mais escasso e precioso, que constituem a pedra angular da competitividade de qualquer organização.

Durante o treinamento se aprende que o chefe é diferente de líder. 0 chefe é centralizador. Ocupa o cargo designado por alguém por ser autoritário na distribuição das ordens, objetivando lucros e resultados; que enxerga os subordinados como pessoas que obedecem às ordens responsabilizando-se pelos resultados que devem sempre ser positivos, enquanto a líder motiva a sua equipe valorizando as habilidades, pensando sempre no bem-estar coletivo para conseguir juntos os resultados satisfatórios. A liderança também exige cursos de aperfeiçoamento, muito embora existam pessoas que sejam líderes natos, possuem iniciativa, capacidades de comunicação e influência, sempre prontas a ensinar e orientar sua equipe. Os que têm efeitos carismáticos são imensamente apreciados na competência. 0 líder com este perfil conquista os seus liderados pela confiança em sua atuação, na forma de agir e pelos valores que possuem. São inúmeros os benefícios que uma boa liderança trás para a empresa.

Figura 1: - Valoração dos colaboradores - do 1ํo ao último patamar.

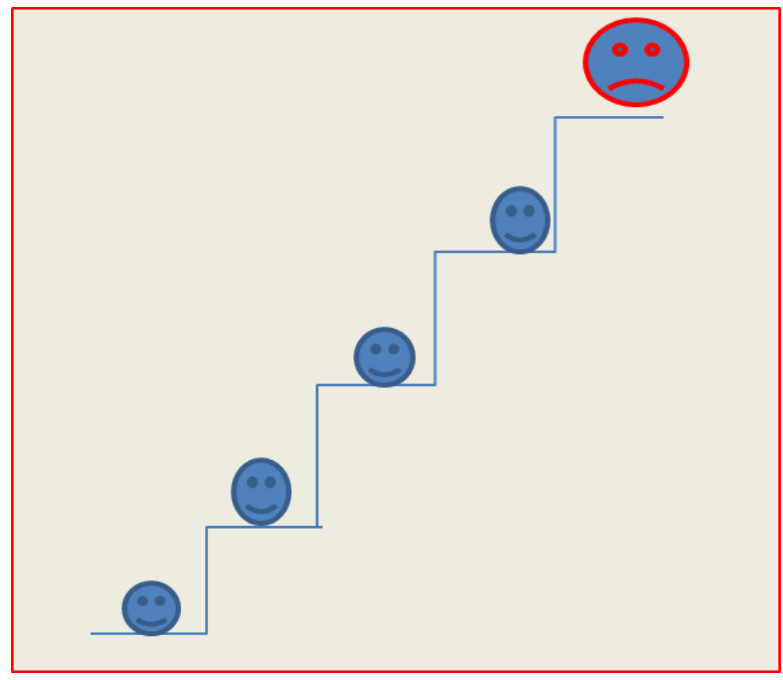

Fonte: autor. 
De tal sorte que, a figura acima, reforça que o tema liderança é altamente significativo para as organizações contemporâneas, evidenciando a enorme importância deste trabalho. Ratifica-se que a liderança bem conduzida possibilita a boa produtividade de grupos. 0 líder troca informações com os subordinados, pois a ausência de feedback e de flexibilidade, dificulta o relacionamento com a equipe ocasionando baixo desempenho nos negócios e um ambiente laboral insustentável. 0 profissional que deixa de ser chefe para ser um incentivador de pessoas é o líder ideal para qualquer empresa, pois focam em resultados satisfatórios, especialmente, em desenvolver equipes capazes de oferecer resultados positivos.

Segundo CHIAVENATO "liderança é o processo de conduzir um grupo de pessoas. É a habilidade de motivar e influenciar os liderados para que contribuam da melhor forma com os objetivos do grupo ou da organização".

Este comportamento pode-se dizer que é recente. Havia anteriormente a LIDERANÇA AUTOCRÁTICA, líder tipo autoritário. Com o decorrer dos anos floresceram outros tipos com nova postura profissional focada na gerencia da equipe com colaboração e crescimento organizacional.

DUBRIN, corroborando com CHIAVENATO enfatiza que "Liderança é a capacidade de influenciar os outros a alcançar objetivos que são importantes para eles e para a organização". Ressalta também a necessidade dos líderes em buscar a persuasão, inspirar e motivar o outro na busca de mudanças úteis.

MAXIMIANO ensina que "Liderança é um processo de conduzir as ações ou influenciar o comportamento e a mentalidade de outras pessoas".

WALTON citado por Limongi França (2010) explica Qualidade de Vida no Trabalho como algo além da legislação trabalhista.

ROBBINS: "gerentes conseguem que as coisas sejam feitas através de outras pessoas. Eles tomam decisões, alocam recursos e dirigem as atividades de outros para atingirem objetivos". E mais: "quando os gerentes motivam seus subordinados, dirigem as atividades de outros, selecionam os canais de comunicação mais eficazes ou resolvem conflitos entre seus membros, eles estão empenhados em liderar".

MINICUCCI afirma que "o desempenho dos indivíduos e a utilização dos objetos materiais supõem um modelo geralmente reconhecido e aceito pelos participantes. Sem dúvida, o sucesso da organização repousa sobre a motivação das pessoas conseguida por meio da estruturação afetiva das relações de grupo e de importância fundamental é o fato de o indivíduo sentir-se importante e valioso na organização".

Pode-se dizer que na Liderança Participativa ou Democrática o trabalho é realizado em conjunto na obtenção dos objetivos traçados.

MINICUCCI diz que "existem provas que, quando estão numa situação social ambígua e difícil, ou há uma situação de tensão instalada, as pessoas tendem a aceitar mais favoravelmente a liderança autoritária [...] uma situação de tensão pode mudar o estilo da liderança".

WEBER afirmava que "todos os líderes que revelam uma missão transcendente ou curso de ação que atrai seguidores potenciais, mas representa que os seguidores acreditam que o líder seja extraordinariamente dotado" E mais: "transcendência tanto é atribuída às qualidades do líder quanto ao conteúdo de sua missão, descrito como sobrenatural, sobre-humano ou excepcional".

TANNEMBAUM E SCHMIDT lembram que o sucesso do grupo não leva em conta apenas o líder como também o posicionamento dos liderados. Equilíbrio de tempo, de energia nas tarefas, de prazos, há que ser levados em conta nas atividades a serem executadas.

MINICUCCI enfatiza ainda que "tem haver com a capacidade de mudar a situação quando necessário, o que exige repertório variado de comportamento - residência de estilo".

É importante lembrar que há a teoria do Caminho/Objetivo aludida por SPECTOR, leva em consideração a complexidade das relações no ambiente de trabalho, pois o supervisor ao acrescer a motivação e a satisfação dos subordinados pode utilizar quaisquer estilos de supervisão, ou seja, de apoio, diretivo, participativo ou de realização.

SPECTOR expõe a visão de HOUSE E MITCHEL, onde tais estilos seriam utilizados de outra forma caso as tarefas fossem rotineiras, perigosas ou se não fossem estruturadas e os liderados despreparados. 
CHIAVENATO, explica que o setor de Gestão de Pessoas possui uma grande responsabilidade na formação dos profissionais visando desenvolver e colaborar para o crescimento da instituição e do próprio profissional.

Atualmente estamos em uma economia global, onde os mercados mundiais não são mais somente regionais ou nacionais. A competição está em nível planetário, e o mundo se tornou mais complexo e turbulento. A globalização, o mundo tecnológico e a transformação da sociedade fazem com que a sobrevivência e a excelência organizacional vejam cada vez mais a importância das habilidades e competências das pessoas que ali trabalham.

A tendência é de construir equipes autônomas de trabalho, bem como, reduzir os níveis hierárquicos, desenvolver lideranças para motivar e desenvolver as pessoas, conseguir promover, através da aprendizagem, o diálogo entre as pessoas das diferentes áreas da organização e abrir espaço para pôr em prática as estratégias organizacionais tanto em nível intermediário quanto no operacional.

Para mobilizar e engajar as pessoas em suas atividades, as empresas estão mudando seus conceitos e alterando suas práticas gerenciais cotidianamente. Ao invés de investir diretamente em produtos e serviços, estão investindo em pessoas que entendam destes e saibam criá-los, desenvolvê-los, produzi-los e melhorá-los. As pessoas passam a constituir o elemento básico para o sucesso organizacional.

ZANELLI relata que, para que um bom líder cumpra suas finalidades, que envolvem desde a preocupação com a motivação e o desenvolvimento de sua equipe até o crescimento e a melhoria de resultados desta, ele também deve ter algumas ações necessárias para desenvolver um bom trabalho. São elas: planejamento, ações que serão realizadas e colocadas em prática e os objetivos a serem alcançados com esta ação. É necessário que os objetivos específicos sejam determinados e mensuráveis, com prazos finais e alcançáveis.

O líder tem que estar ciente do trabalho a ser realizado para que possa definir as atividades que serão realizadas, a divisão do trabalho, e integrar e coordenar os esforços das pessoas a fim de facilitar o alcance dos resultados, além de monitorar os ajustes necessários a serem feitos. Outro ponto para obter sucesso na realização do papel de liderança é ter senso de direção, que se refere ao estabelecimento de uma comunicação adequada e boas relações interpessoais com as pessoas que fazem parte da organização.

É papel do líder compreender as diferenças e as similaridades entre seus colaboradores. Um líder pode contribuir muito no desenvolvimento profissional de cada subordinado, quando se conscientiza das necessidades individuais e das diferenças que existem nas situações interpessoais e reconhece as potencialidades que subsistem nas diferenças individuais.

Um líder precisa saber reconhecer as competências de seus colaboradores, fazer com que seus liderados exponham suas potencialidades, seja na forma de diálogo, observação, ou por um ambiente favorável. Cada empresa tem sua missão, desafios e metas a serem atingidas. Para que se cumpram estes fatores, a empresa faz um planejamento, mas para realizá-lo, é preciso um conjunto de competências especiais, independente de serem individuais ou coletivas, para que adaptação ao ambiente externo (mercado).

Um gerente eficaz deve saber desenvolver em seus colaboradores padrões adultos de autocontrole e de auto direção, sabendo focalizar as necessidades de liberar o potencial das pessoas que podem fazer seu trabalho de maneira diferente, e assim, encará-las de forma igualmente diferente. Para desenvolver líderes melhores, torna-se necessário identificar e aprimorar alguns atributos próprios da liderança como caráter, integridade, energia e o pensamento estratégico, além de alavancar as competências pessoais.

Alguns autores destacam outras características entre os líderes, identificada através de um estudo que realizaram: a consciência, energia, inteligência, domínio, autoconfiança, sociabilidade, abertura às experiências, conhecimento de tarefas relevantes e a estabilidade emocional.

Na busca de resultados e explicações sobre os assuntos reinantes nesta seara, muitas obras foram consultadas na Internet, postadas pelos estudiosos. Os novos contextos organizacionais tendem a cuidar da flexibilidade e da cooperação entre seus membros, enaltecendo, consequentemente, a figura do líder. Assim, tanto a informação, o conhecimento, a criatividade como o sentido de oportunidade, são recursos estratégicos utilizados nesta era contemporânea.

Ratifica-se que a importância deste estudo sobre os ingredientes na inovação alcança também a abrangência de seus impactos, pois o campo é amplo inclusive nas relações de poder (elemento envolvendo a habilidade para se conseguir que outra pessoa faça alguma coisa que, de outra forma, não seria feita) das atividades laborais. Essa estratégia abrange assim a preocupação das empresas não só com 
a sua saúde como também a forma física dos seus colaboradores: ser simultaneamente pró-pessoas e prólucros, ambos caminhando juntos para a via certa em direção a excelência.

Pesquisas realizadas em 100 empresas constataram que aquelas que refizeram seus processos optando pela Reengenharia de forma mais ampla possível, obtiveram reduções nos custos totais da ordem de 17\%, enquanto que as empresas que adotaram uma perspectiva mais estreita tiveram reduções insignificantes (menores que 1\%). Concluindo que a Reengenharia alicerçada somente para o processo não garante melhor desempenho da organização. A vantagem da Reengenharia de Negócios não está apenas em evitar os problemas existentes. A Reengenharia de Negócios propicia maiores possibilidades de enfrentamento das resistências e as barreiras de transição. Na verdade, constataram que um projeto estruturado de Reengenharia de Negócios funcionará como uma concussão para a organização durante o processo de transformação. Nesta seara ratificaram que é preciso levar em consideração também os motivos que levam os funcionários (desmotivadores -- como a qualidade de vida que nem sempre correspondem as suas expectativas) a desenvolverem suas atividades com grande entusiasmo e qualidade.

Enfim, explicam que cada empresa deve identificar um conjunto de motivações próprias que propulsione a investir em inovação. Entre estas motivações particulares, algumas das mais frequentes são: inovação dos processos de fabricação ou de direção dos trabalhos com a modernização tecnológica; investimento na imagem frente ao mercado visando proteção contra os ciclos econômicos; reforço da capacidade competitiva no mercado além da redução de custos de produção; aproveitamento de economias de escala; aproveitamento das sinergias - gama de produtos, tecnologias, estrutura comercial; melhoria da qualidade dos produtos, com a diversificação visando aumento dos lucros com a satisfação dos clientes. Na procura de respostas nesse contexto referencial - um dos principais focos deste estudo levou-se em conta a rápida disseminação no ambiente empresarial e a grande repercussão na sociedade.

Os resultados obtidos foram plenamente satisfatórios, vez que com o presente trabalho, pode-se expor sobre a importância de Lean Manufacturing e o desenvolvimento sustentável, que dentro dos princípios de sustentabilidade, não se pode separar as questões sociais das questões ambientais. 0 objetivo fundamental de qualquer organização é obter o maior lucro possível e, com mudanças no sentido global, em termos de muitos problemas relacionados ao meio ambiente, as empresas começam a ter que se adequar a essa responsabilidade; e comprovados os ganhos em competitividade, as indústrias atualmente vêm incentivando projetos e processos com produtos voltados ao desenvolvimento sustentável pelo ganho econômico, social e ambiental. Como se pode concluir, o conceito de desenvolvimento sustentável está intimamente ligado às dimensões ambientais, econômicas e sociais, e todas as empresas pesquisadas no presente estudo caminham na direção da excelência de atuação, mantendo-se características de sustentabilidade, via indicadores, com o objetivo de se alcançar o ponto de equilíbrio entre essas dimensões.

No país, os efeitos destas reformas são especialmente graves dadas a inexistência prévia de sistemas de proteção social - sólidos e abrangentes. A busca por competitividade, através de redução de custos e ganhos de produtividade, está fazendo com que as organizações procurem por inovações na gestão, sustentabilidade, inclusive tecnológicas que permitam superação. 0 complexo arsenal de metas a serem cumpridas com que se deparam as organizações atualmente, evidencia a necessidade de a gerência ampliar seu projeto de planejamento e controle, para poder atender às expectativas da sociedade com relação às empresas.

Por outro lado, a concepção do Estado enquanto promotor e defensor do bem-estar geral na Nação supõem duas funções básicas: a de orientação do desenvolvimento, através, de políticas globais e setoriais, e a de agente econômico direto, através de investimentos complementares à iniciativa privada. A abertura política está procurando trazer um equilíbrio entre a técnica moderna de equacionar e solucionar problemas com as verdadeiras necessidades práticas do homem da sociedade.

Enfim, constatou-se que é um desafio imenso a busca dessas novas fórmulas, dessas novas medidas de crescimento e de sobrevivência, por parte dos empregadores, pois há também as pressões psicossociais dos próprios trabalhadores atingidos diante da atual conjuntura econômica onde a questão crucial é competitividade X competitividade ou falência. Assim a tarefa é complexa. As empresas, numa competição acirrada buscam fórmulas de adequação ao desenvolvimento econômico e ao processo tecnológico.

A questão que também se coloca é à medida que deve elas se adequar nessa globalização nos dias atuais devido inclusive à tecnologia com o contínuo desenvolvimento. A gestão de competências e a de desempenho deve funcionar num contexto interativo dentro da gestão organizacional. Os métodos devem ter um conteúdo concreto e operacional numa atitude descentralizada tendo também como objetivo fundamental a satisfação dos clientes. Mudanças nas empresas visam a atribuir uma função prática às 
novas ideias e viabilizar o resultado para o uso comercial. Inovar seria, então, ideia com um novo significado a produtos, serviços e processos para que sejam integrados ao mercado.

\section{CONCLUSÃO}

Em suma, as empresas devem neste mercado competitivo utilizar as diretrizes do Lean Manufacturing \& Sustentabilidade para melhorar a qualidade dos produtos/serviços; melhorar o ambiente de trabalho e atendimento ao usuário; melhorar a qualidade de vida dos funcionários; maximizar o aproveitamento dos recursos disponíveis; reduzir gastos e desperdícios; otimizar o espaço físico; reduzir e prevenir acidentes; melhorar as relações humanas, pois as organizações contemporâneas passam por transformações sociais e tecnológicas que influenciam no sucesso organizacional. Um dos requisitos é adquirir líder com competências e habilidades específicas. Essa estratégia abrange a preocupação das empresas não só com a sua saúde como também a forma física e psicológica dos seus colaboradores.

Lean Manufacturing \& Sustentabilidade embasa a combinação ideal para qualquer empresa. Com a Sustentabilidade ter-se-á o crescimento e os lucros que a empresa obterá a médio e longo prazo, sem contar o impacto positivo que advém desse posicionamento empresarial. A gestão empresarial está relacionada com a preocupação maior que se relaciona com os desafios a enfrentar no futuro.

Para responder as indagações propostas nesta pesquisa pode-se ratificar que todas as empresas possuem necessidade de vender seus serviços satisfazendo seus consumidores. Que há precisão urgente deste projeto estar alicerçado na administração TQM (Total Quality Management).

Assim, esta pesquisa propiciará ou não, a confirmação sobre as especificidades dos líderes se estiverem em organizações alicerçados no apoio; no desenvolvimento gerencial da equipe; na ética e na qualidade dos processos e crescimento organizacional além de Qualidade de Vida no Trabalho, obterão resultados satisfatórios.

Se a empresa decidir embarcar num projeto de Reengenharia deverá realizar uma série de opções conscientes que definam as reais possibilidades do processo organizacional e seu objetivo negocial. Essas opções propiciarão que a organização utilize a otimização em seus procedimentos objetivando resultados rápidos e positivos. Os resultados esperados e a conclusão construída a partir da análise da literatura e que devem ser considerados, pois é preciso que a estratégia empresarial, de grande relevância no mundo dos negócios, onde são visualizados inúmeros obstáculos para as organizações, seja inserida em um ambiente altamente sadio, embora competitivo e turbulento que se transforma com uma velocidade alucinante, exigindo das mesmas um sistema de informação ágil que acompanhe o ritmo das transformações realizadas.

Naturalmente, se o sistema adotado for à reengenharia poderá haver alteração no processo de trabalho onde certos tipos de tarefas diminuirão ou cessarão, criando-se outras como eliminação de postos de supervisão para florescer postos de nível de gerência; Mudança no perfil da mão-de-obra: Exigência de novas especializações, habilidades e qualificação; Burocratização da organização em função da grande quantidade de informação, o que aumentará o número de relatórios, procedimentos e rotinas, favorecendo a centralização das decisões na direção, diminuindo a influência da gerência média, devido à integração entre os departamentos proporcionada pelo sistema. A estratégia ofensiva deverá saber a importância da inovação para o líder que deverá realizar o diferencial.

O gerente na Reengenharia buscará o entusiasmo e comprometimento de todos os envolvidos nas alterações da infraestrutura buscando solucionar os problemas, com treinamento apropriado em uma homogeneidade organizacional para operar especificamente nos processos negativos. Abrir as possibilidades para garantir os procedimentos benéficos e modificar ou extinguir os procedimentos negativos.

Assim, a Reengenharia de Negócios reduzirá a possibilidade de riscos existentes na Reengenharia de Processos. 0 gerente realiza mudanças na infraestrutura juntamente com os demais membros. Os sistemas de informação, recursos humanos e estrutura organizacional deverão funcionar organizadamente. Atento a dimensão do negócio constatará se a Reengenharia de Negócios possibilitará extinguir os riscos que poderão erguer-se na Reengenharia de Processos. Esta fiscalização contínua garantirá resultados satisfatórios. 
Após o exame da doutrina (publicados na Internet) constatou-se que as empresas mais bem-sucedidas foram as que fizeram seus processos de Reengenharia de forma ilimitada, utilizando-a também na forma de Negócios alicerçada numa base forte para o enfrentamento das dificuldades que poderão florescer.

Concluindo pode-se dizer que na escolha do sistema a ser utilizado um insight cognitivo pode ser útil com a perspicácia ou solução de forma repentina para solução de problemas. Cada empresa deve identificar um conjunto de motivações próprias que propulsione a investir em inovação.

Hoje, o procedimento das empresas através de seus administradores tem que sofrer transformações para impulsionar as pessoas a contribuírem com o máximo de seus esforços, principalmente em uma época de recessão onde seus salários não têm o mesmo patamar de consumo de outras épocas e os trabalhadores visam primeiramente uma forma de manter-se empregados.

Entre estas motivações particulares, algumas das mais frequentes são: inovação dos processos de fabricação ou de direção dos trabalhos com a modernização tecnológica; investimento na imagem frente ao mercado visando proteção contra os ciclos econômicos; reforço da capacidade competitiva no mercado além da redução de custos de produção; aproveitamento de economias de escala; aproveitamento das sinergias - gama de produtos, tecnologias, estrutura comercial; melhoria da qualidade dos produtos, com a diversificação visando aumento dos lucros com a satisfação dos clientes.

Na procura de respostas nesse contexto referencial há que se ter em conta também a rápida disseminação no ambiente empresarial e a grande repercussão na sociedade. Lembre-se que o conceito econômico de empresa se alicerceia na organização dos fatores da produção: natureza, capital e trabalho. Sobre o aspecto objetivo, a empresa visa lucro. 0 empresário, aquele que exerce profissionalmente uma atividade econômica organizada, para a produção e circulação de bens e serviços, muitas vezes se difere do empreendedor, que tem como característica básica o espírito criativo e pesquisador. Assim, o empresário para ser bem-sucedido, deverá ser um empreendedor e um administrador do futuro.

O papel de uma liderança dentro de uma organização é o de conseguir fazer transformações pela ação de seus colaboradores. 0 líder deve procurar criar um ambiente favorável para que as pessoas dentro da organização possam ter a possibilidade de realizar suas atividades e atingir seus êxitos e consequentemente os resultados que a empresa está buscando.

Nesta seara, ratifica-se, é preciso levar em consideração também os motivos que levam os funcionários (desmotivadores -- como a qualidade de vida que nem sempre correspondem as suas expectativas) a desenvolverem suas atividades com grande entusiasmo e qualidade. Assim, tanto a informação, o conhecimento, a criatividade como o sentido de oportunidade, são recursos estratégicos utilizados nesta era contemporânea. Sabendo que as empresas têm a necessidade de vender seus serviços satisfazendo seus consumidores continua-se ratificando que a empresa só poderá ascender com sucesso nos negócios se a esses bens houver interação das pessoas. 0 pressuposto básico da empresa reinventada é que as pessoas são o seu bem mais escasso e precioso, que constituem a pedra angular da competitividade de qualquer organização.

Os líderes devem conseguir lidar e conviver com a diversidade, valorizando as diferentes perspectivas, também devem aprender continuamente e auxiliar a aprendizagem dos liderados, e ter interesse autêntico pelas pessoas, buscando soluções baseadas nas reflexões conjuntas e no aproveitamento das experiências. Também devem procurar dirigir o conhecimento adquirido aos propósitos da organização, tanto quanto devem buscar alternativas para o desenvolvimento das pessoas. Por fim, devem se preocupar em alinhar a estratégia à missão, ao desenvolvimento da autonomia e das competências individuais, tendo ciência da necessidade da constante avaliação dos processos implantados como procedimentos vitais para estruturar a organização.

Em suma, as empresas para obter êxito nesta fase contemporânea, seja qual for o sistema adotado, precisará utilizar em suas atividades um pensamento sistêmico com aprendizado organizacional alicerçado numa cultura da inovação, orientação por processos e informações, liderança e constância de propósito. Além disso, deverá ter uma visão de futuro com base em geração de valor, valorização das pessoas, conhecimento sobre o mercado e o cliente, responsabilidade social e desenvolvimento de parcerias. Os modelos hodiernos de gestão têm como desafio promover o desenvolvimento sustentável das organizações, gerando valor para as empresas, para as pessoas e para o meio ambiente, harmonizando desenvolvimento econômico, ambiental, social e cultural. Conhecer e dominar os fundamentos de viabilidade econômica e financeira do projeto desejado é o grande desafio. 


\section{REFERÊNCIAS}

[1] ABREU, Fábio de Souza. Reengenharia - em busca de uma teoria. Rev. adm., empres., Out. 1994, vol.34, no.5, p.49-61. ISSN 0 034-7590.

[2] ALBUQUERQUE, C. Relacionamento Interpessoal. 2012: Disponível em: < http://www.alcancesolucoes.com.br/artigos/cassia/Relacionamento-Interpessoal-Artigo.pdf> Acessado em: 12 Jun. 2012.

[3] ANSOFF, H. Igor. A nova estratégia empresarial. São Paulo: Atlas 1993.

[4] ANTUNES, R.: Adeus ao Trabalho? São Paulo: Cortez, 1995.

[5] BARBIERI, J. C.; CAJAZEIRA, J. E. R. Responsabilidade social empresarial e empresa sustentável: da teoria à prática. São Paulo: Saraiva, 2009.

[6] BELLUZZO, R.C.B. Unidades de informação sob a ótica da gestão - protocolos de certificação para acesso universal. Coordenadoria de documentação e informação jurídica. XXII CBBD, 2007. Disponível em: Acesso em: 20 ago. 2010.

[7] BENNIS, W.G.; Spreitzer, G.M.; Cumming, T.G. O Futuro da Liderança. São Paulo: Futura. 2001.

[8] BERGAMINI Cecília Whitaker. Psicologia Aplicada a Administração de Empresas. São Paulo, Brasiliense, 1982.

[9] BIGNETTI, Luiz Paulo. O processo de inovação em empresas intensivas em conhecimento. Rev. adm. contemp. vol.6 no.3 Curitiba Sept./Dec. 2002http://dx.doi.org/10.1590/S1415-65552002000300003.

[10] BLANCHARD, K. Et.al. Liderança de alto nível - edição revisada e ampliada: como criar e liderar organizações de alto desempenho. Porto Alegre: Bookman. 2011.

[11] BLANCHARD, K. et. al. Liderança de alto nível: como criar e liderar organizações de alto desempenho. Tradução de Rosália Neuman Garcia. Porto Alegre: Bookman, 2007.

[12] BRANDÃO, H. P.; Guimarães, T. A. (2001). Gestão de Competências e Gestão de Desempenho: tecnologias distintas ou instrumentos de um mesmo construto? Revista de Administração de Empresas. Disponível em: (Acessado em 18/01/2016).

[13] BROWN, M. E., Treviño, L. K., \& Harrison, D. A. (2005). Ethical leadership: A social learning perspective for construct development and testing. Organizational Behavior and Human Decision Processe, 97, 117-134. doi: 10.1016/j.obhdp. 2005.03.002.

[14] BROWN, M.; TREVIÑO, L. Ethical leadership: A review and future directions. The Leadership Quarterly, v. 17, pp. 595-616, 2006.

[15] BURKE, P. 2003 (Uma história social do conhecimento: de Gutenberg a Diderot. Tradução Plinio Dentzien. Rio de Janeiro: Jorge Zahar Editor).

[16] CABESTRÉ, S. A.; BELLUZZO, R C. B. Desenvolvimento e inovação no cotidiano do profissional de relações públicas. Anuário UNESCO/Metodista de Comunicação Regional, Ano 12 n.12, p. 141-158, jan./dez. 2008. Disponível em: Acesso em: 26 jun. 2011.

[17] CHIAVENATO, Idalberto. Introdução à Teoria Geral da Administração: na administração das organizações. Edição Compacta. $3^{\circ}$ Ed. Rio de Janeiro: Elsevier, 2004.

[18] ------------- Recursos Humanos. 7ª ed., São Paulo Atlas, 2002.

[19] ----------- Os novos paradigmas: como as mudanças estão mexendo com as empresas. Barueri, SP: Manole. 2008.

[20] ----------. Treinamento e desenvolvimento de recursos humanos: como incrementar talentos na empresa. Barueri, SP: Manole. 2009.

[21] - -------.. Gestão de pessoas: o novo papel dos recursos humanos nas organizações. Barueru, SP: Manole. 2014.

[22] COVEY, Stephen R. Liderança baseada em princípios. Rio de Janeiro: Campus, 2002.

[23] COVEY, Stephen R. Os sete hábitos das pessoas altamente eficazes. São Paulo: Best Sele, 2003 14ª edição p 121-182.

[24] DAVEnPORT, T.H.: Reengenharia de Processos. Ed. Campos, Rio de Janeiro, 1994.

[25] DAVENPORT, T. \& SHORT J.: "The New Industrial Engineering: Information Technology and Business Process Redesign". Sloan Management Review, pp.11-27, Summer 1990. 
[26] DUBRIN Andrew J. Fundamentos do comportamento organizacional. São Paulo: Pioneira Thomson Learning, 2003.

[27] FREITAS, J. C. D.S.; KLEIN, A.Z.; FARGUNDES, P.M. (2015) Uma proposta de instrumento quanti-qualitativo para auto avaliação de competências de liderança. Revista de Administração da UNIMEP. Disponível em: (Acessado em: 11/02/2016).

[28] GIL, Antonio C. Como elaborar projetos de pesquisa. 4⿳ạ ed. São Paulo: Atlas, 2002.176 p.

[29] GONÇALVES, José Ernesto Lima. Reengenharia: um guia de referência para o executivo.Rev. adm. empres. vol.34 no.4 São Paulo July/Aug. 1994 http://dx.doi.org/10.1590/S0034-75901994000400004.

[30] HERSEY, PAUL; BLANCHARD, KENNETH H- Psicologia para Administradores: As teorias e as técnicas da liderança situacional. São Paulo: EPU. 1986.

[31] HAMMER, M. \& CHAMPY, J.: Reengenharia - Revolucionando a Empresa em função dos Clientes, da Concorrência e das Grandes Mudanças da Gerência. Ed. Campus, Rio de Janeiro, 1990.

[32] HAMPTON, D. R. Administração: comportamento organizacional. Tradução de André Olympio Mosselman Du Chenory Castro. São Paulo: McGraw-Hill, 1990.

[33] HOUSE, R. J., \& Mitchell, T. R. (1974). Path-goal theory of leadership. Journal of Contemporary Business, 3(4).

[34] LODI, João Bosco. Estratégia de negócios: planejamento a longo prazo. Rev. adm. empres. vol.9 no.1 São Paulo Jan./Mar. 1969. http://dx.doi.org/10.1590/S0034-75901969000100001.

[35] MAXIMIANO, A. C. A. Teoria geral da administração. São Paulo: Atlas, 2008.

[36] MELO, M.: “O exercício da função gerencial em tempos de novas tecnologias organizacionais: da gestão profissional à gestão compartilhada". In: Encontro Da Associação Nacional Dos Programas De Pós-Graduação Em Administração, 20, 1996, Rio de Janeiro. ANAIS... Rio de Janeiro: ANPAD, 1996.

[37] MINICUCCI, A. Psicologia aplicada à administração. 5. ed. São Paulo: Atlas, 1995.

[38] PETERS, T. \& WATERMAN, R.: In Search of Excellence: lessons from America's best-run companies. New York, Time Warner, 1984.

[39] PORÉM, M.E. 2005(A gestão da comunicação e da informação nas empresas contemporâneas sob a ótica da responsabilidade social, p. 25).

[40] ROBBINS, SEPHEN P. Comportamento Organizacional. 3a Edição, Rio de Janeiro: Livros Técnicos e Científicos Editora S/A, 1998.

[41] ROCHA, H. Fatores Críticos de Sucesso de Start-up de Veículos e a Qualidade (CMMI) no Desenvolvimento de Produtos no Sul Fluminense. 2005. 353 f. Dissertação (Mestrado em Sistemas de Gestão) - Universidade Federal Fluminense, Niterói, 2005.

[42] RODRIGUES, R. R.; SANTIN BRANCALION, P. H; ISERNHAGEN, I. Pacto pela restauração da mata atlântica: Referencial dos conceitos e ações de restauração florestal. ERF/ESALQ: Instituto BioAtlântica. - São Paulo: 2009.

[43] ROEDER, M. A. Atividade Física, Saúde Mental \& Qualidade de Vida. Rio de Janeiro: Shape, 2003.

[44] SAVIANI, J.R.: Repensando as Pequenas e Médias Empresas. Ed. Pioneira, São Paulo, 1994.

[45] SilveiRA, N. L. Á. P.; Bastias, A. D. C. P. (2004). Desafios e Oportunidades - O Verdadeiro Papel do Líder. (2a ed.). Porto Alegre: SEBRE/RS.

[46] SIQUEIRA, WAGNER. Avaliação de Desempenho: uma ferramenta estratégica, (2002) disponível em: <www.portaladm.adm.br/Tga/tga45.htm> Acesso em 17 Maio. 2013.

[47] SPECTOR, Paul E. Psicologia nas Organizações. São Paulo: Saraiva, 2002.

[48] STAIR, Ralph M. e REYNOLDS George W. Princípios de Sistemas de Informações: Uma abordagem Gerencial. 4 ํe. São Paulo: LTC, 2002.

[49] TANNENBAUM, R.; SCHMIDT, W. H. How to Choose a leadership Pattern. In: Harvard Business Review, 36. Jg. 1958.

[50] WALTON, R. E. 'The diffusion of new work structures: Explaining why success didn't take', Organizational Dynamics, Winter, 1975.

[51] WEBER, M. The theory of social and economic organization. New York: The Free Press, 1947.

[52] ZANELLI, José Carlos; SILVA, Narbal. Interação humana e gestão: a construção psicossocial das organizações de trabalho. - São Paulo: Casa do Psicólogo, 2008. 


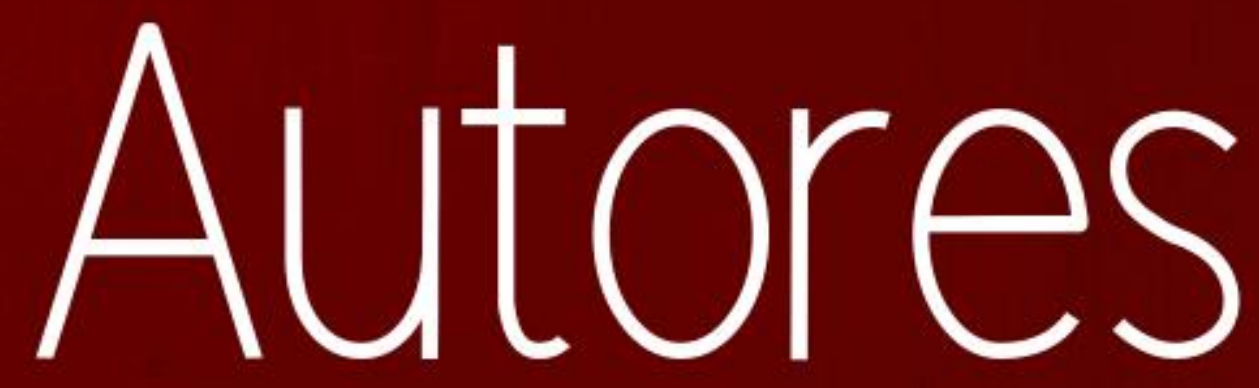




\section{RAFAEL ALVES PEDROSA (ORGANIZADOR)}

Consultor de Gestão com enfoque em Logística Portuária e de Transportes, com graduação em Administração, Comércio Exterior, Logística e Transporte Multimodal e Gestão Portuária; Pós Graduação em Gestão de Comércio Exterior e Logística; Gestão Empresarial; Gestão, Docência e Tecnologias do Ensino Superior; MBA em Docência do Ensino Superior pela Fundação Getúlio Vargas - FGV; Mestre em Sustentabilidade de Sistemas Costeiros com dissertação voltada a Dragagem de Aprofundamento do Porto de Santos/SP; Doutorado em Planejamento e Gestão pela Universidade Federal do $\mathrm{ABC}$ (UFABC) com tese voltada ao impactos da expansão portuária do Porto de Santos na integração porto/cidade. Autor e organizador de livros e capítulos de livros relacionados a sua área de atuação. Coordenador de projetos de pesquisa e revisor de periódicos ligados as áreas de Logística e Comércio Exterior e planejamento territorial e urbano. Professor conteudista de cursos superiores em EaD. Possui cursos de atualização nas áreas de Administração, Logística e Comércio Exterior, fez intercâmbio na Argentina adquirindo fluência no idioma Espanhol, além de participar constantemente de fóruns destinados a estas áreas. Coordenador do curso de pós graduação em Gestão Portuária e Operações Internacionais. Com experiências na coordenação de Logística e transportes em empresas multinacionais sendo responsável pelo planejamento de distribuição e Logística das regiões Sul e Sudeste do país. Tendo sido contemplado com o prêmio de Melhor ideia inovadora 2010 . Atuou ainda no papel de Coordenador de Operações Portuárias. Já na docência foi contemplado com o prêmio Mérito Docente por atuação acadêmica destacada e foi contemplado com o prêmio Dr. Milton Teixeira pela orientação do melhor trabalho de iniciação cientifica.

\section{ADRIANO FRANCO DA SILVA}

Pesquisador; Graduação em Gestão de Produção industrial; Faculdade Metropolitana de Manaus FAMETRO; Manaus/Amazonas;

\section{ANA LUIZA FIGUEIREDO VIEGAS}

Graduanda em Ciências Contábeis pela Pontifícia Univerdade Católica de Minas Gerais. Graduada em Administração pelo Centro Federal de Educação Tecnológica de Minas Gerais (2018) com extensão acadêmica em Administração para Negócios em Berlim (2017). Tem experiência nas áreas de Administração e Auditoria, com ênfase em administração de empresas, gestão estratégica e gestão da produção.

\section{ANDERSON ORZARI RIBEIRO}

Graduado em Licenciatura e Bacharelado em Química pela Faculdade de Filosofia, Ciências e Letras da Universidade de São Paulo em Ribeirão Preto (1999), Mestrado em Química (2002) e Doutorado em Química Inorgânica pela mesma Universidade de São Paulo (2004). Pós-Doutorado em Química Orgânica na Univerisdade de Aveiro em Portugal (2005). Atualmente é Professor Associado do Centro de Ciências Naturais e Humanas da Universidade Federal do ABC, campus em Santo AndréSP.

\section{ANTONIO CARLOS FREIRE ROBOREDO}

Pesquisador do CNPq. CAPES. Líder Do Diretório De Pesquisa. Professor Adjunto da Universidade Federal Fluminense - UFF por Concurso Público de provas e títulos, leciona as disciplinas de: Direito Constitucional, Direito Empresarial, Direito e Legislação I e II, Aspectos e Assuntos Jurídicos, Direito Social, Direito e Processo do Trabalho, Direito Securitário, Direito e Processo Civil, Direito e Processo Penal, Direito Administrativo, Deontologia Jurídica e Ética Profissional, Português Jurídico, Tópicos em Atuariais, entre outras. Mestre em Sistemas de Gestão pela LATEC UFF. Mestrando Acadêmico em Ciência Política e Relações Internacionais (C.P./R.I.) pelo Instituto Universitário de Pesquisa do Estado do Rio de Janeiro IUPERJ./UCAM - Universidade Cândido Mendes. Pós graduado com especialização em Direito do Trabalho e Direito Processual do Trabalho (D.T./D.P.T.) pela Universidade Gama Filho - UGF. Professor Orientador de Monografia de Graduação em Direito. Membro de bancas examinadoras de Monografia de conclusão de curso e de 
concurso público. Escritor/Autor de várias obras publicadas, entre elas autor do livro: "A Globalização E Os Impactos Na Contabilidade Das Empresas - Era Contemporânea". Periódicos: "Políticas Públicas: Enfoque Jurídico"; "Direitos Humanos: O Tratado de Não-Proliferação Nuclear HUMAN RIGHT: Non-Proliferation Treaty"; "Gestão Do Sistema Carcerário: Aspectos Da Ressocialização No Brasil" (CNEG/UFF/LATEC). Foi professor assistênte do professor titular Evânio José Sá na UFF e na UNIVERSO. Foi professor em outras universidades e cursos. CNEGINOVARE - PALESTRANTE - coordenador técnico de sessão. faculdades integradas Helena Antipoff - Pestalozzi - Niterói. Recebeu o Título de "notável saber jurídico" e "personalidade jurídica do ano" concedido em Solenidade realizada na Câmara Municipal de Niterói pelo ACAERJ e pelo CAN. Foi DIRETOR Superintendente de Gabinete da Secretaria Municipal De Educação De Niterói (SME). Fo

\section{BÁRBARA GABRIELLE SILVA}

Mestranda em Administração pelo Centro Federal de Educação Tecnológica de Minas Gerais. Possui graduação em Administração pelo Centro Federal de Educação Tecnológica de Minas Gerais (2018) com extensão acadêmica em Auditoria, Sistemas de Controle de Gestão e Informática em Portugal (2017). Tem experiência na área de Administração, com ênfase em administração de empresas, gestão estratégica e empreendedorismo.

\section{BRUNNO JOSÉ FAGUNDES}

Graduação em Ciência da Computação pela Universidade de Santa Cruz do Sul e Pós-graduação (Mestrado) em Sistemas e Processos Industriais também pela Universidade de Santa Cruz do Sul. Possui experiência acadêmica na área de Ciência da Computação e experiência em Redes de Computadores a nível de mercado, atuando como sócio-proprietário e Diretor de Tecnologia da Informação de uma empresa de Acesso à Internet. Atualmente, também desempenha a função de professor junto ao Departamento de Engenharias, Arquitetura e Computação na Universidade de Santa Cruz do Sul.

\section{CARLO ROSSANO MANICA}

Mais de 20 anos de experiência profissional e acadêmica em Soluções Tecnológicas e Inovação, Gerência de Projeto, Produção e Manutenção. É mestre em Inovação pelo PGDesign - UFRGS. Possui MBA em Gestão Estratégica de Instituições de Ensino, MBA em Gestão Empresarial e Especialização em Engenharia de Segurança do Trabalho. Participou do Programa de Desenvolvimento e Aperfeiçoamento de Lideranças (PDAL). Também possui Graduação em Engenharia de Produção e Licenciatura Plena, Técnico em Automação Industrial e Aperfeiçoamento em Eletrônica. Atualmente é professor de graduação e pós graduação no Centro Universitário IPA. Professor de Pós Graduação na UCS. Atua também como Diretor na empresa Télios Desenvolvimento de Expertises. Na UFRGS é pesquisador do Núcleo de Desenvolvimento de Produtos (NDP).

\section{CARLOS ALBERTO SANTOS NASCIMENTO}

Pesquisador; Graduação em Gestão da Produção Industrial - Faculdade Metropolitana de Manaus.

\section{CLAUDEMIR MORAES DE SÁ}

Pesquisador; Graduação em Gestão da Produção Industrial - Faculdade Metropolitana de Manaus.

\section{CLAYBERSON ALVES CARVALHO}

Graduando em Gestão de Produção Industrial pela Faculdade Metropolitana de Manaus (FAMETRO). Atuou como Lider de Produção e no Planejamento de Produção e atualmente, atua como Planejador de Manutenção, ADM \& Serviços na empresa RECOFARMA Industria de Alimentação LDTA. 


\section{DANIEL MACIEL DE MENEZES}

Pesquisador; Graduação em Gestão da Produção Industrial - Faculdade Metropolitana de Manaus; Especialista em Introdução de Novos Produtos.

\section{DANIELLI COSSUL}

Bolsista de iniciação científica da Universidade de Santa Cruz do Sul. Estudante de graduação em Psicologia na Universidade de Santa Cruz do Sul.

\section{FELIPE AMORIM SOARES MACEDO}

Graduando em Engenharia Mecânica pela Universidade Federal do Rio de Janeiro no polo de Macaé.

\section{FERNANDO CESAR MENDONÇA}

Engenheiro de Produção e mestre em Engenharia pela UFSCar, Licenciado em Ciências Exatas pelo IQSC/USP. Desde 2017 é docente do IFSP, campus São Paulo/Pirituba e desde 2018 é coordenador do curso de Engenharia de Produção de seu câmpus.

\section{IVANA SALVAGNI ROTTA}

Engenheira de Produção Materiais (UFSCar). Mestre em Engenharia Mecânica (EESC-USP). Doutora em Engenharia de Produção (UFSCar). Atualmente docente do Núcleo de Engenharia. Integrante do Núcleo de Pesquisa em Engenharia (NUPENG), e Coordenadora do Grupo de Projetos na área de Organizações, Trabalho, e Tecnologia nos Processos Produtivos, com fomento do Programa Institucional de Bolsas de Iniciação Científica e Apoio à Pesquisa (PIC) do Centro Universitário Hermínio Ometto - FHO (Uniararas).

\section{JAYSON LUIS DA SILVA RIBEIRO}

Pesquisador com foco em gestão de projetos, desenvolvimento de novos negócios e inovação. Doutorando em Biotecnociência e Mestre em Engenharia e Gestão da Inovação pela universidade federal do ABC. Possui MBA em gestão estratégica de negócios e pós em gestão de projetos pela fundação Getúlio Vargas. Participou do SAC na Califórnia State University (EUA) e atuou em diversos projetos de inovação em empresas nacionais e internacionais.

\section{JEDSON ORIEL DE MELO NOGUEIRA}

Graduado em Ciência e Tecnologia pela Universidade Federal Rural do Semi-Árido Campus Angicos. Cursando Engenharia de Produção pela Universidade Federal Rural do Semi-Árido Campus Angicos.

\section{KENNEDY FRANCA KRAMER}

Graduando em Gestão de Produção Industrial pela Faculdade Metropolitana de Manaus (FAMETRO).

\section{LIANE MAHLMANN KIPPER}

Bolsista produtividade CNPq. Professora titular da Universidade de Santa Cruz do Sul. Atua na graduação e na pós-graduação stricto sensu (PPGSI, PPGPSI e PPGTA). Atua nas áreas de gestão do conhecimento, inovação e criatividade, gerenciamento de processos e métodos e técnicas de pesquisa; desenvolve ensino, pesquisa e extensão com foco em: melhoria e gestão de processos, sistemas enxutos: inovação, criatividade, design thinking, design science research, 
desenvolvimento de produtos e tecnologias para otimização e melhoria de processos. Tem também experiência na área de Física e Física Experimental.

\section{LUAN SANTOS}

Professor do Programa de Engenharia de Produção da Universidade Federal do Rio de Janeiro (PEP/COPPE/UFRJ) e do curso de Engenharia de Produção (UFRJ-Macaé). É Doutor e Mestre em Planejamento Energético e Ambiental (PPE/COPPE/UFRJ), bem como graduado em Matemática (IME/UFF) e em Administração (FACC/UFRJ). É membro da Brazilian Research Alliance for Sustainable Finance and Investment (BRASFI). Tem como principais linhas de pesquisa os seguintes temas: política climática, precificação de carbono, finanças sustentáveis e gestão sustentável da produção.

\section{LUCIANA OLIVEIRA DO VALLE CARMINE}

Professora da Graduação e Pós-Graduação do Centro Universitário Fametro. Formada em Ciências Econômicas pela Universidade Federal do Amazonas com Mestrado em Engenharia de Produção também pela Universidade Federal do Amazonas.

\section{LUCIANA OLIVERA DO VALLE CARMINE}

Professora da Graduação e Pós-Graduação do Centro Universitário Fametro. Formada em Ciências Econômicas pela Universidade Federal do Amazonas com Mestrado em Engenharia de Produção também pela Universidade Federal do Amazonas.

\section{LUCIANO DOS SANTOS DINIZ}

Doutor em Ciências Sociais, professor adjunto II do Departamento de Ciências Sociais Aplicadas do CEFET/MG, pesquisador dos grupos de pesquisa CITIES - Núcleo Interdisciplinar de Pesquisas em Cidades Inteligentes, Tecnológicas, Inovativas, Empreendedoras e Sustentáveis (CEFET-MG); NEPUR - Núcleo de Estudos e Pesquisa Urbana (PUC-SP) e LOGOS - Processos e Sistemas Decisórios em Arranjos Organizacionais (CEFET/MG),

\section{LUIZ CLAUDIO L. PINHEIRO}

Possui graduação em Engenheiro de Produção pela Universidade Metodista do Sul (IPA), Especialização em Engenharia de Produção com ênfase em Sistema Lean pela Universidade Federal do Rio Grande do Sul (UFRGS). Também possui formação Técnica em Eletrônica Industrial, Elétrica Industrial e mais 500h em cursos e palestras na área de Lean Systems. Profissional com mais de 10 anos de experiência em Assistência Técnica para áreas de Manutenção e Automação Industrial. Atualmente atua como Engenheiro de Produção e Consultor em Gestão de Operações e Lean System.

\section{LUIZ VITOR DE OLIVEIRA GONZAGA}

Pesquisador; Graduação em Gestão de Produção industrial; Faculdade Metropolitana de Manaus FAMETRO; Manaus/Amazonas;

\section{LUIZA MACIEL GONÇALVES}

Graduanda em Engenharia de Produção pela Universidade Federal do Rio de Janeiro em programa de duplo diploma com a École Nationale d'Ingénieur de Metz em Engenharia Generalista com Master em Supply Chain Management na França. No seu último estágio foi responsável pelo projeto de implementação de uma nova linha de produção em uma fábrica de painéis solares, mas já participou também de outros projetos ligados a inovação, empreendedorismo, indústria 4.0 e estratégia. 


\section{MICHELLE TELES DE ABREU}

Pesquisadora; Michelle Teles de Abreu, Graduação em Gestão de Produção industrial; Faculdade Metropolitana de Manaus - FAMETRO; Manaus/Amazonas;

\section{OTTOMAR ANTÔNIO GALIZIO DE OLIVEIRA}

Contador, Brasileiro, inscrito no CRC/RS 042873/0-3 T-SC. Pós Especialização em Auditoria e Perícia. Contábil, (UNIDAVI, 2007), Pós Especialização em Gestão de Negócios Internacionais (UNIDAVI, 2004), Bacharel em Ciências Contábeis pela (UNISINOS, 1996). Atualmente Contador Perito MPSC. Experiência profissional Contador da Prefeitura de Ilhota-SC, (08/2019 à 08/2020). Contador da Prefeitura de Ituporanga-SC, (02/2019 à 07/2019).

\section{PAULA PRENHOLATO ALVES}

Possui graduação em Engenharia de Produção pela Universidade Federal do Paraná. Atualmente cursa MBA em inteligência financeira pela Universidade Positivo.

\section{PAULO CHRISTIAN BEZERRA PASTOR}

Ensino técnico - senai. Graduação em engenharia eletrônica pelo centro universitário do norte. Graduando em Gestão de produção pela faculdade metropolitana de Manaus - FAMETRO. Cursos correlatos a área de Lean manufacturing. Analista de engenharia em processo/produto, Gestão de manufatura.

\section{PAULO FERNANDES SANCHES JUNIOR}

Professor Associado III do Centro Federal de Educação Tecnológica de Minas Gerais (CEFET-MG). Doutor em Engenharia Civil pela UNICAMP, Mestre em Engenharia de Produção pela UFSC. Atua em estudos de Organizações, Logística e Qualidade.

\section{REGINALDO OTTO NAU}

Graduado em Engenharia de Produção pela Universidade Para o Desenvolvimento do Alto Vale do Itajaí (2007) - UNIDAVI, pós-graduado em Gestão Estratégica Empresarial (2008) e Engenharia de Produção (2010), ambos pelo Instituto Catarinense de pós-graduação. Professor da Universidade do Estado de Santa Catarina - UDESC e proprietário do Grupo R.N. Soluções. Experiência profissional na área de Engenharia de Produção e Inteligência de Negócios com ênfase em Microsoft Excel e Power BI, onde atua com consultoria especializada na área.

\section{REJANE FROZZA}

Doutorado em Computação pela Universidade Federal do Rio Grande do Sul. Realização de estágio doutoral sanduíche na Université Joseph Fourier (Grenoble/France). Atualmente, é professora adjunta da Universidade de Santa Cruz do Sul, Santa Cruz do Sul, RS, no Departamento de Engenharias, Arquitetura e Computação e no Programa de Pós-Graduação em Sistemas e Processos Industriais - Mestrado. Tem experiência na área de Computação, com ênfase em Inteligência Artificial, atuando principalmente nos seguintes temas: Sistemas Tutores Inteligentes, Agentes Pedagógicos em Sistemas Virtuais de Aprendizagem, Gestão do Conhecimento, Sistemas Multiagentes, Redes Neurais Artificiais, Sistemas Difusos, Sistemas de Raciocínio Baseado em Casos.

\section{RICARDO GASPAR}

Possui graduação em Engenharia Civil pela Universidade de Mogi das Cruzes (1989), graduação em Movimento de Terra e Pavimentação pela Faculdade de Tecnologia de São Paulo (1985), mestrado em Engenharia Civil pela Universidade de São Paulo (1997) e doutorado em Engenharia Civil pela 
Universidade de São Paulo (2003). Atualmente é prefeito universitário da Universidade Federal do $\mathrm{ABC}$ e professor adjunto da Universidade Federal do ABC. Tem experiência na área de Engenharia Civil, com ênfase em Engenharia de Estruturas, atuando principalmente nos seguintes temas: pontes, ensino, esforços solicitantes e estudo da fadiga das estruturas.

\section{RODRIGO CRIPRIANO}

Formado em Inglês Avançado (Yázigi) e Graduando em Engenharia de Produção (UFRJ Universidade Federal do Rio de Janeiro). Jovem Aprendiz na empresa Halliburton (Assistente Adminstrativo) e Estagiário no CRIOS (Centro de Referência em Inovação para Operações Sustentáveis).

\section{RUTH MARGARETH HOFMANN}

Possui graduação em Ciências Econômicas, mestrado e Doutorado em Educação pela Universidade Federal do Paraná. Atualmente é professora do curso de graduação em Engenharia de Produção da UFPR.

\section{SILVIO LUIZ ALVIM}

Doutorando em Engenharia de Produção pela Universidade Federal de Santa Catarina UFSC (2020 atual). Mestre em Engenharia Civil, área de concentração: Gestão da Cadeia de Suprimentos, Logística e Transportes pelo LALT- Laboratório de Aprendizagem em Logística e Transporte da UNICAMP. Especialização em Gestão e Estratégia Empresarial pelo Instituto de Economia da UNICAMP e graduado em Engenharia de Produção pela PUCRS. Professor Titular do MBA de Logística na Business School - Universidade Lasalle - (2009 a 2016). Atualmente, colabora no Laboratório de Sistemas Produtivos e Logísticos Inteligentes (ProLogIS) da UFSC.

\section{THAISI DOS SANTOS FAGUNDES}

Mestre em Sistemas e Processos Industriais e graduada em Licenciatura em computação, ambos pela Universidade de Santa Cruz do Sul - UNISC.

\section{YOHANA DE AZEVEDO CARVALHO}

Graduanda em engenharia de produção na Universidade Federal do Rio de Janeiro - Campus Macaé. Nos últimos 3 anos atuou em projetos no Centro de Referência em Inovação para Operações Sustentáveis da UFRJ nas áreas ligadas principalmente a Inovação, Gestão Organizacional e Mapeamento de Processos. Atuou em projetos para elaboração de um plano de Gestão da Inovação, e implementação de realidade virtual. Formação técnica em eletromecânica pelo Instituto Federal Fluminense (2009 - 2013). Estagiária Petrobras com atribuições de verificação de plantas da parte elétrica das plataformas e verificação de conformidades necessárias para homologação de helipontos (2012 - 2013). 


\section{$\mathrm{N}^{2} \mathrm{~S}_{2}$}

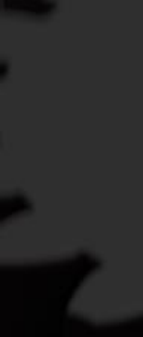

$2+.+5$

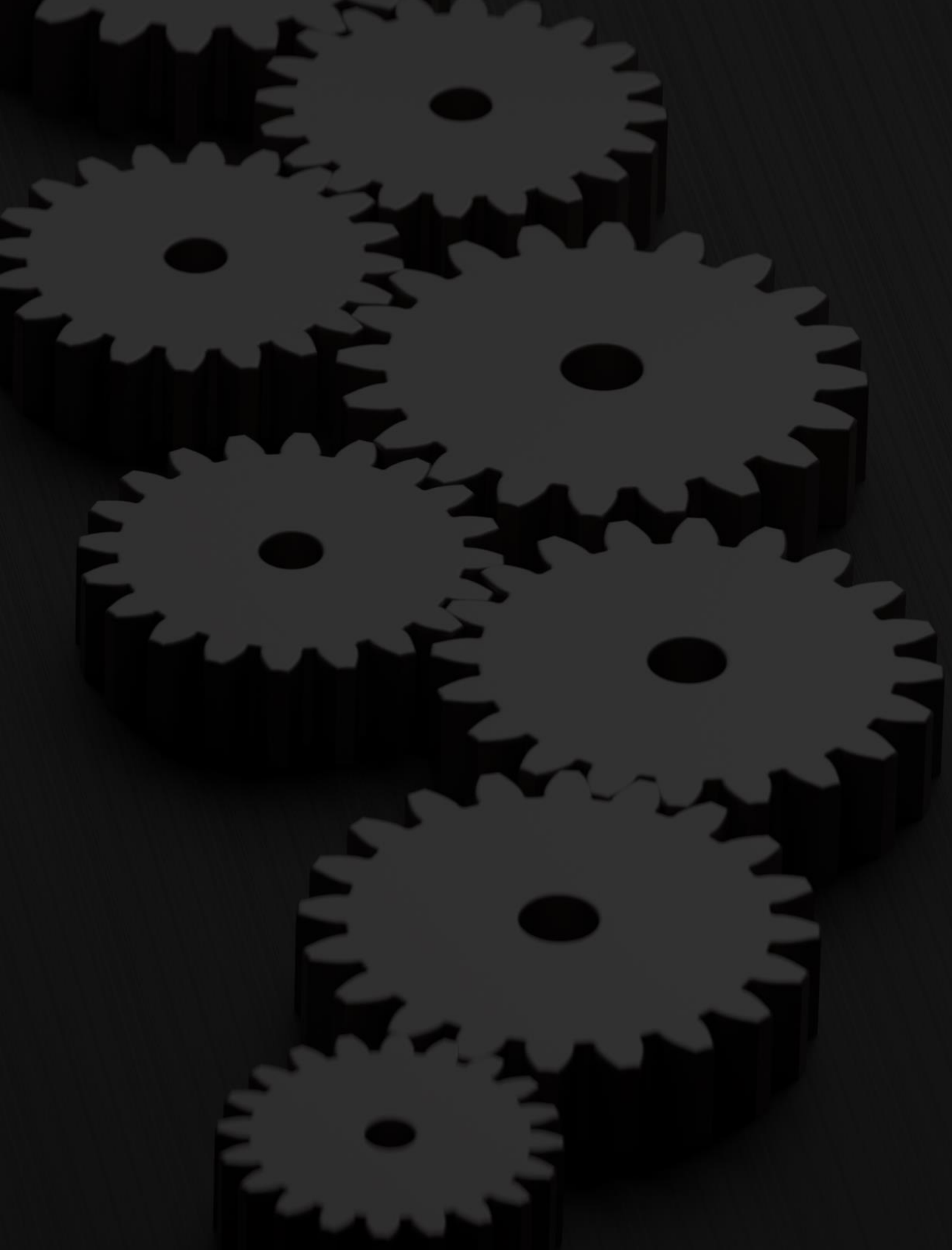

